\title{
LUCIO ABIMAEL MEDRANO CASTILLO
}

\section{Modelo Integrado para a Implantação e Desenvolvimento da Gestão do Conhecimento}

Dissertação apresentada à Escola de Engenharia de São Carlos da Universidade de São Paulo, para obtenção do título de mestre em engenharia de produção.

Área de concentração:

Economia,organizações e gestão do conhecimento

Orientador: Prof. Dr. Edson Walmir Cazarini

São Carlos

2011 
Autorizo a reprodução e divulgação total ou parcial deste trabalho, por qualquer meio convencional ou eletrônico, para fins de estudo e pesquisa, desde que citada a fonte.

Ficha Catalográfica preparada pela Seção de Tratamento da Informação do Serviço de Biblioteca - EESC/USP

\section{Medrano Castillo, Lucio Abimael}

M492m

Modelo integrado para a implantação e desenvolvimento da gestão do conhecimento / Lucio Abimael Medrano Castillo ; orientador Edson Walmir Cazarini. - São Carlos, 2010.

Dissertação (Mestrado) - Programa de Pós-Graduação e Área de concentração em Engenharia de Produção - Escola de Engenharia de São Carlos da Universidade de São Paulo.

1. Gestão do conhecimento. 2. Modelagem organizacional. 3. Modelo de gestão do conhecimento. I. Título. 


\section{FOLHA DE JULGAMENTO}

\section{Candidato(a): Bachiller LUCIO ABIMAEL MEDRANO CASTILLO.}

Dissertaçĩo defendida e julgada em 10.03.2011 perante a Comissấo Julgadora:
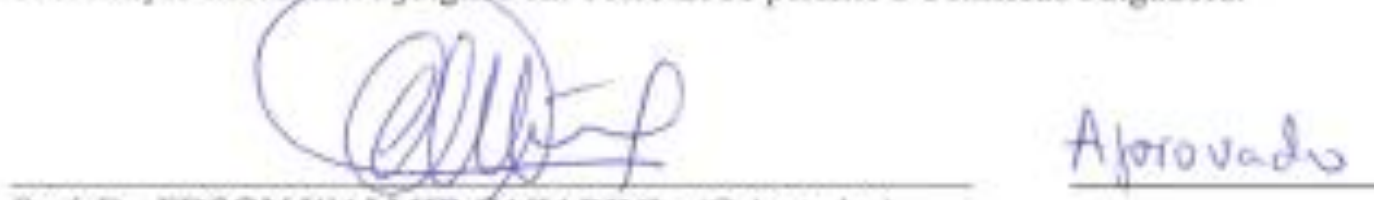

Prof. Dr. EDSON WALMIR CAZARINI - (Orientador)

(Escola de Engenharia de Sio Carlos/USP)
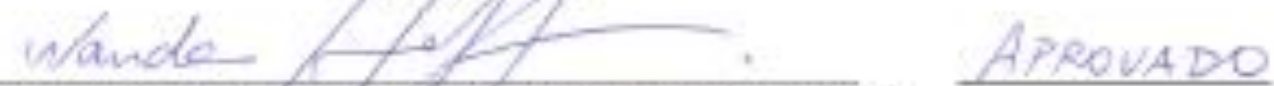

PNOE. DE, WANDA APARECIDA MACHAUO HOPFMANN

(Universidade Federal de São Carlos/UFSCar)

Prof. Associado SERGIO LUIS DA SILVA
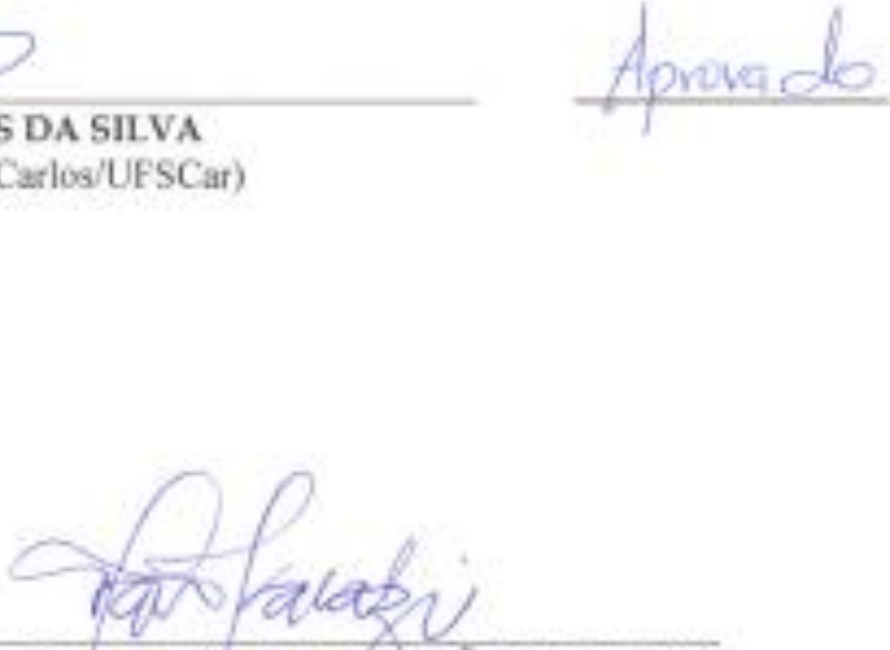

Prof. Associado AQUIL.ES ELIE GUIMARÃES KALATZIS

Coordenador do Programa de Pós-Graduagso em

Engenharia de Produça

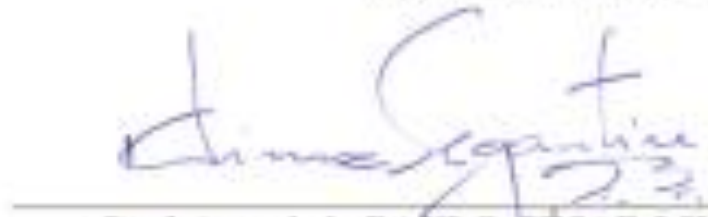

Prof: Associado PAULO CESAR LIMA SEGANTINE

Presidente da Connissio da Pós-Graduação da EESC 


\section{DEDICATÓRIA}

Dedico este trabajo a mis padres, Lucio Medrano Aguirre y María Pilar Castillo, por la educación inculcada, a mi hermana Madeleine Rocio, por el apoyo incondicional, a mis hermanas Flor Rosário y Yennyfer Esperanza, por las fuerzas dadas y a mis amigos, por ofrecerme compañía en el transcurrir de este estudio. 


\section{AGRADECIMENTOS}

Ao Dr. Edson Walmir Cazarini, pelo aprendizado gerado em mim, de quem tenho grande admiração, não só em assuntos acadêmicos, mas também em assuntos pessoais.

Ao departamento de engenharia de produção, professores e funcionários, pelo apoio no meu processo de formação.

À Escola de Engenharia de São Carlos pela oportunidade de realização do curso de mestrado

À Coordenação de Aperfeiçoamento de Pessoal de Nível Superior, pela concessão da bolsa de mestrado e pelo apoio financeiro para a realização desta pesquisa.

Aos pesquisadores que contribuíram com este trabalho, fazendo possível sua culminação.

Aos amigos e colegas do programa de mestrado, especialmente aos amigos do grupo de pesquisa DECIDIR. 


\section{RESUMO}

MEDRANO CASTILLO, L.A. (2010). Modelo integrado para a implantação e desenvolvimento da gestão do conhecimento. Dissertação (Mestrado) - Escola de Engenharia de São Carlos, Universidade de São Paulo, São Paulo, 2010.

O conhecimento tem se tornado um dos recursos estratégicos mais importantes no atual ambiente competitivo das empresas, fonte de vantagem competitiva sustentável. Devido a sua importância no sucesso organizacional, geri-lo adequadamente é uma das principais preocupações dos executivos. Com esse fim foram desenvolvidos modelos e metodologias para implantar a Gestão do Conhecimento nas companhias, trabalhos que apresentam limitações e levam às organizações a intentos falhos ou abordagens parciais do tema, limitações como a excessiva orientação sobre as tecnologias de informação, a falta de alinhamento com as estratégias da organização, a insuficiente atenção sobre os fatores humanos e culturais, o desenvolvimento de modelos sem base metodológica, e principalmente, a abordagem dividida da implantação da gestão do conhecimento. Fundamentado em uma exaustiva análise e reflexão dessas limitações, este trabalho tem como objetivo o desenvolvimento de um modelo integrado para a implantação e desenvolvimento da Gestão do Conhecimento, utilizando a metodologia de modelagem Enterprise Knowledge Development (EKD). Para a consecução do objetivo foi desenvolvida uma pesquisa bibliográfica, gerando a primeira versão do modelo, posteriormente este foi validado com especialistas em modelagem organizacional e gestão do conhecimento, obtendo-se da análise dessas apreciações uma versão aprimorada. O trabalho tem como resultado a confrontação e relação dos pareceres dos especialistas com a construção teórica, tendo como base o modelo proposto. O modelo proposto poderá orientar às organizações na prática da gestão do Conhecimento e servir de referência para sua melhor compreensão.

Palavras-chave: Gestão do conhecimento. Modelagem organizacional. Modelo de gestão do conhecimento. EKD. 


\begin{abstract}
MEDRANO CASTILLO, L.A. (2010). Integrated model for the implementation and development of knowledge management. Dissertação (Mestrado) - Escola de Engenharia de São Carlos, Universidade de São Paulo, São Paulo, 2010.

Knowledge has become one of the most important strategic resource in the current competitive business environment, a source of sustainable competitive advantage. Due to its importance in organizational success, managing it properly is a major concern of executives. To this goal models and methodologies have been developed to implement knowledge management in companies, researches that have limitations and lead organizations to failed attempts or partial approaches, limitations as the excessive orientation on the information technologies, the lack of alignment with organizational strategy, insufficient attention on human and cultural factors, the development of models without methodological basis, and mainly, an divided approach of the implementation of knowledge management. Based on a thorough analysis and reflection of these limitations, this study aims to develop an integrated model for the implementation and development of practices of knowledge management, using the Enterprise Knowledge Management (EKD) modeling methodology. To achieve the goal it was be developed a literature search, generating the first version of the model, after that it was be validated with experts in organizational modeling and knowledge management, resulting of the analysis of these appreciations an improved version. The work has resulted in the confrontation and relation of opinions of experts with the theoretical construct, based on the model. The model proposed can guide organizations in this practice and serve as a reference for its better understanding.
\end{abstract}

Keywords: Knowledge management. Organizational modeling. Knowledge management model. EKD. 


\section{LISTA DE FIGURAS}

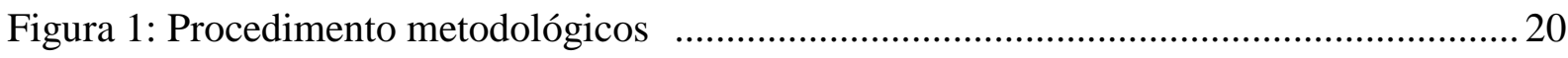

Figura 2: Inter-relação entre dado, informação e conhecimento ........................................... 24

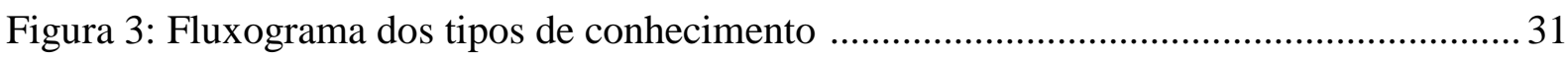

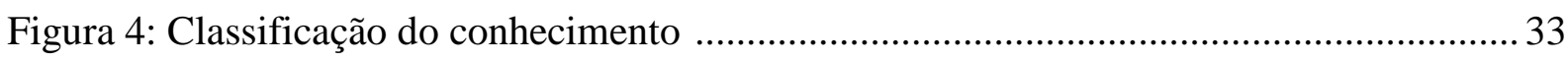

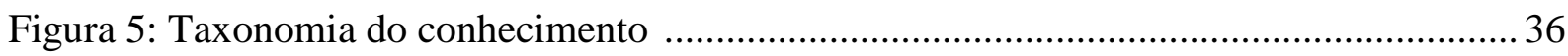

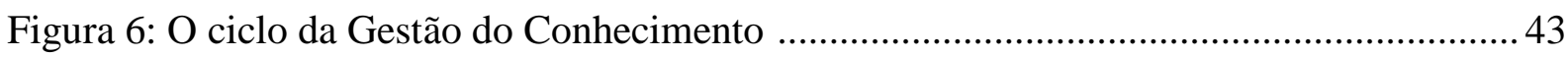

Figura 7: O ciclo de vida do conhecimento e o ambiente dos processos do negócio .............. 45

Figura 8: Modelo do ciclo da Gestão do Conhecimento .......................................................... 47

Figura 9: Modos de conversão do conhecimento ................................................................. 51

Figura 10: As duas dimensões da criação e conversão do conhecimento ................................51

Figura 11: Modelo de cinco fases do processo de criação do conhecimento ............................52

Figura 12: Três elementos do modelo da criação do conhecimento .......................................53

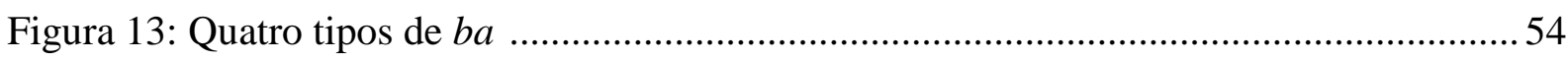

Figura 14: Quadro categorias de ativos de conhecimento ................................................. 55

Figura 15: Objetos da Gestão do Conhecimento e as abordagens organizacionais ................. 57

Figura 16: Estrutura integrada da Gestão do Conhecimento ................................................ 58

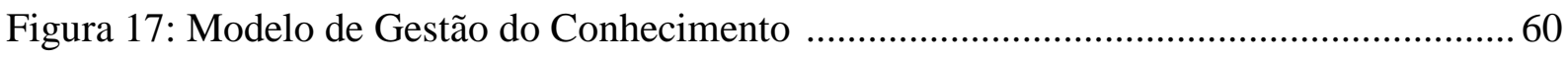

Figura 18: Formulando uma estratégia de Gestão do Conhecimento .................................... 76

Figura 19: Sobreposição da cultura organizacional com o conhecimento organizacional ...... 78

Figura 20: Sobreposição da cultura organizacional com a Gestão do Conhecimento ............. 79

Figura 21: Dez fatores para o desenvolvimento da cultura de conhecimento ......................... 80

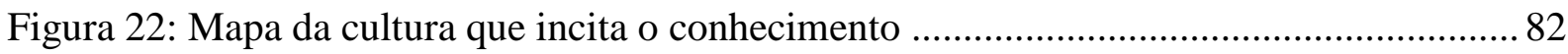

Figura 23: Modelo de implantação da Gestão do Conhecimento .......................................... 95

Figura 24: Estrutura de implantação da Gestão do Conhecimento ........................................ 96 
Figura 25: Modelo organizacional EKD

Figura 26: Ameaças do ambiente organizacional ............................................................. 113

Figura 27: Ameaças do ambiente organizacional - versão aprimorada ................................ 114

Figura 28: Objetivos organizacionais para responder às ameaças do ambiente .................... 115

Figura 29: Objetivos organizacionais para responder às pressões do ambiente - versão

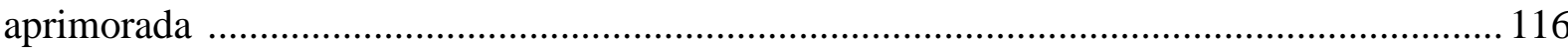

Figura 30: Importância do conhecimento para atingir os objetivos organizacionais ............. 117

Figura 31: Objetivo Gerir Conhecimento e os sub-objetivos para atingi-lo ........................... 118

Figura 32: Objetivo Gerir Conhecimento e os sub-objetivos para atingi-lo - versão

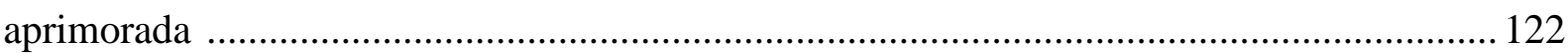

Figura 33: Modelo Regras atrelado ao Modelo de Objetivos ............................................ 124

Figura 34: Modelo de Regras atrelado ao Modelo de Objetivos - versão aprimorada ......... 127

Figura 35: Modelo de objetivos e Modelo de Regras para a implantação e desenvolvimento da

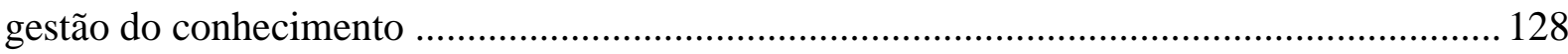

Figura 36: Legenda do Modelo de Objetivos e Modelo de Regras ...................................... 130

Figura 37: Modelo de conceitos para a implantação e desenvolvimento da Gestão do

Conhecimento

Figura 38: Parecer sobre a classificação do conhecimento proposta

Figura 39: Parecer sobre o responsável pelo desenvolvimento do processo do conhecimento

Figura 40: Parecer sobre a ação direta da GC sobre o trabalhador do conhecimento

Figura 41: Legenda do modelo de conceitos

Figura 42: Modelo de processos para a implantação e desenvolvimento da Gestão do Conhecimento

Figura 43: Parecer dos especialistas sobre a sequência dos processos

Figura 44: Parecer dos especialistas sobre a importância de ter uma equipe responsável pela

GC 
Figura 45: Parecer dos especialistas sobre a aplicação dos processos da GC sobre os processos intensivos em conhecimento

Figura 46: Modelo de processos aprimorado para a implantação e desenvolvimento da Gestão do Conhecimento - versão aprimorada

Figura 47: Legenda do modelo de conceitos 145

Figura 48: Modelo de atores e recursos para a implantação e desenvolvimento da Gestão do Conhecimento

Figura 49: Legenda do modelo de atores e recursos 147

Figura 50: Modelo de requisitos e componentes técnicos 149

Figura 51: Legenda do modelo de requisitos e componentes técnicos 150

Figura 52: Parecer dos especialistas sobre a integração dos modelos propostos 


\section{LISTA DE QUADROS}

Quadro 1: Críticas às definições tradicionais de conhecimento .............................................23

Quadro 2: Cinco modelos para definir dado (D), informação (I) e conhecimento (C) ............ 25

Quadro 3: Definições de dado, informação e conhecimento ................................................. 28

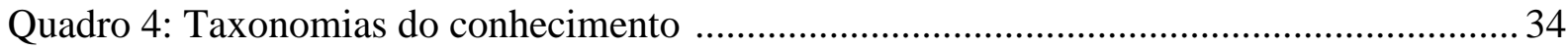

Quadro 5: Fluxo teórico da Gestão do Conhecimento ............................................................. 38

Quadro 6: Principais definições da Gestão do Conhecimento ............................................ 40

Quadro 7: Definiç̧̃̃es da Gestão do Conhecimento .......................................................... 41

Quadro 8: Evolução das funções dos elementos da Gestão do Conhecimento ........................58

Quadro 9: Modelo geral de maturidade da Gestão do Conhecimento ..................................... 63

Quadro 10: Componentes comuns dos modelos da Gestão do Conhecimento ........................ 65

Quadro 11: Fatores críticos de sucesso da Gestão do Conhecimento ......................................69

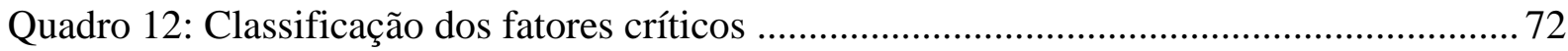

Quadro 13: Taxonomia da estratégia da Gestão do Conhecimento ........................................ 75

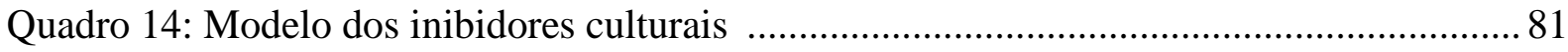

Quadro 15: Responsabilidade técnicas e funcionais do Diretor do Conhecimento .................. 86

Quadro 16: Ferramentas da Gestão do Conhecimento ........................................................ 91

Quadro 17: Comparação entre as metodologias de modelagem ......................................... 102

Quadro 18: Características das metodologias de modelagem ........................................... 102

Quadro 19: Importância dos objetivos organizacionais ................................................ 115

Quadro 20: Importância dos sub-objetivos para gerir conhecimento ................................... 121

Quadro 21: Comparação do modelo proposto com os modelos da literatura ........................ 154

Quadro 22: Estudo do Intellectual Capital Management Group ........................................... 180

Quadro 23: Indicadores propostos por Ross et al. (1998) .................................................. 180

Quadro 24: Reporte do Canadian Management Accountant .............................................. 180

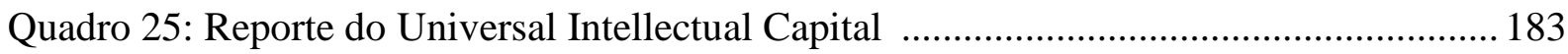




\section{LISTA DE SIGLAS}

\begin{tabular}{ll} 
CoPs & Conhecimento \\
D & Comunidades de Prática \\
DS & Dado \\
DU & Domínio Subjetivo \\
EKD & Enterprise Knowledge Development \\
GC & Gestão do conhecimento \\
I & Informação \\
MAR & Modelo de Atores e Recursos \\
MC & Modelo de Conceitos \\
MO & Modelo de Objetivos \\
MPN & Modelo de Processos do Negócio \\
MRCT & Modelo de Requisitos e Componentes Técnicos \\
\hline
\end{tabular}




\section{SUMÁRIO}

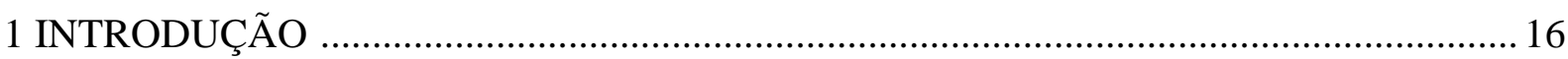

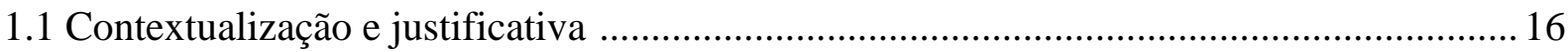

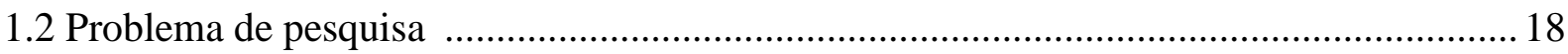

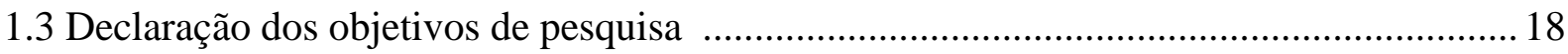

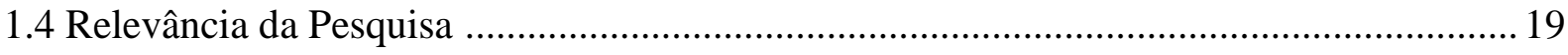

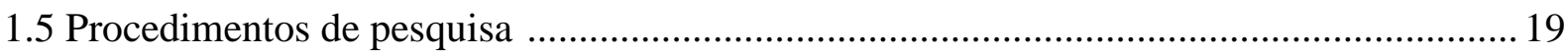

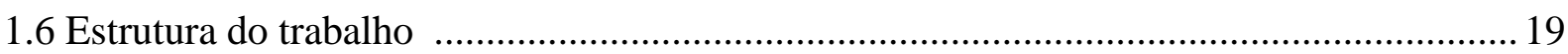

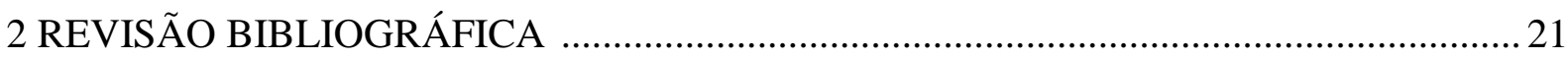

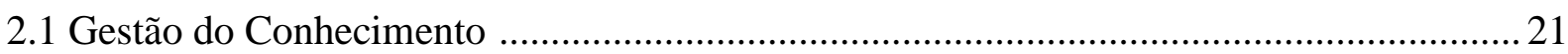

2.1.1 Conceitos importantes na Gestão do Conhecimento .................................................... 21

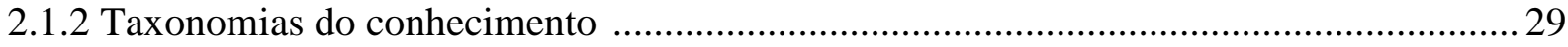

2.1.3 Conceituação da Gestão do Conhecimento .................................................................. 36

2.1.4 O ciclo da Gestão do Conhecimento ou processo do conhecimento ............................... 42

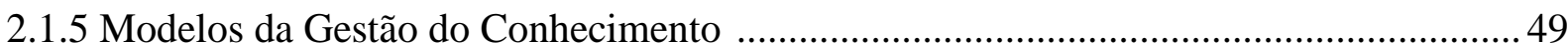

2.1.6 Fatores críticos de sucesso da Gestão do Conhecimento ................................................65

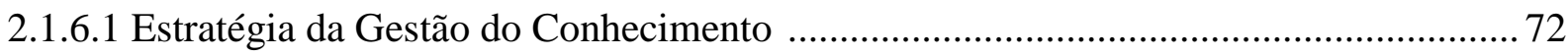

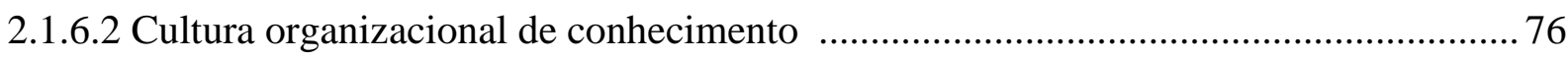

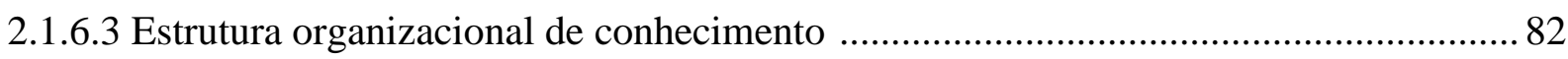

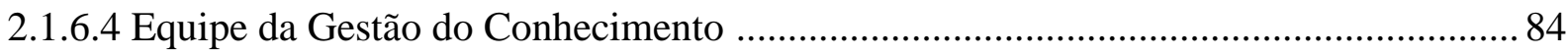

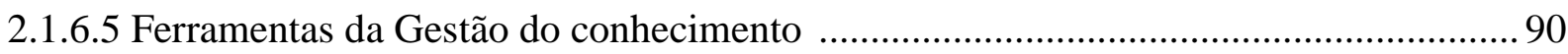

2.1.6.6 Ciclos ou processos da Gestão do Conhecimento .................................................... 91

2.1.6.7 Métricas da Gestão do Conhecimento ...................................................................... 91 


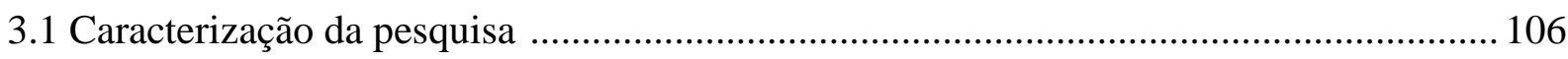

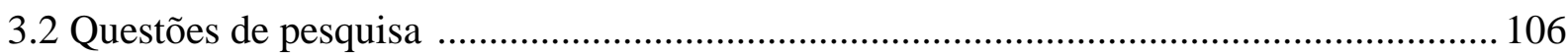

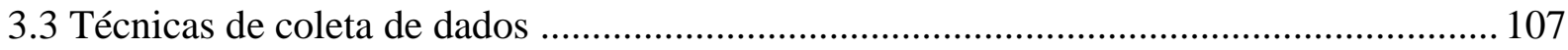

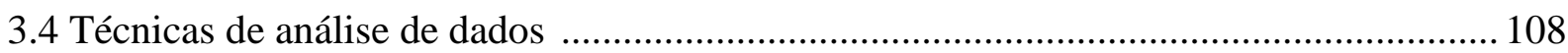

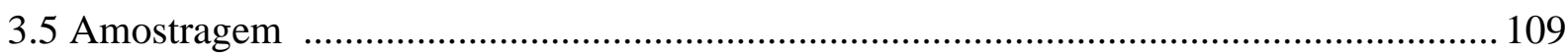

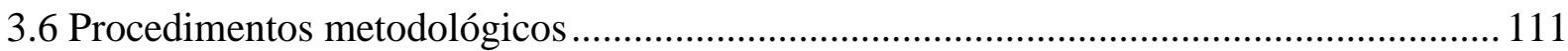

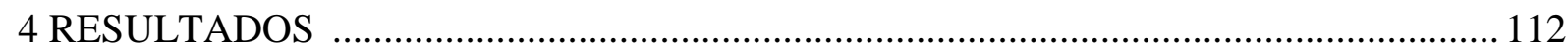

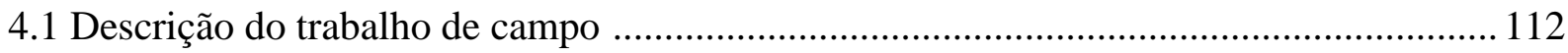

4.2 Apresentação do modelo e análise de resultados......................................................... 113

4.2.1 Modelo de objetivos para a implantação e desenvolvimento da Gestão do Conhecimento

4.2.1.1 Modelo de objetivos e regras do negócio ............................................................ 113

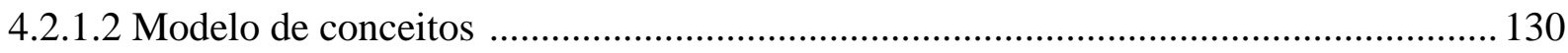

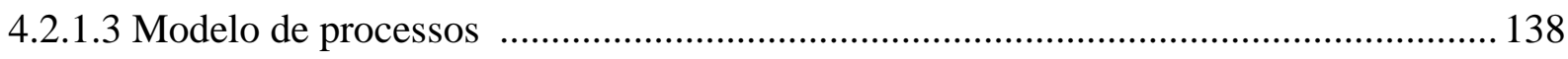

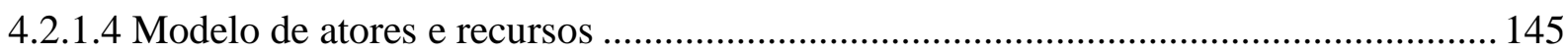

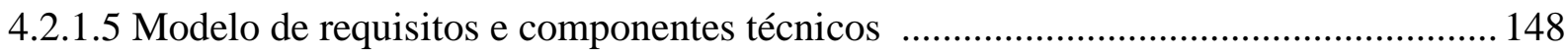

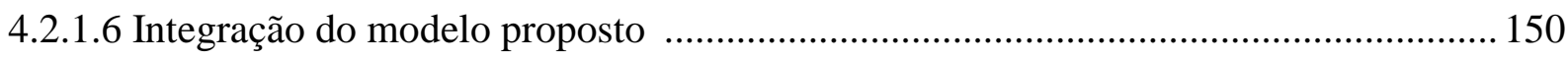

4.2.1.7 Comparação do modelo proposto com os modelos da literatura ............................... 151 


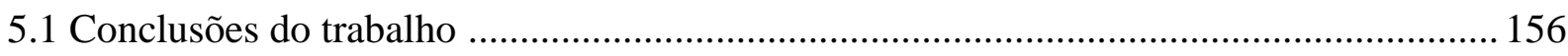

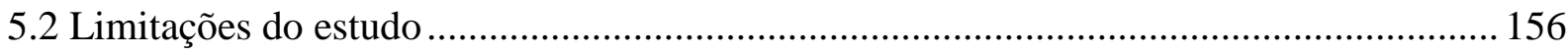

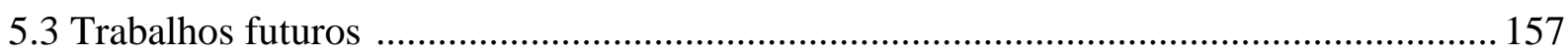

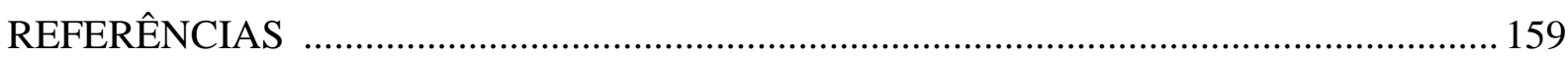

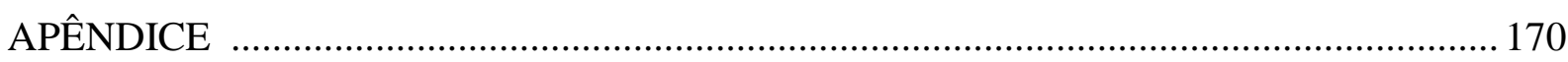

APÊNDICE A: Instrumentos de coleta de dados, entrevista semi-estruturada para a validação

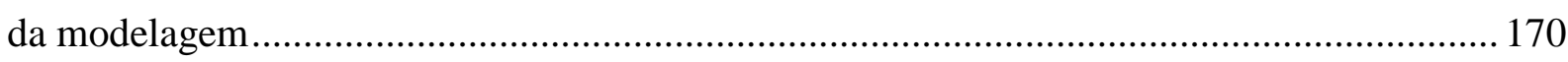

APÊNDICE B: Instrumentos de coleta de dados, questionário semi-estruturado para a

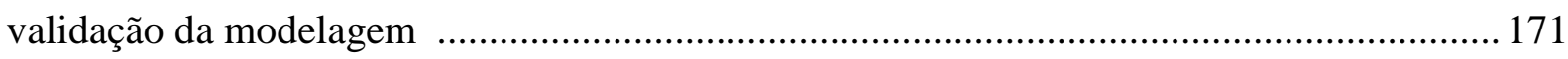

APÊNDICE C: Instrumentos de coleta de dados, questionário semi-estruturado para a

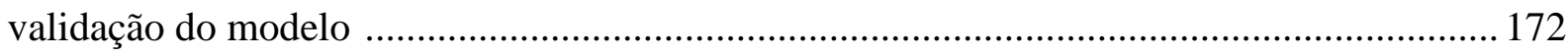

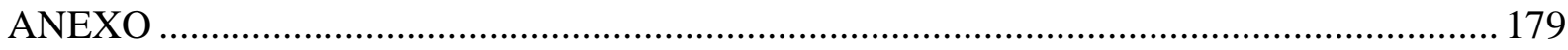

ANEXO I: Estudos para a determinação das métricas para os ativos do conhecimento ....... 179 


\section{INTRODUÇÃO}

\subsection{Contextualização e justificativa}

A economia baseada no conhecimento é o paradigma de desenvolvimento econômico pósindustrial dominante, que se originou nos anos 80, com uma ênfase sobre a criação e disseminação do conhecimento como principais condutores no processo do crescimento econômico, na distribuição da renda, na crescente importância das redes de trabalho baseadas em conhecimento dentro das organizações e na interface entre os negócios do governo e os cidadãos nas economias avançadas (HARRIS, 2001).

Essa era é reconhecida como a terceira revolução industrial, ancorada sobre novas tecnologias incorporadas em computadores, e o potencial de novas tecnologias de informação (HARRIS, 2001), que quando somadas às suas características de constante mudança, a crescente competição entre organizações e dinamicidade das preferências dos consumidores, vê no conhecimento o maior ativo para o desenvolvimento (ARORA, 2002; CHOI et al., 2008; VALENZUELA et al., 2008).

O conhecimento é agora tratado como um meio para a produtividade e o crescimento econômico, levando a um novo enfoque o papel da informação, da tecnologia e da aprendizagem no desempenho econômico (HARRIS, 2001).

Em termos simples, a economia baseada no conhecimento fundamenta-se na idéia de que o bem estar econômico é criado por meio da criação, produção, distribuição e aplicação do conhecimento e nos produtos baseados em conhecimento. Sendo que a referida economia não é uma nova idéia. Ela tem representado um papel importante, mas não preponderante na análise econômica desde os dias de Adam Smith. O que é novo é a visão de que a economia baseada no conhecimento tem se tornado o principal ou mesmo o mais importante aspecto na economia como um todo (HARRIS, 2001).

Dentro das organizações, quando o conhecimento é criado e disseminado, ele tem o potencial de contribuir no valor da companhia ao melhorar sua capacidade de responder às novas e incomuns situações (CHOI et al., 2008). Sendo assim, no mundo de hoje, é absolutamente 
crítico construir, preservar e aprimorar o conhecimento (ARORA, 2002; HARRIS, 2001; HOFFMANN, 2009; SILVA, 2004).

Devido à importância do conhecimento para explicar a diferença de desempenho entre organizações e o desenvolvimento da economia, sua adequada gestão tem sido alvo de debates entre gerentes, consultores e acadêmicos. Enquanto gerentes entendem que a única vantagem competitiva que as organizações têm reside na sua habilidade de aprender mais rápido que seus competidores, consultores oferecem modelos e soluções de Gestão do Conhecimento (GC) para saciar o apetite das organizações pela gestão efetiva de seus ativos de conhecimento. Finalmente, acadêmicos tentam explicar como o conhecimento, recurso valioso, inimitável, e insubstituível, é a última fonte para lograr vantagens competitivas sustentáveis (WU; LIN, 2009).

Nesse contexto, foram propostos modelos e metodologias para a implantação da GC nas organizações (ARORA, 2002; CHALMETA; GRANGEL, 2008; KJÆRGAARD; KAUTZ, 2008; WU; LIN, 2009), trabalhos que abordam o tópico sob diferentes perspectivas. A literatura sobre esse assunto depara-se com várias limitações, identificadas na análise pelo autor deste trabalho e com base em estudos que visam sua crítica construtiva (DUFOUR; STEANE 2007), desta forma, os modelos para a GC propostos até agora, presentes na literatura apresentam (CHEN; HUANG, 2007; LAM, 2005; LIEBOWITZ, 2008; WU; LIN, 2009):

- Excessiva orientação sobre as tecnologias de informação: os modelos priorizam exageradamente a parte "física" da GC, que compreendem os sistemas de GC, os portais corporativos, as diferentes tecnologias de informação e comunicação etc., sustentando que o uso de um sistema de GC será suficiente para garantir o sucesso da GC na organização;

- Falta de atenção sobre os fatores humanos e culturais: decorrente da primeira limitação, os modelos negligenciam a parte humana da GC, os aspectos culturais, individuais e organizacionais, muitos importantes em termos de conhecimento, embora este aspecto seja mencionado tem-se uma tendência ao discurso sem sua prática efetiva.

- Falta de alinhamento com as estratégias da organização: Os modelos estão isolados e fora do contexto organizacional, carentes de apoio da alta gerência e até contraditórios aos objetivos da organização;

- Abordagem dividida da implantação e desenvolvimento da GC: A GC é composta de inúmeros elementos, sendo difícil abordar o tópico de forma integral, mas ela pode ser 
estruturada sobre alguns fatores críticos de sucesso, que ao serem trabalhados de forma holística oferecem uma visão útil sobre o funcionamento desta prática. O problema é seu estudo divido, mostrando só uma de suas partes ou elementos (parte tecnológica, parte cultural, parte estratégica, parte de processos, parte de ferramentas etc.) o que limita sua compreensão, e ainda mais, induz a pensar em novos pesquisadores que a GC só é compreendida desses elementos.

- Falta de detalhamento nos trabalhos apresentados: determinados modelos são muito gerais, fugindo de tópicos ainda polêmicos na literatura e até mesmo confundindo os leitores;

- Desenvolvimento de modelos sem base metodológica: as propostas que surgem do pensamento dos pesquisadores e com base nos seus estudos são compartilhadas por meio de figuras, quadros, e desenhos empíricos, desprovidos de metodologias de modelagem que sustentem cientificamente e estruturem os resultados de seus trabalhos;

\subsection{Problema de pesquisa}

Fundamentado em uma exaustiva análise e reflexão dessas limitações, o problema de pesquisa pode ser descrito por meio da seguinte pergunta.

Como seria um modelo para a Gestão do Conhecimento integrado, detalhado e com uma base metodológica?

O problema de pesquisa visa motivar a superação das limitações apresentadas no item anterior, que são entendidas nos termos "integrado", as primeiras quatro limitações; “detalhado", a quinta limitação, e evidentemente "base metodológica" a última limitação.

\subsection{Declaração dos objetivos de pesquisa}

Com base no problema de pesquisa, o trabalho tem como objetivo propor um modelo integrado para a implantação e desenvolvimento da Gestão do Conhecimento nas organizações, com uma descrição detalhada de seus componentes e utilizando a metodologia de modelagem Enterprise Knowledge Development (EKD) como base para sua estruturação.

Sendo o modelo uma proposta do autor deste trabalho e visando sua melhor aceitação pela comunidade científica, o segundo objetivo de pesquisa é validar o modelo proposto com especialistas em Modelagem Organizacional e Gestão do Conhecimento. 


\subsection{Relevância da pesquisa}

A pesquisa poderá contribuir com a comunidade científica, as organizações e a sociedade como um todo, principalmente em dois aspectos: a revisão da literatura sobre a GC e o modelo gerado como uma nova ferramenta para seu desenvolvimento.

Devido à importância do conhecimento como fator estratégico para atingir vantagens competitivas sustentáveis, a GC tornou-se uma das principais atividades das organizações. Embora ela tenha sido alvo de muitas pesquisas e a causa de muitos debates, tanto no setor acadêmico quanto na indústria, ainda há muitas dúvidas sobre os conceitos e elementos que compõem a GC; e sobre a forma como ela deveria ser desenvolvida. A revisão da literatura e o modelo proposto por este trabalho poderão ajudar no esclarecimento e preenchimento destas lacunas de conhecimento.

A revisão da literatura visa não só a descrição dos principais trabalhos da área, mas sua análise crítica, escolha e formação de uma linha teórica que sirva de fundamento para o desenvolvimento do modelo proposto e para futuros trabalhos na área.

O modelo, resultado do trabalho, poderá servir de guia para as organizações que desejem implantar e/ou aprimorar suas atividades de GC.

\subsection{Procedimento de pesquisa}

Desenvolver-se-á uma pesquisa bibliográfica sobre a GC e sobre a modelagem organizacional, especificamente a metodologia de modelagem organizacional EKD. Com base nesta revisão da literatura será elaborada a primeira versão do modelo proposto, seguindo os procedimentos indicados pela metodologia EKD.

Posteriormente, essa primeira versão será submetida à análise e apreciação por parte de especialista em GC e modelagem organizacional com o objetivo de sua validação, tanto da comunidade científica quanto de organizações. Finalmente, o modelo será aprimorado com base na informação que será obtida na fase anterior, apresentado-se sua versão final. A figura 1 mostra os procedimentos metodológicos que serão utilizados pelo trabalho.

\subsection{Estrutura do trabalho}

Além deste primeiro capítulo em que se apresentam as características gerias do estudo. $\mathrm{O}$ trabalho é composto por os fundamentos teóricos sobre a GC e a modelagem organizacional, 
especificamente a metodologia de modelagem EKD, na revisão da bibliografia, capitulo $2 . \mathrm{Na}$ sequência, é apresentado de forma detalhada os métodos de pesquisa utilizados, a caracterização da pesquisa, as técnicas de coleta e análise de dados, a amostragem e os procedimentos metodológicos realizados, capítulo 3. Em seguida, é descrita a versão validada e aprimorada do modelo proposto, somada à análise dos dados coletados dos especialistas, capítulo 4. Por último, são abordadas as considerações finais, o referencial teórico, os apêndices e os anexos.

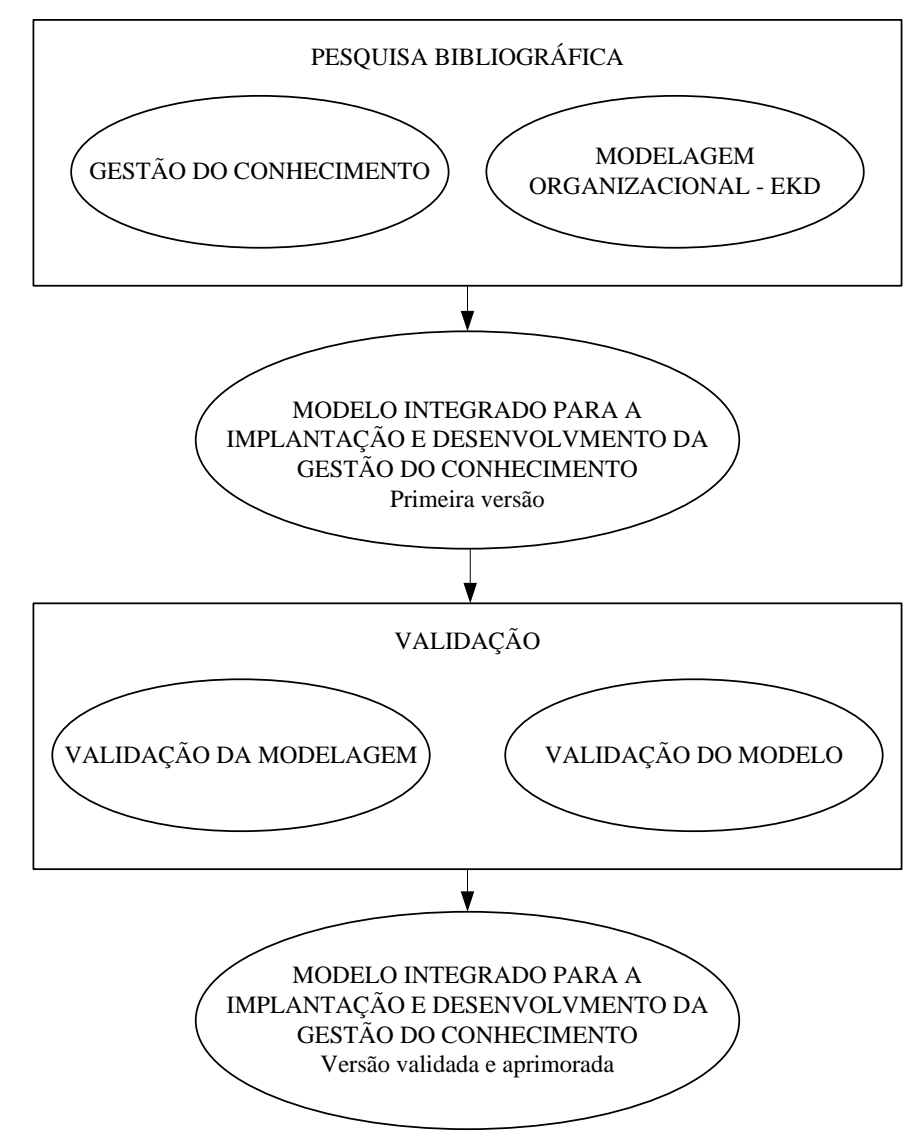

Figura 1- Procedimentos metodológicos 


\section{REVISÃO BIBLIOGRÁFICA}

\subsection{Gestão do conhecimento}

A Gestão do Conhecimento (GC) caracteriza-se por sua multidisciplinaridade, abrangendo áreas como a ciência organizacional, a ciência cognitiva, as tecnologias da informação, sociologia e antropologia, ciências da comunicação, psicologia, entre outras disciplinas. Por causa dessa característica ela é abordada desde muitas perspectivas, a saber, a perspectiva de negócio, a perspectiva da ciência cognitiva ou ciência do conhecimento e a perspectiva da tecnologia ou processo, sendo abrangente para poder sustentar as diferentes atividades organizacionais, mas, ao mesmo tempo, gerando confusão nas empresas e na comunidade científica (DALKIR, 2005). Com relação a essa cotação, embora alguns estudos possuam bases firmes para sua argumentação e desenvolvimento de teorias, outros carecem de bons fundamentos conceituais que suportem suas propostas, gerando ainda mais incerteza sobre o tema e incrementando sua complexidade, colocando até em dúvida a veracidade de sua utilidade e aporte ao sucesso organizacional. Baseado nesse problema, a revisão da literatura da GC tem como objetivo apresentar os principais autores, linhas teóricas e perspectivas da área, visando o esclarecimento desses tópicos e a formação de uma base conceitual robusta que sirva de alicerce para o modelo proposto.

\subsubsection{Conceitos importantes na Gestão do Conhecimento}

Adequadas definições de dado, informação e conhecimento são consideradas críticas por permitir o correto entendimento da GC. Tanto a comunidade científica quanto as organizações têm conceituado esses termos de diferentes formas, baseados nas visões de seus campos de estudo e do contexto, e ainda hoje um consenso está longe de ser alcançado. O que se pode afirmar é a inter-relação entre eles (ZINS, 2007).

Estes conceitos tiveram uma evolução em suas abordagens, sendo continuamente aprimorados, incitando optar um pensamento aberto, e em constante desenvolvimento por parte dos pesquisadores e das organizações.

Segundo Lee et al. (2006), três perspectivas sobre a definição do conhecimento têm ganhado destaque ao longo da evolução de sua conceituação: conhecimento como potencial, 
conhecimento como um ponto final em um continuum entre dado - informação conhecimento, e conhecimento como um objeto ou como um processo.

Dentro da primeira perspectiva, Churchman (1971) argumenta que o conhecimento é concebido como um potencial muito forte, que permite a uma pessoa ajustar seu comportamento de acordo com as circunstâncias e lhe oferece a habilidade de tornar os dados e a informação em ação efetiva.

Dentro da segunda perspectiva, Bell (1999) define dado como uma sequência ordenada de eventos ou estatísticas. O significado da informação distingue-se dos dados, e inclui o saber sobre notícias, eventos e acontecimentos. A importância do significado das notícias, eventos e acontecimentos, verificados por um contexto ou uma teoria, constituem o conhecimento.

Davenport e Prusak (1998), ainda dentro da segunda perspectiva, descrevem dados como um conjunto de fatos, objetivos e discretos sobre eventos. A informação é derivada dos dados por meio da contextualização, categorização, cálculo, correção, ou condensação e que pode tomar a forma de uma mensagem em um documento ou em comunicação visível ou audível. O conhecimento deriva da informação pelo processo de comparação, conversação, consequência e a realização de conexões com conhecimentos prévios. Davenport e Prusak (1998) definem o conhecimento como o conjunto de experiências, valores, informação contextual e insight de especialistas que oferecem uma estrutura para a avaliação e incorporação de novas experiências e informação.

Bierly et al. (2000) e Haywood (1995) estendem o continuum além do conhecimento e incluem a sabedoria e os insights. Haywood (1995) descreve o trabalho mental em que o entendimento é construído e inicia pela aquisição de dados, passando pela informação, conhecimento, sabedoria e insight. Bierly et al. (2000) ressalta que a sabedoria organizacional, o julgamento, a seleção e o uso de um conhecimento específico para um contexto específico, é importante, embora limitado, constructo da teoria organizacional baseado no conhecimento.

Muitas variações sobre esta segunda perspectiva foram desenvolvidas. Ackoff (1989) insere o termo "entendimento", Pór (1997) insere o termo "inteligência" entre o conhecimento e a sabedoria. Tuomi (1999) inverte a ordem da hierarquia, argumentando que o conhecimento deve vir primeiro e tem que ser usado para corrigir a semântica (o significado da estrutura), 
esta estrutura é posteriormente, usada, para representar a informação, e somente depois os dados podem surgir.

Dentro da terceira perspectiva, o conhecimento pode ser visto como um objeto independente do indivíduo conhecedor. Neste caso, o conhecimento é equiparado a patentes, relatórios, equações matemáticas ou planos, que podem ser capturados, distribuídos, mensurados e geridos. De forma alternativa, o conhecimento pode também ser visto como o processo de conhecer e de criar sentido, sendo, neste caso, inseparável do indivíduo conhecedor, e não tem significado algum em sua ausência; então, só as pessoas podem ser conhecedoras, não livros ou bancos de dados (LEE et al., 2006).

Sob uma abordagem da ciência da computação, Setzer (1999) apresenta os dados como abstrações formais quantificáveis puramente sintáticos; informação como abstrações informais que representam algum significado para alguém; e conhecimento como abstrações pessoais geradas a partir da experiência.

Uma terceira referência para a definição e inter-relação destes termos é sustentada por Firestone e McElroy (2003), dentro da denominada nova gestão do conhecimento (Firestone, 2001) ou a segunda geração da gestão do conhecimento (Zinz, 2007). Firestone e McElroy (2003) analisam criticamente as definições tradicionais sobre conhecimento (quadro 1), e realizam uma proposta enriquecida sobre a definição de dado, informação, conhecimento e de sua inter-relação.

\begin{tabular}{|l|l|}
\hline \multicolumn{1}{|c|}{$\begin{array}{c}\text { Definições tradicionais de } \\
\text { conhecimento }\end{array}$} & \multicolumn{1}{|c|}{$\begin{array}{c}\text { Crítica de Firestone e McElroy (2003) às definições } \\
\text { tradicionais de conhecimento }\end{array}$} \\
\hline $\begin{array}{l}\text { Platón - Nonaka e Takeuchi (1995): o } \\
\text { conhecimento são crenças verdadeiras } \\
\text { justificadas }\end{array}$ & $\begin{array}{l}\text { O conhecimento não pode ser justificado por falta de } \\
\text { evidências suficientes para provar sua veracidade ou } \\
\text { falsidade. }\end{array}$ \\
\hline $\begin{array}{l}\text { Davenport e Prusak (1998): o } \\
\text { conhecimento é informação em contexto }\end{array}$ & $\begin{array}{l}\text { Não há distinção entre informação e conhecimento, aspecto } \\
\text { demonstrável pela impossibilidade de existir informação } \\
\text { fora de contexto. }\end{array}$ \\
\hline $\begin{array}{l}\text { Sveiby (1998): o conhecimento é a } \\
\text { capacidade de agir }\end{array}$ & $\begin{array}{l}\text { Mesmo que o conhecimento seja necessário para a ação, } \\
\text { ele não é suficiente, já que também são indispensáveis a } \\
\text { intenção para o ato (atitude) e a capacidade ou poder para } \\
\text { efetivá-lo (habilidade). }\end{array}$ \\
\hline
\end{tabular}

Quadro 1: Críticas às definições tradicionais de conhecimento 
Com relação às criticas feitas por Firestone e McElroy (2003), após uma análise dos trabalhos publicados posteriores à publicação de Nonaka e Takeuchi (1995) e de trabalhos base na ciência organizacional, Nonaka e Krogh (2009) redefinem ou esclarecem o conceito de conhecimento, focando seu significado sobre as crenças justificadas, que resulta do processo em que pessoas, individual ou coletivamente justificam crenças na organização, e posicionam a verdade como fator importante por que permite à teoria adotar uma definição do conhecimento mais abrangente, em vez de simplesmente representações individuais ou organizacionais da realidade pré-concebida.

Firestone e McElroy (2003), baseados nos estudos de Popper (1999), definem três tipos de conhecimento: 1) conhecimento do mundo 1, ou conhecimento biológico, estruturas codificadas em sistemas físicos que permitem a esses objetos adaptar-se ao ambiente (o código genético no DNA, por exemplo); 2) conhecimento do mundo 2, ou conhecimento mental, crenças validadas sobre o mundo, o belo e o justo (na mente do indivíduo - domínio subjetivo); 3) conhecimento do mundo 3, ou conhecimento cultural, formulações lingüísticas validadas sobre o mundo, o belo e o justo (na sociedade - domínio objetivo ou universal).

Dentro da perspectiva do conhecimento do mundo 3 (domínio objetivo ou universal), Firestone e McElroy (2003) definem dado como o valor de um atributo observável, mensurável ou calculável. Os dados são sempre especificados em algum contexto conceitual, sempre existente (denominado de "só informação"), e é este contexto conceitual que expressa os dados em um formato estruturado, sendo o dado parte da informação. Informação são dados somados a compromissos conceituais e interpretações, ou somente esses compromissos e interpretações (só informação). Conhecimento é informação extraída, filtrada, formatada e processada numa forma especial; informação que passou por testes e validações somada ao contexto, compromissos e interpretações (figura 2).

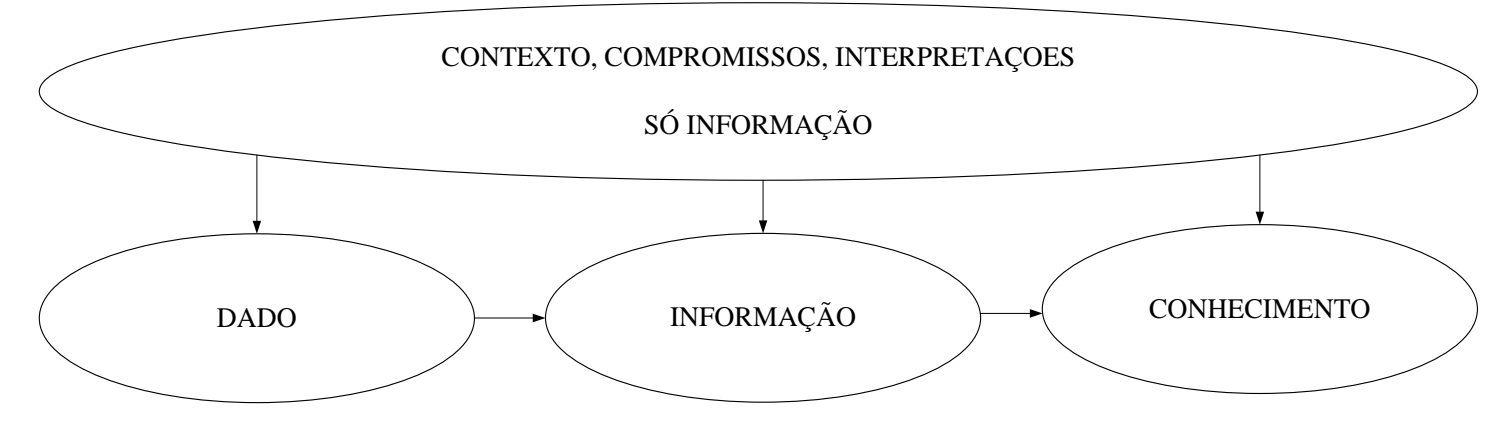

Figura 2 - Inter-relação entre dado, informação e conhecimento Fonte: adaptado de Firestone (2001) 
Dentro da perspectiva do conhecimento do mundo 2 (domínio subjetivo), as crenças sobre o mundo, o belo e o justo são considerados tanto como conhecimento quanto informação, desde que não sejam validadas, ou invalidadas, por serem próprias do indivíduo. Dados são crenças sobre experiências observáveis que o indivíduo compara com outras crenças passadas e as válidas, inválidas ou rejeitadas pela experiência.

Para Firestone e McElroy (2003) as pessoas nascem com conhecimento geneticamente codificado (conhecimento do mundo 1), que lhes permite interagir com o mundo externo e ter a capacidade de aprender. Este conhecimento é mais abundante em quantidade que todo o conhecimento que as pessoas adquirirão por meio da aprendizagem pelo resto da suas vidas. Elas utilizam este conhecimento para estruturar o mundo com mitos e crenças (conhecimento do mundo 2 e do mundo 3). Com estas predisposições e crenças as pessoas criam e estruturam experiências, e neste processo produzem dados, informação e conhecimento continuamente sem nenhuma ordem em particular.

Alinhado com a subjetividade e objetividade do conhecimento apresentado por Firestone e McElroy (2003), Zins (2007), sob uma visão da ciência da informação, desenvolveu um estudo com 57 pesquisadores de 16 países no mundo todo, abrangendo líderes em cada subárea da ciência de informação. Esse estudo teve como objetivo mapear as definições e a interrelação entre dado, informação e conhecimento, tendo as definições analisadas principalmente características não-metafísicas, centradas nas pessoas, baseadas na cognição e espontaneidade, resultando em cinco modelos de definição e inter-relação entre estes conceitos (quadro 2).

\begin{tabular}{|c|c|c|c|c|c|c|c|c|c|}
\hline \multicolumn{2}{|c|}{ Modelo 1 } & \multicolumn{2}{c|}{ Modelo 2 } & \multicolumn{2}{c|}{ Modelo 3 } & \multicolumn{2}{c|}{ Modelo 4 } & \multicolumn{2}{c|}{ Modelo 5 } \\
\hline DU & DS & DU & DS & DU & DS & DU & DS & DU & DS \\
\hline D & & D & & D & & D & D & D & D \\
\hline I & & & I & I & I & I & I & I & I \\
\hline & C & & C & C & C & & C & C & C \\
\hline
\end{tabular}

Quadro 2 - Cinco modelos para definir dado (D), informação (I), e conhecimento (C) (DU: Domínio Universal, DS: Domínio Subjetivo)

Fonte: Zins (2007)

Segundo Zins (2007), dado, informação e conhecimento, têm dois domínios de existência: domínio subjetivo (DS), próprio do indivíduo conhecedor, mundo interno da pessoa, conhecimento privado (sentimentos, sonhos, objetivos ocultos, incentivos etc.), seria o 
conhecimento do mundo 2 descrito por Firestone e McElroy (2003); e domínio objetivo ou domínio universal (DU), equivalente ao dizer que o conhecimento é um objeto, pertencente ao mundo externo da pessoa, conhecimento público (artigos, livros etc.), seria o conhecimento do mundo 3 descrito por Firestone e McElroy (2003).

O primeiro modelo considera dado e informação como fenômenos externos, e conhecimento como fenômeno interno. O segundo modelo considera dados como fenômenos externos, e informação e conhecimento como fenômenos internos. O terceiro modelo considera dado como fenômeno externo, e informação e conhecimento como fenômenos tanto internos quanto externos. O quarto modelo considera que dado e informação podem ser fenômenos internos e externos, e que conhecimento é fenômeno interno. Por último, o quinto modelo considera dado, informação e conhecimento fenômenos tanto internos quanto externos. Este último modelo é também sustentado por Firestone e McElroy (2003).

Para Zins (2007), em concordância com o quinto modelo, dado, informação e conhecimento podem ser definidos desde a perspectiva subjetiva e desde a perspectiva universal. Sob a primeira abordagem, dados são estímulos aos sentidos, ou seu significado, a percepção empírica. Informação é conhecimento empírico. Conhecimento é um pensamento da pessoa que é caracterizado pela crença justificável de que este é verdade, que pode ser empírico ou não-empírico.

Sob a perspectiva universal, dado, informação e conhecimento são artefatos humanos, que são representados por sinais empíricos (sinais que o indivíduo pode notar por meio dos sentidos), podendo tomar diferentes formas, figuras, letras, sons etc. Os dados são um conjunto de sinais que representam estímulos ou percepções empíricas; informação é um conjunto de sinais que representam conhecimento empírico, e o conhecimento é um conjunto de sinais que representam o significado (ou conteúdo) dos pensamentos que o indivíduo justificadamente, acredita que são verdadeiros.

Segundo Muller-Merbach (2006), a pluralidade do entendimento de conceitos como dado, informação, conhecimento, inteligência etc. trazem certa liberdade terminológica, esta liberdade deve ser bem-vinda por que permite que os conceitos sejam desenvolvidos, aprimorados, desdobrados e revelados com o tempo. Muller-Merbach (2006), sob uma visão filosófica sobre o conhecimento e sua gestão, cita a Eysenck (1979) para sugerir que uma definição operacional deve ser expressa por orações como: "conhecimento neste contexto deve ser entendido como..." e não por orações como: “conhecimento é...”. 
O quadro 3 resume as principais definições formuladas pelos autores citados, sobre dado, informação e conhecimento, independentemente de sua perspectiva de análise.

\begin{tabular}{|c|c|c|c|}
\hline AUTOR & DADO & INFORMAÇÃO & CONHECIMENTO \\
\hline $\begin{array}{l}\text { Davenport e } \\
\text { Prusak (1998) }\end{array}$ & $\begin{array}{l}\text { Conjunto de fatos, } \\
\text { objetivos e } \\
\text { discretos sobre } \\
\text { eventos. }\end{array}$ & $\begin{array}{l}\text { Informação é derivada dos } \\
\text { dados por meio da } \\
\text { contextualização, } \\
\text { categorização, cálculo, } \\
\text { correção, ou condensação. }\end{array}$ & $\begin{array}{l}\text { Conjunto de experiências, } \\
\text { valores, informação } \\
\text { contextual e insight de } \\
\text { expertos que oferecem uma } \\
\text { estrutura para a avaliação e } \\
\text { incorporação de novas } \\
\text { experiências e informação. }\end{array}$ \\
\hline Bell (1999) & $\begin{array}{l}\text { Sequência ordenada } \\
\text { de eventos ou } \\
\text { estatísticas. }\end{array}$ & $\begin{array}{l}\text { Dados mais significado, e } \\
\text { inclui o saber sobre notícias, } \\
\text { eventos e acontecimento. }\end{array}$ & $\begin{array}{l}\text { A importância do significado } \\
\text { das notícias, eventos e } \\
\text { acontecimentos, verificados } \\
\text { por um contexto ou uma } \\
\text { teoria. }\end{array}$ \\
\hline Setzer (1999) & $\begin{array}{l}\text { Abstrações formais } \\
\text { quantificáveis } \\
\text { puramente } \\
\text { sintáticos }\end{array}$ & $\begin{array}{l}\text { Abstrações informais que } \\
\text { representam algum } \\
\text { significado para alguém. } \\
\text { Contêm semântica e não } \\
\text { podem ser formalizadas } \\
\text { segundo uma teoria } \\
\text { matemática ou lógica }\end{array}$ & $\begin{array}{l}\text { Abstrações internas e } \\
\text { pessoais geradas a partir da } \\
\text { experiência }\end{array}$ \\
\hline $\begin{array}{l}\text { Firestone (2001) } \\
\text { Firestone e } \\
\text { McElroy (2003) }\end{array}$ & $\begin{array}{l}\text { Valor de um } \\
\text { atributo observável, } \\
\text { mensurável ou } \\
\text { calculável. } \\
\text { Crenças sobre } \\
\text { experiências } \\
\text { observáveis. }\end{array}$ & $\begin{array}{l}\text { Dados somados a } \\
\text { compromissos conceituais e } \\
\text { interpretações } \\
\text { Só informação: contexto } \\
\text { conceitual, compromissos } \\
\text { conceituais e interpretações }\end{array}$ & $\begin{array}{l}\text { Informação que passou por } \\
\text { testes e validações somadas } \\
\text { ao contexto, compromissos, } \\
\text { interpretações. } \\
\text { Crenças sobre o mundo, o } \\
\text { belo e o justo, não podendo } \\
\text { ser validadas ou invalidadas }\end{array}$ \\
\hline Lee et al. (2006) & & & $\begin{array}{l}\text { Objeto independente do } \\
\text { indivíduo conhecedor, } \\
\text { equiparado com patentes, } \\
\text { reportes, equações } \\
\text { matemática, podem ser } \\
\text { capturados, distribuídos, } \\
\text { mensurados e geridos. } \\
\text { Processo de conhecer e de }\end{array}$ \\
\hline
\end{tabular}




\begin{tabular}{|c|c|c|c|}
\hline & & & criar sentido. \\
\hline Zins (2007) & $\begin{array}{l}\text { Estímulos aos } \\
\text { sentidos, ou seu } \\
\text { significado, a } \\
\text { percepção empírica. } \\
\text { Conjunto de sinais } \\
\text { que representam } \\
\text { estímulos ou } \\
\text { percepções } \\
\text { empíricas. }\end{array}$ & $\begin{array}{l}\text { Conhecimento empírico. } \\
\text { Conjunto de sinais que } \\
\text { representam conhecimento } \\
\text { empírico. }\end{array}$ & $\begin{array}{l}\text { Pensamento da pessoa, que é } \\
\text { caracterizado pela crença } \\
\text { justificável que este é } \\
\text { verdade, pode ser empírico } \\
\text { ou não-empírico. } \\
\text { Conjunto de sinais que } \\
\text { representam o significado } \\
\text { (ou conteúdo) dos } \\
\text { pensamentos que o individuo } \\
\text { justificadamente, acredita } \\
\text { que são verdadeiros. }\end{array}$ \\
\hline
\end{tabular}

Quadro 3: Definições de dado, informação e conhecimento

A importância de se ter definiçõoes claras e escolher uma linha teórica para os conceitos básicos da GC se faz evidente por que segundo os trabalhos adotados como referência, o desenvolvimento e perspectivas da GC mudarão na organização. Por exemplo, segundo Lee et al. (2006), caso o conhecimento seja considerado como símbolo de poder, o seu compartilhamento dentro da organização se verá dificultado. Caso ele seja considerado como um continuum entre dado-informação-conhecimento, poderá criar rejeição entre os funcionários ao pensarem que eles precisam realizar esforços para poder obter conhecimento após o desenvolvimento desse processo de conversão. Finalmente, caso o conhecimento seja considerado objeto ou processo, a organização dará uma ênfase maior às estratégias voltadas ao conhecimento explícito ou às estratégias voltadas ao capital humano, respectivamente. Da mesma forma no caso do conhecimento objetivo e subjetivo.

Adicionalmente, segundo a escolha dos autores e linha teórica, aceitar-se-ão ou rejeitar-se-ão definições como contextualização, somente informação, conhecimento biológico e verdade absoluta.

Para a delimitação conceitual deste trabalho com relação aos termos dado, informação e conhecimento, serão tomadas como referência as definições apresentadas por Firestone e McElroy (2003), alinhadas ao quinto modelo e as definições fundamentadas por Zins (2007), devido à lógica do fundamento e por estarem em concordância com a visão conceitual dos autores deste trabalho. 
Portanto, conceitua-se dado como um valor de um atributo observável, mensurável ou calculável, representado por sinais empíricos (domínio objetivo), e como crenças sobre experiências observáveis, estímulos aos sentidos (domínio subjetivo). Informação é os dados somados a compromissos conceituais e interpretações, ou só esses compromissos conceituais e interpretações, contexto (domínio objetivo), e crenças sobre o mundo, o belo e o justo (domínio subjetivo). Conhecimento é informação que passo por testes e validações somada ao contexto, compromissos e interpretações, que o indivíduo justificadamente acredita que são verdadeiros (domínio objetivo), e crenças sobre o mundo, o belo e o justo, que o indivíduo acredita que são verdadeiros (domínio subjetivo). Adicionalmente reconhece-se a existência de um conhecimento base (conhecimento do mundo 1), necessário para a interação com o mundo e para a aprendizagem e o desenvolvimento dos outros dois tipos de conhecimento (conhecimento do mundo2 e conhecimento do mundo 3 ).

\subsubsection{Taxonomias do conhecimento}

Somente com a claridade conceitual do conhecimento e a consciência de seus vários tipos os gerentes do conhecimento podem iniciar um empreendimento eficaz na GC nas suas organizações (LEE et al., 2006).

A taxonomia do conhecimento foi abordada por vários autores, pesquisas que visaram aportar ao entendimento desse conceito e sua classificação, a seguir são apresentados os principais trabalhos relacionados ao tópico.

\section{A taxonomia do conhecimento segundo Lundvall e Johnson}

Lundvall e Johnson (1994) propuseram os termos know-what, know-why, know-how e knowwho. O know-what refere-se aos fatos, o know-why refere-se ao conhecimento sobre a causalidade, e elimina a necessidade de julgamento e erro, o know-how refere-se às habilidades ou a capacidade para fazer alguma coisa, e o know-who abrange o conhecimento sobre quem sabe que e quem sabe fazer que, ele também inclui as habilidades sociais que permitem a cooperação e a comunicação com colegas e colaboradores.

\section{A taxonomia do conhecimento segundo Blackler}

Blackler (1995) define conhecimento pessoal (embrained), como conhecimento que depende das habilidades conceituais e cognitivas; conhecimento incorporado (embodied) como ação orientada, mais provável de ser explícito; conhecimento cultural, como entendimentos 
compartilhados, relacionado aos processos de socialização e culturalização; conhecimento embutido (embedded), que reside nas rotinas sistemáticas; e conhecimento codificado, como informação transmitida por sinais e símbolos.

Conhecimento explícito versus conhecimento tácito: Nonaka e Takeuchi (1995), baseados nos estudos de Polanyi (1966), sustentam dois tipos de conhecimento, conhecimento explícito e conhecimento tácito. O conhecimento explícito pode ser expresso em letras, números, e compartilhado na forma de dados, fórmulas científicas, manuais etc. O conhecimento tácito inclui percepções subjetivas, intuições e palpites, é altamente pessoal e difícil de ser formalizado, o que faz complexo seu compartilhamento. Ele está profundamente enraizado nas ações e experiências do indivíduo, bem como nas suas idéias, valores e emoções. Segundo Nonaka e Krogh (2009) o conhecimento tácito é a pedra angular na teoria de criação de conhecimento organizacional.

A compreensão e caracterização do conhecimento tácito é ainda um desafio na comunidade científica, motivando vários estudos que objetivam sua delimitação e aprofundamento. Linde (2001) subdivide o conhecimento tácito em social, físico, e em outros conhecimentos. Schindler (2002) sustenta um conhecimento não-explícito, composto por conhecimento processual e possível de ser articulado, um componente cognitivo que não pode ser explicitado, e um conhecimento tácito incorporado, também impossível de ser articulado. Spender (2003) sustenta que a emoção é um tipo de conhecimento tácito. Nonaka (1994) e Takeuchi (2001) argumentam que o conhecimento tácito possui duas dimensões, a dimensão técnica, alinhada com as habilidades pessoais, e a dimensão cognitiva, consistente de crenças, ideais e valores.

Nickols (2000), baseado nos estudos de Polanyi (1966), sustenta o conceito de conhecimento implícito, que é o conhecimento que pode ser articulado, mas que ainda não foi; e aquele conhecimento que não pode ser articulado em um determinado momento é considerado conhecimento tácito. Por exemplo, um conferencista de mais de dez anos de experiência em comércio eletrônico realiza uma palestra a um público de cem pessoas por duas horas, tentando passar os conhecimentos que ele adquiriu nos dez anos, desde os conceitos e idéias básicas, até as mais complexas. Ele sem dúvida não poderá compartilhar todo o conhecimento que ele possui, não só por motivos de tempo, mas também por falta de recursos, meios ou formas para transmitir esse conhecimento. Ele pode não ter as palavras adequadas, ele pode carecer de casos que exemplifique bem os tópicos tratados ou mesmo não saber explicar bem 
os conceitos. Desta forma, o conhecimento nos slides será considerado conhecimento explícito, aquele conhecimento que ele seja capaz de transmitir é considerado segundo Nickols (2000) como conhecimento implícito, e aquele conhecimento que não seja capaz transmitir nessa palestra, nesse lapso de tempo, é considerado conhecimento tácito. Claro está que em oportunidades futuras, com mais recursos e meios de transmissão, o referido conhecimento tácito passará a ser implícito e posteriormente compartilhado. A figura 3 representa o fluxograma dos tipos do conhecimento sustentando por Nickols (2000).

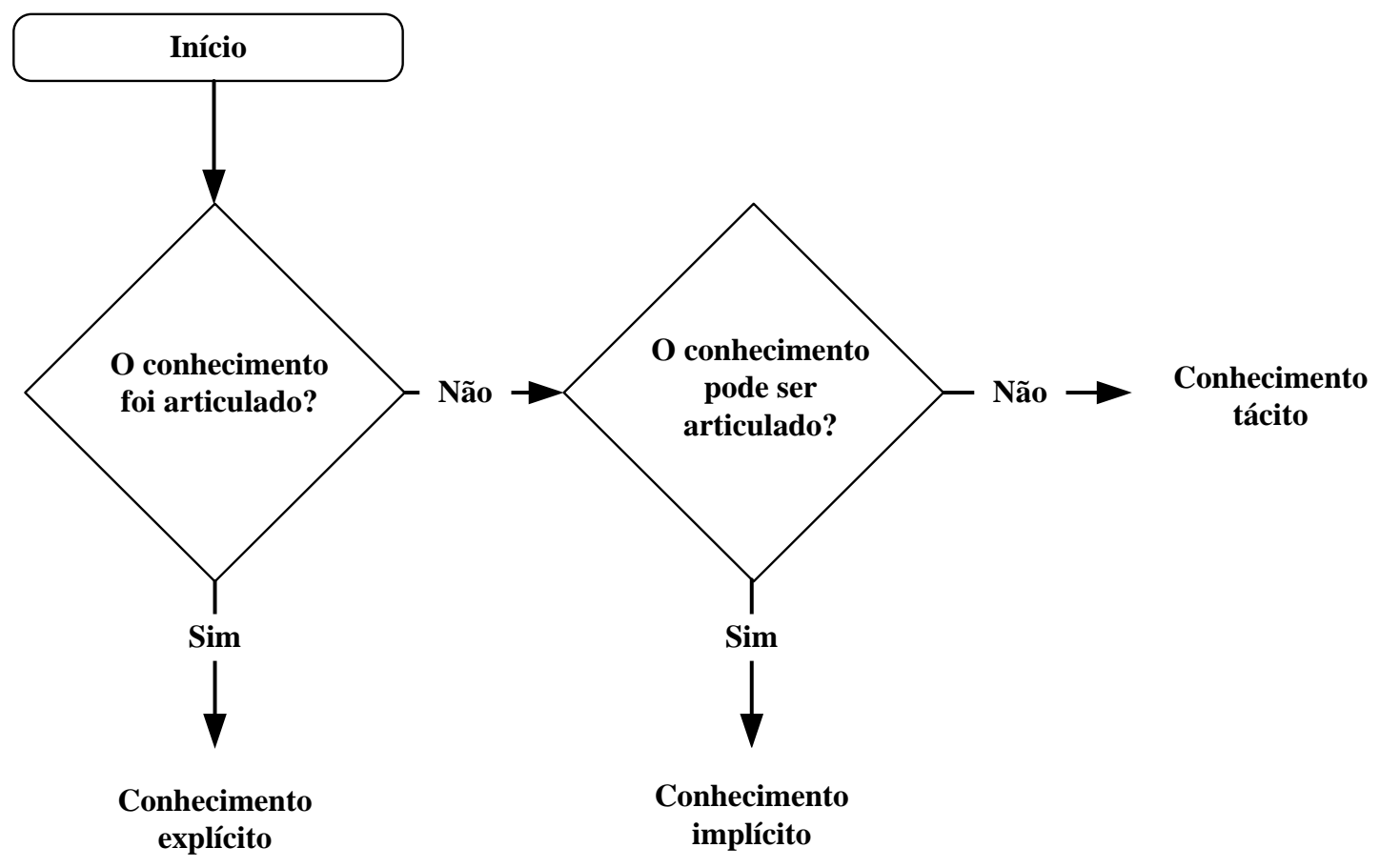

Figura 3 - Fluxograma dos tipos de conhecimento Fonte: Adaptado de Nickols (2000)

Segundo Frappaolo (2008), o conhecimento implícito tem um alto valor para a organização, e representa uma nova fronteira da $\mathrm{GC}$, mas as companhias devem empreender ações estratégicas com o objetivo de posicioná-lo adequadamente, identificando e quantificando suas fontes e sua natureza, desenvolvendo processos de garimpagem e conversão; processos baseados em metodologias estruturadas que aplicam técnicas de entrevista e esquemas para a captura de processos de razoamento. Frappaolo (2008) sugere a metodologia nomeada Knowledge Harvesting, desenvolvida por Wilson (2010).

Conhecimento positivo versus conhecimento negativo: o conhecimento sobre as falhas ou erros dos empreendimentos ou atividades da organização é tão importante quando o conhecimento dos sucessos empresariais (TEECE, 1998). Enquanto, é obvio que novo 
conhecimento útil para alguma inovação é desejado (conhecimento positivo), deve ser também reconhecido que experiências que conduzem a becos sem saída podem ser valiosas para a orientação e focalização de recursos que tenham resultados promissores no futuro (conhecimento negativo) (LEE et al., 2006). Segundo O`Dell e Grayson (1998) a rejeição da parte da gestão que fala sobre projetos que não deram certo (conhecimento negativo) dirigiria a uma cultura de compartilhamento de anti-conhecimento.

A taxonomia do conhecimento segundo Zack: Zack (1999) sustenta um conhecimento declarativo, ou conhecimento sobre algo, que se refere às etiquetas, categorias e distinções utilizadas para representar as coisas importantes para a organização; um conhecimento processual, ou "saber como", que inclui rotinas e rituais organizacionais e se refere ao entendimento de uma apropriada sequência de eventos ou a habilidade de desempenhar um conjunto particular de ações; um conhecimento causal, ou "saber por quê", que se refere ao entendimento do por quê as coisas acontecem. Estes dois últimos conhecimentos estão alinhados ao know-how e know-why, respectivamente, sustentado por Lundvall e Johnson (1994); e um conhecimento relacional, que se refere ao entendimento da relação entre os tipos de conhecimento.

Desde uma perspectiva estratégica, Zack (1999) define um conhecimento básico como o nível mínimo de conhecimento requerido pela organização para atuar no mercado; um conhecimento avançado como aquele conhecimento que permite que a organização seja competitivamente viável; e um conhecimento inovador como o conhecimento que permite à firma estar na frente de seus competidores. Zack (1999) adverte que o conhecimento não é estático, e que o conhecimento inovador de hoje pode se transformar em conhecimento básico amanhã, mas que todos os tipos de conhecimento são necessários para o saudável funcionamento da empresa. Com base nessa tipologia do conhecimento, Zack (1999) classifica as companhias em inovadoras, líderes, competidores viáveis, retardadas e em risco, dependendo do tipo de conhecimento possuído pela companhia com relação a seus competidores (Figura 4).

Taxonomias adicionais foram apresentadas por Morky (2003), que define conhecimento útil, como o conhecimento acumulado quando as pessoas observam fenômenos naturais no ambiente e tentam estabelecer regularidades e padrões. Este conhecimento pode ser o "que" ou conhecimento preposicional, relacionado com crenças sobre os fenômenos naturais e suas regularidades, e o "como" ou conhecimento instrucional ou prescritivo, relacionado com as 
técnicas. Conhecimentos relacionados ao know-what e ao know-how respectivamente, sustentados por Lundvall e Johnson (1994).

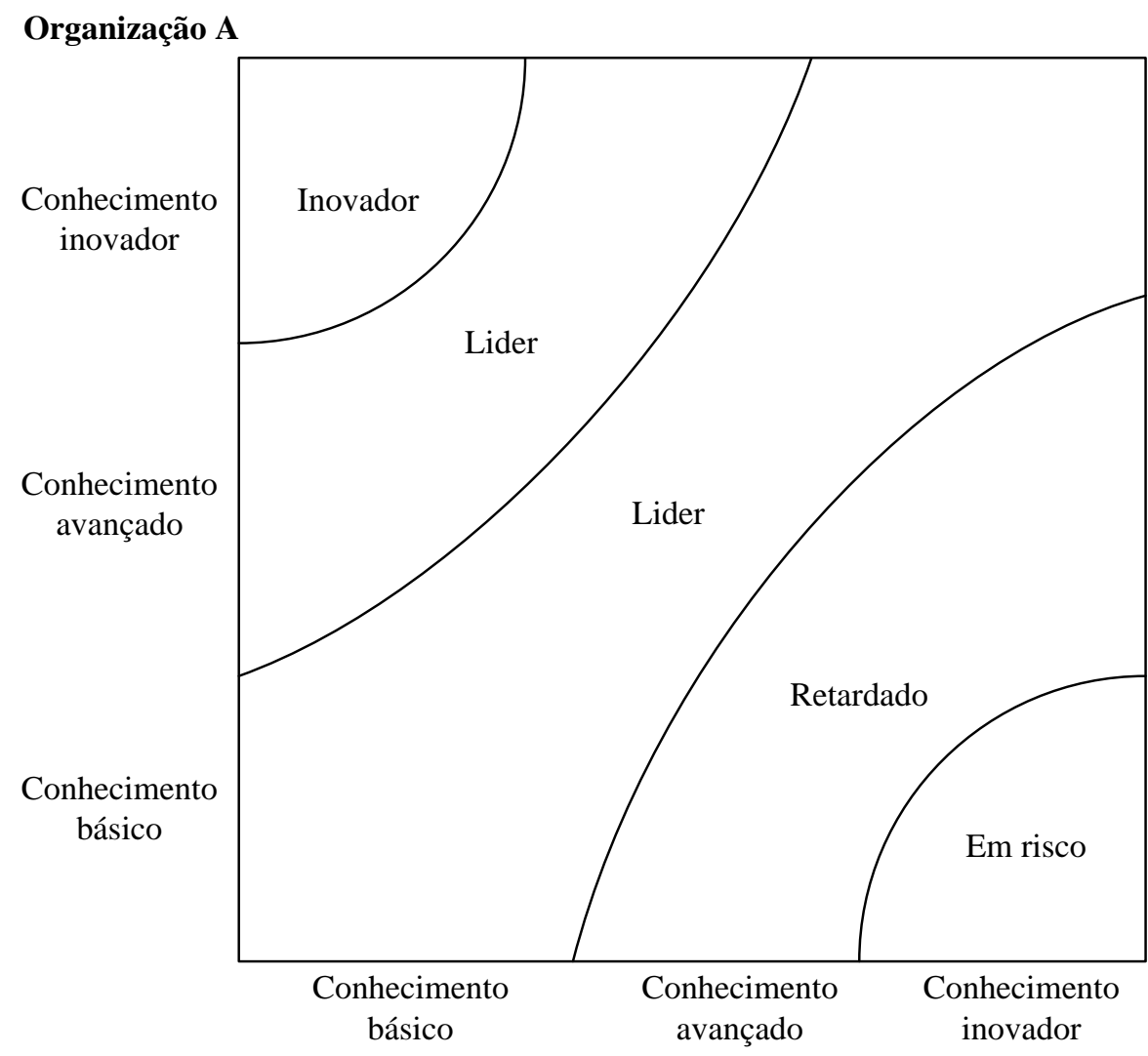

Competidores da organização A

Figura 4 - Classificação do conhecimento

Fonte: Adaptado de Zack (1999)

Aguayo (2004) divide o conhecimento em duas categorias, conhecimento substantivo, ou conhecimento sobre o campo específico de análise; e conhecimento empreendedor, que é o conhecimento de como monetizar ou comercializar o conhecimento substantivo. Aguayo (2004) argumenta que em uma organização há muitas pessoas com conhecimento substantivo para cada pessoa com conhecimento empreendedor, reconhecendo que para cada pessoa com boas idéias é necessário uma pessoa com boa visão de negócio, com o objetivo de obter resultados financeiros das idéias.

Schwalbe (2005) introduz o termo "conhecimento silencioso" para se referir ao conhecimento que permite a uma pessoa interagir com outra em várias situações, ele é usualmente não falado e é geralmente capturado por aprendizes em vez de ser ensinado pelos especialistas, ou 
lido em um livro. Classificações adicionais do conhecimento foram feitas por Boisot (1998), Machlup (1961), Price (1963), Wiig (1999) e foram identificados registros até na bíblia (conhecimento bom e conhecimento mau) (LEE et al., 2006). Além da classificação feita por Firestone e McElroy (2003) (conhecimento do mundo 1, do mundo 2 e do mundo 3) já apresentada no item anterior. $\mathrm{O}$ quadro 4 resume as taxonomias expostas.

\begin{tabular}{|c|c|}
\hline Autor & Taxonomia do conhecimento \\
\hline Lundvall e Johnson (1994) & $\begin{array}{l}\text { know-what } \\
\text { know-why } \\
\text { know-how } \\
\text { know-who. }\end{array}$ \\
\hline Blackler (1995) & $\begin{array}{c}\text { Conhecimento pessoal } \\
\text { Conhecimento incorporado } \\
\text { Conhecimento cultural } \\
\text { Conhecimento embutido } \\
\text { Conhecimento codificado }\end{array}$ \\
\hline Nonaka e Takeuchi (1995) & $\begin{array}{l}\text { Conhecimento explícito } \\
\text { Conhecimento tácito }\end{array}$ \\
\hline Teece (1998) & $\begin{array}{l}\text { Conhecimento positivo } \\
\text { Conhecimento negativo }\end{array}$ \\
\hline Zack (1999) & $\begin{array}{c}\text { Conhecimento declarativo } \\
\text { Conhecimento processual } \\
\text { Conhecimento causal } \\
\text { Conhecimento relacional } \\
\text { Conhecimento básico } \\
\text { Conhecimento avançado } \\
\text { Conhecimento inovador }\end{array}$ \\
\hline Nickols (2000) & Conhecimento implícito \\
\hline Firestone e McElroy (2003) & $\begin{array}{l}\text { Conhecimento do mundo } 1 \\
\text { Conhecimento do mundo } 2 \\
\text { Conhecimento do mundo } 3\end{array}$ \\
\hline Aguayo (2004) & $\begin{array}{l}\text { Conhecimento substantivo } \\
\text { Conhecimento empreendedor }\end{array}$ \\
\hline Schwalbe (2005) & Conhecimento silencioso \\
\hline
\end{tabular}

Quadro 4 - Taxonomias do conhecimento

Os diferentes tipos de conhecimento apresentados são considerados complementares entre eles, e são criados no ambiente externo e dentro da organização, interagem em uma forma caótica e ineficiente, combinados de formas imprevisíveis que resultam na criação de novos conhecimentos. No caso do conhecimento explícito e o conhecimento tácito, Mooradian 
(2005), como base nos estudos de Polanyi (1966), defende sua complementaridade ao afirmar que o conhecimento explícito depende do conhecimento tácito, quer dizer que para todo conhecimento explícito há algum conhecimento tácito por trás, formando uma estrutura, negando a contradição e separação entre esses dois tipos de conhecimento, negação também sustentada por Nonaka e Krogh (2009), que afirmam que "na teoria da criação do conhecimento organizacional o conhecimento tácito e o conhecimento explícito não devem ser vistos como entidades separadas, mas como mutuamente complementares e com base no mesmo continuum".

Para este trabalho se considerarão como referência duas classificações do conhecimento. Parcialmente, a classificação proposta por Nonaka e Takeuchi (1995) (conhecimento explícito e conhecimento tácito), somada à definição de conhecimento implícito sustentada por Nickols (2000), e ao conceito de conhecimento tácito apresentada por Polanyi (1966), e a classificação argumentada por Firestone e McElroy (2003) (conhecimento do mundo 1, do mundo 2 e do mundo 3). Então, serão utilizados os termos, conhecimento explícito para definir o conhecimento articulado, conceito igual ao proposto por Nonaka e Takeuchi (1995), e conhecimento não-explícito (independentemente da utilização feita por Schindler, 2002), composto pelo conhecimento implícito, que é o conhecimento não-explícito possível de ser codificado, conceito alinhado à definição feita por Nickols (2000), e o conhecimento tácito, que é o conhecimento impossível de ser codificado em um determinado momento, definição sustentada por Polanyi (1966). Sendo assim, deixa-se de lado o conceito de conhecimento tácito proposto por Nonaka e Takeuchi (1995).

Essa classificação é relacionada à taxonomia proposta por Firestone e McElroy (2001) apresentada no item anterior, catalogando o conhecimento do mundo 3 como conhecimento explícito, e o conhecimento do mundo 1 e 2 como conhecimento não-explícito. Sendo assim, o conhecimento biológico (conhecimento do mundo 1) e o conhecimento mental (conhecimento do mundo 2) são considerados conhecimentos não-explícitos, que podem ser implícitos ou tácitos, é dizer, passiveis de serem explicitados ou não, em um determinado momento; e o conhecimento cultural (conhecimento do mundo 3) é considerado conhecimento explícito. A figura 5 ajuda na compreensão desta delimitação conceitual.

Considerar a existência do conhecimento implícito e do conhecimento tácito é importante por que da mesma forma que as definições de dado, informação e conhecimento influenciam na perspectiva de tratamento da GC, aceitar que há um tipo de conhecimento que em um 
determinado momento não pode ser explicitado (conhecimento tácito), faz pensar no desenvolvimento de novas estratégias de compartilhamento e abordagem do conhecimento, como cursos de treinamento em mapas mentais, discursos, uso de metáforas, uso de casos, mentoring etc. Adicionalmente, rejeita-se a classificação feita por Nonaka e Takeuchi (1995) por considerá-la simplista e generalista, ao pensar que um termo tão complexo como é o conhecimento pode ter uma classificação de só dois itens, mostrando que a referida simplificação pode prejudicar as futuras ações e estratégias da GC, tornando-as também generalistas, questão difícil de aceitar quando o centro do negócio são as pessoas.

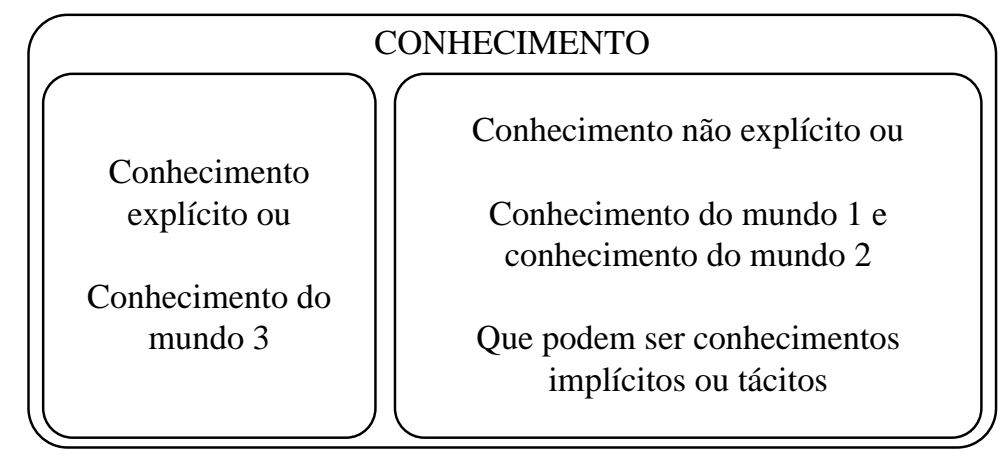

Figura 5 - Taxonomia do conhecimento

\subsubsection{Conceituação da Gestão do Conhecimento}

As teorias da GC emergiram de uma abrangente variedade de outros campos de estudo, sendo assim, sua legitimidade como um campo da ciência é mais amplo e forte, mas ao mesmo tempo difícil de conseguir um consenso de suas bases conceituais entre os membros tanto da comunidade científica quanto das organizações.

Segundo Dalkir (2005), a GC tem uma natureza multidisciplinar baseada em campos como a ciência organizacional, ciência cognitiva, linguística e linguística computacional, ciência da informação, jornalismo, antropologia, sociologia, educação, estudos de comunicação, entre outras áreas. Esta multidisciplinaridade é uma espada de dois gumes. Por um lado, isto é uma vantagem por que todos perceberam um fundamento familiar em que basear seu entendimento sobre a GC. Por outro lado a diversidade da GC apresenta alguns desafios com relação a suas fronteiras. Cépticos argumentam que a GC não é e não pode ser uma disciplina separada com um único corpo de conhecimento. Desta forma torna-se importante poder listar e descrever um conjunto de atributos necessários e suficientes para constituir à GC como uma disciplina e uma área que possa ser distinguida das outras. 
No mesmo contexto, Baskerville e Dulipovici (2006), sustentam que a GC tem como fundamentos teóricos com relação a sua base racional ou lógica às economias da informação e à gestão estratégica; com relação aos seus processos, à cultura, à estrutura e ao comportamento organizacional, e à inteligência artificial; e com relação a sua avaliação, à gestão da qualidade e à medição do desempenho organizacional. Cada um destes fundamentos teóricos apresentaram teorias que motivaram pressupostos chaves para a gestão do conhecimento. O quadro 5 mostra esse fluxo teórico.

\begin{tabular}{|c|c|c|c|c|}
\hline $\begin{array}{l}\text { Propósito } \\
\text { aplicado } \\
\text { na GC }\end{array}$ & $\begin{array}{l}\text { Fundamentos } \\
\text { teóricos }\end{array}$ & $\begin{array}{l}\text { Teorias chave } \\
\text { produtos dos } \\
\text { fundamentos } \\
\text { teóricos }\end{array}$ & $\begin{array}{c}\text { Teorias chave } \\
\text { desenvolvidas para a } \\
\text { GC }\end{array}$ & $\begin{array}{c}\text { Exemplo da aplicação } \\
\text { das teorias na GC }\end{array}$ \\
\hline \multirow[b]{2}{*}{$\begin{array}{l}\text { Base } \\
\text { racional } \\
\text { ou lógica }\end{array}$} & $\begin{array}{l}\text { Economia da } \\
\text { informação }\end{array}$ & $\begin{array}{l}\text { Capital intelectual, } \\
\text { propriedade } \\
\text { intelectual }\end{array}$ & $\begin{array}{l}\text { Economia do } \\
\text { conhecimento, redes de } \\
\text { conhecimento, ativos do } \\
\text { conhecimento, difusão } \\
\text { do conhecimento, gestão } \\
\text { da continuidade }\end{array}$ & $\begin{array}{l}\text { Tordoir (1995), Inkpen } \\
\text { e Tsang (2005), Teece } \\
\text { (2000), Foray (2004), } \\
\text { Beazley et al. (2002) }\end{array}$ \\
\hline & $\begin{array}{l}\text { Gestão } \\
\text { estratégica }\end{array}$ & $\begin{array}{l}\text { Competências } \\
\text { essenciais, } \\
\text { capacidades } \\
\text { dinâmicas }\end{array}$ & $\begin{array}{l}\text { Dumbsizing, alianças de } \\
\text { conhecimento, estratégia } \\
\text { do conhecimento, } \\
\text { mercado do } \\
\text { conhecimento, } \\
\text { capacidade do } \\
\text { conhecimento }\end{array}$ & $\begin{array}{l}\text { Conner e Prahalad } \\
\text { (1996), Eisenberg } \\
\text { (1997), Inkpen e Dinur } \\
\text { (1998), (Conner \& } \\
\text { Prahalad (1996), } \\
\text { Baskerville e Pries- } \\
\text { Heje (1999), Kafentzis } \\
\text { et al. (2004) }\end{array}$ \\
\hline \multirow{4}{*}{$\begin{array}{l}\text { Definição } \\
\text { dos } \\
\text { processos }\end{array}$} & $\begin{array}{l}\text { Cultura } \\
\text { organizacional }\end{array}$ & $\begin{array}{l}\text { Valores culturais, } \\
\text { poder, controle e } \\
\text { confiança }\end{array}$ & Cultura do conhecimento & $\begin{array}{l}\text { Graham \& Pizzo } \\
\text { (1996), De Long \& } \\
\text { Fahey (2000) }\end{array}$ \\
\hline & $\begin{array}{l}\text { Estrutura } \\
\text { organizacional }\end{array}$ & $\begin{array}{l}\text { A busca das metas } \\
\text { organizacionais }\end{array}$ & $\begin{array}{l}\text { Organizações do } \\
\text { conhecimento }\end{array}$ & $\begin{array}{l}\text { Starbuck (1997), Dyer } \\
\text { \& Nobeoka (2000) }\end{array}$ \\
\hline & $\begin{array}{l}\text { Comportament } \\
\text { o } \\
\text { organizacional }\end{array}$ & $\begin{array}{l}\text { Criatividade } \\
\text { organizacional, } \\
\text { inovação, } \\
\text { aprendizagem } \\
\text { organizacional, } \\
\text { memória } \\
\text { organizacional }\end{array}$ & $\begin{array}{l}\text { Criação do } \\
\text { conhecimento, } \\
\text { codificação do } \\
\text { conhecimento, } \\
\text { reutilização e } \\
\text { transferências do } \\
\text { conhecimento }\end{array}$ & $\begin{array}{l}\text { Nonaka e Takeuchi } \\
\text { (1995), Wiig (1995), } \\
\text { Hansen et al. (1999), } \\
\text { Markus (2001), } \\
\text { Nonaka e Toyama } \\
\text { (2003) }\end{array}$ \\
\hline & Inteligência & Sistemas baseados & Infra-estrutura do & Davenport et al. \\
\hline
\end{tabular}




\begin{tabular}{|c|c|c|c|c|}
\hline & artificial & $\begin{array}{l}\text { no conhecimento, } \\
\text { mineração de } \\
\text { dados. }\end{array}$ & $\begin{array}{l}\text { conhecimento, } \\
\text { arquitetura do } \\
\text { conhecimento, } \\
\text { descoberta do } \\
\text { conhecimento }\end{array}$ & $\begin{array}{l}\text { (1998), O’Leary } \\
\text { (1998b), Zhuge } \\
\text { (2002), Fayyad et al. } \\
\text { (1996), Shaw et al. } \\
\text { (2001) }\end{array}$ \\
\hline \multirow{2}{*}{ Avaliação } & $\begin{array}{l}\text { Gestão da } \\
\text { qualidade }\end{array}$ & $\begin{array}{l}\text { Gestão do risco, } \\
\text { benchmarking }\end{array}$ & $\begin{array}{l}\text { Equidade do } \\
\text { conhecimento, estruturas } \\
\text { qualitativas }\end{array}$ & $\begin{array}{l}\text { Glazer (1998), Jordan } \\
\text { e Jones (1997), King e } \\
\text { Zeithaml (2003) }\end{array}$ \\
\hline & $\begin{array}{l}\text { Medição do } \\
\text { desempenho } \\
\text { organizacional }\end{array}$ & $\begin{array}{l}\text { Medição do } \\
\text { desempenho } \\
\text { financeiro }\end{array}$ & Índices de desempenho & $\begin{array}{l}\text { Ahn e Chang (2004), } \\
\text { Chang Lee et al. } \\
\text { (2005) }\end{array}$ \\
\hline
\end{tabular}

Quadro 5 - Fluxo teórico da Gestão do Conhecimento

Fonte: Baskerville e Dulipovici (2006)

Uma vez que a GC fornece o fundamento para que uma organização possa entender e alimentar suas fontes e atividades de conhecimento, torna-se imperativo que uma definição standard ou operacional da GC seja desenvolvida e promulgada. Isto deve permitir às empresas compartilhar experiências utilizando o mesmo construto, embora poucos concordariam com uma definição comum sobre seu conceito, sendo evidente que não há uma acepção standard para este termo (McMANUS; SNYDER, 2003).

Pillania (2009) apresenta algumas implicações devido à falta de consenso e de uma definição clara da GC:

- A luta pela apropriação do conceito entre as várias áreas funcionais, particularmente a TI e os recursos humanos tem criado confusão entre os usuários deste termo no mercado, nas universidades e nas escolas de negócio.

- A confusão e a falta de informação criada em torno do conceito tem gerado uma percepção maior de complexidade e complicação, incentivando questionamentos sobre sua própria credibilidade.

- Ao focar e trazer o conceito dentro de um domínio funcional como a TI, o conceito é forçado a dito referencial e seu desempenho é limitado. Este é utilizado mais como uma estratégia de minimização de riscos. Então, é essencial olhar o conceito de uma forma abrangente e dentro do seu verdadeiro espírito ou essência.

No intuito de conceituar a GC, McManus e Snyder (2003) fizeram uma análise sobre as principais definições propostas na literatura identificando as premissas em que elas se fundamentam (quadro 6). 


\begin{tabular}{|c|c|c|}
\hline Fonte & Definição da GC & Premissa \\
\hline Martin (2000) & $\begin{array}{l}\text { Processo de identificação, } \\
\text { captura e alavancagem do } \\
\text { conhecimento para ajudar na } \\
\text { competitividade da organização }\end{array}$ & $\begin{array}{l}\text { A gestão do conhecimento visa a } \\
\text { entrega de valor ao consumidor } \\
\text { por meio da aquisição, criação, } \\
\text { compartilhamento e reuso de } \\
\text { qualquer aspecto de } \\
\text { conhecimento relevante à } \\
\text { organização e seu ambiente, } \\
\text { interno e externo. }\end{array}$ \\
\hline Barth (2001) & $\begin{array}{l}\text { Metodologia sistemática para } \\
\text { ajudar no fluxo da informação e } \\
\text { do conhecimento para as pessoas } \\
\text { certas para que elas possam agir } \\
\text { de formas mais efetiva. }\end{array}$ & $\begin{array}{l}\text { A gestão do conhecimento está } \\
\text { relacionada à criação de uma } \\
\text { cultura organizacional que } \\
\text { aprenda da experiência, de forma } \\
\text { que se erros acontecem eles não } \\
\text { se repitam. }\end{array}$ \\
\hline Dzinkowiski (2001) & $\begin{array}{l}\text { A gestão do conhecimento está } \\
\text { relacionada à localização ou à } \\
\text { criação de conhecimento útil e } \\
\text { sua disseminação pela } \\
\text { organização. }\end{array}$ & $\begin{array}{l}\text { A habilidade de gerir } \\
\text { conhecimento será uma das } \\
\text { vantagens competitivas duráveis } \\
\text { que a companhia terá ao longo } \\
\text { do tempo. }\end{array}$ \\
\hline Koch e Hope (2002) & $\begin{array}{l}\text { A aplicação do conhecimento, } \\
\text { manipulação das habilidades } \\
\text { para o desenvolvimento de } \\
\text { atividades de manipulação de } \\
\text { conhecimento que operam nas } \\
\text { fontes de conhecimento da } \\
\text { organização com o objetivo de } \\
\text { atingir a aprendizagem } \\
\text { organizacional e projeção. Este } \\
\text { processo é tanto facilitado } \\
\text { quanto constrangido pela } \\
\text { influência da GC e é } \\
\text { desencadeada pela necessidade } \\
\text { de conhecimento. }\end{array}$ & $\begin{array}{l}\text { A habilidade organizacional de } \\
\text { gerir conhecimento poderá ser a } \\
\text { única fonte de vantagem } \\
\text { competitiva. }\end{array}$ \\
\hline Buhler (2002) & $\begin{array}{l}\text { A habilidade de utilizar } \\
\text { efetivamente o conhecimento } \\
\text { para desenvolver novos produtos } \\
\text { e serviços ou fazer mudanças } \\
\text { importantes na forma em que o } \\
\text { negócio é dirigido. }\end{array}$ & $\begin{array}{l}\text { Somente pelo desenvolvimento } \\
\text { da aprendizagem organizacional } \\
\text { por meio do conhecimento que } \\
\text { as organizações adquirem, elas } \\
\text { podem adaptar-se e responder a } \\
\text { seu ambiente em constante }\end{array}$ \\
\hline
\end{tabular}




\begin{tabular}{|c|c|c|}
\hline & & mudança. \\
\hline Dusseldorp (2003) & $\begin{array}{l}\text { Uma definição geral da gestão } \\
\text { do conhecimento é conseguir a } \\
\text { informação certa para as pessoas } \\
\text { certas no tempo certo com o } \\
\text { objetivo de eles tomarem } \\
\text { melhores decisões. }\end{array}$ & $\begin{array}{l}\text { Retenção da expertise de } \\
\text { funcionários chave e o } \\
\text { melhoramento da interação entre } \\
\text { a tecnologia, pessoas e } \\
\text { processos. Investimento em uma } \\
\text { variedade de software e serviços } \\
\text { para suportar as iniciativas da } \\
\text { GC. }\end{array}$ \\
\hline
\end{tabular}

Quadro 6 - Principais definições da Gestão do Conhecimento

Fonte: McManus e Snyder (2003)

Definições adicionais sobre a GC, consideradas relevantes pelo autor deste trabalho, são apresentadas no quadro 7 .

\begin{tabular}{|c|c|}
\hline Autor & Definição \\
\hline Wiig (1999) & $\begin{array}{l}\text { A GC deve ser entendida sob três perspectivas: } \\
\text { Desde a perspectiva de negócio: focado no por que, onde e em que medida a } \\
\text { organização deve investir ou explorar seu conhecimento. } \\
\text { Desde a perspectiva da gestão: focado em determinar, organizar, dirigir, facilitar e } \\
\text { monitorar as atividades e práticas relacionadas ao conhecimento requeridas para } \\
\text { atingir as estratégias e objetivos desejados pelo negócio. } \\
\text { Desde a perspectiva operacional: focado na aplicação da expertise para conduzir } \\
\text { tarefas e trabalhos relacionados ao conhecimento explícito. }\end{array}$ \\
\hline $\begin{array}{l}\text { Firestone e } \\
\text { McElroy (2003) }\end{array}$ & $\begin{array}{l}\text { A gestão do conhecimento é uma atividade humana que faz parte do processo da } \\
\text { gestão do conhecimento de um agente ou um conjunto de agentes. O processo da } \\
\text { gestão do conhecimento é uma rede contínua, persistente e proposital de } \\
\text { interações entre agentes que visam a gestão (manipular, dirigir, governar, } \\
\text { controlar, coordenar, planejar, organizar) de outros agentes, componentes e } \\
\text { atividades, participando no processo básico do conhecimento (produção e } \\
\text { integração do conhecimento) com o objetivo de produzir um todo unificado, bem } \\
\text { planejado e dirigido; produzindo, mantendo, aprimorando,adquirindo, e } \\
\text { transmitindo a base de conhecimento da organização. }\end{array}$ \\
\hline Pillania (2004) & $\begin{array}{l}\text { A gestão do conhecimento como um processo contínuo, sistemático, organizado e } \\
\text { explícito de criação, disseminação, aplicação, renovação e atualização do } \\
\text { conhecimento com a finalidade de atingir os objetivos organizacionais. }\end{array}$ \\
\hline Dalkir (2005) & $\begin{array}{l}\text { A GC é a coordenação deliberada e sistemática das pessoas, estrutura, processos e } \\
\text { tecnologia organizacional com o objetivo de agregar valor por meio da } \\
\text { reutilização do conhecimento e a inovação. Esta coordenação é atingida por meio } \\
\text { da criação, compartilhamento e aplicação do conhecimento, assim como da }\end{array}$ \\
\hline
\end{tabular}


\begin{tabular}{|l|l|}
\hline & $\begin{array}{l}\text { incorporação de lições aprendidas e melhores práticas dentro da memória } \\
\text { organizacional, visando o fomento da aprendizagem organizacional continua. }\end{array}$ \\
\hline
\end{tabular}

Quadro 7: Definições da Gestão do Conhecimento

Firestone e McElroy (2003) explicitam um erro comum em algumas das definições apresentadas, indicando um falso foco no processo do conhecimento para a definição da GC, afirmando que a GC não é o processo de produção e integração do conhecimento, sendo este na verdade o processo do conhecimento. Adicionalmente esses autores comentam que muitas definições carecem de uma falta de tratamento da "gestão" assim como do "conhecimento", como se os especialistas pensassem que a GC não é uma forma de gestão.

É importante comentar que a referida gestão aplica-se não sobre o conhecimento, por ser considerado elemento dependente da pessoa conhecedora e sim sobre os fatores envolta do conhecimento (estrutura organizacional, cultura, tecnologias de informação etc.) por serem considerados elementos independentes da pessoa conhecedora, visão alinhada com os estudos de Davenpork e Prusak (1998).

No mesmo contexto, é relevante explicitar que as definições apresentadas estão fundamentadas em paradigmas influenciados pelas diferentes áreas de conhecimento que vem cada um dos autores e principalmente pela definição de conhecimento que sustenta cada um deles.

Por último, Dalkir (2005) sugere que uma organização deve desenvolver sua própria definição sobre a GC e sobre os principais conceitos relacionados a ela, de modo a criarem um norte para suas atividades, existindo variadas definições na literatura e no mercado sobre a GC, mas com apenas uma adotada pela companhia. Ele sugere a técnica de análise de conceito para atingir a referida definição.

A definição que norteará este trabalho está alinhada às definições sustentadas por Firestone e McElroy (2003) e por Dalkir (2005), sendo assim, define-se a GC como a atividade de gestão (planejar, organizar, coordenar, dirigir, controlar, avaliar) de pessoas, estrutura, processos, ferramentas e demais componentes organizacionais, com o objetivo de agregar valor para a organização por meio da produção e integração do conhecimento (ciclo da gestão do conhecimento ou processo do conhecimento).

A definição apresentada evidencia a abrangência que deve ter a GC na organização, compreendendo aos seus principais elementos, dando fundamento ao enunciado que sustenta 
que a GC dá origem a uma nova forma de gestão organizacional; Adicionalmente, a definição explicita o principal objetivo da GC (a agregação de valor) e sua base operacional (o processo do conhecimento).

\subsubsection{O ciclo da Gestão do Conhecimento ou o processo do conhecimento}

Segundo Birkinshaw e Sheehan (2002) os modelos de ciclo de vida desenvolvidos na literatura aplicados a diferentes áreas de conhecimento têm sido sucedidamente utilizados como uma ferramenta para o entendimento de produtos, tecnologia, e atividades organizacionais.

Para King et al. (2008), o ciclo da GC oferece uma forma útil de organizar o próprio pensamento sobre a GC. Ele é considerado a base operacional da sua implantação (CHANG et al., 2005; DALKIR, 2005; NISSEN, 2002). Segundo Wong (2005) é importante que as organizações abordem o assunto sob esta consideração devido à relevância que ela tem na criação de sucedidas companhias baseadas no conhecimento.

Em seguida serão apresentados três modelos do ciclo da GC, considerados pelo autor deste trabalho os mais relevantes por terem sido validados, aplicados e/ou fundamentados pela análise da literatura sobre o tema, e por que descrevem de forma detalhada e clara seus componente, processos e a interação entre eles.

\section{O ciclo integrado da gestão do conhecimento de Dalkir}

Baseado na análise dos principais modelos do ciclo da gestão do conhecimento, Dalkir (2005) propõe um ciclo integrado composto de três estágios principais, como apresentado na Figura 6 e explicado a seguir:

1. Criação e/ou captura do conhecimento;

2. Disseminação e compartilhamento do conhecimento; e

3. Aquisição e aplicação do conhecimento.

Na transição do primeiro estágio para o segundo, o conhecimento é avaliado. Na passagem do segundo estágio para o terceiro o conhecimento é contextualizado com o objetivo de ser entendido (aquisição) e utilizado (aplicação). Esses estágios realimentam o primeiro estágio e o atualizam. 
A captura do conhecimento refere-se à identificação e consequente codificação de conhecimento e know-how interno existente (geralmente não notado anteriormente) e/ou conhecimento do ambiente externo à organização.

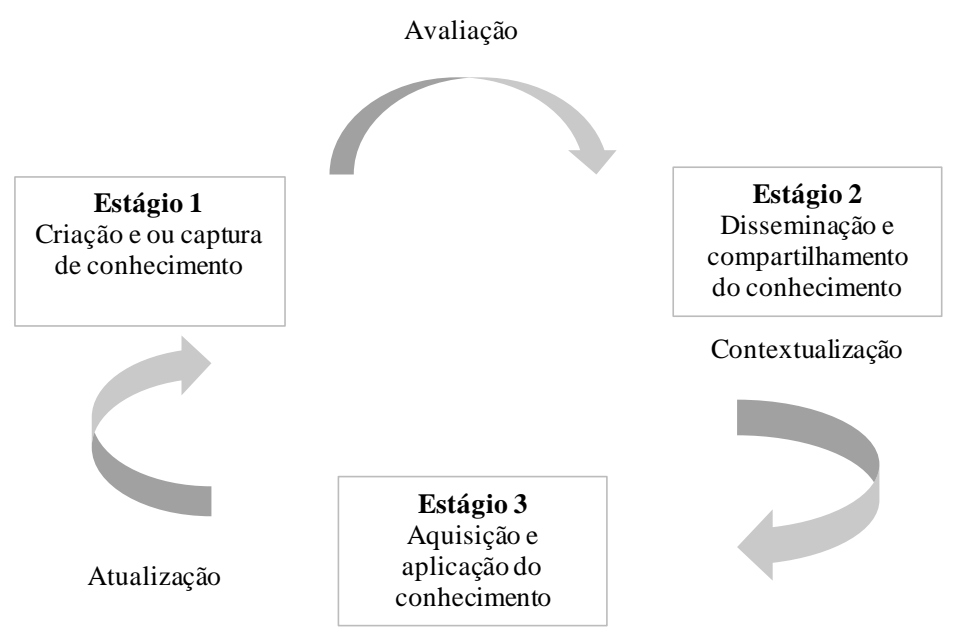

Figura 6 - O ciclo da gestão do conhecimento

Fonte: Dalkir (2005)

A criação do conhecimento é o desenvolvimento de novo conhecimento e know-how, inovações que não foram previamente existentes na organização. Quando o conhecimento é inventariado dessa forma, a seguinte fase critica é apresentar uma avaliação contra uma seleção de critérios altamente relacionados com os objetivos organizacionais.

Uma vez que se tem decidido que o novo conteúdo ou aquele recentemente identificado tem valor suficiente, ele é disseminado e compartilhado por toda a organização. O seguinte estágio é sua contextualização. Ela envolve manter uma relação entre o conhecimento e aquilo que se conhece sobre ele. Contextualização também implica identificar os atributos chave do conteúdo com o objetivo de oferecê-lo de forma adequada para a variedade de usuários.

O ciclo da gestão do conhecimento é posteriormente reiterado quando os usuários entendem e decidem fazer uso do conteúdo. Os usuários validam sua utilidade e comunicam quando o conteúdo está ultrapassado ou quando já não é mais aplicável. Adicionalmente, os usuários validam o escopo do conteúdo e o nível de generalização que as melhores práticas e lições aprendidas devem ter. Além disso, eles geralmente contribuem com novo conteúdo, que alimenta a um novo ciclo da gestão do conhecimento. 


\section{O ciclo de vida do conhecimento e o ambiente dos processos do negócio de McElroy e} Firestone

Firestone e McElroy (2005) e McElroy (2000), dentro da denominada segunda geração da GC, propõem um modelo delimitado pela teoria de sistemas adaptativos complexos (CAS Theory), que visa representar o processo pelo qual as organizações produzem, disseminam e aplicam novos conhecimentos sobre os processos do negócio, por meio da aprendizagem organizacional, baseada na tomada de decisão (Figura 7).

Firestone e McElroy (2005) fundamentam que a GC é uma função natural nas organizações. A GC não gerencia, cria ou integra diretamente a maioria dos resultados do conhecimento nas organizações, mas somente impacta os processos do conhecimento.

Este modelo é balizado e pode ser entendido pelas seguintes premissas:

- Todo conhecimento inicia-se na mente do indivíduo. Sendo assim, uma fase primária na produção e compartilhamento de novo conhecimento é a aprendizagem individual.

- Quando os indivíduos aprendem, eles confrontam suas experiências com sua atual forma de pensar. No caso de desacordo é criada uma tensão que deve ser resolvida. Isto pode acontecer na mente das pessoas. Posteriormente estes indivíduos procuram outras pessoas e em conjunto são submersos em um processo de comiseração e diálogo construtivo. Eles criam seu próprio conhecimento ou suas próprias regras. É desta forma que comunidades de conhecimento, interesse ou prática emergem.

- A seguir, estas comunidades são envoltas em um processo contínuo de criação e negociação de conhecimento. Cada membro apresenta sua declaração de conhecimento, logo, todas elas são analisadas, discutidas, modificadas e refinadas. Desta forma novo conhecimento é formado. No caso em que a declaração do conhecimento validada pela comunidade esteja contra o saber e a prática atual, é criada uma nova tensão, mas esta vez em um nível organizacional.

- Ao adotar e criar novo conhecimento as comunidade tentam pô-lo na prática, ou integrá-lo na organização. Esta é a fase de integração. No primeiro estágio desta fase, o novo conhecimento é propagado na organização, seja de forma espontânea (compartilhamento) ou planejada (treinamento, pesquisa, difusão).

- As declarações do conhecimento são armazenadas ma mídia e nos sistemas de informação. No caso das crenças e as predisposições das crenças são armazenadas nas mentes dos agentes. Por meio da base do conhecimento organizacional as crenças e as 


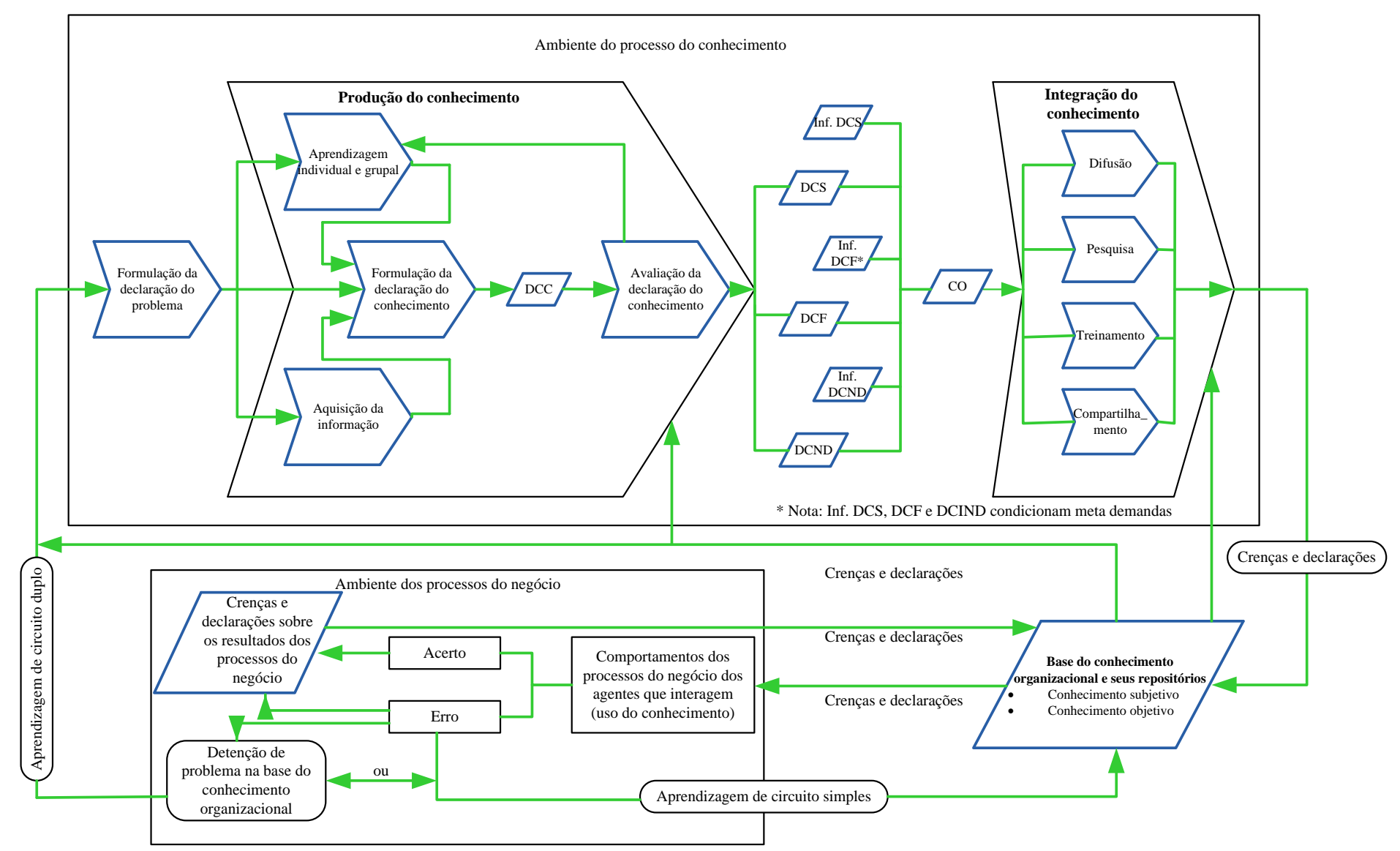

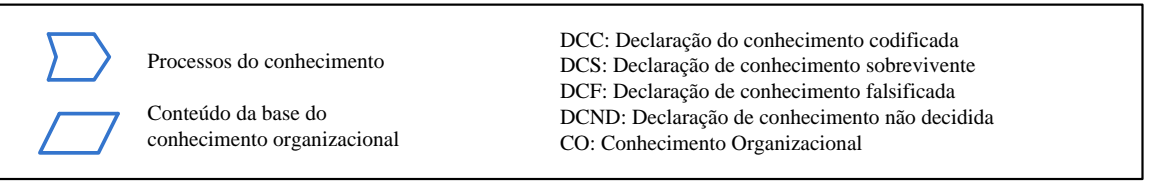

Figura 7 - O ciclo de vida do conhecimento e o ambiente dos processos do negócio

Fonte: McElroy (2000) e Firestone e McElroy (2005) 
declarações do conhecimento são acessíveis em diferentes graus pelos indivíduos, no processo de tomada de decisão, dentro do ambiente dos processos do negócio e do ambiente dos processos do conhecimento, gerando ciclos contínuos.

- As crenças e declarações do conhecimento quando aplicadas nos processos do negócio geram dois tipos de aprendizagem: aprendizagem de circuito simples, quando um erro é detectado e corrigido sem questionar ou alterar as crenças ou declarações do conhecimento envolvidos no sistema; e aprendizagem de circuito duplo, quando uma desconformidade é corrigida examinando e alterando as crenças e declarações do conhecimento (ARGIRYS; SCHON, 1978).

O ciclo da GC proposto por Firestone e McElroy (2005) e McElroy (2000) pode ser resumido nas seguintes fases: produção do conhecimento, avaliação do conhecimento, integração do conhecimento e utilização do conhecimento. Na utilização se gera questionamentos que motivam a aprendizagem de circuito simples e de circuito duplo a nível individual, grupal ou organizacional.

Segundo Dalkir (2005) uma das vantagens do modelo proposto por Firestone e McElroy (2005) e McElroy (2000) é a clara descrição da avaliação do conhecimento e a decisão consciente de sua integração na memória organizacional.

\section{$O$ ciclo da gestão do conhecimento de King}

King et al. (2008) estruturam o ciclo da GC nas seguintes fases (Figura 8): criação/aquisição, refinamento, armazenamento, transferência/compartilhamento e utilização, que finalmente tem como alvo o aprimoramento do desempenho organizacional.

O modelo proposto por King et al. (2008) foi baseado na revisão de 68 artigos de autores de 21 países, validado e aprovado por 117 revisores de 24 países, e fundamentado nos nove artigos mais importantes do management science journal.

A figura 8 mostra que a iniciação do modelo envolve tanto a criação quanto a aquisição de conhecimento pela organização. A criação do conhecimento envolve o desenvolvimento de novo conhecimento ou substituição de conhecimento existente com novo conteúdo. 


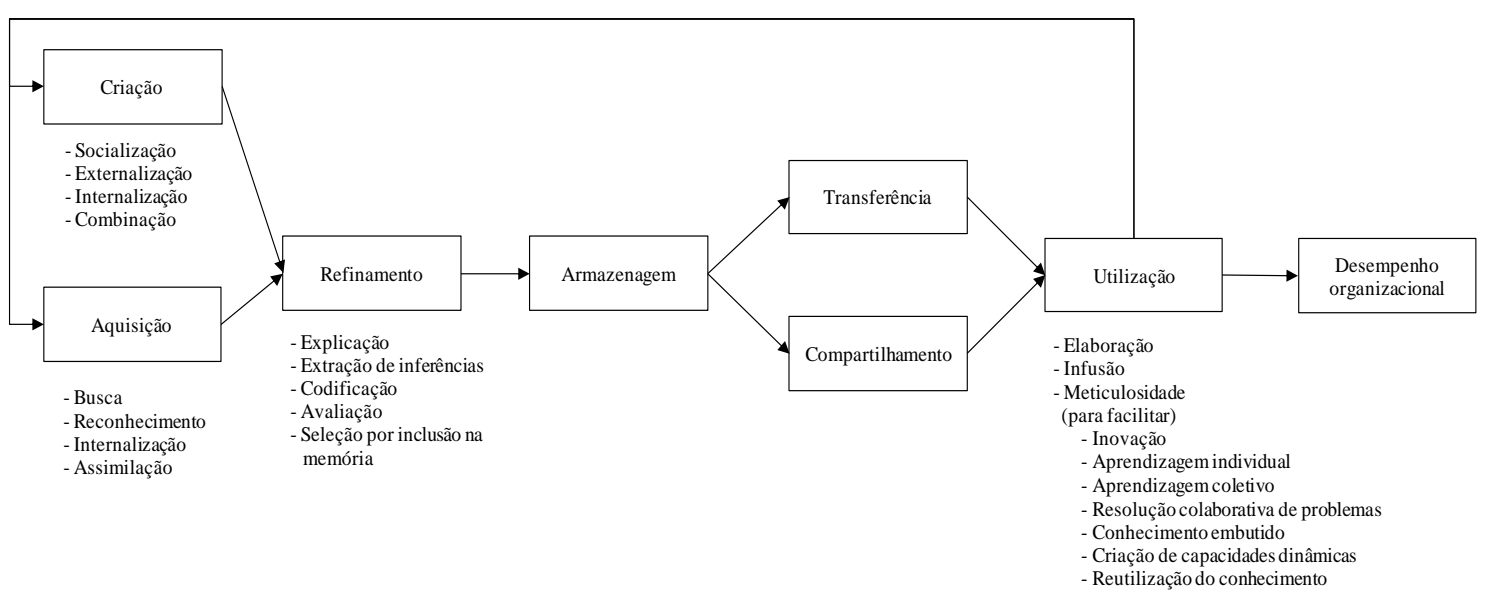

Figura 8 - Modelo do ciclo da gestão do conhecimento

Fonte: Adaptado de King et al. (2008)

Os quatro pontos embaixo da fase da criação referem-se aos quatro modos de criaçãosocialização de conhecimento propostos por Nonaka e Takeuchi (1995) amplamente conhecidos na comunidade científica.

Em contraste da criação do conhecimento interno, a aquisição envolve a busca, o reconhecimento e a assimilação de conhecimento potencialmente valioso, geralmente fora da organização. Os pontos embaixo da fase da aquisição ilustram alguns processos para adquirir conhecimento de fonte externas.

Após o conhecimento ser criado o adquirido, os mecanismos da gestão do conhecimento devem prepará-lo para ser ingressado dentro da memória da organização e para a máxima reutilização no longo prazo. O refinamento do conhecimento refere-se ao conjunto de processos e mecanismos que são utilizados para selecionar, filtrar, purificar e otimizar o conhecimento para sua inclusão em vários meios de armazenagem.

Os pontos embaixo da fase de refinamento sugerem que o conhecimento tácito ou implícito deve ser explicado, codificado e organizado em um formato apropriado e avaliado de acordo com um conjunto de critérios para sua inclusão dentro da memória organizacional. O conhecimento explícito precisa somente ser formatado, avaliado e selecionado.

A memória organizacional inclui o conhecimento armazenado na mente dos membros da organização, e o conhecimento que é mantido em repositórios eletrônicos ou físicos, que foram adquiridos e mantidos por grupos ou equipes e que estão embutidos nos relacionamentos internos e externos, nos processos do negócio, nos produtos e serviços. 
Com o objetivo de que o conhecimento tenha um amplo impacto organizacional, este usualmente deve ser transferido ou compartilhado. Transferência e compartilhamento podem ser conceituados como dos extremos de um continuum. Transferência envolve a comunicação propositada e focalizada de conhecimento de um remetente para um receptor de conhecimento. Compartilhamento é uma disseminação menos focalizada, como através de um repositório, para pessoas que usualmente são desconhecidas pelo contribuinte.

Uma vez que o conhecimento é transferido ou compartilhado com outros, este pode ser utilizado ou aplicado através de um processo de elaboração (o desenvolvimento de diferentes interpretações), infusão (a identificação de questões subjacentes) ou meticulosidade (o desenvolvimento de múltiplos entendimentos por diferentes indivíduos ou grupos) com o objetivo de ser útil para a inovação, a aprendizagem coletiva, a aprendizagem individual e/ou para a resolução colaborativa de problemas. Este pode ser embutido nas práticas, sistemas, produtos, e relacionamentos da organização através da criação de capacidades organizacionais de conhecimentointensivo.

No final do ciclo, a produção do conhecimento tem impacto no desempenho organizacional. King et al. (2008), afirmam que aqueles que trabalham e pesquisam tanto na GC quanto na aprendizagem organizacional tem que estar conscientes que estes dois tópicos ao final tratam sobre este assunto, desempenho organizacional.

Além dos trabalhos descritos, outros ciclos da GC foram apresentados por Alavi e Leidner (2001), Bhatt (2000), Chang et al. (2005), Edwards (2003), Meehan e Richardson (2003), Nissen (2002), Rus e Lindvall (2002), Wiig (1993).

Os ciclos da GC apresentados são evidentemente complementares, diferenciando-se unicamente pelo detalhe de seu tratamento e a abrangência dos conceitos utilizados para a explicação de suas fases. É importante evidenciar novamente que cada um destes modelos é baseado em perspectivas diferentes do conceito e tipologia do conhecimento, além das bases conceituais que cada autor possui dificultando a escolha de um dos modelos para a delimitação deste trabalho.

Este trabalho considerará como guia conceitual o ciclo da GC sustentando por Firestone e McElroy (2003, 2005): 1) por estar alinhado às escolhas feitas nos conceitos 
anteriores (dado, informação, conhecimento e taxonomia do conhecimento); 2) por estar em concordância com a visão de GC do autor deste trabalho; e 3) pelo detalhamento que ele oferece ao apresentar as fases do ciclo da GC e especialmente pela integração com os processos e a aprendizagem da organização, fatos não muito claros ou ausentes nos modelos propostos por Dalkir (2005) e King et al. (2008); sendo a clareza e o detalhe principais objetivos deste trabalho.

\subsubsection{Modelos da Gestão do Conhecimento}

Segundo Dalkir (2005), entender os diferentes estágios da GC por meio do seu ciclo é muito importante, mas não suficiente. Desde uma perspectiva prática a GC precisa de um princípio organizacional, uma estrutura que ajude na classificação dos diferentes tipos de atividades e funções necessárias para lidar com todo o trabalho relacionado ao conhecimento dentro e entre organizações, é aí que surge a necessidade de um modelo mais sistêmico para a GC.

Embora os ciclos da GC apresentados no item anterior poderiam ser chamados de modelos, o nível de tratamento que fazem do tema é delimitado pelo processo do conhecimento, sendo a idéia de modelo sustentada neste tópico de um nível organizacional, integrando não só os processos do conhecimento, mas também outros elementos da GC e da organização.

Segundo Pee e Kankanhalli (2009), os modelos da GC propostos na literatura podem ser categorizados como modelos orientados ao processo, de capacitadores socio-ténicos, contingenciais e orientados ao conhecimento.

Os modelos orientados ao processo examinam o processo da captura, compartilhamento e aplicação do conhecimento para enterder os mecanismo pelos quais o valor é derivado do conhecimento; modelos de capacitadores socio-ténicos identificam os fatores que podem influenciar a adoção e sucesso das ferramentas e práticas da GC; modelos contingenciais reconhecem que o sucesso das iniciativas em GC depende do contexto em que elas são implementadas; por último, os modelos orientados ao conhecimento focam-se na exploraçao dos ativos do conhecimento e na mensuraçao do valor do capital intelectual.

Nesta seção serão apresentados os principais modelos presentes na literatura, tendo cada um deles uma mistura das características das categorias apresentadas por Pee e 
Kankanhalli (2009). Os modelos a serem apresentados são connsiderados complementares, oferecendo cada um deles um aporte para o melhor entendimento da GC.

\section{O modelo de geração do conhecimento}

Nonaka e Takeuchi (1995) apresentam um modelo para representar a criação do conhecimento, abordando o tema sobre duas dimensões, a ontológica e a epistemológica.

A dimensão ontologia considera o alcance em torno da criação do conhecimento, é dizer, o ambiente ao redor do conhecimento, existindo neste ponto uma preocupação com os níveis de entidades criadoras do conhecimento (individual, grupal, organizacional e inter organizacional).

Neste contexto, Nonaka e Takeuchi (1995) consideram que o conhecimento é criado só por indivíduos. Uma Organização não pode criar conhecimento sem indivíduos. A organização apóia a criatividade individual e disponibiliza o contexto para que os indivíduos gerem conhecimento. Está visão é compartilhada por autores como Argyris e shon (1978) e por Firestone e McElroy (2003).

A dimensão epistemológica está baseada no processo de comunicação do conhecimento por meio dos modos de conversão entre o conhecimento tácito e explícito. Dada a indisociabilidade desses dois tipos de conhecimento, existe um pressuposto crítico de que o conhecimento humano é criado e expandido através da interação social entre o conhecimento tácito e explícito.

Essa interação, denominada por Nonaka e Takeuchi (1995) de conversão do conhecimento acontece como se mostra na Figura 9, e abrange os processos de socialização, externalização, combinação e internalização; gerando respectivamente conteúdos naturalmente diferentes: conhecimento compartilhado, conhecimento conceitual, conhecimento sistêmico e conhecimento operacional.

A união das duas dimensões apresentadas anteriormente (ontológica e epistemológica) permite a transferência do conhecimento do individuo para o grupo, para a organização e entre organizações. A Figura 10 permite ter uma visão geral do descrito. 


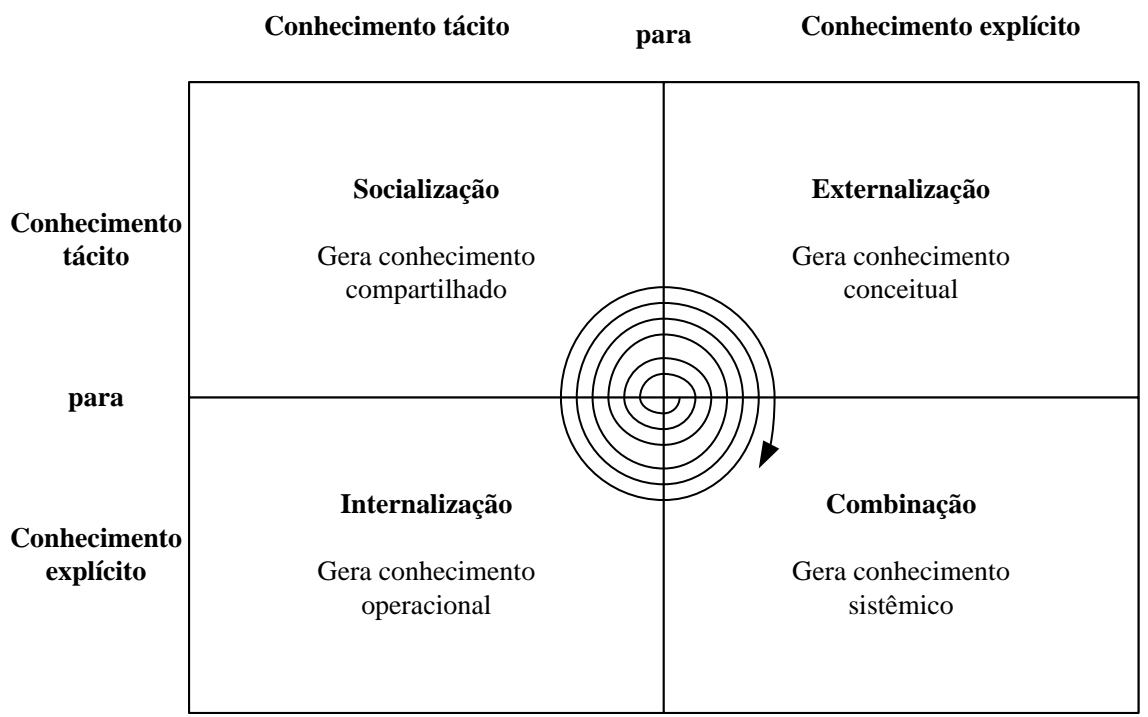

Figura 9 - Modos de conversão do conhecimento Fonte: Nonaka e Takeuchi (1995)

Adicionalmente Nonaka e Takeuchi (1995) apresentam cinco condições necessárias para o desenvolvimento adequado da espiral do conhecimento: intenção, autonomia, flutuação e caos criativo, redundância e variedade de requisitos.

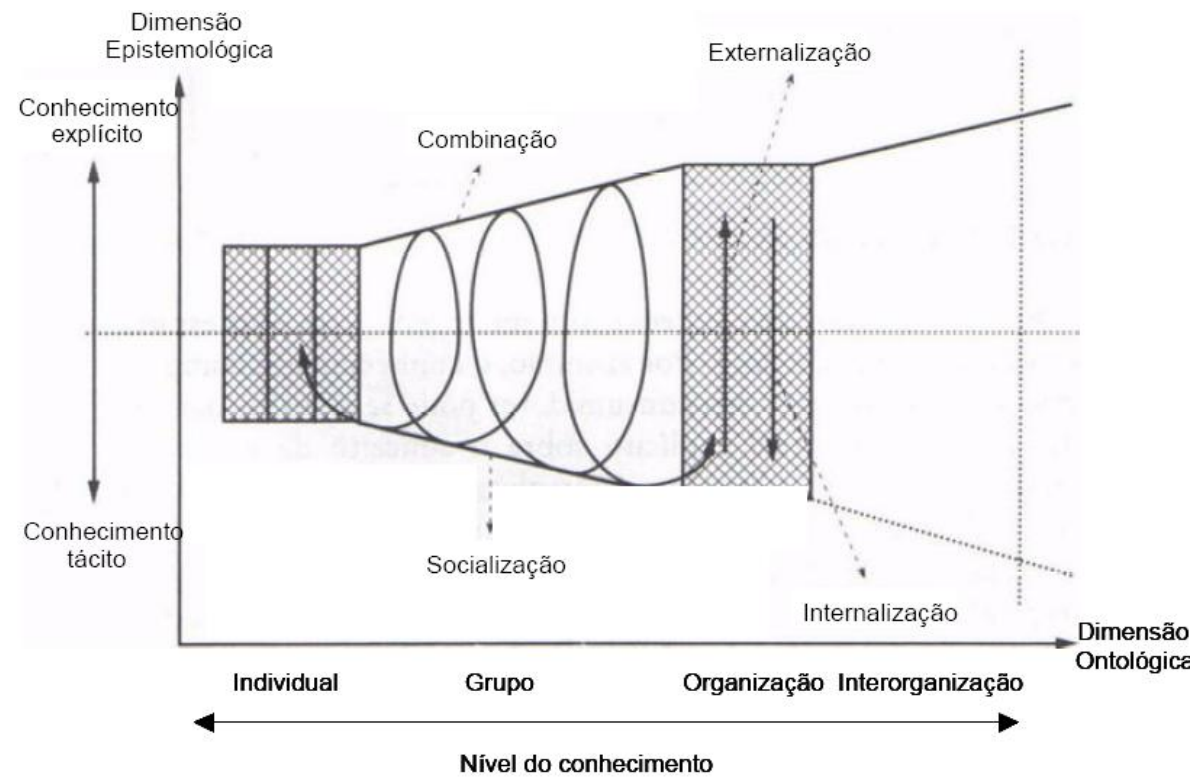

Figura 10 - As duas dimensões da criação e conversão do conhecimento Fonte: Nonaka e Takeuchi (1995)

A dimensão "tempo" tem papel muito importante nos processos de criação e conversão do conhecimento organizacional, uma vez que ocorrem através de sucessivas interações entre indivíduos e grupos. Para incorporar essa dimensão na teoria, Nonaka e Takeuchi (1995) apresentam um modelo integrado de cinco fases do processo de criação do conhecimento organizacional, a partir das análises dos quatro modos de conversão e das 


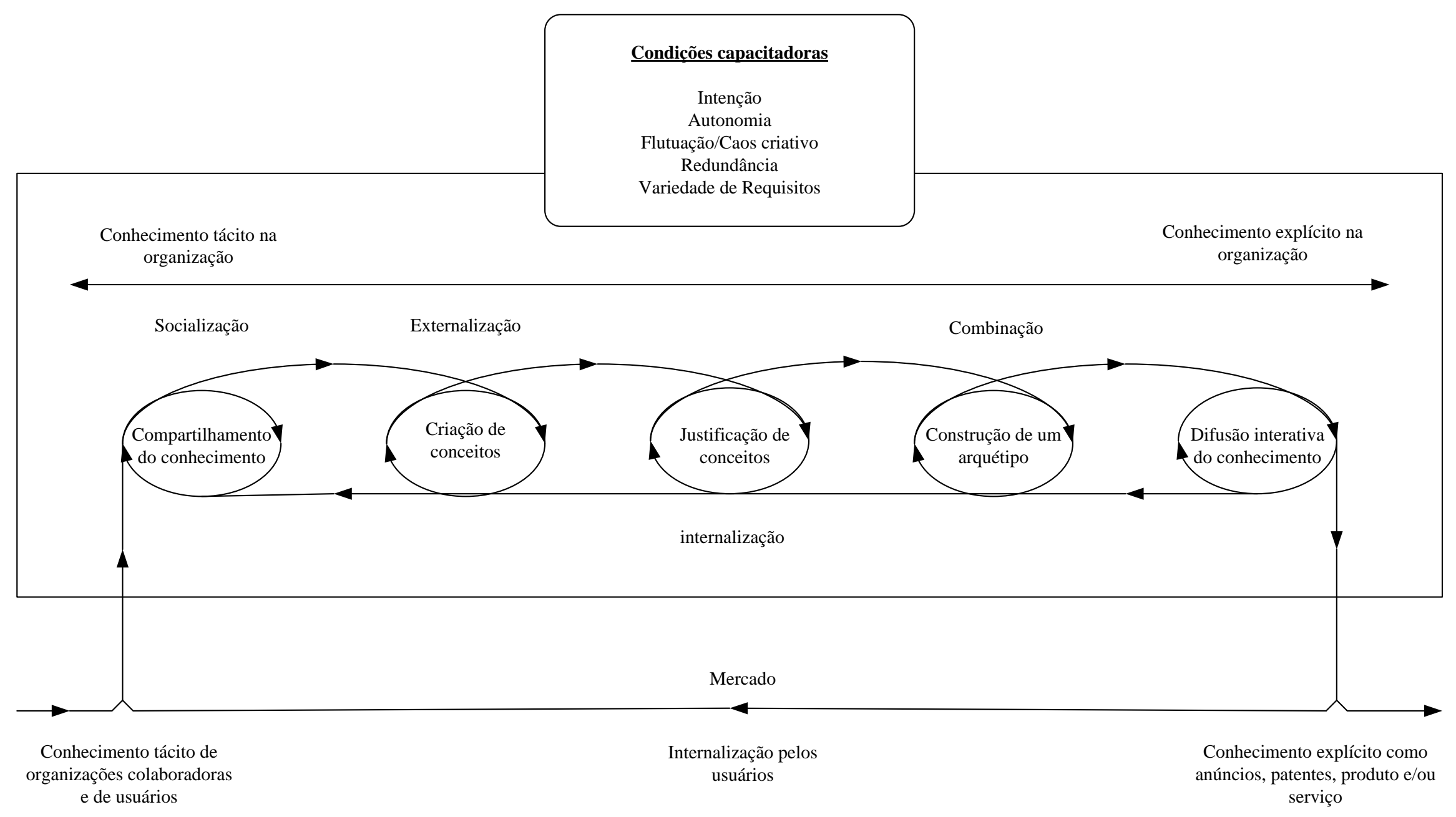

Figura 11 - Modelo de cinco fases do processo de criação do conhecimento Fonte: Nonaka e Takeuchi (1995) 
cinco condições capacitadoras: compartilhamento de conhecimento tácito, criação de conceitos, justificação de conceitos, criação de um arquétipo e difusão interativa do conhecimento (Figura 11):

O modelo proposto por Nonaka e Takeuchi (1995), não só aborda os modos de conversão do conhecimento, mas também as condições necessárias para sua realização e descreve seu processo no ambiente organizacional.

Baseados nos estudos apresentados, Nonaka et al. (2000) propõem um modelo aprimorado para a criação do conhecimento composto de três elementos: 1) o processo SECI, o processo da criação do conhecimento por meio da conversão entre o conhecimento tácito e explícito; 2) $b a$, o contexto compartilhado para a criação do conhecimento; e 3) os ativos de conhecimento, entradas, saídas e mediadores do processo de criação do conhecimento (Figura 12).

O conceito de $b a$ relaciona-se ao contexto compartilhado que sustenta a criação do conhecimento. $\mathrm{O}$ conhecimento precisa um contexto físico para ser criado, ba (que em realidade significa lugar) oferece tal contexto. $B a$ é o contexto compartilhado em que o conhecimento é difundido, criado e reutilizado. No processo de criação do conhecimento a geração e regeneração de $b a$ é crítica devido a que é ela que fornece de energia, qualidade e lugar para desempenhar a conversão individual e crescer ao longo da espiral do conhecimento.

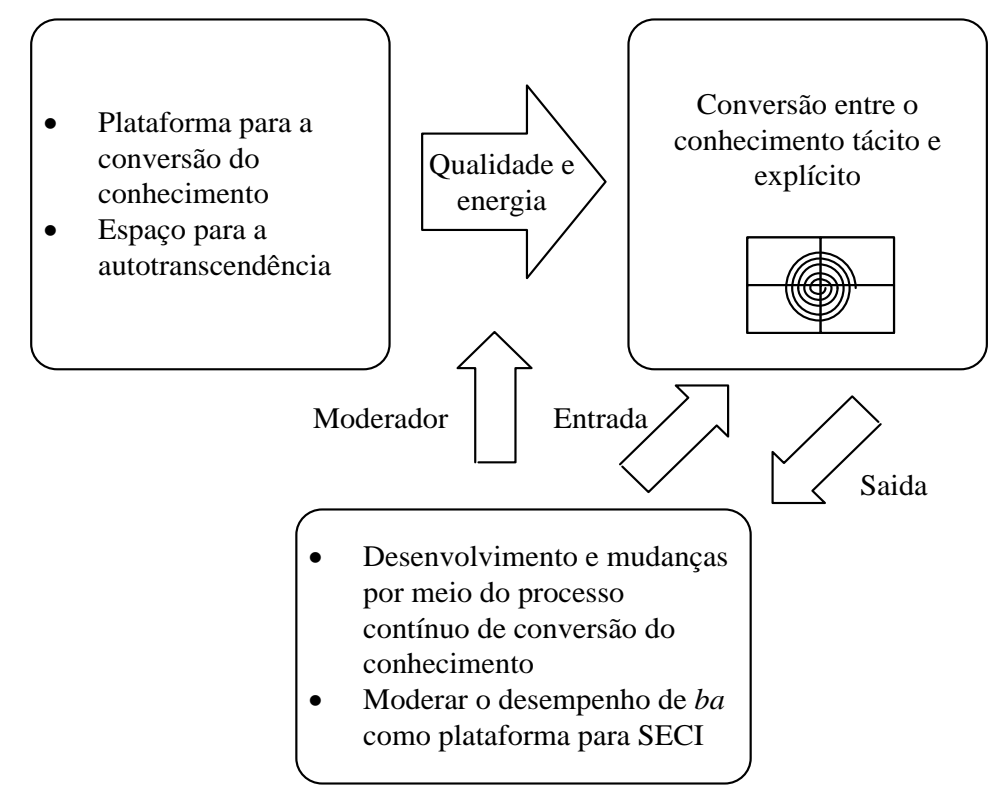

Figura 12 - Três elementos do modelo da criação do conhecimento Fonte: Nonaka et al. (2000) 
Há quatro tipos de $b a$ : $b a$ originador, $b a$ dialogador, $b a$ sistematizador e $b a$ exercitador, todas elas definidas por duas dimensões de interação (Figura 13). Uma dimensão é o tipo de interação, se ela é realizada individual ou coletivamente. A outra dimensão é a mídia usada nessa interação, se a interação é por médio de contato face-to-face ou por médio de mídia virtual como livros, manuais, e-mails ou teleconferências.

\section{Tipo de interação}

Individual

Coletivo

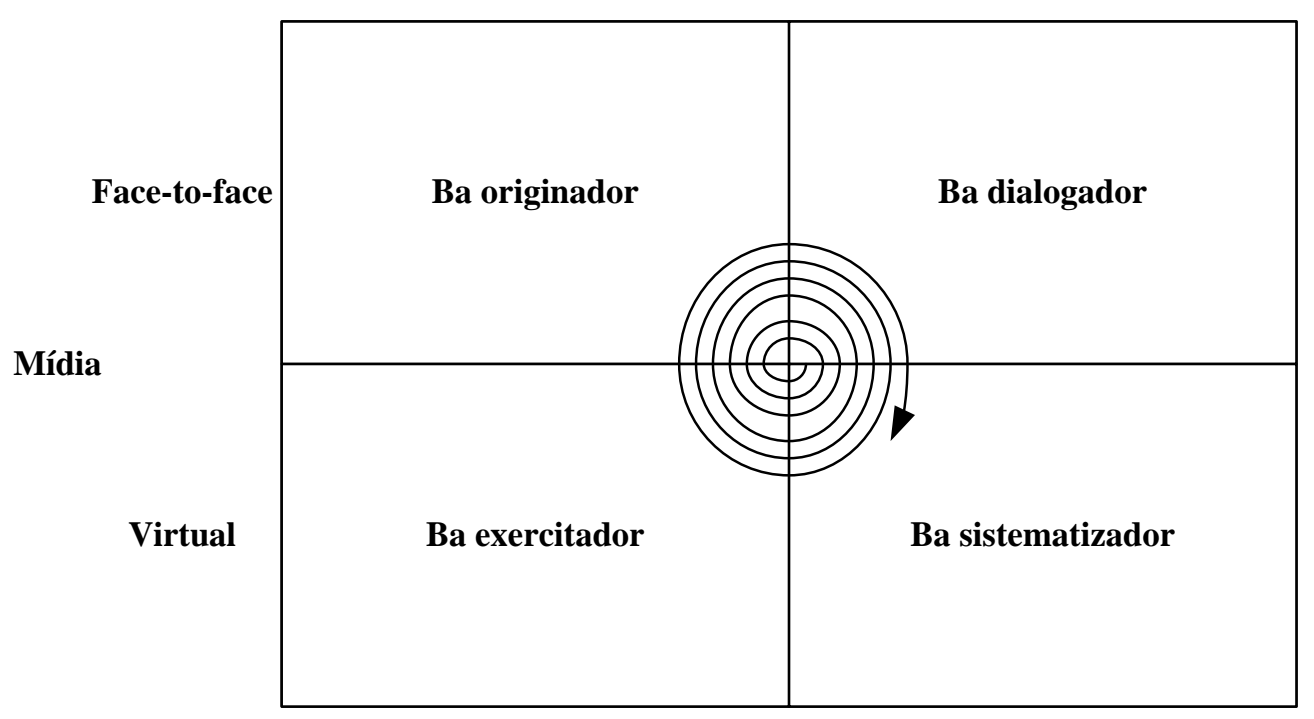

Figura 13 - Quatro tipos de $b a$

Fonte: Nonaka et al. (2000)

O $B a$ existe em muitos níveis ontológicos e estes níveis podem ser ligados para formar o $b a$ maior. Indivíduos formam o $b a$ para as equipes, que por sua vez formam o $b a$ para a organização. Posteriormente, o ambiente do mercado torna-se o $b a$ da organização. Sendo assim, $b a$ é um conceito que transcende as fronteiras entre o micro e o macro. A interação orgânica destes diferentes níveis de $b a$ podem amplificar o processo de criação do conhecimento.

O terceiro componente do modelo proposto por Nonaka et al. (2000) são os ativos de conhecimento, eles formam a base para o processo de criação do conhecimento. Ativo é definido como os recursos que são indispensáveis para criar valor na organização. Os ativos de conhecimento são as entradas, saídas e os fatores moderadores do processo de criação do conhecimento. Por exemplo, a confiança entre os membros da organização é criada como uma saída do processo de criação do conhecimento, ao mesmo tempo ela 
modera como o $b a$ funciona como uma plataforma para o processo de criação do conhecimento.

Para entender como os ativos de conhecimento são criados, adquiridos e explorados, Nonaka et al. (2000) propõem uma categorização do conhecimento em quatro tipos: ativos de conhecimento experienciais, ativos de conhecimento conceituais, ativos de conhecimento sistemáticos e ativos de conhecimento rotineiros (Figura 14).

\begin{tabular}{|c|c|}
\hline $\begin{array}{l}\text { Ativos de conhecimento experienciais } \\
\text { Conhecimento tácito compartilhado por } \\
\text { meio de experiências comuns } \\
\text { - Habilidades e know-how dos } \\
\text { indivíduos } \\
\text { - Cuidado, amor, confiança e } \\
\text { seguridade } \\
\text { - Energia, paixão e tensão }\end{array}$ & $\begin{array}{l}\text { Ativos de conhecimento conceituais } \\
\text { Conhecimento explícito articulado por } \\
\text { médio de imagens, símbolos e } \\
\text { linguagem } \\
\text { - Conceitos de produtos } \\
\text { - Desenho } \\
\text { - } \quad \text { Equidade de marca }\end{array}$ \\
\hline $\begin{array}{l}\text { Ativos de conhecimento rotineiros } \\
\text { Conhecimento tácito rotineiros e } \\
\text { incorporados em ações e práticas } \\
\text { - Know how de operações do dia a } \\
\text { dia } \\
\text { - Rotinas organizacionais } \\
\text { - Cultura organizacional }\end{array}$ & $\begin{array}{l}\text { Ativos de conhecimento sistemáticos } \\
\text { Conhecimento explicito sistematizado e } \\
\quad \text { empacotados } \\
\text { - } \quad \begin{array}{l}\text { Documentos, especificações, } \\
\text { manuais }\end{array} \\
\text { - Banco de dados } \\
\text { - Patentes e licenças }\end{array}$ \\
\hline
\end{tabular}

Figura 14 - Quatro categorias de ativos de conhecimento Fonte: Nonaka et al. (2000)

Segundo Nonaka et al. (2000), para gerir efetivamente a criação e exploração do conhecimento a companhia deve mapear seus estoques de ativos de conhecimento, mas que a catalogação do conhecimento existente não é suficiente, devido a que os ativos de conhecimento são dinâmicos, e novos ativos de conhecimento podem ser criados de ativos existentes.

Resumindo o modelo, poderia se disser que, utilizando os ativos de conhecimento existentes, uma organização cria novo conhecimento por meio do processo SECI que toma lugar no $b a$. Logo, o conhecimento criado torna-se parte dos ativos de conhecimento da organização, que por sua vez torna-se a base para uma nova espiral de criação do conhecimento.

Por último, Nonaka et al. (2000), argumenta que $b a$ deve ser energizada para poder oferecer energia e qualidade ao processo SECI, com esse objetivo, o produtores de 
conhecimento têm que fornecer as condições necessárias, nomeadas como condições capacitadoras, já apresentadas anteriormente (intenção, autonomia, flutuação/caos criativo, redundância, variedade de requisitos), e que no artigo de Nonaka et al. (2000) acrescenta-se o amor, o cuidado, a confiança e o compromisso.

Segundo Nonaka et al. (2000), promover o amor, o cuidado, a confiança e o compromisso entre os membros da organização é importante devido a que formam o fundamento para a criação do conhecimento. Para pode fazer esta promoção, os produtores de conhecimento precisam estar altamente inspirados e comprometidos com o objetivo, precisando ser também desinteressados e altruístas; eles não devem tentar monopolizar o conhecimento criado pela organização ou tomar o crédito dos logros dos outros.

A importância de descrever a teoria completa e a evolução do trabalho de Nonaka e Takeuchi (1995) e Nonaka et al. (2000), embora de forma resumida, advêm do limitado estudo e abordagem que fazem alguns estudos sobre a teoria da criação do conhecimento, restringindo sua visão ao estudo da espiral do conhecimento, e negligenciando o $b a$ e os Ativos de Conhecimento, assim como a dimensão tempo, elementos muito importantes no estudos dos referidos autores. Adicionalmente, sendo objetivo deste trabalho propor um modelo para a GC, não poderia deixar de lado a revisão de um dos modelos mais relevantes da literatura para sua posterior comparação, atividade realizada no item resultados.

\section{O modelo de estágios para a gestão do conhecimento}

Lee e Kim (2001) identificaram vários componentes alvo da GC, entre eles, o conhecimento propriamente dito, os processos de gestão, os trabalhadores do conhecimento, as relações humanas baseadas na confiança, as tecnologias da informação, a cultura baseada no conhecimento, a estrutura organizacional flexível, o desempenho e a recompensa. Destes componentes foram selecionados quatro (Figura 15), o conhecimento organizacional, os trabalhadores do conhecimento, o processo da gestão do conhecimento e as tecnologias da informação. Lee e Kim (2001) argumentam a desconsideração dos elementos adicionais baseados na complexidade, abrangência ou imprecisão que eles apresentam. Adicionalmente, Lee e Kim (2001) evidenciam na Figura 15 as abordagens para o desenvolvimento das práticas da GC. 
Esses elementos, ao longo da evolução da GC na organização, desempenham funções cada vez mais completas, permitindo o sucesso das práticas da GC (quadro 8).

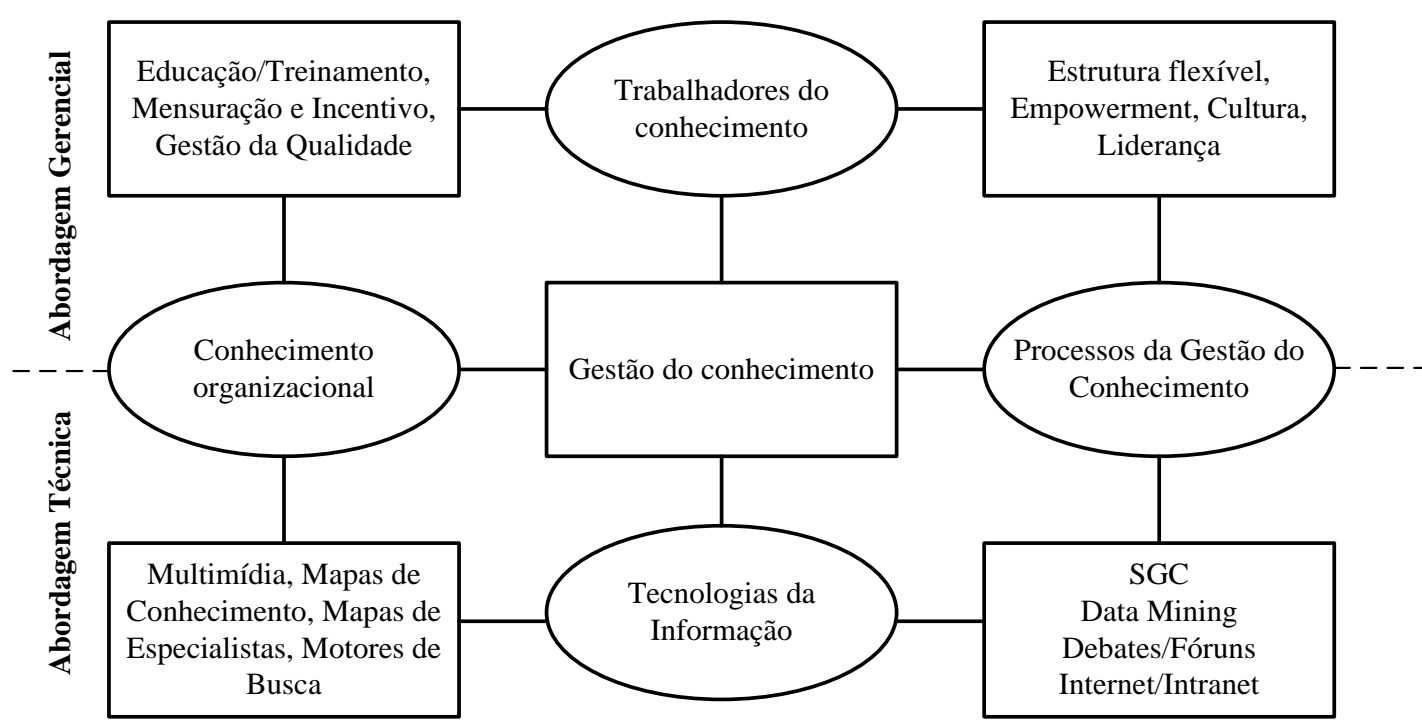

Figura 15 - Objetos da Gestão do Conhecimento e as abordagens organizacionais Fonte: Lee e Kim (2001)

No quadro 8, pode-se observar que o ciclo da $\mathrm{GC}$, resumido na criação, compartilhamento e utilização do conhecimento, e apresentado em mais detalhe no item 4 deste capítulo, é a base para a estruturação dos elementos da GC no modelo proposto por Lee e Kim (2001), embora esta característica não seja totalmente explícita para todas as fases.

\begin{tabular}{|c|c|}
\hline Elementos & Evolução da organização \\
\hline Conhecimento organizacional & $\begin{array}{l}\text { Aquisição do conhecimento } \\
\text { Criação do conhecimento } \\
\text { Integração do conhecimento } \\
\text { Conhecimento em rede }\end{array}$ \\
\hline Trabalhadores do conhecimento & $\begin{array}{l}\text { Absorvedor do conhecimento } \\
\text { Criador do conhecimento } \\
\text { Especialista do conhecimento } \\
\text { Coordenador do conhecimento }\end{array}$ \\
\hline $\begin{array}{l}\text { Processos da gestão do } \\
\text { conhecimento }\end{array}$ & $\begin{array}{l}\text { Aquisição } \\
\text { Criação } \\
\text { Compartilhamento interno } \\
\text { Compartilhamento global }\end{array}$ \\
\hline $\begin{array}{l}\text { Sistemas de tecnologias de } \\
\text { informação }\end{array}$ & $\begin{array}{l}\text { Fechados } \\
\text { Isolados } \\
\text { Nível empresarial }\end{array}$ \\
\hline
\end{tabular}




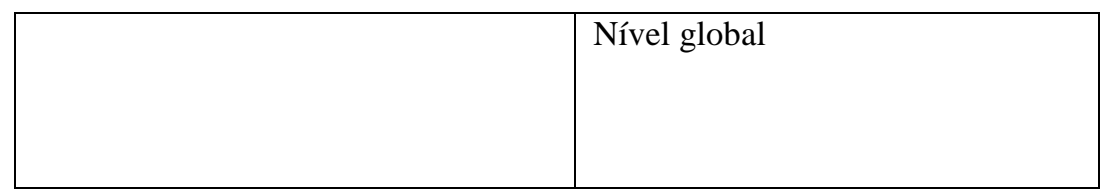

Quadro 8 - Evolução das funções dos elementos da Gestão do Conhecimento

Fonte: Adaptado de Lee e Kim (2001)

O modelo proposto por Lee e Kim (2001) para um estágio de maturidade da GC possuiria uma estrutura em que o conhecimento é compartilhado e integrado em rede em toda a organização, os trabalhadores do conhecimento são especialistas e coordenam as atividades de seu domínio, e os sistemas de informação são utilizados por todos os membros da companhia. Tudo isto com o objetivo de aprimorar as atividades organizacionais.

\section{O modelo integrado da gestão do conhecimento}

Hanzick (2003), baseada na necessidade de uma visão holística, uma consistência terminológica e uma unidade de análise, propõe uma estrutura integrada para a GC (Figura 16).

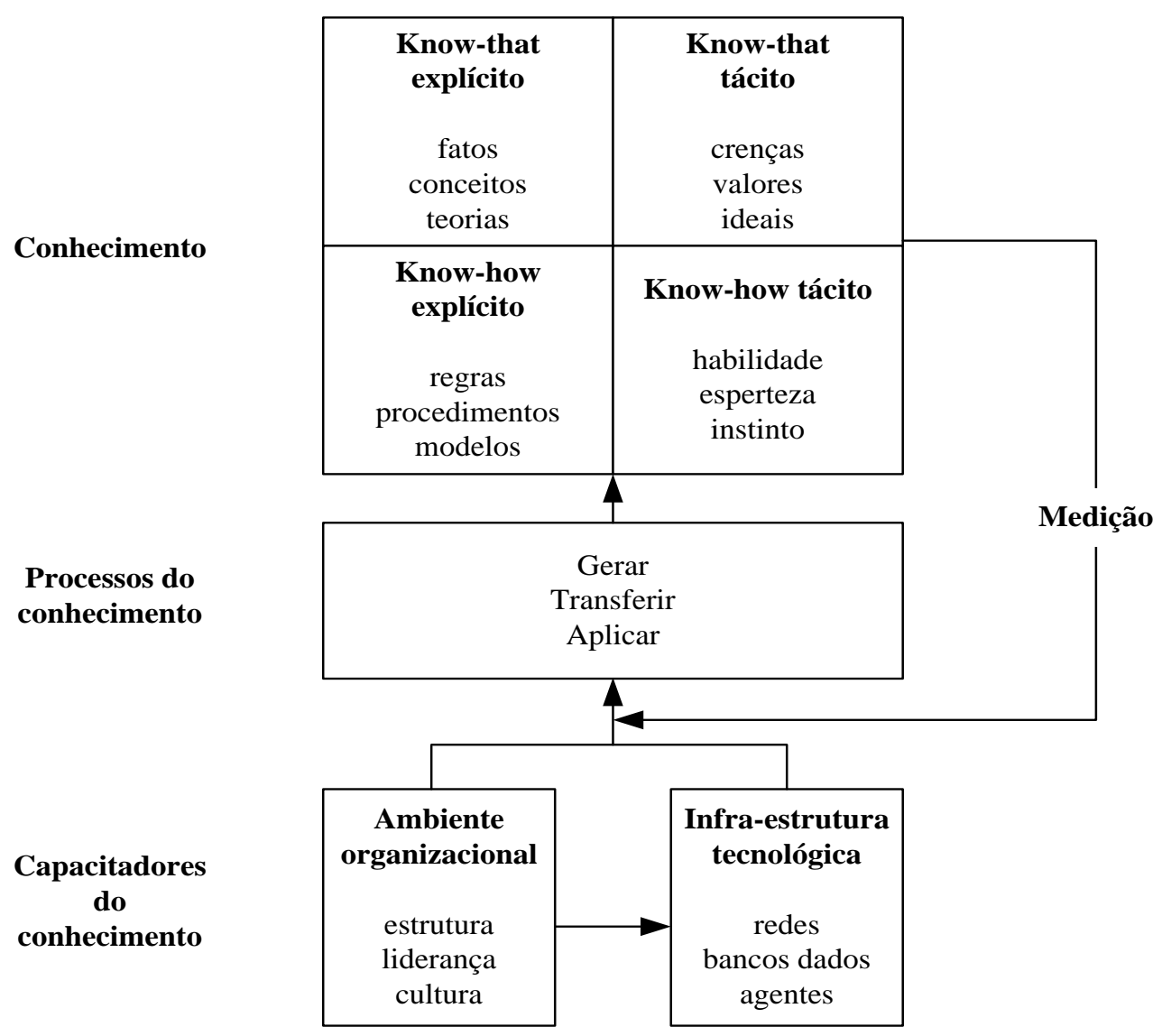

Figura 16 - Estrutura integrada da Gestão do Conhecimento

Fonte: Hanzick (2003) 
O modelo abrange os conceitos, os processos e os capacitadores do conhecimento e três capas de inter-relação entre esses elementos. O conhecimento ou conhecimento trabalhador (working knowledge) é definido como o conhecimento que a organização deve possuir e utilizar para manter o sucesso. Esta primeira capa responde à consideração sobre a localização do conhecimento e sua natureza, ela está composta de uma matriz dois por dois com as dimensões tácita e explícita. Conhecimento explicito para Hanzick (2003) é definido como o conhecimento que tem sido externalizado e existe nos artefatos de conhecimento. Conhecimento tácito é definido como o conhecimento incorporado dentro da mente dos membros da organização, diferenciando-se do conceito tradicional proposto por Nonaka e Takeuchi (1995) no sentido em que inclui todo o conhecimento mantido na mente das pessoas, indiferente de sua dificuldade de articulação ou comunicação. Com relação a sua natureza, know that é conceituado como conhecimento cognitivo e engloba aspectos sobre o que, onde, quando, quem etc. Know-how refere-se a conhecimento técnico, o processo passo a passo para a realização de alguma tarefa.

Com relação aos processos do conhecimento, o modelo distingue três tipos, aqueles que geram conhecimento novo, os que transferem o conhecimento existente e os processos que aplicam o conhecimento possuído para a produção de novo conhecimento. Adicionalmente, a estrutura propõe dois grandes grupos de fatores sócio-técnicos como principais capacitadores do conhecimento, o ambiente organizacional e a infra-estrutura tecnológica. Por último, o modelo incorpora um elemento de medição na forma de um circuito de realimentação que sugere a necessidade de uma auditoria contínua do conhecimento e potenciais correções da estratégia da GC com o passar do tempo.

\section{O modelo da efetiva gestão do processo do conhecimento}

Orzano et al. (2008) baseados em uma aplicação no setor saúde propõem um modelo para a GC (Figura 17), focado na efetiva gestão do processo do conhecimento com o objetivo de impactar no desempenho organizacional e a satisfação do trabalho de tal forma que aprimore a tomada de decisão e a aprendizagem organizacional.

Orzano et al. (2008) definem a GC como o processo em que as pessoas na organização descobrem, compartilham e desenvolvem o conhecimento para a ação, o que implica que: a) um artefato de conhecimento, que é o conhecimento codificado, está em uma forma insuficiente para o uso efetivo do conhecimento na prática; b) um número de 
interdependências são necessárias para a GC; c) existe dimensões sociais e técnicas para esses processos como um resultado da natureza tácita e explícita do conhecimento e; d) a ação origina-se da dimensão tácita do conhecimento e dos processos envolvidos na consecução da missão da organização.

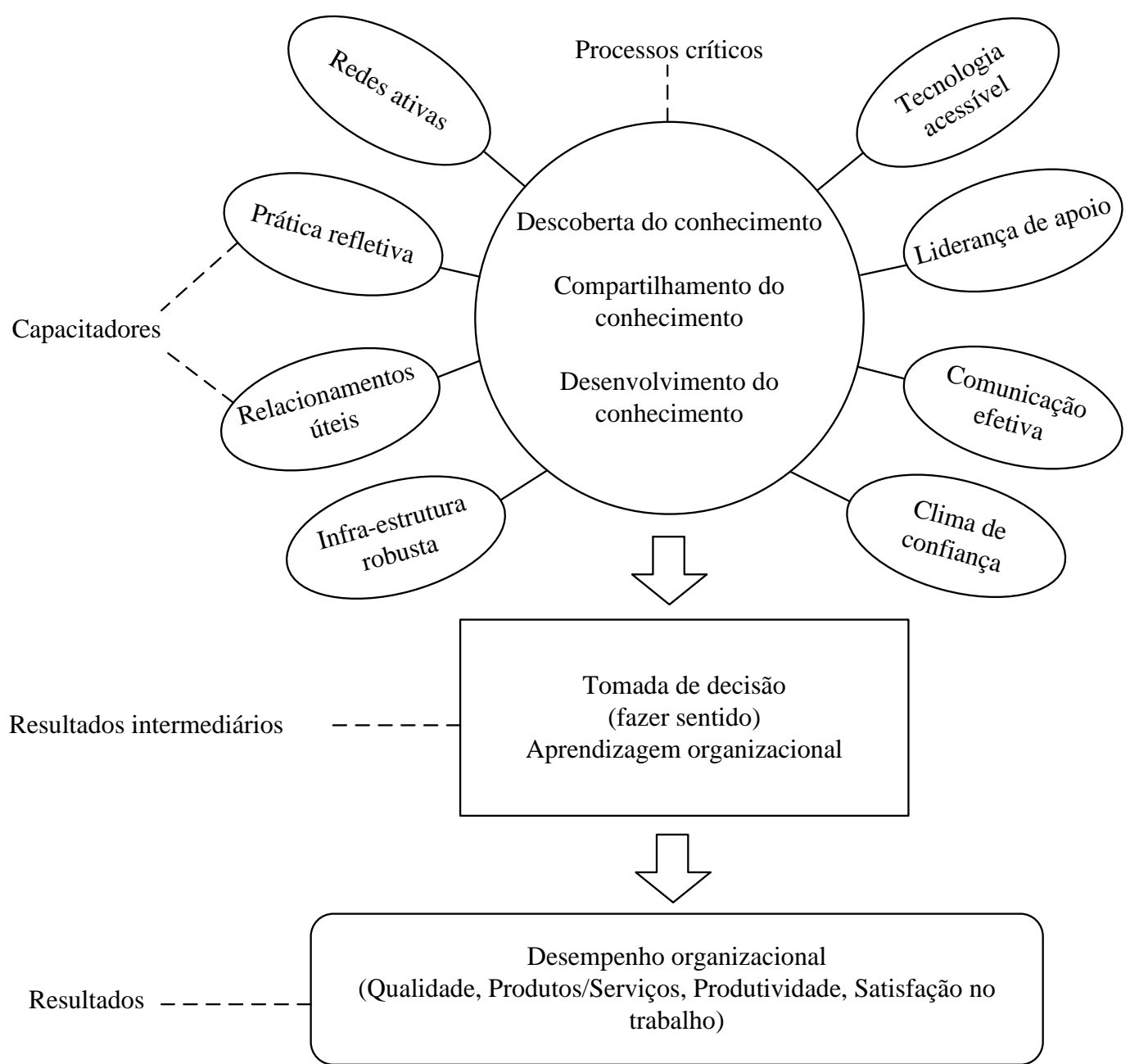

Figura 17 - Modelo de Gestão do Conhecimento Fonte: Orzano et al. (2008)

O modelo está composto de capacitadores, processos críticos e as consequências de efetivos programas de GC.

Os capacitadores fornecem o fundamento necessário para a organização incrementar sua efetividade nas práticas GC, eles são as redes ativas, a prática refletiva, os relacionamentos úteis, a infra-estrutura robusta, a tecnologia acessível, a liderança de apoio, comunicação efetiva e o clima de confiança. 
Os processos críticos incluem a descoberta, compartilhamento e desenvolvimento do conhecimento. A descoberta do conhecimento abrange os processos que permitem à organização fazer sentido e utilizar objetos de dados, informação e conhecimento que podem estar presentes na organização, mas não estão codificados, analisados ou acessíveis para os membros. Os processos de descoberta também estão relacionados à prevenção de perda de conhecimento por agentes que deixam a organização.

O compartilhamento do conhecimento compreende a transferência e difusão do conhecimento, incluindo processos que aprimoram a disposição e habilidade de membros conhecedores na organização para compartilhar o que eles sabem visando ajudar os outros na sua aprendizagem e conhecimento.

O desenvolvimento ou criação do conhecimento descreve os processos que permitem aos membros da organização criar novos entendimentos, inovações e uma síntese do que é conhecido até agora.

A aplicação da GC facilita a tomada de decisão e a aprendizagem individual e organizacional visando atingir a missão organizacional e aprimorar o desempenho.

\section{O modelo geral de maturidade da gestão do conhecimento}

Pee e Kankanhalli (2009) baseados na teoria do ciclo de vida e na análise dos modelos que abordam a GC sob esta perspectiva, descrevem os processos pelos quais a GC é explicitamente definida, gerida, controlada e efetuada nas organizações intensivas em conhecimento.

O modelo denominado como modelo geral de maturidade da gestão do conhecimento fundamenta-se em uma estrutura de estágios e tem dois componentes principais (quadro 9): o nível de maturidade e as áreas de processos críticos, estas últimas definidas como áreas em que a organização deve focar seus esforços para garantir o sucesso das práticas da GC.

No modelo cada nível de maturidade é caracterizado em termos de três áreas de processos críticos (pessoas, processos e tecnologia), e cada área é descrita por um conjunto de características. Essas características especificam práticas chave que ao serem desenvolvidas coletivamente, ajudam a organização na consecução dos objetivos de um nível em particular. 


\begin{tabular}{|c|c|c|c|c|c|}
\hline \multirow{2}{*}{\multicolumn{2}{|c|}{$\begin{array}{c}\text { Nível de } \\
\text { maturidade }\end{array}$}} & \multirow{2}{*}{$\begin{array}{c}\text { Descrição } \\
\text { geral }\end{array}$} & \multicolumn{3}{|c|}{ Áreas de processos críticos } \\
\hline & & & Pessoas & Processos & Tecnologia \\
\hline 1 & Inicial & $\begin{array}{l}\text { Pouca o } \\
\text { nenhuma } \\
\text { intenção de } \\
\text { gerir } \\
\text { formalmente o } \\
\text { conhecimento } \\
\text { organizacional }\end{array}$ & $\begin{array}{l}\text { A organização e sua } \\
\text { gente não são cientes } \\
\text { da necessidade de } \\
\text { gerir formalmente } \\
\text { seus recursos de } \\
\text { conhecimento }\end{array}$ & $\begin{array}{l}\text { Não há processos } \\
\text { formais de } \\
\text { captura, } \\
\text { compartilhamento } \\
\text { e reutilização do } \\
\text { conhecimento } \\
\text { organizacional }\end{array}$ & $\begin{array}{l}\text { Nenhuma tecnologia } \\
\text { ou infra-estrutura } \\
\text { específica de gestão } \\
\text { do conhecimento } \\
\text { instalada }\end{array}$ \\
\hline 2 & Consciente & $\begin{array}{l}\text { A organização } \\
\text { é ciente e tem } \\
\text { a intenção de } \\
\text { gerir seu } \\
\text { conhecimento, } \\
\text { mas } \\
\text { desconhecem } \\
\text { como fazê-lo }\end{array}$ & $\begin{array}{l}\text { A gerência é } \\
\text { consciente da } \\
\text { necessidade de uma } \\
\text { gestão do } \\
\text { conhecimento forma }\end{array}$ & $\begin{array}{l}\text { O conhecimento é } \\
\text { indispensável para } \\
\text { o desempenho das } \\
\text { rotinas, as tarefas } \\
\text { são documentadas }\end{array}$ & $\begin{array}{l}\text { Projetos pilotos em } \\
\text { gestão do } \\
\text { conhecimento são } \\
\text { iniciados (não } \\
\text { necessariamente pela } \\
\text { gerência) }\end{array}$ \\
\hline 3 & Definido & $\begin{array}{l}\text { A organização } \\
\text { instala uma } \\
\text { infra-estrutura } \\
\text { básica para } \\
\text { suportar a } \\
\text { gestão do } \\
\text { conhecimento }\end{array}$ & 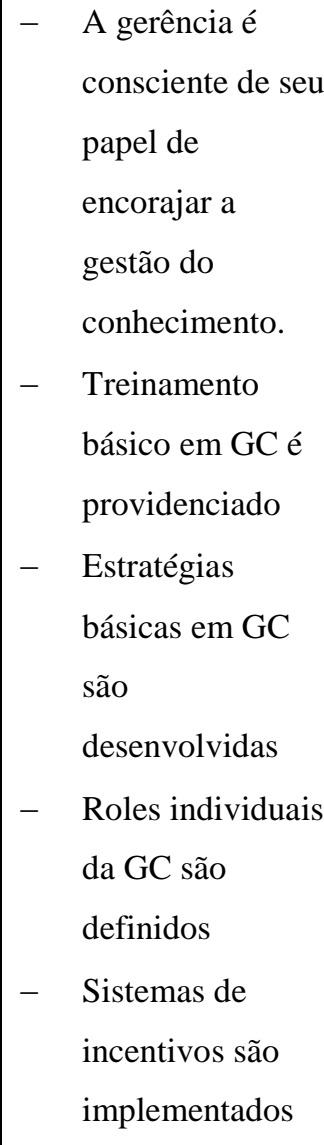 & 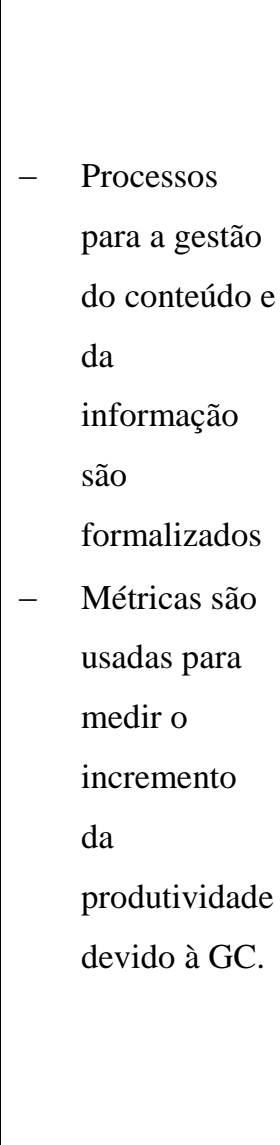 & $\begin{array}{ll}- & \text { Estruturas } \\
& \text { básicas para a } \\
& \text { GC são } \\
& \text { instaladas. } \\
- & \text { Alguns projetos } \\
& \text { de bom nível em } \\
\text { GC são } & \\
\text { desenvolvidos. }\end{array}$ \\
\hline 4 & Gerido & $\begin{array}{l}\text { Iniciativas da } \\
\text { GC são bem } \\
\text { estabelecidas } \\
\text { na }\end{array}$ & 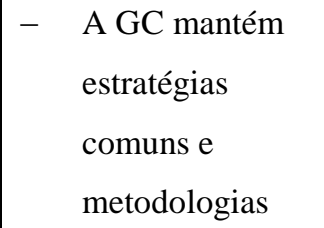 & $\begin{array}{l}\text { Medição } \\
\text { quantitativa dos } \\
\text { processos da } \\
\text { gestão do }\end{array}$ & $\begin{array}{ll}\text { - } & \text { Sistemas de GC } \\
& \text { são amplamente } \\
& \text { instalados na } \\
& \text { organização }\end{array}$ \\
\hline
\end{tabular}




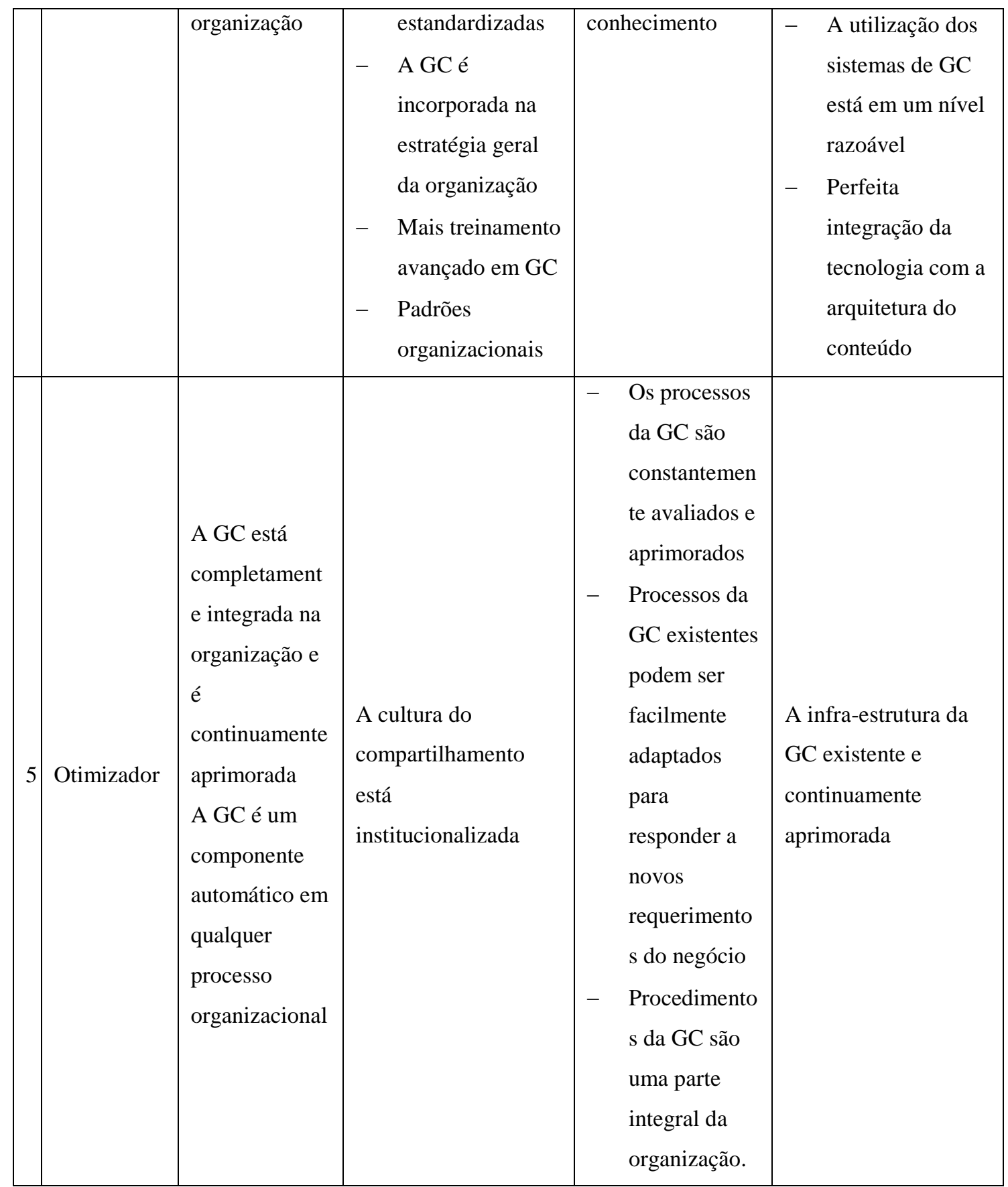

Quadro 9 - Modelo geral de maturidade da Gestão do Conhecimento Fonte: Pee e Kankanhalli (2009)

A área crítica pessoas inclui aspectos relacionados à cultura organizacional, estratégias e políticas; a área crítica de processos refere-se a aspectos concernentes às atividades da GC tais como o compartilhamento, aplicação e criação do conhecimento; e a área crítica de tecnologia relaciona-se a aspectos sobre a tecnologia e infra-estrutura da GC.

Para reforçar a idéia do modelo de maturidade para a GC, Pee e Kankanhalli (2009) propõem um instrumento de avaliação de maturidade, estruturado nessas áreas críticas e em perguntas que foram geradas em base a instrumentos de avaliação identificados na literatura ou de própria autoria desses autores. 
O presente trabalho apresentou os modelos da GC com o objetivo de formar uma base de referência que sustente o modelo a ser proposto pelo autor por meio de comparação e análise. Sendo assim, não se tomará nenhum modelo em particular para delimitar o fundamento conceitual nem os resultados deste trabalho.

É importante evidenciar componentes comuns ou relevantes nos modelos apresentados para que sirvam para a análise dos resultados deste estudo. Dessa forma, foram identificados cinco componentes: O processo ou ciclo da GC (criação, captura, compartilhamento e utilização do conhecimento), os capacitadores da GC ou fatores críticos de sucessos, os resultados da GC, os tipos de conhecimento e sua interação, e os níveis de maturidade da GC. O quadro 10 resume estes componentes para cada modelo.

\begin{tabular}{|c|c|c|c|c|c|}
\hline Modelo & Processos da GC & $\begin{array}{c}\text { Capacitadores } \\
\text { da GC }\end{array}$ & $\begin{array}{c}\text { Resultados da } \\
\text { GC }\end{array}$ & $\begin{array}{c}\text { Tipos de } \\
\text { conhecimento }\end{array}$ & $\begin{array}{c}\text { Níveis de } \\
\text { maturidade }\end{array}$ \\
\hline $\begin{array}{l}\text { Nonaka e } \\
\text { Takeuchi } \\
(1995) \text { e } \\
\text { Nonaka } \\
\text { et al. } \\
(2000)\end{array}$ & $\begin{array}{l}\text {-Criação } \\
\text {-Compartilhamento } \\
\text { - Justificação } \\
\text {-Construção de } \\
\text { arquétipo } \\
\text { - Difusão }\end{array}$ & $\begin{array}{l}\text {-Intenção } \\
\text {-Autonomia } \\
\text { - Flutuação/Caos } \\
\text { criativo } \\
\text { - Redundância } \\
\text {-Variedade de } \\
\text { Requisitos } \\
\text {-Cuidado, amor, } \\
\text { confiança e } \\
\text { compromisso } \\
\text {-Ba }\end{array}$ & $\begin{array}{l}\text {-Ativos de } \\
\text { conhecimento } \\
\text { experienciais } \\
\text {-Ativos de } \\
\text { conhecimento } \\
\text { conceituais } \\
\text {-Ativos de } \\
\text { conhecimento } \\
\text { sistemáticos } \\
\text {-Ativos de } \\
\text { conhecimento } \\
\text { rotineiros }\end{array}$ & $\begin{array}{l}\text {-Conhecimento } \\
\text { tácito } \\
\text {-Conhecimento } \\
\text { explícito }\end{array}$ & - \\
\hline $\begin{array}{l}\text { Orzano } \\
\text { et al. } \\
(2008)\end{array}$ & $\begin{array}{l}\text { - Descoberta } \\
\text { - Compartilhamento } \\
\text { - Desenvolvimento }\end{array}$ & $\begin{array}{l}\text {-Redes ativas } \\
\text {-Prática reflexiva } \\
\text {-Relacionamento } \\
\text { s úteis } \\
\text {-Infra-estrutura } \\
\text { robusta } \\
\text {-Tecnologia } \\
\text { acessível } \\
\text {-Liderança de } \\
\text { apoio } \\
\text {-Comunicação } \\
\text { efetiva }\end{array}$ & $\begin{array}{l}\text { - Tomada de } \\
\text { decisão } \\
\text {-Aprendizagem } \\
\text { organizacional } \\
\text {-Desempenho } \\
\text { organizacional }\end{array}$ & $\begin{array}{l}\text {-Conhecimento } \\
\text { tácito } \\
\text {-Conhecimento } \\
\text { explícito }\end{array}$ & - \\
\hline
\end{tabular}




\begin{tabular}{|c|c|c|c|c|c|}
\hline & & $\begin{array}{l}\cdot \text { Clima de } \\
\text { confiança }\end{array}$ & & & \\
\hline $\begin{array}{l}\text { Lee e } \\
\text { Kim } \\
(2001)\end{array}$ & $\begin{array}{l}\text { - Aquisição } \\
\text {-Criação } \\
\text { •Compartilhamento } \\
\text { - Integração }\end{array}$ & $\begin{array}{l}\text { - Trabalhadores } \\
\text { do } \\
\text { conhecimento } \\
\text {-Conhecimento } \\
\text { organizacional } \\
\text {-Tecnologias da } \\
\text { informação } \\
\text {-Processos da } \\
\text { GC }\end{array}$ & $\begin{array}{l}\text {-Desempenho } \\
\text { organizacional }\end{array}$ & - & $\begin{array}{l}\text { •Iniciação } \\
\text {-Propagação } \\
\text { •Integração } \\
\text { •Trabalho em } \\
\text { rede }\end{array}$ \\
\hline $\begin{array}{l}\text { Hanzick } \\
(2003)\end{array}$ & $\begin{array}{l}\text { •Geração } \\
\text { •Transferência } \\
\text {-Aplicação }\end{array}$ & $\begin{array}{l}\text {-Ambiente } \\
\text { Organizacional } \\
\text { - Infra-estrutura } \\
\text { tecnológica } \\
\text {-Medição }\end{array}$ & $\begin{array}{l}\text { - Desempenho } \\
\text { organizacional }\end{array}$ & $\begin{array}{l}\cdot \text { Know-that } \\
\text { explícito } \\
\text { - Know-that } \\
\text { tácito } \\
\text {-Know-how } \\
\text { explícito } \\
\text { - Know-how } \\
\text { tácito }\end{array}$ & - \\
\hline $\begin{array}{l}\text { Pee e } \\
\text { Kankanh } \\
\text { alli } \\
(2009)\end{array}$ & $\begin{array}{l}\text { Captura } \\
\text { Compartilhamento } \\
\text { Reutilização }\end{array}$ & $\begin{array}{l}\text { Pessoas } \\
\text { Processos } \\
\text { Tecnologia }\end{array}$ & $\begin{array}{l}\text {-Desempenho } \\
\text { organizacional }\end{array}$ & - & $\begin{array}{l}\text {-Inicial } \\
\text {-Consciente } \\
\text {-Definido } \\
\text { - Gerido } \\
\text {-Otimizador }\end{array}$ \\
\hline
\end{tabular}

Quadro 10 - Componentes comuns dos modelos da Gestão do Conhecimento

\subsubsection{Fatores críticos de sucesso da gestão do conhecimento}

A idéia de identificar os fatores críticos de sucesso como base para determinar a informação que os gerentes precisam foi proposta nos anos 60, mas só tornou-se popular com Rockart (1979), que definiu o conceito de fator de sucesso (VALENZUELA, 2008).

Segundo Rockart (1979), em qualquer organização alguns fatores são considerados chave para seu sucesso, se os objetivos associados aos fatores não são atingidos a organização falirá, possivelmente de forma catastrófica. Os fatores críticos de sucesso são o número limitado de áreas em que os resultados, se satisfatórios, assegurarão um sucedido desempenho competitivo para a organização. São as áreas chaves onde as coisas devem andar bem para assegurar o sucesso de uma organização. 
Em termos da GC, os fatores críticos podem ser vistos como aquelas atividades e práticas que devem ser desenvolvidas com o objetivo de assegurar o sucesso da implantação e desenvolvimento da GC (WONG, 2005).

A literatura aborda este tópico desde diferentes perspectivas, trabalhos que visam a identificação dos fatores críticos de sucesso de setores organizacionais específicos, ou realidades regionais diferentes, estudando instituições de diversos tipos e tamanhos, ou até identificando fatores de fracasso com o objetivo de evidenciar os elementos críticos na GC, no quadro 11 apresenta-se um resumo destes trabalhos.

\begin{tabular}{|c|c|}
\hline Autor & Fatores críticos de sucesso \\
\hline $\begin{array}{l}\text { Skyrme e } \\
\text { Amidon } \\
(1997)\end{array}$ & $\begin{array}{l}\text { - Forte ligação a um imperativo do negócio } \\
\text { - Visão e arquitetura forte para a GC } \\
\text { - Liderança de conhecimento } \\
\text { - Cultura de criação e compartilhamento do conhecimento } \\
\text { - Aprendizagem contínua } \\
\text { - Infra-estrutura de tecnologia bem desenvolvida para apoiar a GC } \\
\text { - Processos de conhecimento organizacionais sistemáticos. }\end{array}$ \\
\hline $\begin{array}{l}\text { Davenport } \\
(1998)\end{array}$ & $\begin{array}{l}\text { - Relacionar a GC com o desempenho econômico ou o valor da indústria } \\
\text { - Propósito e linguagem clara } \\
\text { - Estrutura de conhecimento flexível e standard } \\
\text { - Múltiplos canais para a transferência do conhecimento } \\
\text { - Cultura de conhecimento amigável } \\
\text { - Infra-estrutura organizacional e técnica } \\
\text { - Mudança nas práticas motivacionais } \\
\text { - Suporte da alta gerência }\end{array}$ \\
\hline $\begin{array}{l}\text { Liebowitz } \\
\text { (1999) }\end{array}$ & $\begin{array}{l}\text { - Estratégia de GC suportada pela alta gerência } \\
\text { - Gerente do conhecimento } \\
\text { - Infra-estrutura de GC } \\
\text { - Repositórios e ontologia de conhecimento } \\
\text { - Sistemas e ferramentas de GC } \\
\text { - Incentivos para encorajar o compartilhamento do conhecimento e uma cultura de } \\
\text { sustento }\end{array}$ \\
\hline $\begin{array}{l}\text { APQC } \\
(1999)\end{array}$ & $\begin{array}{l}\text { - Estratégia de GC } \\
\text { - Liderança de conhecimento } \\
\text { - Cultura de criação, compartilhamento e utilização do conhecimento } \\
\text { - Tecnologia de sustento para as práticas de GC } \\
\text { - Medição ou avaliação da GC }\end{array}$ \\
\hline
\end{tabular}




\begin{tabular}{|c|c|}
\hline $\begin{array}{l}\text { Hasanali } \\
\text { (2002) }\end{array}$ & $\begin{array}{l}\text { - Liderança de conhecimento } \\
\text { - Cultura voltada a GC } \\
\text { - Estrutura organizacional para a GC } \\
\text { - Roles e responsabilidades bem definidos para atividades de GC } \\
\text { - Infra-estrutura de TI de sustento para a GC } \\
\text { - Medição ou avaliação da GC }\end{array}$ \\
\hline $\begin{array}{l}\text { Wong } \\
(2005) \\
\text { pequena e } \\
\text { média } \\
\text { empresa }\end{array}$ & $\begin{array}{l}\text { - Suporte e liderança gerencial para exemplificar o comportamento desejado para a GC } \\
\text { - Cultura que valora o conhecimento e encoraja sua criação, compartilhamento e } \\
\text { aplicação. Cultura de cooperação, confiança e inovação } \\
\text { - Tecnologia da Informação para sustentar os processos da GC na organização } \\
\text { - Estratégia clara e bem definida para saber como atingir os objetivos da GC } \\
\text { - Medição ou avaliação das atividades da GC } \\
\text { - Infra-estrutura organizacional, estabelecendo um conjunto de papeis e equipes para } \\
\text { desempenhar as atividades da GC } \\
\text { - Processos e atividades da GC determinados de forma sistemática e estruturada } \\
\text { - Auxílio motivacional para praticar a GC. Incentivos, prêmios, ou ajuda motivacional } \\
\text { para encorajar às pessoa a compartilhar e utilizar conhecimento } \\
\text { - Recursos financeiros e capital intelectual para sustentar, coordenar e executar os } \\
\text { papeis relacionados ao conhecimento } \\
\text { - Treinamento e educação para que os membros tenham consciência da necessidade da } \\
\text { GC e vejam ao conhecimento como um recurso chave para a viabilidade da companhia } \\
\text { - Gestão de recursos humanos, principalmente no recrutamento, desenvolvimento e } \\
\text { retenção de membros com perfil propício para a GC }\end{array}$ \\
\hline $\begin{array}{l}\text { Chua e } \\
\text { Lam } \\
(2005) \\
\text { Fatores de } \\
\text { fracasso }\end{array}$ & $\begin{array}{l}\text { - Tecnologia (conectividade, usabilidade, confiança, custo de manutenção) } \\
\text { - Cultura (políticas, compartilhamento do conhecimento, imagem percebida, } \\
\text { compromisso da alta gerência) } \\
\text { - Conteúdo (cobertura, estrutura, relevância e precisão, destilação do conhecimento) } \\
\text { - O projeto da GC (envolvimento dos usuários, especialista técnicos e de negócio, } \\
\text { gestão de conflito, estratégia de lançamento, custo do projeto, avaliação do projeto, } \\
\text { envolvimento de consultores externos) }\end{array}$ \\
\hline $\begin{array}{l}\text { Chong e } \\
\text { Choi } \\
(2005)\end{array}$ & $\begin{array}{l}\text { - Treinamento do pessoal não só nas atividades da GC, mas em toda atividade } \\
\text { organizacional, visando tornar-se uma organização em aprendizagem } \\
\text { - Envolvimento do pessoal nas decisões organizacionais. Refere-se ao grau que os } \\
\text { funcionários compartilham a informação, o conhecimento, os prêmios e o poder em } \\
\text { toda a empresa. } \\
\text { - Equipes de trabalho para o enriquecimento de habilidades na solução de problemas } \\
\text { organizacionais e o fortalecimento da confiança em ter seus membros } \\
\text { - Empowerment dos funcionários para preencher suas necessidades de conhecimento e } \\
\text { permiti-lhes desempenhar melhor suas funções, além de oferecer sentido de liberdade }\end{array}$ \\
\hline
\end{tabular}




\begin{tabular}{|c|c|}
\hline & $\begin{array}{l}\text { - Liderança e compromisso da alta gerência com a GC } \\
\text { - Infra-estrutura de sistemas de informação para apoiar as atividades da GC } \\
\text { - Avaliação do desempenho e do impacto do conhecimento na organização } \\
\text { - Cultura de conhecimento amigável para facilitar os processos do conhecimento } \\
\text { - Benchmarking para a captura de conhecimento realmente útil para a organização e a } \\
\text { comparação das práticas de GC intra e inter organizações. } \\
\text { - Estrutura de conhecimento, para apoiar sua criação, compartilhamento e utilização de } \\
\text { forma individual o em grupo, de dentro ou fora da organização } \\
\text { - Eliminação de barreiras organizacionais que restringem as atividades de GC em geral } \\
\text { de toda a organização (hierarquia, regulamento rígido, falta de incentivos, centralismo } \\
\text { etc.) }\end{array}$ \\
\hline $\begin{array}{l}\text { Yeh et al. } \\
(2006)\end{array}$ & $\begin{array}{l}\text { - Estratégia de negócio bem definida que guie as práticas de GC } \\
\text { - Liderança e apóio da alta gerência para a GC } \\
\text { - Cultura organizacional de cooperação, fluxo do conhecimento e confiança } \\
\text { - Pessoas como o centro para a criação, compartilhamento e uso do conhecimento } \\
\text { organizacional } \\
\text { - Tecnologia da informação que sustente e coordene a GC }\end{array}$ \\
\hline $\begin{array}{l}\text { Jafari et al. } \\
(2007)\end{array}$ & $\begin{array}{l}\text { - Trabalho em equipe e recursos de GC (envolvimento e consciência do pessoal, } \\
\text { estrutura do conhecimento, criação e compartilhamento do conhecimento, arquitetura } \\
\text { do conhecimento, comunidades de prática) } \\
\text { - Liderança e compromisso da alta gerência (suporte e compromisso da alta gerência, } \\
\text { metodologia sistemática para a GC, gerente de conhecimento responsável) } \\
\text { - Apropriada infra-estrutura organizacional (disponibilidade da companhia para a GC, } \\
\text { infra-estrutura organizacional, integração da GC aos sistemas atuais) } \\
\text { - Piloto, benchmarking e sistemas de GC } \\
\text { - Segurança no trabalho e enriquecimento laboral } \\
\text { - Cultura, gestão da mudança e estratégia (confiança) } \\
\text { - Organização flexível e colaborativa (colaboração, comunicação, tomada de risco } \\
\text { estrutura organizacional flexível e dinâmica) } \\
\text { - Treinamento e aprendizagem (Educação e treinamento do pessoal, aprendizagem } \\
\text { contínua) }\end{array}$ \\
\hline $\begin{array}{l}\text { Bishop et } \\
\text { al. (2008) }\end{array}$ & $\begin{array}{l}\text { - Estabelecer um alto nível de compreensão e uma clara definição da GC por toda a } \\
\text { organização } \\
\text { - Assegurar que a iniciativa da GC responda as necessidades dos objetivos de negócio } \\
\text { dos indivíduos e da organização } \\
\text { - Integrar a iniciativa dentro da organização e a vida diária dos funcionários } \\
\text { - Designar responsáveis da GC e uma equipe de suporte } \\
\text { - Estabelecer o suporte da alta gerência } \\
\text { - Demonstrar e comunicar claramente os benefícios e sucessos iniciais da iniciativa. }\end{array}$ \\
\hline
\end{tabular}




\begin{tabular}{|c|c|}
\hline & $\begin{array}{l}\text { - Determinar a adequação de recompensas financeiras e não financeiras } \\
\text { - Lograr um balance entre as pessoas e a TI }\end{array}$ \\
\hline $\begin{array}{l}\text { Chang et } \\
\text { al. (2009) }\end{array}$ & $\begin{array}{l}\text { - Missão e valores organizacionais (prioridade, implementação, domínio do know-how, } \\
\text { atitude da alta gerência) } \\
\text { - Aplicação da TI (engenharia de busca, interface, mecanismos de importação, } \\
\text { retroalimentação e avaliação) } \\
\text { - Documentação da GC (taxonomia, categoria, documentação digital) } \\
\text { - Processo de gestão e estrutura (conhecimento explícito, implícito, análise de } \\
\text { conhecimento, estrutura organizacional, criação do conhecimento) } \\
\text { - Ativos de recursos humanos (mapas dos ativos, consultoria, treinamento, classificação } \\
\text { de tarefas) } \\
\text { - Captura e transformação do conhecimento (adição de valor e inovação) } \\
\text { - Desempenho organizacional (efetividade, crescimento, bdesempenho do sistema, auto- } \\
\text { realização) } \\
\text { - Compartilhamento do conhecimento e adição de valor (brain storming, } \\
\text { retroalimentação e avaliação) }\end{array}$ \\
\hline
\end{tabular}

Quadro 11 - Fatores Críticos de Sucesso da Gestão do Conhecimento

São muitos os fatores críticos identificados, e alguns deles são compostos de subitens, incrementando a quantidade de elementos de análise, mas também é evidente a complementaridade e até a repetição de alguns deles. Aproveitando estas similaridades, os fatores críticos ou mega fatores críticos (por abranger subitens) que serão abordados neste trabalho seguindo os seguintes itens:

a) Estratégia da Gestão do Conhecimento

b) Cultura organizacional de conhecimento

c) Estrutura organizacional de conhecimento

d) Equipe da GC

Líderes de conhecimento

Trabalhador do conhecimento

e) Ferramentas da GC

f) Ciclos da GC

g) Métricas da GC

Segundo Backer (1995), classificar ou agrupar objetos em categorias é uma atividade bastante comum e vem sendo intensificada devido ao número elevado de informações que estão disponíveis atualmente. 
Tendo como fundamento essa classificação, os fatores identificados na literatura são agrupados como mostra o quadro 12, e detalhados a continuação.

\begin{tabular}{|c|c|}
\hline Mega fatores Críticos & ríticos identificados na literatura \\
\hline Estratégia da GC & $\begin{array}{l}\text { - Forte ligação a um imperativo do negócio } \\
\text { - Relacionar a GC com o desempenho econômico ou o valor da } \\
\text { indústria } \\
\text { - Propósito e linguagem clara } \\
\text { - Suporte da alta gerência } \\
\text { - Estratégia de GC suportada pela alta gerência } \\
\text { - Recursos financeiros e capital intelectual para sustentar, coordenar e } \\
\text { executar os papeis relacionados ao conhecimento } \\
\text { - O projeto da GC (envolvimento dos usuários, especialistas, técnicos e } \\
\text { de negócio, gestão de conflito, estratégia de lançamento, custo do } \\
\text { projeto, avaliação do projeto, envolvimento de consultores externos) } \\
\text { - Assegurar que a iniciativa da GC responda as necessidades dos } \\
\text { objetivos de negócio dos indivíduos e da organização } \\
\text { - Missão e valores organizacionais (prioridade, implementação, domínio } \\
\text { do know-how, atitude da alta gerência) }\end{array}$ \\
\hline $\begin{array}{l}\text { Cultura organizacional de } \\
\text { conhecimento }\end{array}$ & $\begin{array}{l}\text { - Cultura de criação e compartilhamento do conhecimento } \\
\text { - Cultura de conhecimento amigável para facilitar os processos do } \\
\text { conhecimento } \\
\text { • Cultura de criação, compartilhamento e utilização do conhecimento } \\
\text { • Cultura que valora o conhecimento e encoraja sua criação, } \\
\text { compartilhamento e aplicação. Cultura de cooperação, confiança e } \\
\text { inovação } \\
\text { - Cultura (políticas, compartilhamento do conhecimento, imagem } \\
\text { percebida, compromisso da alta gerência) } \\
\text { - Cultura organizacional de cooperação, fluxo do conhecimento e } \\
\text { confiança } \\
\text { - Cultura, gestão da mudança e estratégia (confiança) } \\
\text { - Eliminação de barreiras organizacionais que restringem as atividades } \\
\text { de GC em geral de toda a organização (hierarquia, regulamento rígido, } \\
\text { falta de incentivos, centralismo etc.) } \\
\text { - Gestão da mudança }\end{array}$ \\
\hline $\begin{array}{l}\text { Estrutura organizacional } \\
\text { de conhecimento }\end{array}$ & $\begin{array}{l}\text { - Estrutura de conhecimento flexível e standard } \\
\text { - Estrutura organizacional flexível e dinâmica } \\
\text { - Apropriada infra-estrutura organizacional (disponibilidade da } \\
\text { companhia para a GC, infra-estrutura organizacional, integração da }\end{array}$ \\
\hline
\end{tabular}




\begin{tabular}{|c|c|}
\hline & GC aos sistemas atuais) \\
\hline Equipe da GC & 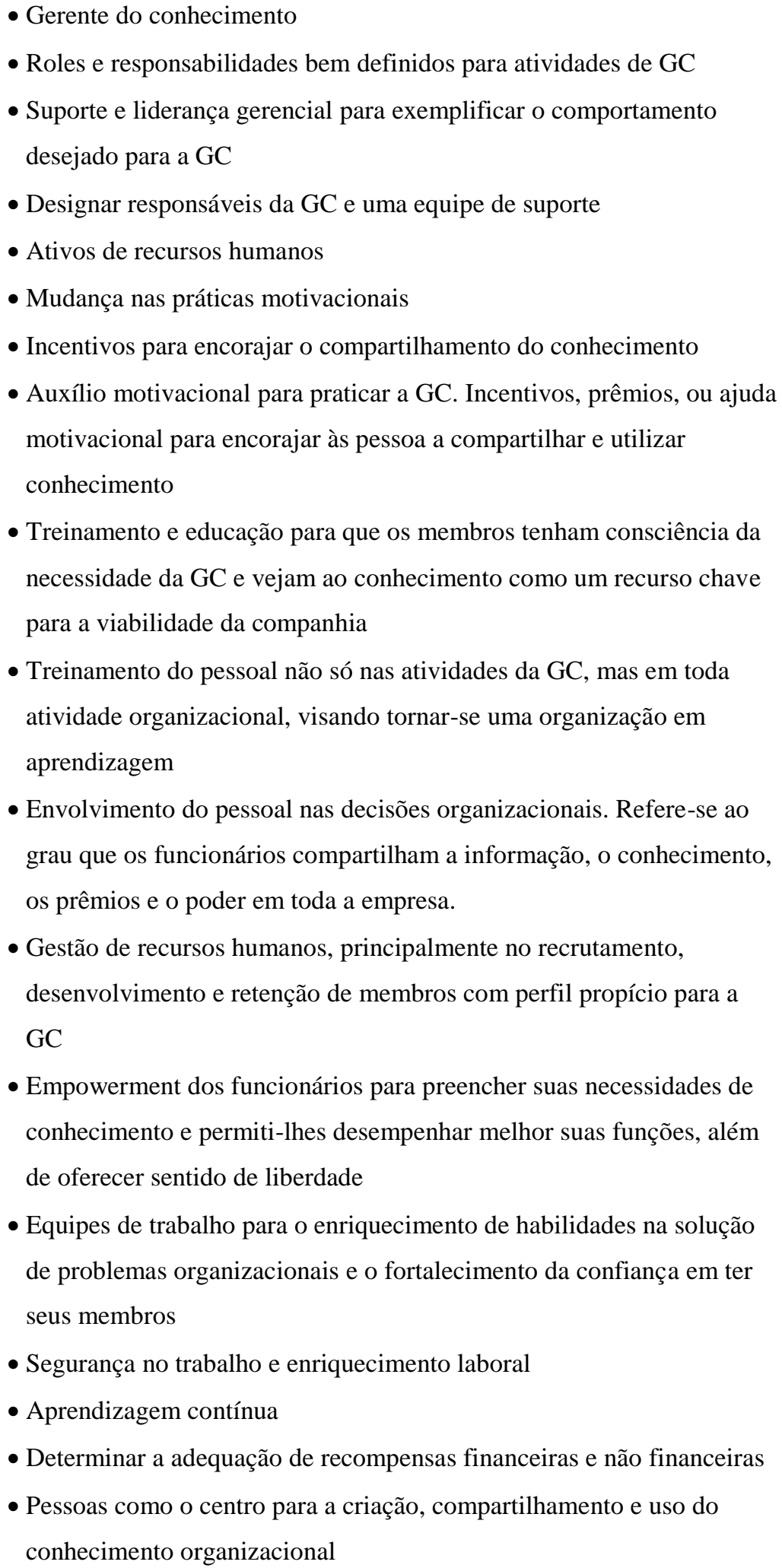 \\
\hline Ferramentas da GC & $\begin{array}{l}\text { - Infra-estrutura de tecnologia bem desenvolvida para apoiar a GC } \\
\text { - Múltiplos canais para a transferência do conhecimento } \\
\text { - Infra-estrutura organizacional e técnica } \\
\text { - Repositórios e ontologia de conhecimento }\end{array}$ \\
\hline
\end{tabular}




\begin{tabular}{|l|l|}
\hline \multirow{1}{*}{ • Sistemas e ferramentas de GC } \\
- Tecnologia (conectividade, usabilidade, confiança, custo de \\
manutenção) \\
• Aplicação da TI (engenharia de busca, interface, mecanismos de \\
importação, retroalimentação e avaliação)
\end{tabular}

Quadro 12 - Classificação dos fatores críticos

\subsubsection{Estratégia da Gestão do Conhecimento}

No contexto na GC, estratégia refere-se à intenção e condições organizacionais que permitam a criação do conhecimento (NONAKA; TAKEUCHI, 1995). Segundo Lee e Kim (2001), a estratégia da GC está focada na aquisição, explicação e comunicação da missão de especialização profissional específica que é tácita por natureza para os participantes da organização, de uma forma focada, relevante e oportuna. A estratégia fornece o fundamento de como a organização pode desenvolver suas capacidades e recursos para atingir os objetivos da GC (WONG, 2005). Ela compreende uma visão compartilhada da GC, missão, objetivos, metas e procedimentos bem definidos.

Choi et al. (2008) sugerem que as estratégias de GC podem ser categorizadas baseadas em duas dimensões: o foco da GC, e a fonte da GC. Na dimensão do foco da GC, as estratégias podem ser categorizadas como explícito-orientadas ou tácito-orientadas. A 
estratégia explícito-orientada visa aprimorar a eficiência organizacional por meio da codificação e reutilização do conhecimento, principalmente com base no uso da TI (GREINER et al., 2007; HASEN et al, 1999; KESKIN, 2005; ZACK, 1999). A estratégia tácito-orientada está fundamentada na abordagem de personalização em que o conhecimento tácito é comunicado por meio da interação face-to-face e por meio de processos de socialização (GREINER et al., 2007; SCHULZ e JOBE, 2001; SWAN et al., 2000; ZACK, 1999).

A segunda dimensão para orientar a estratégia da GC está baseada nas principais fontes de conhecimento da organização. Dentro dessa dimensão as estratégias podem ser classificadas como interno-orientadas ou externo-orientadas. A estratégia internoorientada foca-se na geração e compartilhamento do conhecimento dentro das fronteiras da organização (PAI, 2005; ZACK,1999). A estratégia externo-orientada visa trazer conhecimento de fonte externas, por meio da aquisição ou imitação para sua posterior transferência dentro da organização (BIERLY; CHAKRABARTI, 1996; ZACK,1999).

Segundo Greiner et al. (2007), a seleção de uma estratégia da GC adequada não só depende do tipo do conhecimento a ser compartilhado, mas também do ambiente organizacional em que a organização opera.

Choi et al. (2008), em concordâncias com Zack (1999), sugere uma aplicação complementar destas estratégias, sendo o mix composto por estratégias tácito-orientadas e interno-orientadas por um lado, e estratégias explícito-orientadas e externo-orientadas pelo outro, o que implicaria efeitos sinérgicos da estratégia da GC sobre o desempenho organizacional.

No mesmo contexto, Jasimuddin (2008), baseado em um caso de estudo apresenta uma estratégia para a transmissão do conhecimento fundamentada nos seus dois tipos, tácito e explícito, dando lugar a diferentes mecanismos de transmissão para cada tipo. Os mecanismos de transmissão para o conhecimento tácito são baseados em interações face-to-face, e para o conhecimento explícito são baseados em tecnologias de informação e comunicação. Segundo Jasimuddin (2008), essa perspectiva é uma extensão à apresentada por Hansen et al. (1999), que sustenta as estratégias de personalização e codificação para a GC, anteriormente apresentadas. 
Segundo Malhotra (2004), a estratégia de codificação é mais voltada para companhias cuja estratégia de negócio requer a reutilização do conhecimento; e a estratégia de personalização resulta mais efetiva para companhias com uma estratégia de negócio que requer a criação de novo conhecimento, soluções específicas para clientes e a inovação de produtos.

Por último Jasimuddin (2008) suporta, com base na análise de um caso de estudo e na revisão da literatura, uma aplicação híbrida destas duas estratégias para a obtenção de melhores resultados, fundamento claramente alinhado com as pesquisas de Choi et al.(2008) e Zack (1999) .

Complementarmente, Earl (2001) define uma taxonomia das estratégias da GC baseado nas escolas de GC que ele identificou na sua pesquisa (quadro 13), cada escola é proposta como seu tipo ideal, apresentando orientações particulares para a organização, mas não sendo mutuamente excludentes.

Earl (2001), baseado na taxonomia proposta, sugere uma metodologia para a formulação de uma estratégia de GC (Figura 18). Na Figura 18, a fase da visão deve encapsular a contribuição que a criação de valor baseada no conhecimento pode fazer para a organização. A analise das lacunas de desempenho do negócio deve ser dirigida para a identificação de áreas onde possam ser aplicadas iniciativas de GC.

Posteriormente, perguntar como o conhecimento pode fazer a diferença implica examinar como uma melhor aquisição, distribuição, uso ou proteção do conhecimento pode ajudar a remediar a lacuna de desempenho organizacional. O quarto estágio é necessário para identificar e examinar possíveis iniciativas da GC, para operacionalizar a intenção da estratégia da GC.

O quinto estágio é um teste de validade em que é perguntado se as iniciativas a serem empreendidas estão alinhadas à estratégia e cultura do negócio. Por último, o sexto estágio confirma o programa da GC, disponibiliza recursos para sua consecução e planeja sua execução.

A evidência da influência que tem a estratégia da GC no desempenho e desenvolvimento do negócio foi enfatizada por Hasen e Al-hawari (2003), Yang (2008). Enquanto Greiner et al. (2007) sustenta que a direção estratégica da organização deve determinar a direção das atividades da GC. 


\begin{tabular}{|c|c|c|c|c|c|c|c|}
\hline \multirow[t]{2}{*}{ Escola } & \multicolumn{3}{|c|}{ Tecnocrática } & \multirow{2}{*}{$\frac{\text { Econômica }}{\text { Comercial }}$} & \multicolumn{3}{|c|}{ Comportamental } \\
\hline & Sistemas & Cartográfica & Engenharia & & Organizacional & Espacial & Estratégica \\
\hline Foco & Tecnologia & Mapas & Processos & Renda & Redes de trabalho & Espaço & Mentalidade \\
\hline Alvo & $\begin{array}{l}\text { Bases de } \\
\text { conhecimento }\end{array}$ & $\begin{array}{l}\text { Diretórios de } \\
\text { conhecimento }\end{array}$ & $\begin{array}{l}\text { Fluxos de } \\
\text { conhecimento }\end{array}$ & $\begin{array}{l}\text { Ativos de } \\
\text { conhecimento }\end{array}$ & $\begin{array}{l}\text { Compartilhamento } \\
\text { de conhecimento }\end{array}$ & $\begin{array}{l}\text { Intercâmbio de } \\
\text { conhecimento }\end{array}$ & $\begin{array}{l}\text { Capacidades de } \\
\text { conhecimento }\end{array}$ \\
\hline Unidade & Domínio & Empresa & Atividade & Know-how & Comunidades & Lugar & Negócio \\
\hline Exemplo & Xerox & AT\&T & HP & IBM & Shell & Skandia & Unilever \\
\hline $\begin{array}{l}\text { Fatores } \\
\text { críticos de } \\
\text { sucesso }\end{array}$ & $\begin{array}{l}\text { Conteúdo } \\
\text { Validação } \\
\text { Incentivos para } \\
\text { prover de } \\
\text { conteúdo }\end{array}$ & $\begin{array}{l}\text { Cultura/incentivos para } \\
\text { compartilhar } \\
\text { conhecimento } \\
\text { Redes para conectar } \\
\text { pessoas }\end{array}$ & $\begin{array}{l}\text { Distribuição } \\
\text { irrestrita de } \\
\text { informação e } \\
\text { aprendizagem de } \\
\text { conhecimento }\end{array}$ & $\begin{array}{l}\text { Equipes } \\
\text { especializadas } \\
\text { Processos } \\
\text { institucionalizados }\end{array}$ & $\begin{array}{l}\text { Cultura sociável } \\
\text { Intermediários de } \\
\text { conhecimento }\end{array}$ & $\begin{array}{l}\text { Desenho do propósito } \\
\text { Incentivo/motivação }\end{array}$ & $\begin{array}{l}\text { Retórica } \\
\text { Artefatos }\end{array}$ \\
\hline $\begin{array}{l}\text { Contribuição } \\
\text { principal da } \\
\text { TI }\end{array}$ & $\begin{array}{l}\text { Sistemas } \\
\text { baseados no } \\
\text { conhecimento }\end{array}$ & $\begin{array}{l}\text { Perfis e diretórios na } \\
\text { Internet }\end{array}$ & $\begin{array}{l}\text { Bancos de dados } \\
\text { compartilhados }\end{array}$ & $\begin{array}{l}\text { Ativos intelectuais } \\
\text { registrados em } \\
\text { sistemas de } \\
\text { processamento }\end{array}$ & $\begin{array}{l}\text { Groupware e } \\
\text { intranets }\end{array}$ & $\begin{array}{l}\text { Ferramentas de } \\
\text { representação e } \\
\text { acesso }\end{array}$ & Eclético \\
\hline Filosofia & Codificação & Conectividade & Capacidade & Comercialização & Colaboração & Contacto & Consciência \\
\hline
\end{tabular}

Quadro 13 - Taxonomia das estratégias da Gestão do Conhecimento

Fonte: Earl (2001) 


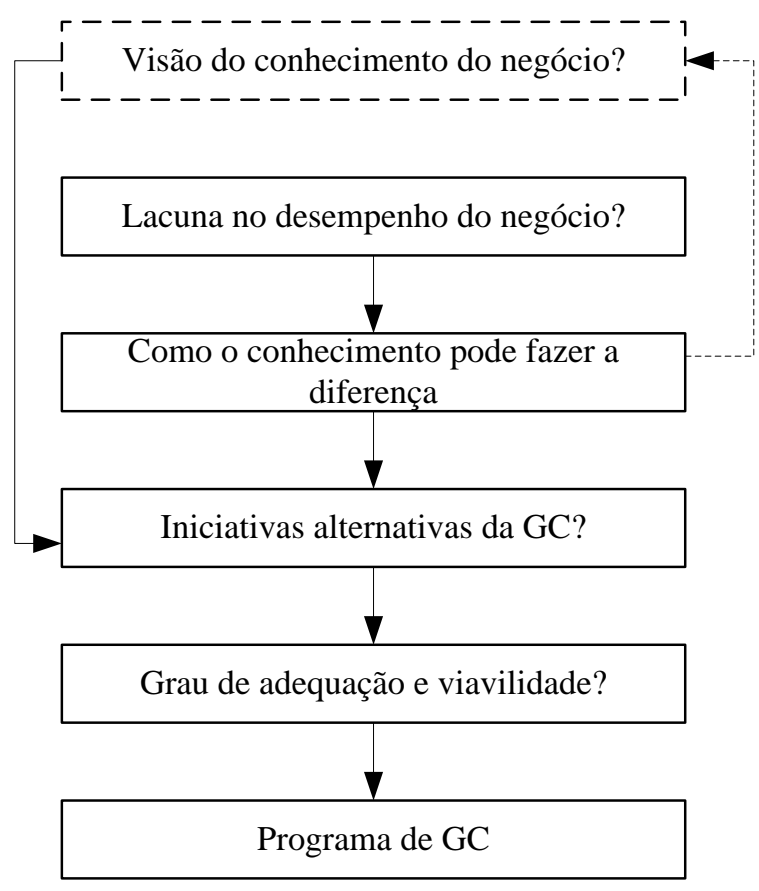

Figura 18 - Formulando uma estratégia de Gestão do Conhecimento Fonte: Earl (2001)

Nesse aspecto, o alinhamento da estratégia de GC com a estratégia do negócio foi evidenciada por Choi et al (2008), Ekionea e Swain (2008), Hansen et al. (1999), Vera (2001), Wu e Lin (2009), Zack (1999),.

O presente trabalho tomará como referência de estratégia para a GC, a fundamentada por Choi et al. (2008) e Zack (1999). Considerando então o mix das estratégias tácitointerno-orientadas, e as estratégias explícito-externo-orientadas, como adequadas para o desenvolvimento das atividades da GC.

\subsubsection{Cultura organizacional de conhecimento}

Schein (1992), considerado um dos mais importantes autores da cultura organizacional, define cultura como um padrão de pressupostos básicos compartilhados que o grupo aprendeu ao resolver seus problemas de adaptação externa e integração interna, que tem funcionado bem o suficiente para ser considerado válido e, portanto, ser ensinado aos novos membros como a maneira correta de perceber, pensar, e sentir em relação a esses problemas.

A cultura pode ser analisada em três níveis: nível de artefato, nível de valores e nível de pressupostos. O nível de artefato refere-se a todo tipo de fenômeno que pode ser observado, escutado, sentido quando uma pessoa encontra-se em um novo grupo com uma cultura não familiar. O nível de valores é considerado mais profundo que o nível de 
artefatos, ele refere-se aos princípios sociais, filosóficos, metas e padrões considerados de valor intrínseco. Por último, o nível de pressupostos são considerados os elementos mais profundos da cultura, referem-se às crenças sobre a realidade e a natureza humana. (SCHEIN, 1992).

Segundo Oliver e Kandadi (2006) a cultura não é algo que a organização tem, ela é algo que a organização é. No âmbito da GC, uma cultura de conhecimento é definida como uma forma de vida da organização que permite e motiva às pessoas na criação, compartilhamento e utilização do conhecimento para o benefício e duradouro sucesso da organização (OLIVER; KANDADI, 2006).

A relação entre a cultura organizacional e a GC foi evidenciada por vários estudos a nível mundial. Lichtenstein e Brain (2006) pesquisaram o serviço educacional australiano e evidenciaram que a cultura de compartilhamento do conhecimento não pode ser considerada isolada da cultura da organização, sua estratégia e sua estrutura. Li et al. (2006) examinaram as companhias de manufatura da China e mostraram que a cultura organizacional a e GC são altamente correlacionadas, e que tem um impacto significativo na desempenho organizacional. Lee (2006) estudou 42 organizações na Coréia e mostrou que um clima organizacional de conhecimento em que há confiança, coesão e cooperação entre os membros, estão relacionadas a um alto desempenho da GC.

Segundo Liebowitz (2008), há duas linhas de pensamento sobre a relação cultura-GC. A primeira escola sustenta que a cultura organizacional deve-se mudar antes da implantação da GC. A segunda escola fundamenta que a GC deve-se encaixar na atual cultura da organização, para uma mudança individual que origine posteriormente uma mudança organizacional. Segundo Liebowitz (2008), devido a que a mudança da cultura organizacional é uma fato difícil de alcançar no curto prazo, o segundo fundamento poderia ser melhor considerado para a implantação da GC, isto é, alinhada com a atual cultura organizacional.

Liebowitz (2008) apresenta os tipos de comportamento que se querem influenciar da cultura organizacional por meio da GC:

- O compartilhamento do conhecimento é poder e não o conhecimento é poder.

- A habilidade de pensar criticamente 
- Comunicação efetiva

- Trabalho em equipes

- Gestão de projetos

- Compromisso com a missão da organização, os valores e as crenças compartilhadas

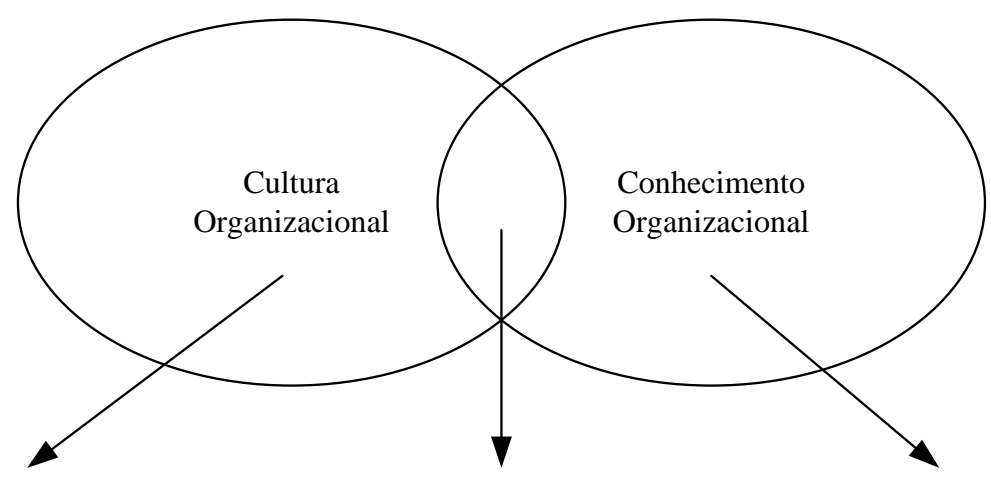

Componente materialisticos da cultura

- Histórias

- Práticas

- Rotinas

- Mitos

- Simbolos
Conhecimento cultural organizacional

- Cognição compartilhada

- Referência de percepção comum

- Conhecimento social

- Conhecimento arquitetônico
Conhecimento não cultural

- Conhecimento técnico

- Conhecimento estruturado

- Conhecimento humano

- Conhecimento de componentes

Figura 19 - Sobreposição da cultura organizacional com o conhecimento organizacional Fonte: Zheng (2005)

A relação destas duas áreas foi melhor explorada por Zheng (2005), quem propõe um terceiro tipo de relacionamento, em que á idéia de que a organização deve modificar sua cultura para acomodar suas práticas de GC ou que os projetos de GC devem encaixar na cultura existente da organização, é enriquecida com uma nova visão que sustenta que a cultura organizacional não é um fator estranho ao conhecimento organizacional, mas constitui parte desse conhecimento; e que a cultura organizacional e a GC compartilham ingredientes comuns, o que quer dizer que gerir o conhecimento implica gerir a cultura organizacional (Figura 19).

Zheng (2005) argumenta que alguns dos componentes da cultura organizacional são considerados tipos de conhecimento, sendo então a cultura organizacional um fator endógeno à GC. O fundamento de que a cultura organizacional sobrepõe-se com a GC é evidenciado na Figura 20.

De forma complementar, Oliver e Kandadi (2006), em base a estúdios de caso em empresas multinacionais, identificaram dez elementos que influenciam na criação e 
desenvolvimento da cultura de conhecimento dentro das organizações, apresentados na Figura 21, juntos com suas principais características.

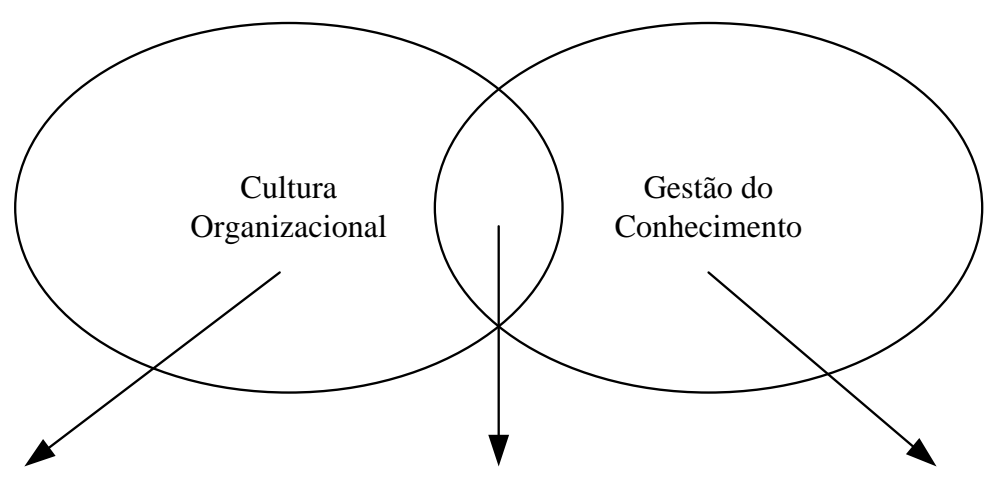

Componente materialisticos da

Gestão do conhecimento cultural

Gestão do conhecimento não cultura

organizacional

cultural

- Histórias

- Práticas

- Rotinas

- Mitos

- Simbolos

Figura 20 - Sobreposição da cultura organizacional com a Gestão do Conhecimento Fonte: Zheng (2005)

Por outro lado, Lam (2005) explicita fatores culturais que impedem o sucesso e a institucionalização da GC, baseado na revisão da literatura e um estudo de caso em uma companhia indiana, sendo eles:

- A competitividade entre funcionários

- A falta de um sistema de incentivos

- Preocupação dos funcionários sobre a segurança do trabalho e sua desvalorização.

- Estigma associado com a dependência das idéias de alguma outra pessoa.

- Preferência de um modo de compartilhamento do conhecimento face-to-face sobre o uso da utilização das Tecnologias de Informação e Comunicação

- Dúvidas sobre a qualidade do conhecimento compartilhado por funcionários menos experientes.

Por último, Zheng (2009) critica a abordagem fragmentada que realizaram os estudos anteriores sobre a relação entre a cultura organizacional e a GC, dando como resultados listas longas de elementos culturais que dificultam uma visão integrada que permita a análise critica e avaliação dessa relação. Em base a essa crítica, Zheng (2009), propõe 
uma abordagem integrada dessas duas áreas, sintetizando trabalhos anteriores e estabelecendo um marco teórico, seguindo o método de construção teórica.

Zheng (2009) categoriza os fatores culturais relacionados à GC em três grupos: fatores orientados ao conhecimento, fatores orientados às pessoas e fatores orientados ao trabalho.

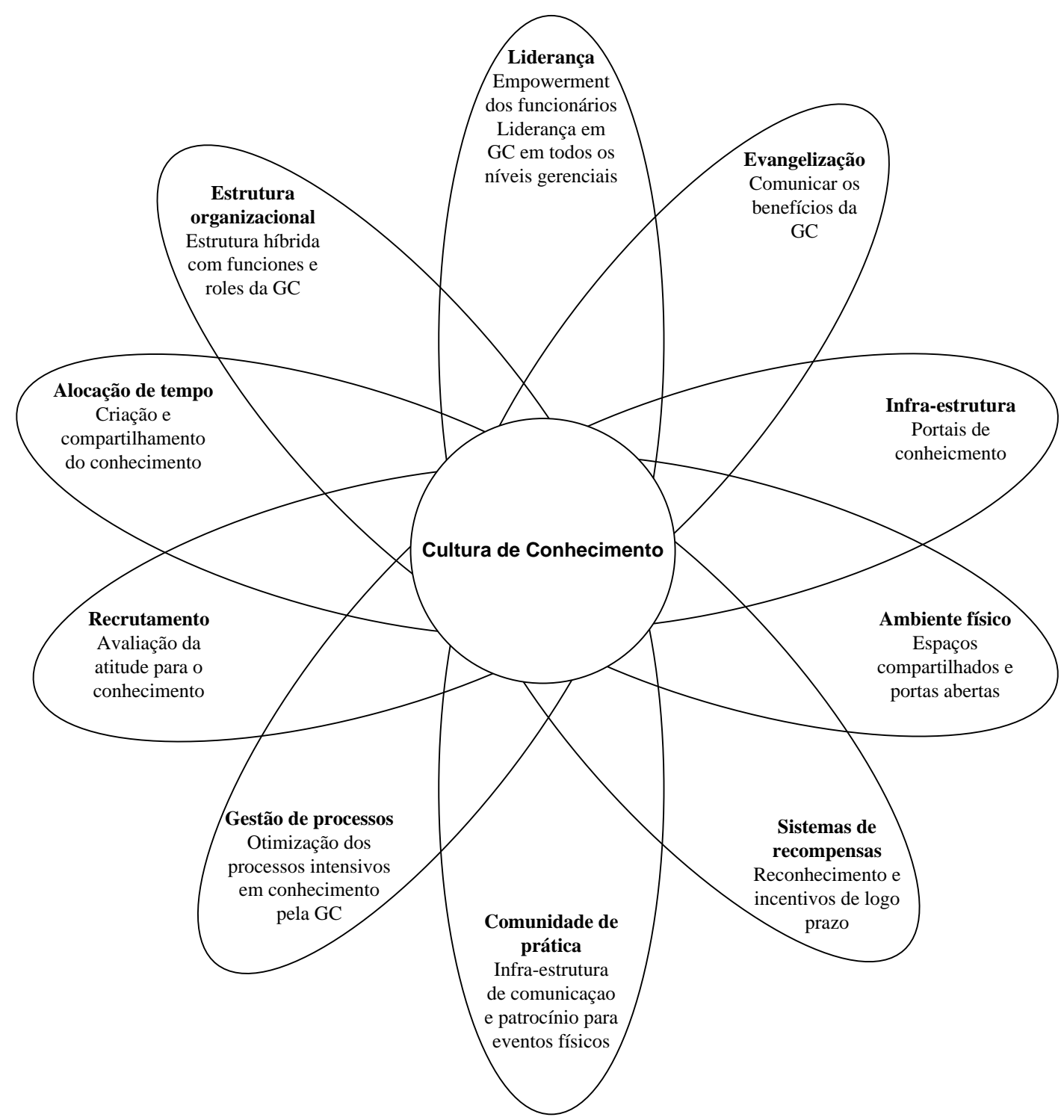

Figura 21 - Dez fatores para o desenvolvimento da cultura de conhecimento Fonte: Oliver e Kandadi (2006)

Os fatores orientados ao conhecimento descrevem as percepções compartilhadas e atitudes sobre o conhecimento pelos membros da organização. Inclui o sentido das pessoas sobre a propriedade compartilhada do conhecimento, a priorização dos diferentes tipos de conhecimento e uma atitude crítica sobre o conhecimento existente. 
Adicionalmente, Lam (2005) propõe um modelo que evidencia os inibidores culturais da GC, apresentado no quadro 14.

\begin{tabular}{|c|c|c|c|c|}
\hline & \multicolumn{3}{|c|}{ Processo do conhecimento } \\
\hline & & $\begin{array}{c}\text { Captura, } \\
\text { documentação e } \\
\text { acondicionamento } \\
\text { do conhecimento }\end{array}$ & $\begin{array}{c}\text { Distribuição e } \\
\text { disseminação do } \\
\text { conhecimento }\end{array}$ & $\begin{array}{l}\text { Reutilização do } \\
\text { conhecimento }\end{array}$ \\
\hline \multirow[t]{2}{*}{ Percepção } & $\begin{array}{l}\text { Individual } \\
\text { (O que } \\
\text { beneficia o } \\
\text { indivíduo) }\end{array}$ & $\begin{array}{c}\text { Sigilo - } \\
\text { "Conhecimento é } \\
\text { poder e segurança" }\end{array}$ & $\begin{array}{l}\text { Apropriação - "Por que } \\
\text { devo compartilhar com } \\
\text { outros, qual é o } \\
\text { benefício para mim } \\
\text { (ex. financeiro ou } \\
\text { desenvolvimento da } \\
\text { carreira)?" }\end{array}$ & $\begin{array}{c}\text { Egoísmo - "Eu sou o } \\
\text { especialista, eu } \\
\text { conheço tudo o que } \\
\text { deve ser conhecido" }\end{array}$ \\
\hline & $\begin{array}{l}\text { Grupo }(\mathrm{O} \\
\text { que outros } \\
\text { no grupo } \\
\text { pensarão) }\end{array}$ & $\begin{array}{l}\text { Desconfiança - “Eu } \\
\text { não confio neste } \\
\text { conhecimento ou de } \\
\text { onde ele veio" }\end{array}$ & $\begin{array}{c}\text { Fraqueza - "Não quero } \\
\text { pedir ajuda, as pessoas } \\
\text { o verão como um sinal } \\
\text { de fraqueza" }\end{array}$ & $\begin{array}{l}\text { Sobre-dependência - } \\
\text { "As pessoas me verão } \\
\text { como dependente dos } \\
\text { pensamentos dos } \\
\text { outros" }\end{array}$ \\
\hline
\end{tabular}

Quadro 14 - Modelo dos inibidores culturais da GC

Fonte: Lam (2005)

Os fatores orientados às pessoas referem-se às atitudes e pressupostos compartilhados que as pessoas têm sobre outros membros da organização. Eles envolvem como as pessoas pensam e se relacionam. Abrangem fatores como a confiança, cuidado, abertura, cooperação e coesão.

Os fatores orientados ao trabalho referem-se às atitudes e normas dos membros da organização sobre seu trabalho. Como o trabalho deve ser realizado? Quais são as expectativas comuns para trabalhar? São considerados principalmente dois fatores: o empreendedorismo e a perspectiva positiva.

A Figura 22 mostra a relação deste conjunto de fatores e sua principal influência sobre a GC. Segundo Zheng (2009), a presença dos três conjuntos de fatores fornece a essencial base cultural para a GC.

Pode-se ainda explicitar que a cultura organizacional é considerada o fator ou elemento mais importante e desafiante da GC, (JANZ; PRASARNPHANICH, 2003; ZHENG, 
2009). Segundo Pacanowsky e O’Donnell-Trujillo (1983), a cultura organizacional não é simplesmente outra peça do puzzle, ela é o puzzle.

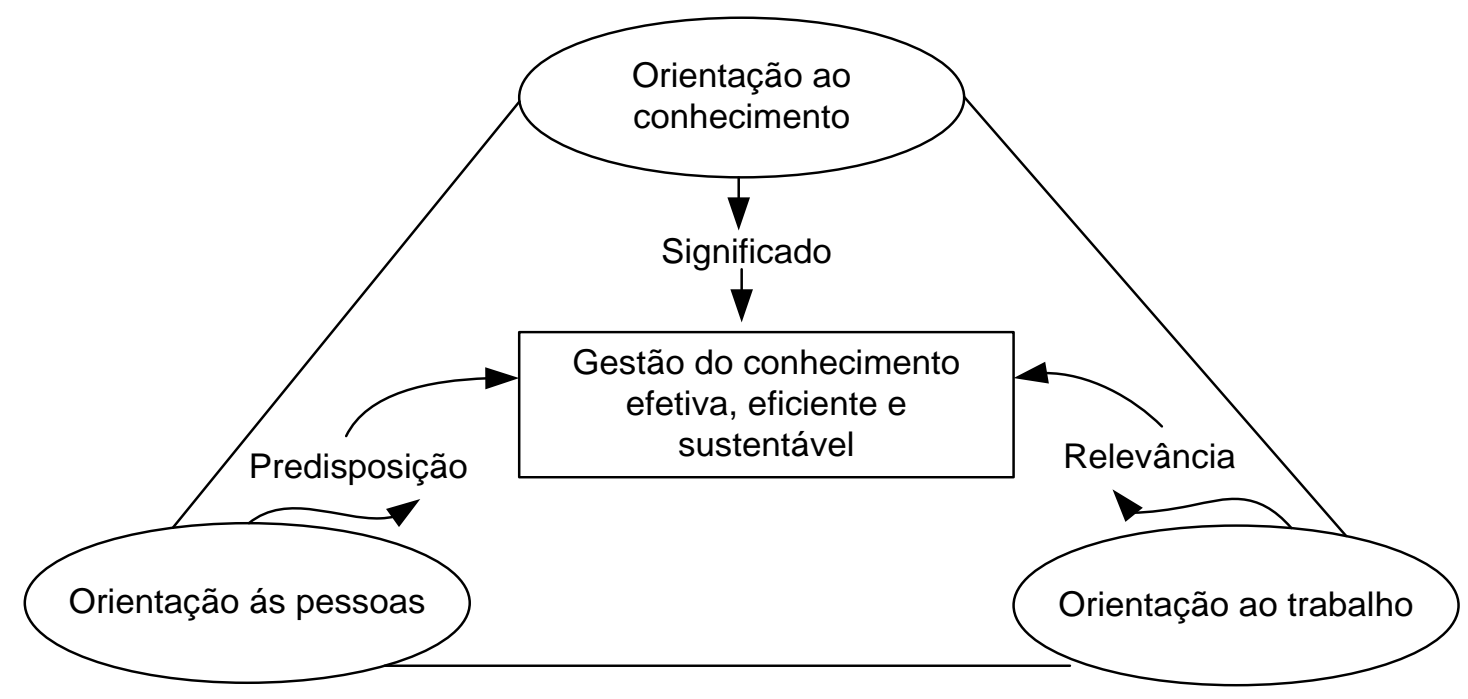

Figura 22 - Mapa da cultura que incita o conhecimento Fonte: Zheng (2009)

Adotar-se-á como referência para a estruturação do modelo a ser proposto neste trabalho, os fundamentos teóricos da cultura organizacional suportados por Schein (1992), com relação a seu conceito e níveis; Oliver e Kandadi (2006), referente à definição para a cultura de conhecimento; Zheng (2005), sobre o relacionamento entre a GC e a cultura organizacional; e Zheng (2009), para a abordagem integral da cultura de conhecimento. Os trabalhos não citados servirão também de referência complementar e reforço para a revisão da literatura.

\subsubsection{Estrutura organizacional de conhecimento}

Segundo Cortés et al. (2007), a forma em que as companhias estão organizadas determina o grau em que o conhecimento circula, dentro da organização e entre a organização e seu ambiente de negócio.

A estrutura organizacional é geralmente categorizada em três elementos, a formalização, a centralização e a integração (CHEN; HUANG, 2007). A formalização refere-se ao grau de estandardização dos trabalhos dentro da organização e ao grau em que o comportamento dos funcionários é guiado por regras e procedimento. Segundo Chen e Huang (2007) e Lichtarski (2009), em organizações com alta formalização há regras e procedimentos explícitos que é provável que limitem a espontaneidade e flexibilidade necessária para a inovação interna. Inversamente, em organizações com baixa 
formalização, os comportamentos de trabalho são relativamente não estruturados e os membros têm maior liberdade para lidar com as demandas de suas tarefas.

Centralização refere-se à localização da autoridade da tomada de decisão nos mais altos níveis da hierarquia. A centralização cria um ambiente não participativo, que reduz a comunicação, o compromisso e o envolvimento com os projetos e as tarefas por parte dos funcionários. Por outro lado, se os indivíduos têm mais liberdade, independência e discrição para determinar que ações são requeridas e qual é a melhor forma de desenvolvê-las, eles aceitarão a decisão resultante, por ter a oportunidade de fornecer idéias durante o processo de decisão. Sendo assim, quanto maior autonomia eles possuam, maior será a responsabilidade que eles sentirão pelo trabalho e pelo contexto (CHEN; HUANG, 2007).

A integração refere-se na medida em que as várias subdivisões de um trabalho organizacional se inter-relacionam. Os funcionários devem ter acesso à mais ampla variedade de conhecimento para o trabalho e a solução de problemas. Uma estrutura de trabalho integrado fornece a oportunidade para os funcionários aprenderem de seus colegas (CHEN; HUANG, 2007).

Chen e Huang (2007), baseados no estudo de 146 casos em companhias tailandesas, apresentam como características da estrutura organizacional propícias para a GC uma estrutura menos formalizada, mais descentralizada e mais integrada para que a interação social entre os membros da organização seja mais favorável e como consequência se logre o aprimoramento das atividades da GC

De forma complementar, Cortés et al. (2007), baseados no estudo de múltiplos casos em empresas espanholas, pretenderam responder à pergunta, Quais são as características da estrutura organizacional que sustentam a GC? Sendo as principais características identificadas uma estrutura horizontal e flexível, com poucos níveis hierárquicos e ampla comunicação em toda a organização.

A estrutura horizontal não só implica o aprimoramento da comunicação, mas também a descentralização da tomada de decisões e o empowerment, as companhias apresentaram uma tendência ao modelo orgânico-adhocrático (BURNS; STALKER, 1961; MINTZBERG, 1994), baixo controle e supervisão, proliferação do trabalho em equipes e grupos baseados em projetos, que incrementam o relacionamento entre gerentes e 
colaboradores e uso de comunidades de prática, permitindo aos funcionários tirarem vantagem de suas habilidades individuais, criarem rotinas individuais e incrementarem o valor de suas contribuições graças à liberdade de ação (CORTÉS et al., 2007).

\subsubsection{Equipe da Gestão do Conhecimento}

Segundo Wong (2005), estabelecer um grupo com responsabilidades específicas e formais é crucial para o sucesso da GC.

Abell e Oxbrow (1999) apresentam uma estrutura de papéis e responsabilidades da GC que podem ser reconhecidas dentro das organizações:

- Campeões da GC e estrategistas;

- Planejadores da GC e facilitadores;

- Colaboradores da GC; e

- Os trabalhadores do conhecimento presentes em toda a organização

Dalkir (2005) lista os principais papeis na GC;

- Papeis de diretores e de nível médio: Diretor do Conhecimento, Gerentes do Conhecimento.

- Líderes do conhecimento, responsáveis por promover a GC dentro da organização.

- Navegadores do conhecimento, responsáveis por saber onde o conhecimento está localizado.

- Sintetizadores do conhecimento, responsáveis por facilitar o registro do conhecimento valioso para a memória organizacional.

- Editores de conteúdo, responsáveis por codificar e estruturar o conteúdo, também chamados de administradores de conteúdo.

- Desenvolvedores de Web, Publicadores eletrônicos, Gerentes de Intranet.

- Papéis orientados à aprendizagem, treinadores, facilitadores, mentores, responsáveis pelo desenvolvimento das habilidades informacionais e de conhecimento

- Papeis de recursos humanos, com responsabilidades específicas de desenvolver programas e processos que encorajem uma cultura e comportamentos orientados ao conhecimento

Segundo Burstein et al. (2010), alguns papeis da GC são re-alinhamentos ou extensões de papéis já existentes na organização com o objetivo de refletir uma melhor focalização da GC; mas novos papeis específicos à GC também estão sendo criados. 
Eles podem ser de tempo completo ou meio tempo, enquanto alguns funcionários também desenvolvem deveres adicionais. Posições como a do gerente de recursos humanos ou gerente de TI são consideradas de tempo completo. Segundo O`Dell e Leavitt (2004), posições relacionadas ao treinamento e desenvolvimento tornar-se-ão novos papeis da GC, incluindo responsabilidades como o treinamento dos funcionários na utilização dos sistemas da GC.

No mesmo contexto, segundo Burstein et al. (2010), uma equipe de GC pode ser constituída por um campeão do conhecimento ou gerente de nível alto, funcionários de Tecnologias de Informação e os usuários ou trabalhadores do conhecimento.

Os papeis descritos serão classificados em dois grandes grupos, os líderes do conhecimento e os trabalhadores do conhecimento.

Os líderes do conhecimento: Também denominados campeões do conhecimento. No nível mais alto, os líderes do conhecimento são geralmente diretores que possuem uma visão holística da organização.

Segundo Burstein et al. (2010), a liderança é considerada um fator crítico em toda iniciativa da GC. Prover de liderança à GC permite uma efetiva promoção da criação e do compartilhamento do conhecimento por meio da criação de uma apropriada cultura organizacional e de recursos que assegurem a disponibilidade do conhecimento.

Geralmente o máximo líder do conhecimento e chamado de Diretor do Conhecimento (Chief Knowledge Officer - CKO) (BURSTEIN et al., 2003; OXBROW, 2004). Ele é um executivo de alto nível cuja responsabilidade é impulsionar o conhecimento dentro da organização, geralmente ao liderar um programa da GC.

Burstein et al. (2010), baseados em uma síntese da literatura, apresentam as principais responsabilidades técnicas e organizacionais de um Diretor do Conhecimento, quadro 15.

\begin{tabular}{|l|c|c|}
\hline \multicolumn{1}{|c|}{ Responsabilidades Organizacionais } & \multicolumn{3}{|c|}{ Responsabilidades Técnicas } \\
\hline - Assegurar que a estratégia da GC seja alinhada & - Assegurar que adequada infra-estrutura \\
com a estratégia do negócio & tecnológica esteja disponível para cumprir as \\
- Identificar as lacunas de conhecimento & necessidades da estratégia da GC & \\
- Criar uma cultura de compartilhamento do & - Identificar requerimentos por fonte de \\
conhecimento & conhecimento & \\
\hline
\end{tabular}


- Disponibilizar métricas para o trabalho de conhecimento e estruturas de incentivos

- Desenvolver Comunidades de Prática pela organização.

- Difundir as melhores práticas

- Conduzir o treinamento

- Estruturar os processos e promover melhor entendimento sobre os tipos de conhecimento criados e seu uso

- Remover barreiras técnicas e sócio-culturais para o compartilhamento do conhecimento

- Criar processos de desencadeamento para o aprimoramento da reutilização do conhecimento existente

- Assegurar que a GC seja parte da rotina de trabalho

- Maximizar o retorno ao investimento em conhecimento

- Promover e aprimorar a inovação da companhia

- Minimizar a perda do conhecimento

- Colaborar com outros profissionais da informação para criar arquiteturas integradas de informação para cumprir com os requerimentos de informação e conhecimento
- Construir diretórios para criar transparência das fontes de conhecimento tácito

- Criar canais técnicos para registrar e promover resultados mensuráveis das iniciativas da GC

- Prover ferramentas de tecnologia colaborativa e novas políticas para suportar o trabalho em equipe

- Prover ferramentas para a solução colaborativa de problemas

- Construir repositórios para a armazenagem das lições aprendidas.

- Capturar conhecimento externo

- Construir canais para a distribuição de conhecimento explícito e compartilhamento do conhecimento tácito e a transferência de documentos

- Introduzir ferramentas inter-funcionais

- Incentivar a transferência de conhecimento tácito, aprimorando ferramentas para este fim vídeo conferências, mapas mentais, etc.

- Estender a intranet e integrá-la com as tarefas diárias dos trabalhadores do conhecimento.

- Realizar monitoramento para manter as bases de conhecimento

- Implantar sistemas de suporte ao trabalho de conhecimento baseados em tecnologias sociais e de inteligência.

Quadro 15 - Responsabilidades técnicas e organizacionais do Diretor do Conhecimento

Fonte: Burstein et al. (2010)

É importante explicitar que as responsabilidades técnicas e organizacionais devem estar interconectadas e devem ser planejadas tendo um alinhamento com os outros departamentos organizacionais que lidam com fontes de informação e conhecimento (BURSTEIN et al., 2010).

Além disso, deve ser notado que ao não existir uma determinação formal da posição do Diretor do Conhecimento, esta pode ser adquirida por um grupo de pessoas que desempenhariam as funções mencionadas como uma equipe. 
De forma complementar, Singh (2008), com base em um estudo de 331 trabalhadores do conhecimento em uma companhia de desenvolvimento de softwares na Índia, sustenta que tanto a liderança de estilo diretivo quanto a liderança de estilo suportador tem uma relação contraditória com a GC, o que quer dizer que quanto mais controlados são os trabalhadores do conhecimento menor será a contribuição para as metas organizacionais de criação e GC. Por outro lado, a liderança de estilo consultivo e a liderança de estilo de delegação mostram uma relação positiva com a criação, gestão, aplicação e uso do conhecimento na organização, quer dizer que a alta gerência deve pregar e premiar modos de comportamento de trabalho consultivos e delegativos nos líderes do conhecimento

Nesse contexto, Jones et al. (2003) sugerem uma estrutura para facilitar as atividades da GC que visa:

- Criar posições para inovadores organizacionais dedicados, que facilitem a efetiva aquisição de novo conhecimento de fontes fora da organização (ex. Diretor do Conhecimento)

- Utilizar Diretores do Conhecimento e outros campeões do conhecimento para facilitar o compartilhamento do conhecimento e o uso efetivo da memória organizacional pelos funcionários.

- Utilizar campeões do conhecimento para criar e atualizar diretórios para apropriados centros de conhecimento.

- Utilizar Diretores do conhecimento e outros campeões do conhecimento para facilitar o compartilhamento do conhecimento e o uso efetivo da memória organizacional, por meio da identificação e satisfação das necessidades, desejos e expectativas de conhecimento dos usuários organizacionais e da companhia em geral.

Em um nível intermediário de líderes do conhecimento, Carty e Walsh (2007) e Takeuchi (2001) explicitam a importância dos gerentes de nível médio para o sucesso das práticas da GC. Eles são mediadores entre "o que se busca ser" a mentalidade da alta gerência e "o que é realmente" a mentalidade dos funcionários do chão de fábrica. Nesse aspecto, Abell e Oxbrow (1999), sustentam que os colaboradores da GC suportam as unidades de negócio e as comunidades de conhecimento. 
Dessa forma, a liderança para a GC pode ser composta de um Diretor do Conhecimento e colaboradores de nível médio, pudendo ser estes supervisores das unidades do negócio, líderes de opinião e coordenadores de comunidades de prática, além dos funcionários do departamento de TI.

Por último, pode ser argumentado que os líderes da GC são únicos e devem ser formados e personalizados especificamente para cada tipo de organização (BURSTEIN et al., 2010), mas os lineamentos apresentados poderão servir de base para a determinação desses profissionais.

\section{Os trabalhadores do conhecimento:}

Segundo Tovstiga (1999), entender, aproveitar e capitalizar os atributos dos trabalhadores do conhecimento em formas que contribuam para a sustentação da companhia é cada vez mais crítico para sua a sobrevivência no atual ambiente organizacional.

Drucker (1993) define o trabalhador do conhecimento como o indivíduo que trabalha primordialmente com informação, ou que desenvolve ou usa o conhecimento para realizar sua função.

De forma complementar, Davenport (2002) descreve ao trabalhador do conhecimento como aquela que pessoa com alto grado de educação e expertise que tem como principal propósito de seu trabalho a criação, distribuição e aplicação de conhecimento.

Uma definição alternativa é apresentada por Horvath (2001), que define ao trabalhador do conhecimento como qualquer pessoa que trabalha em tarefas que envolvam o desenvolvimento ou uso de conhecimento. Baseado nessa definição, Ramírez e Nemhard (2004) apresentam como possíveis tarefas baseadas no conhecimento o planejamento, a aquisição, a pesquisa, a análise, a armazenagem, a programação, a distribuição, a decisão, e inúmeras outras tarefas que demandem a transformação de informação de uma forma para outra visando a produção de um produto final; sendo considerados, para Ramírez e Nemhard (2004), trabalhadores do conhecimento os gerentes, engenheiros, contadores, advogados, analistas financeiros, analistas de sistemas e programadores.

Dove (1998) classifica ao trabalhador do conhecimento em três tipos: 
- Criação de trabalho de conhecimento baseado na inovação: Estes trabalhadores, tais como engenheiros, gerentes e inventores, dependem da inovação para fazer seus trabalhos. Eles não têm uma tarefa pré-estabelecida, mas definem e desempenham sua tarefa sempre pela primeira vez. Eles criam ferramentas que serão utilizadas por outros trabalhadores do conhecimento.

- Trabalho do conhecimento portável, baseado em uma utilidade ampla e imediata: Estes trabalhadores possuem o conhecimento que pode ser aplicado de diferentes formas, eles podem usar seu conhecimento em vários cenários e organizações. Alguns exemplos desse tipo são profissionais graduados em MBA ou programadores. Esses trabalhadores utilizam seus conhecimentos para desenvolver operações ou desenvolver ferramentas para realizar seu trabalho. A diferença com o primeiro grupo é que eles desenvolvem tarefas previamente estabelecidas.

- Trabalho de conhecimento especializado, baseado numa utilidade restrita, mas de alto nível: Esses trabalhadores têm o conhecimento específico necessário para realizar a tarefa, eles são considerados expertos no que fazem e seu conhecimento não é facilmente utilizado em outras áreas. Um exemplo desse tipo de trabalhador é um programador que utiliza uma linguagem de programação específica.

Segundo Shoham e Hasgall (2005), são os trabalhadores do conhecimento que fazem acontecer o ciclo da GC, então, são eles que criam/adquirem, disseminam/compartilham e utilizam o conhecimento. A GC depende da habilidade, conhecimento e predisposição dos trabalhadores do conhecimento em realizar esse ciclo e lograr os benefícios que a GC oferece à organização

Segundo Drucker (1999) seis fatores determinam a produtividade de um trabalhador do conhecimento:

- A produtividade do trabalhador do conhecimento demanda se perguntar: qual é a tarefa?

- Demanda que se lhe imponha a responsabilidade de sua produtividade. O trabalhador do conhecimento deve se auto-gerir, ter autonomia.

- A inovação contínua deve ser parte do trabalho, a tarefa e responsabilidade do trabalhador do conhecimento

- O trabalho do conhecimento requer aprendizagem contínua por parte do trabalhador, mas também ensino contínuo. 
- A produtividade do trabalhador do conhecimento não é, pelo menos não primariamente uma questão de quantidade de produção. A qualidade é muito mais importante

- A produtividade do trabalhador do conhecimento requer que este seja visto e tratado como um ativo em vez que como um custo. Isto requer que o trabalhador do conhecimento queira trabalhar na organização em vez que em outros lugares.

Finalmente, Dalkir (2005), propõe uma metodologia para a formação de uma equipe de conhecimento, que consiste em definir os diferentes tipos de profissionais da GC, e os tipos de habilidades, atributos, e expertise que eles idealmente deveriam oferecer, tendo como objetivo final uma lista de habilidades psicomotoras, afetivas e cognitivas atreladas com os níveis de competência requeridos para cada habilidade.

\subsubsection{Ferramentas da Gestão do Conhecimento}

As ferramentas de GC são o conjunto de metodologias, técnicas e tecnologias de informação que apoiarão no desenvolvimento e avaliação das suas práticas.

Dalkir (2005) classifica as ferramentas da GC em base às fases genéricas do ciclo da GC, sendo distribuídas como mostra o quadro 16.

\begin{tabular}{|c|c|c|}
\hline Fase d & $\begin{array}{l}\text { Fase de disseminação e } \\
\text { compartilhamento }\end{array}$ & Fase de aquisição e aplicação \\
\hline $\begin{array}{l}\text { Criação de conteúdo } \\
\text { - } \quad \text { Ferramentas de autoria } \\
\text { - } \quad \text { Modelos - templates } \\
\text { - } \quad \text { Anotações } \\
\text { - } \quad \text { Análise de competências } \\
\text { - } \quad \text { Data mining } \\
\text { - } \quad \text { Blogs } \\
\text { Gestão de conteúdo } \\
\text { - } \quad \text { Edição de metadados } \\
\text { - } \quad \text { Classificação } \\
\text { - } \quad \text { Arquivamento } \\
\text { - } \quad \text { GC pessoal }\end{array}$ & $\begin{array}{l}\text { Tecnologias de comunicação e } \\
\text { colaboração } \\
\text { - } \quad \text { Telefone } \\
\text { - } \text { Fax } \\
\text { - } \quad \text { Videoconferência } \\
\text { - } \quad \text { Salas de chat } \\
\text { - } \quad \text { Mensageria instantânea } \\
\text { - } \quad \text { Telefonia via Internet } \\
\text { - } \quad \text { E-mail } \\
\text { - Fóruns de discussão } \\
\text { - Groupware } \\
\text { - Wikis } \\
\text { - Gestão do fluxo do trabalho } \\
\text { Tecnologias de redes de trabalho } \\
\text { - Intranets }\end{array}$ & $\begin{array}{l}\text { Tecnologias de E-learning } \\
\text { - } \quad \text { CBT } \\
\text { - } \quad \text { WBT } \\
\text { - } \quad \text { EPSS } \\
\text { Inteligência Artificial } \\
\text { - } \quad \text { Sistemas especialistas } \\
\text { - } \quad \text { Sistemas de apóio á Decisão } \\
\text { - } \quad \text { Customização } \\
\text { - } \quad \text { Personalização } \\
\text { - } \quad \text { Sistemas de sugestões } \\
\text { - } \quad \text { Visualização } \\
\text { - } \quad \text { Mapas de conhecimento } \\
\text { - } \quad \text { Agentes inteligentes } \\
\text { - } \quad \text { Sistemas automatizados de }\end{array}$ \\
\hline
\end{tabular}




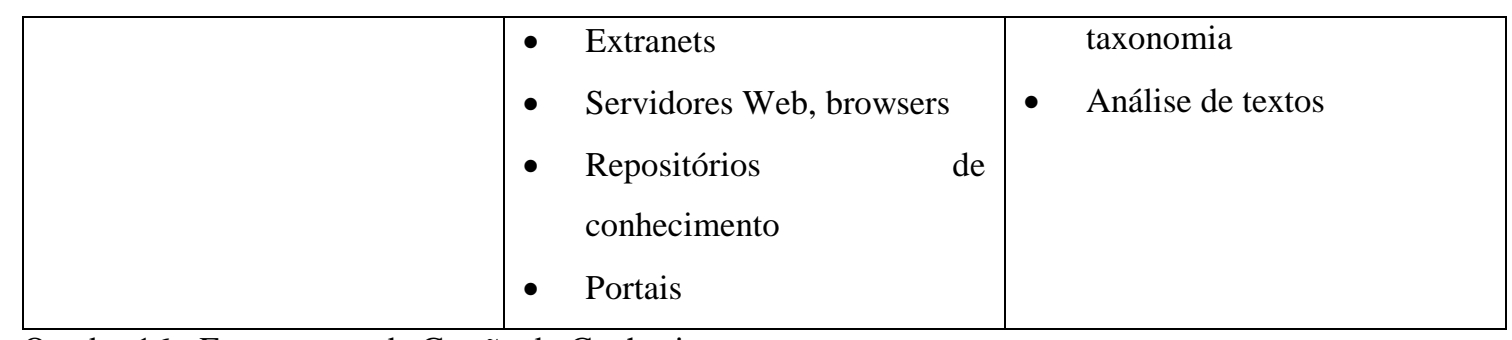

Quadro 16 - Ferramentas da Gestão do Conhecimento

Fonte: Dalkir (2005)

Especial atenção deve ser apontada às Comunidades de Práticas (CoPs). Segundo Li et al. (2009), elas são consideradas uma das mais efetivas ferramentas da GC.

Wenger et al. (2002) definem as CoPs como grupos que possuem preocupações e intenso interesse por determinado assunto, aprofundam conhecimentos e especialidades, compartilham informação, idéias e conselhos, ajudam-se na solução de problemas para criar projetos ou desenvolver entendimento tácito sobre um tema.

Com relação às ferramentas de avaliação das atividades da GC, são utilizadas principalmente metodologias baseadas no Balance Score Card (ARORA, 2002), benchmarking (CHEN; CHEN, 2006) e a Análise de Redes de Trabalho (LOUADI, 2008).

\subsubsection{Ciclos ou processos da Gestão do Conhecimento}

Os ciclos da GC são considerados a base operacional da sua implantação (CHANG et al., 2005 DALKIR, 2005; NISSEN, 2002 ).

Segundo Wong (2005) é importante que as organizações abordem o assunto sob está consideração devido à importância que ela tem na criação de sucedidas companhias baseadas no conhecimento.

A fundamentação teórica deste fator crítico de sucesso foi amplamente explorada no item 2.1.6, em que se sustenta que este trabalho tomará como referência de Ciclo da GC proposto por Firestone e McElroy (2005) e McElroy (2000).

\subsubsection{Métricas da Gestão do Conhecimento}

Segundo Bose (2004), a melhor e a mais lógica metodologia para mensurar o impacto da GC sobre o desempenho organizacional é realizar esta avaliação junto o sistema geral de avaliação de desempenho da organização, podendo ser feito no nível organizacional, ou em processos ou projetos individuais. 
As atuais métricas da GC integram critérios financeiros e não-financeiros. Quatro estudos para a determinação das métricas para os ativos do conhecimento foram identificados na literatura: o estudo do Intellectual Capital Managemet (ICM) (1998), os estudos de Roos et al. (1998), o reporte do Canadian Management Accountant (CMA) (1999), e o reporte do Universal Intellectual Capital (Von Krough et al.,1999) (ANEXO 1).

É importante evidenciar que embora as métricas sejam numerosas e factíveis de serem realizadas, métricas específicas da GC terão que ser adequadas para contextos organizacionais específicos.

De forma complementar, são apresentados quatro métodos para a mensuração ou avaliação das práticas de GC: Balanced Scorecard, Valor economico agregado (VEA), Skandia Navigator e Benchmarking.

Balanced scorecard (BSC): Desenvolvido por Kaplan e Norton (1996), o BSC foca-se no relacionamento entre a estratégia e objetivos da organização por meio da mensuração de quatro perspectivas: financeira, clientes, processos internos, e aprendizagem e desenvolvimento. Ele é um sistema de medição e de gestão que permite às organizações esclarecer sua visão e estratégia e trasladá-las em ações (DALKIR, 2005).

A principal vantagem deste método em termos da GC é que ele relaciona diretamente a aprendizagem com o desempenho dos processos, que por sua vez é relacionado ao desempenho de toda a organização (BOSE, 2004).

Em contraste com as métricas tradicionais, o BSC muda o foco puramente financeiro e inclui três métricas muito importantes de fatores de sucesso intangíveis, composto por: capital intelectual (conhecimento e habilidade dos funcionários), capital estrutural (conhecimento embutido nos processos e sistemas organizacionais), e capital do cliente (relacionamento como o cliente) (BOSE, 2004).

Valor econômico agregado (VEA): Desenvolvido e comercializado pela Stern Stewart \& Company, foca-se na maximização do valor para os acionistas, ele calcula o verdadeiro lucro da companhia (BOSE, 2004).

O VEA é definido como a diferença entre as vendas netas e a soma dos gastos operacionais, impostos e cargos de capital, em que os cargos de capital são calculados 
como o custo médio ponderado de capital multiplicado pelo capital total investido (DILLON; OWERS, 1997). Em geral, o VEA incrementa-se se o custo médio ponderado de capital é menor que o retorno dos ativos totais e vice versa.

Segundo Bose (2004), um sistema baseado no VEA ajuda aos gerentes tomar melhores decisões de investimento, investimento em sistemas de GC, identificação de oportunidades de aprimoramento e consideração de benefícios de curto e longo prazo para a companhia.

Skandia Navigator: O Navigator é uma ferramenta para avaliar os ativos intangíveis de uma organização, assim como um sistema de reporte de gestão que ajuda aos gerentes visualizar e desenvolver métricas que refletem ativos intangíveis.

O Navigator mede o capital intelectual por meio da análise de 164 métricas (91 baseadas na parte intelectual e 73 métricas baseadas na parte financeira tradicional) que cobrem cinco áreas ou perspectivas: financeira, clientes, processos, renovação e desenvolvimento, e humana.

Benchmarking: Criado pela Xerox, como uma ferramenta de planejamento táctico nos anos 70, o Benchmarking é a busca das melhores práticas da indústria que conduz a um aprimoramento do desempenho. Consiste no estudo de companhias similares para determinar quais coisas são as práticas melhor feitas com o objetivo de adequar estes métodos para o próprio uso (também pode ser aplicada dentro da organização, entre as diferentes áreas). Essa técnica vem acompanhada pelo provérbio hindu: "Conhece o primeiro para tornar-se o primeiro"

Segundo Dalkir (2005), na GC, o Benchmarking pode ajudar uma companhia tornar-se uma organização em aprendizagem ao identificar onde ela está em termos da GC com relação a seus competidores.

Tiwana (2000) baseado nos estudos de Spendolini’s (1992) propõe como principais fases para realizar o Benchmarking na $\mathrm{GC}$ as seguintes:

1. Determinar o que Benchmark: Quais processos de conhecimento, produtos, serviços? Por quê? Com que escopo?

2. Formar uma equipe de Benchmanrking 
3. Selecionar uma lista de Benchmanrking - Com que companhias será feito o Benchmanrking?

4. Coletar e analisar a informação

5. Determinar quais mudanças precisam ser feitas como resultado das métricas obtidas

6. Repetir o processo quando uma quantidade de tempo apropriado tenha passado para medir o progresso.

Métodos adicionais para a avaliação da GC são os fluxos de conhecimento, a Análise de Redes Sociais, as auditorias de conhecimento e o Método da Casa da Qualidade (DALKIR, 2005; DATTERO et al., 2007; LIEBOWITZ et al., 2000; NISSEN, 2006).

Por último, Bose (2004) sugere um processo que visa a criação de índices de capital intelectual composto pelas seguintes fases:

1) Definir o conceito do negócio - visão e estratégias da organização

2) Identificar os fatores críticos de sucesso

3) Escolher os principais indicadores de desempenho

4) Ponderar os indicadores

5) Consolidar as métricas, nível hierárquico por nível hierárquico

6) Gerar índices de capital intelectual

7) Utilizar estes índices para focalizar as ações de gestão sobre os fatores críticos.

Bose (2004) argumenta que o futuro do uso da GC depende fortemente da qualidade de suas métricas e se a gestão dos resultados destas métricas fornece valor tangível adicional para a organização.

\subsubsection{Metodologias de implantação da Gestão do Conhecimento}

Com relação a sua implantação, a GC é abordada por uma variedade de ciências sociais, desde a teoria organizacional até as ciências políticas, Dufour e Steane (2007) descrevem as metodologias dominantes sobre a implantação da GC, classificando-as em metodologia clássica, contingencial, comportamental e política. A seguir apresenta-se um resumo das principais características de cada uma delas:

a) Metodologia clássica: perspectiva do planejamento racional, da tomada de decisão, de ferramentas de software e de condições ideais para a implantação;

b) Metodologia contingencial: perspectiva contingencial e de "ajuste"; 
c) Metodologia comportamental: perspectiva da inovação, da cultura e do desenvolvimento organizacional; e

d) Metodologia política: perspectiva do processo burocrático, da negociaçãobarganha e da implantação simbólica.

A variedade existente das metodologias é devido à limitação percebida de procedimentos normativos para a mudança e a implantação, que tem fracassado em abordar adequadamente a complexidade perturbadora da tecnologia e da hipercompetição. Dufour e Steane (2007) expõem que esta diversidade sugere um desenvolvimento mais sofisticado na prática e pensamento da implantação da GC, voltados para a explicação de alternativas mais refinadas.

No mesmo contexto, foram identificados na literatura procedimentos e modelos para a implantação da GC. Wu e Lin (2009) apresentam um processo de implantação baseado na estratégia organizacional, que inicia com a identificação da estratégia competitiva da empresa, base para o desenvolvimento da estratégia de conhecimento, que por sua vez é alicerce para a metodologia de implantação, e que no último nível, influencia o desempenho organizacional (Figura 23). Wu e Lin (2009) explicitam e evidenciam empiricamente a relação positiva e processual entre a seleção da estratégia competitiva, a estratégia de conhecimento e a metodologia de implantação com o desempenho organizacional.

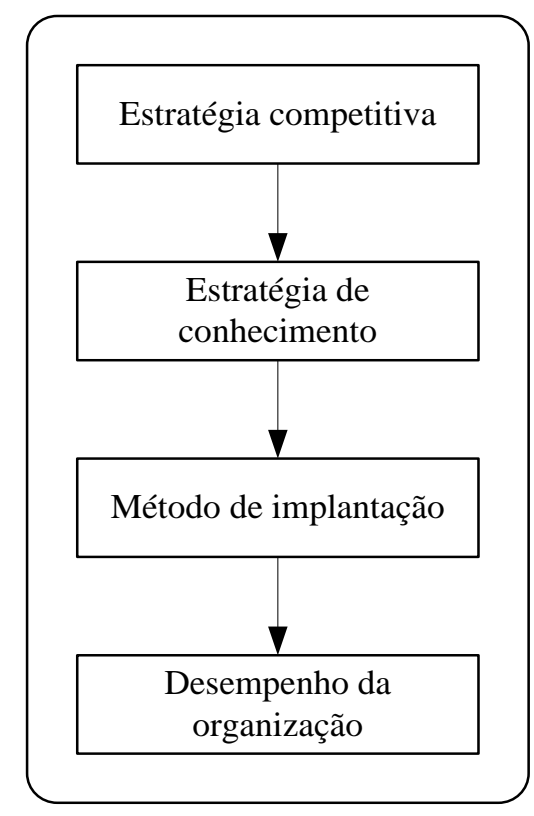

Figura 23 - Modelo de implantação da Gestão do Conhecimento Fonte: Wu e Li (2009) 
De forma complementar, Daghfous e Kah (2006) sustentam uma estrutura de implantação da GC em três fases: iniciação, adoção e implantação (Figura 24). A iniciação geralmente é gerada pelo entusiasmo de um membro da organização quem tem um compromisso e a disposição de conseguir o capital e recursos humanos necessários para o projeto. Posteriormente os objetivos da GC devem ser estabelecidos e alinhados com os objetivos da organização, para ser comunicados a todos os funcionários da empresa. Por último, a fase de iniciação termina com a avaliação da infra-estrutura tecnológica que a organização possui para ver o longe que está do alvo, e que processos precisam ser adotados ao longo do caminho.

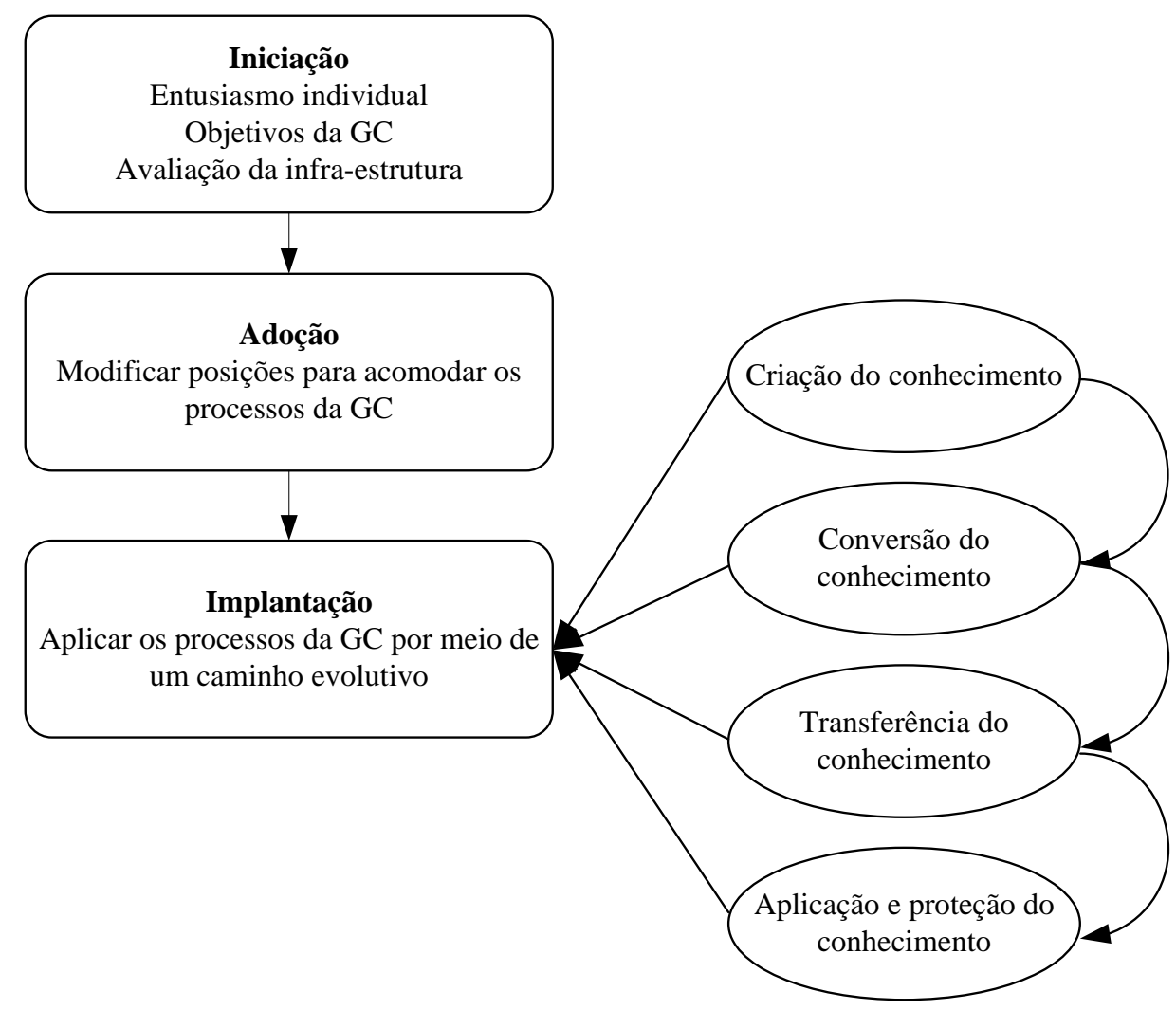

Figura 24 - Estrutura de implantação da Gestão do Conhecimento

Fonte: Daghfous e Kah (2006)

Na fase de adoção, as posições organizacionais são modificados com o objetivo de criar uma orientação positiva para a GC. Por último, na fase de implantação as atividades da GC devem ser executadas (criação,conversão, transferência, aplicação e proteção do conhecimento), nesse processo os recursos de infra-estrutura identificados em fases anteriores são utilizados.

Arora (2002) utiliza a metodologia do Balanced Scorecard como base para a implantação. Maier e Remus (2002) e Al-Sharammari (2008) fundamentam-se no ciclo 
da GC. Além dos autores mencionados, a implantação da GC também foi aborda por Apostolou e Mentzas (2003), Liebowitz e Megbolugbe (2003), Shankar et al. (2003).

A apresentação dos métodos e procedimento de implantação da GC servirá de base para o desenvolvimento do modelo de processos a ser proposto, em que se descreverá o método proposto para a implantação da GC sustenta pelo autor deste trabalho.

\subsection{Metodologia de modelagem organizacional EKD}

Segundo Bubenko et al. (1998) um modelo é uma forma de estruturar o conhecimento organizacional com o objetivo de permitir entender o funcionamento holístico de uma empresa ou um processo do negócio. Esse modelo nunca pode ser uma imagem exata do mundo real, mas uma percepção coletiva, representando os padrões de referência, experiências e backgrounds dos participantes (BUBENKO et al., 2001).

A modelagem organizacional é uma atividade estruturada que cria um modelo organizacional integrado, descrevendo uma organização desde diferentes perspectivas. Esta permite descrever a situação atual ou descrever e analisar situações futuras ou desejadas do negócio (BUBENKO et al., 2001). Segundo Stirna et al., (2007) ha duas razões para utilizar a modelagem organizacional, a primeira, por que ela permite o aprimoramento do negócio, que abrange o desenvolvimento da visão organizacional, suas estratégias, suas operações, seus sistemas de informação etc.; e a segunda, por que assegura a qualidade do negócio, com foco no compartilhamento do conhecimento, a visão e forma como este opera, assim como para assegurar a aceitação das decisões pelos membros da organização.

O Enterprise Knowledge Development (EKD) é uma metodologia que fornece uma forma sistemática de analisar, entender, desenvolver e documentar um negócio e seus componentes, utilizando a modelagem organizacional. Ele tem como objetivos, a descrição clara e não ambígua de como o negócio funciona atualmente, quais são os requisitos e razões para que uma determinada mudança ou nova prática seja desenvolvida na empresa, quais são as alternativas que deveriam ser criadas para cumprir esses requisitos e quais são os critérios e argumentos para a avaliação dessas alternativas (BUBENKO et al., 2001).

Entre os principais benefícios, o EKD permite: a) entender melhor o negócio; b) facilitar a aprendizagem e a comunicação organizacional sobre questões essenciais; c) ajudar a 
entender e a promover as capacidades e processos da organização; d) melhorar a comunicação entre os participantes; e) desenvolver uma descrição estruturada do negócio; e f) chegar a uma descrição dos objetivos da organização, entidades, processos e requisitos (BUBENKO et al., 1998).

Além disso, O EKD auxilia nos seguintes propósitos empresariais: a) na engenharia de requisitos, para definição e especificação de requisitos; b) na análise do negócio, para detecção de problemas; c) na reengenharia de processos do negócio, para definição de novos sistemas de negócio; e d) no gerenciamento do conhecimento organizacional ou aprendizagem organizacional, para formar a base de programação e ampliação de conhecimento (BUBENKO et al., 1998).

O modelo organizacional desenvolvido pela metodologia EKD, apresentado na Figura 25, está composto por um número de sub-modelos ou componentes, representando cada um deles algum aspecto particular da empresa. Estes sub-modelos, assim como as questões relacionadas a eles, são descritos a seguir (BUBENKO et al., 2001):

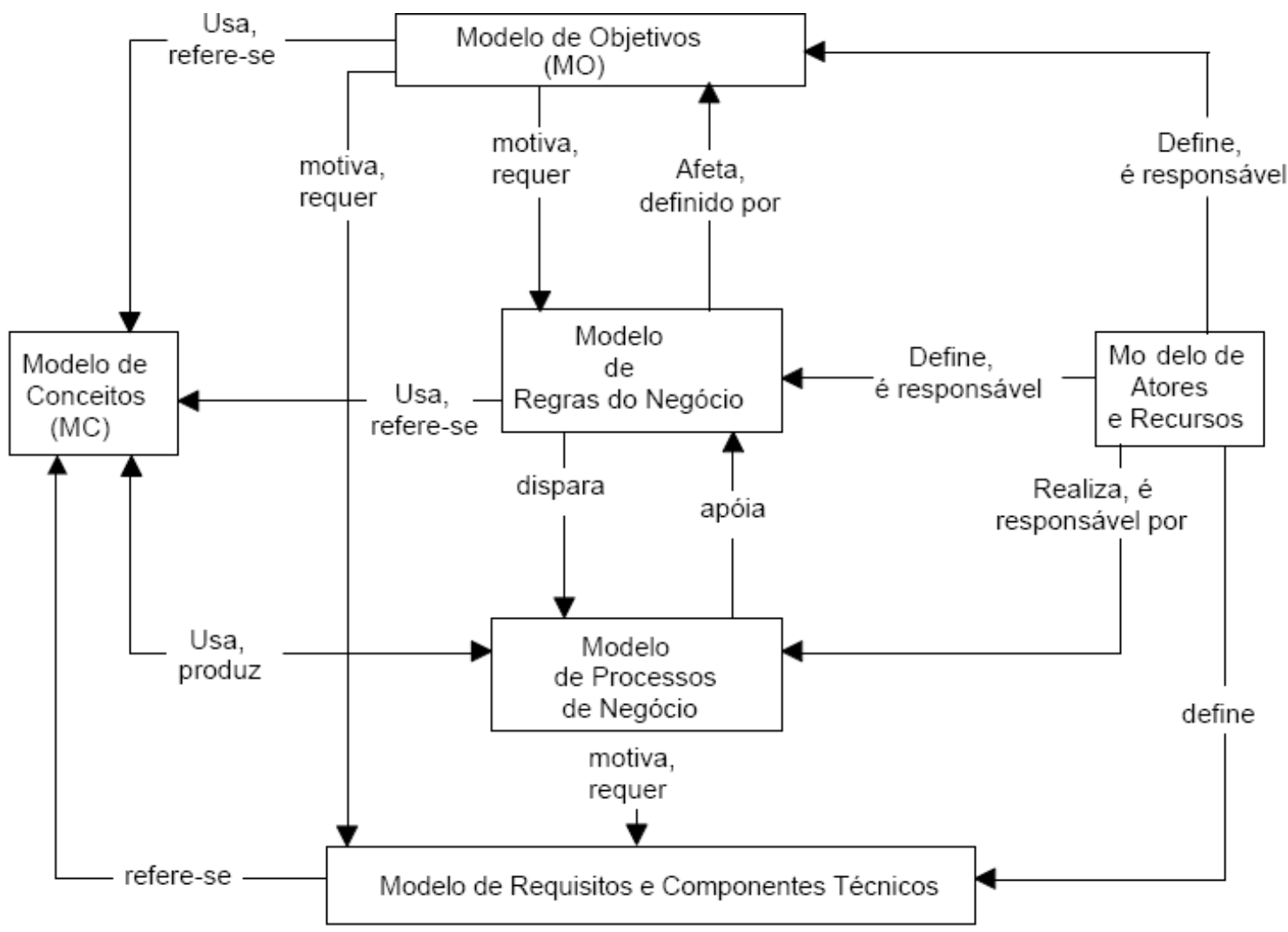

Figura 25 - Modelo organizacional EKD Fonte: BUBENKO et al. (1998) 
a) Modelo de Objetivos (MO): focado na descrição de objetivos de uma empresa e todas as questões associadas para atingi-los. O MO descreve essencialmente a razão ou motivação dos outros componentes nos outro sub-modelos. O MO explica por que os processos e requerimentos existem ou não na organização.

Os componentes do MO são os objetivos, problemas, causas, restrições e oportunidades. A inserção de cada um destes componentes no modelo dependerá na necessidade organizacional e o nível de detalhamento requerido. Além disso, segundo Bubenko et al. (2001), por meio da observação de um número pratico de sessões de modelagem percebeu-se a necessidade de adicionar componentes adicionais ao MO, tais como, comentários, pressupostos, cenários, tarefas etc. Visando sempre o esclarecimento e a claridade do modelo.

b) Modelo de Regras do Negócio (MRN): usado para definir e manter explicitamente regras do negócio formuladas, consistentes com o MO. Podem operacionalizar ou limitar objetivos. Regras do negócio são regras que controlam a organização no sentido de definir e restringir quais ações podem ser executadas nas situações em que são desenvolvidas.

Regras do negócio podem ser descritas das seguintes formas:

- Sentenças precisas que descrevem a forma que o negócio tem escolhido para atingir seus objetivos e implementar suas políticas

- As varias regras externas impostas ao negócio, tais como regulamentos e normais legais.

As regras são definidas por objetivos, e ao mesmo tempo afetam a consecução de outros objetivos, elas acionam os processos do negócio e referem-se aos conceitos definidos no Modelo de Conceitos; finalmente, atores do modelo a Atores e Recursos são responsáveis pela determinação e a realização das regras do negócio.

c) Modelo de Conceitos (MC): utilizado estritamente Para definir "coisas" e "fenômenos" abordados nos outros modelos. Conceitos podem ser tangíveis, exemplo, “carro", ou intangíveis, como por exemplo, “conhecimento". É vital que os conceitos importantes usados nos outros modelos sejam definidos no MC para evitar a possibilidade de mal entendidos entre os participantes e stakeholders. O principal 
objetivo do MC é de servir como um dicionário para o entendimento das coisas ou fenômenos incluídos nos outros modelos.

d) Modelo de Processos do Negócio (MPN): desenhado para a análise dos processos, a forma como eles interagem e a forma como eles processam a informação, assim como materiais. O MPN permite mostrar quais atividades e processos do negócio são reconhecidos na organização, ou deveriam ser, para gerenciá-la de acordo com seus objetivos. Para a obtenção de uma boa abstração e visão, o MPN permite total liberdade para a decomposição dos processos em sub-processos, até qualquer nível de detalhe. Dependendo do propósito da modelagem, os processos descritos podem ser existentes ou processos futuros planejados.

e) Modelo de Atores e Recursos (MAR): define os tipos de atores e recursos evolvidos nas atividades empresariais, o MAR descreve como os diferentes atores e recursos estão relacionados entre eles e entre os componentes dos outros modelos. Ao estudar o MAR e seus relacionamentos com os outros modelos pode-se ver como os diferentes atores exibem dependências entre eles e entre os recursos que utilizam para o desenvolvimento de suas atividades. Os componentes do MAR são indivíduos, unidades organizacionais, recursos não humanos e papeis, sendo inseridos no modelo segundo a caracterização e conveniência da organização modelada.

f) Modelo de Requisitos e Componentes técnicos (MRCT): é uma tentativa inicial de definir toda a estrutura e propriedades do sistema de informação que irá apoiar as atividades do negócio, como definido no MPN. (STIRNA et al., 2007).

Os sub-modelos são desenvolvidos de forma paralela, significando que eles estão em diferentes níveis de exaustividade ou plenitude num certo ponto do tempo. A interrelação entre os sub-modelos tem um papel muito importante por que permite que o conhecimento seja facilmente compartilhado nas diferentes áreas da organização.

A evolução das pesquisas que resultaram na metodologia EKD iniciam com os estudos de Langefors (1968), quem fez importantes contribuições à modelagem organizacional, posteriormente a inícios dos anos oitenta Plandata introduze o método $\mathrm{ABC}$, que foi aprimorado pelo SISU (O Instituto Sueco para o Desenvolvimento de Sistemas), que foi posteriormente estendido em um Método de Modelagem Organizacional no projeto ESPRIT F3 (From Fuzzy to Formal). O método de modelagem F3 (1994) foi 
aprofundado no projeto ESPIRIT ELKD, chegando à atual versão de metodologia de modelagem organizacional EKD (BUBENKO et al., 2001).

As diferentes versões dos métodos propostos por esta escola de pensamento foram aplicadas em várias companhias européias: British Aerospace (Inglaterra), Capital Bank (Inglaterra), National Bank of Greece, PostGirot (Suécia), Public Power Corporation (Grécia), Sema Group (Francia), Telia (Suécia), Vattenfall (Suécia), Volvo (Suécia) etc.

Pádua (2004) realiza uma comparação entre as técnicas de modelagem propostas na literatura (quadro 17 e quadro 18) e evidencia a superioridade da metodologia EKD.

\begin{tabular}{|c|c|c|}
\hline $\begin{array}{c}\text { Técnica ou método } \\
\text { de modelagem }\end{array}$ & Orientada & Principais características \\
\hline ORDIT & Atores & $\begin{array}{l}\text { - Trata a responsabilidade das pessoas envolvidas no trabalho. } \\
\text { - Focaliza como os componentes humanos são organizados no } \\
\text { trabalho. } \\
\text { - Não desenvolve modelos com múltiplas visões. } \\
\text { - Não considera regras do negócio. } \\
\text { - As práticas de trabalho são descritas como responsabilidades e } \\
\text { relacionamentos em vez } \\
\text { de atividades ou processos. } \\
\text { - Não trata objetivos organizacionais. }\end{array}$ \\
\hline Furlan (1997) & $\begin{array}{l}\text { Missão da } \\
\text { organização }\end{array}$ & $\begin{array}{l}\text { - É constituída da definição da missão, objetivos executivos, } \\
\text { objetivos estratégicos, fatores } \\
\text { chaves de sucesso, estratégia, planos de ação. } \\
\text { - Não desenvolve modelos com múltiplas visões. } \\
\text { - Não considera regras do negócio. } \\
\text { - Não tem um modelo dos processos de negócio. } \\
\text { - Não trata especificação dos requisitos organizacionais. } \\
\text { - Não trata o desenvolvimento de Sistemas de informação. } \\
\text { - Não trata os Atores envolvidos. }\end{array}$ \\
\hline $\mathrm{F} 3$ & Objetivos & $\begin{array}{l}\text { - É constituída por cinco modelos elaborados a partir dos } \\
\text { objetivos. } \\
\text { - Relaciona objetivos, atividades, processos e atores. Destaca } \\
\text { áreas da organização. } \\
\text { - Não tem um modelo específico de regras do negócio. Trata as } \\
\text { regras dentro do modelo de objetivos. }\end{array}$ \\
\hline$i^{*}$ & Atores & $\begin{array}{l}\text { - Trata o relacionamento de dependência de atores. } \\
\text { - É composta por dois modelos: o Modelo de Dependências. } \\
\text { Estratégicas (SD) e o Modelo de } \\
\text { Razões Estratégicas (SR). } \\
\text { - Descreve as relações de dependências externas entre os atores } \\
\text { da organização. } \\
\text { - Descreve interesses e conceitos dos participantes e as direções } \\
\text { que podem seguir. } \\
\text { - Não consideram regras do negócio. } \\
\text { - Não tem um modelo dos processos de negócio. }\end{array}$ \\
\hline EKD & Objetivos & $\begin{array}{l}\text { - É uma evolução de F3. } \\
\text { - É composto de seis modelos: de objetivos, regras do negócio, de } \\
\text { conceitos, processos de negócio, } \\
\text { atores e recursos e de requisitos e componentes técnicos. }\end{array}$ \\
\hline
\end{tabular}




\begin{tabular}{|l|l|}
\hline & - Possui um conjunto de questões que apóia o desenvolvimento \\
& de todos os modelos. \\
- Oferece um conjunto de questões para apoio na verificação das \\
ligações entre componentes de \\
todos os modelos. \\
- Captura as melhores práticas do negócio. \\
- Gerenciamento de mudanças. \\
- Gerenciamento das regras do negócio. \\
- Pode ser utilizada para especificação de requisitos. \\
- É orientada para a aprendizagem organizacional. \\
- Trata o gerenciamento do conhecimento organizacional. \\
- Apresenta um conjunto de diretrizes que orienta todo o processo \\
de modelagem.
\end{tabular}

Quadro 17 - Comparação entre as metodologias de modelagem

\begin{tabular}{|c|c|c|c|c|c|}
\hline Características & Furlan & ORBIT & F3 & $\mathbf{I}^{*}$ & EKD \\
\hline $\begin{array}{l}\text { Descreve interesses e conceitos dos participantes e as } \\
\text { direções que podem seguir. }\end{array}$ & & & & $\mathrm{X}$ & \\
\hline $\begin{array}{l}\text { As práticas de trabalho são descritas como responsabilidades } \\
\text { e relacionamentos em vez de atividades ou processos. }\end{array}$ & & $\mathrm{X}$ & & & \\
\hline $\begin{array}{l}\text { As práticas de trabalho são descritas como processos, } \\
\text { responsabilidades, relacionamentos com regras do negócio e } \\
\text { recursos. }\end{array}$ & & & $\mathrm{X}$ & & $\mathrm{X}$ \\
\hline $\begin{array}{l}\text { Trata como os componentes humanos são organizados no } \\
\text { trabalho. }\end{array}$ & & $\mathrm{X}$ & $\mathrm{X}$ & $X$ & $\mathrm{X}$ \\
\hline Trata a responsabilidade das pessoas envolvidas no trabalho. & & $\mathrm{X}$ & $\mathrm{X}$ & $\mathrm{X}$ & $\mathrm{X}$ \\
\hline $\begin{array}{l}\text { Relaciona objetivos, atividades, processos e atores. Destaca } \\
\text { áreas da organização. }\end{array}$ & & & $\mathrm{X}$ & & $\mathrm{X}$ \\
\hline É constituída por modelos elaborados a partir dos atores. & & $\mathrm{X}$ & & $\mathrm{X}$ & \\
\hline $\begin{array}{l}\text { Descreve as relações de dependências externas entre os } \\
\text { atores da organização. }\end{array}$ & & & $\mathrm{X}$ & $X$ & $\mathrm{X}$ \\
\hline É constituída por modelos elaborados a partir dos objetivos. & & & $\mathrm{X}$ & & $\mathrm{X}$ \\
\hline Trata o relacionamento de dependência de atores. & & & & $\mathrm{X}$ & $\mathrm{X}$ \\
\hline Orientada à missão. & $\mathrm{X}$ & & & & \\
\hline Orientada a objetivos. & & & $\mathrm{X}$ & & $\mathrm{X}$ \\
\hline Orientada a atores. & & $\mathrm{X}$ & & $\mathrm{X}$ & \\
\hline Tem um modelo específico de regras do negócio. & & & & & $\mathrm{X}$ \\
\hline $\begin{array}{l}\text { Trata da definição da missão, objetivos executivos, objetivos } \\
\text { estratégicos, fatores chaves de sucesso, estratégia, planos de } \\
\text { ação. }\end{array}$ & $\mathrm{X}$ & & & & \\
\hline Considera regras do negócio. & & & $\mathrm{X}$ & & $\mathrm{X}$ \\
\hline Desenvolve modelos com múltiplas visões. & & & $\mathrm{X}$ & $\mathrm{X}$ & $\mathrm{X}$ \\
\hline Tem um modelo dos processos de negócio. & & & $\mathrm{X}$ & & $\mathrm{X}$ \\
\hline Trata a especificação dos requisitos organizacionais. & & $\mathrm{X}$ & $\mathrm{X}$ & $\mathrm{X}$ & $\mathrm{X}$ \\
\hline Trata o desenvolvimento de Sistemas de informação. & & & $\mathrm{X}$ & & $\mathrm{X}$ \\
\hline Trata os atores (pessoas) envolvidos. & & $\mathrm{X}$ & $\mathrm{X}$ & $\mathrm{X}$ & $\mathrm{X}$ \\
\hline $\begin{array}{l}\text { Apresenta um conjunto de diretrizes que orienta todo o } \\
\text { processo de modelagem. }\end{array}$ & & & & & $\mathrm{X}$ \\
\hline Trata o gerenciamento do conhecimento organizacional. & & & & & $\mathrm{X}$ \\
\hline Orientada para a aprendizagem organizacional. & & & & & $\mathrm{X}$ \\
\hline Trata o gerenciamento de mudanças. & & & & & $\mathrm{X}$ \\
\hline Trata o gerenciamento das regras do negócio. & & & & & $\mathrm{X}$ \\
\hline Captura as melhores práticas do negócio. & & & & & $\mathrm{X}$ \\
\hline $\begin{array}{l}\text { Oferece um conjunto de questões para apoio na verificação } \\
\text { das ligações entre componentes de todos os modelos. }\end{array}$ & & & & & $\mathrm{X}$ \\
\hline $\begin{array}{l}\text { Possui um conjunto de questões que apóia o } \\
\text { desenvolvimento de todos os modelos. }\end{array}$ & & & & & $\mathrm{X}$ \\
\hline
\end{tabular}

Quadro 18 - Características das metodologias de modelagem 
O desenvolvimento do EKD pode iniciar-se em um nível e mover-se para outros níveis da organização, pode ter um fluxo bottom-up, ao trabalhar os processos organizacionais como primeiro estágio da modelagem e chegar aos objetivos estratégicos, ou um fluxo top-down, ao focar os esforços na identificação ou determinação dos objetivos organizacionais e posteriormente no estabelecimento de processos, atores, recursos, etc. para a consecução desses objetivos. De forma similar o EKD pode ter níveis de aprofundamento na sua aplicação, desenvolvendo modelos gerais, sistêmicos e de nível estratégico, ou modelos operacionais, detalhados e de nível operacional, isso dependendo da necessidade da organização (PÁDUA, 2004).

Adicionalmente, a qualidade do modelo desenvolvido pode apresentar um nível inicial e um nível refinado, Bubenko et al. (2001) descrevem os itens que caracterizam a referida classificação:

\section{Nível Inicial}

A dimensão da representação

- As sentenças feitas nos componentes do modelo não são verificadas

- O sub-modelos não estão relacionados, existem componente soltos e as ligações entre os modelos não estão completos.

- O nível de precisão nas sentenças dos componentes do modelo é baixa, refinamentos necessários não são realizados.

- O modelo não é útil para a posterior elaboração aprofundada de sistemas de informação.

A dimensão semântica

- Os sub-modelos (seus componentes e relacionamentos) são imprecisos, difíceis de aprimorar sem um completo re-trabalho.

- O significado dos vários componentes é ambíguo.

- É duvidoso se os corretos tipos de componentes do modelo são usados para a representação das sentenças.

- O foco dos sub-modelos não refletem os objetivos da modelagem.

- O Modelo de Conceitos dos outros sub-modelos não são validos. 
- O modelo não é adequado para ser utilizado como um instrumento de aplicação ou planejamento organizacional.

- O modelo não é útil ou claro semanticamente para a posterior elaboração de um sistema de conceitos.

- É difícil julgar o grau de realização do modelo.

A dimensão Social

- Não é claro se os participantes aceitam o significado dos componentes do modelo da forma como eles estão descritos.

- Não é claro se os participantes aceitam a importância dos componentes do modelo da forma como eles estão descritos.

- Não é claro se os participantes aceitam a relevância dos componentes do modelo da forma como eles estão descritos.

\section{Nível Refinado}

A dimensão da representação

- As sentenças nos componentes do modelo estão apropriadamente tratadas e revisadas.

- Os sub-modelos estão inter-conectados, não há falta de componentes e os relacionamentos entres os modelos estão completos.

- O modelo é útil para a posterior elaboração de sistemas de informação.

A dimensão semântica

- O significado dos vários componentes é claro e não ambíguo.

- Os corretos tipos de componentes são usados para a representação das sentenças.

- O foco dos sub-modelos refletem os objetivos da modelagem

- O relacionamento dentro dos sub-modelos estão validados

- O modelo é adequado para ser usado como um instrumento para o planejamento organizacional

- O modelo é semanticamente útil e correto para a posterior elaboração da modelagem de um sistema de informação. 
A dimensão Social

- Os participantes aceitam o significado dos componentes do modelo da forma como eles estão descritos.

- Os participantes aceitam a relevância dos componentes do modelo da forma como eles estão descritos.

- Os participantes aceitam a importância dos componentes do modelo da forma como eles estão descritos.

Com relação à escolha do método, ela se vê fundamentada pelos quadros 19 e 20, somada às características sistêmicas que o EKD possui, sua orientação à aprendizagem organizacional, aos objetivos e principalmente por ser considerada uma metodologia para o gerenciamento do conhecimento organizacional.

No mesmo contexto, é importante evidenciar a evolução das pesquisas que o EKD teve no âmbito nacional, principalmente pelo grupo de pesquisa DECIDIR, da Universidade de São Paulo, Escola de Engenharia de São Carlos, em que o EKD foi utilizado na geração de modelos aplicados em vários setores e áreas da organização, a saber: no desenvolvimento de sistemas de informação (PÁDUA et al. 2004), na mudança de processos (CASTRO; CAZARINI, 2005), em sistemas de informação gerencial (CAMPOS; CAZARINI, 2005), em sistemas ERP (CASTRO; CAZARINI, 2006), na Gestão do Conhecimento (CASTRO; CAZARINI, 2006), na construção de arquiteturas de referência para redes de empresas (NEVES et al., 2007) (GANGA et al., 2008), no comercio eletrônico (CASTILLO; CAZARINI, 2008), e na tomada de decisão (CASTILLO; CAZARINI, 2009). 


\section{MÉTODO DE PESQUISA}

\subsection{Caracterização da pesquisa}

Segundo Gil (2007), a pesquisa pode ser classificada segundo sua natureza, problema, objetivos e procedimento técnicos.

Com relação à sua natureza a pesquisa é classificada como aplicada, devido a que visa a geração de conhecimento para aplicação prática, dirigida à solução de problemas específicos. Referente ao problema e os fins ou objetivos do estudo, a pesquisa é classificada como qualitativa e de caráter exploratório-descritivo.

A pesquisa exploratória é normalmente o passo inicial no processo de pesquisa pela experiência e um auxílio que traz a formulação de hipóteses significativas para posteriores pesquisas (CERVO; BERVIAN; SILVA, 2007). Esta tem como principal objetivo o aprimoramento de idéias ou a descoberta de intuições (GIL, 2007).

A pesquisa descritiva observa, registra, analisa e correlaciona fatos ou fenômenos sem manipulá-los. Procura descobrir, com a maior precisão possível, a freqüência com que o fenômeno ocorre, sua relação e conexão com outros, sua natureza e suas características (CERVO; BERVIAN; SILVA, 2007).

Com relação aos procedimentos técnicos, o trabalho realiza uma pesquisa bibliográfica ou teórica conceitual. A pesquisa bibliográfica é desenvolvida com base em material já elaborado, construída principalmente de livros e artigos científicos, é o produto de reflexões a partir de fenômenos observados ou de relatos da literatura.

\subsection{Questões de pesquisa}

As questões de pesquisa ajudaram na delimitação do estudo e na construção dos instrumentos de pesquisa.

Elas são divididas em dois grupos, as relacionadas à validação do modelo e as relacionadas à validação da modelagem, elas podem ser compreendidas pelos seguintes questionamentos gerais: 
Com relação à validação do modelo:

- O modelo oferece sustento para a implantação e desenvolvimento da GC?

- O modelo representa adequadamente as atividades da GC?

- Os objetivos e regras da GC considerados no modelo são corretos?

- O processo de implantação considerado no modelo é correto?

- Os atores da GC considerados no modelo são corretos?

- As ferramentas da GC consideradas no modelo são carretas?

- Os requisitos e componentes técnicos da GC considerados no modelo são corretos?

- O modelo é integrado?

Com relação à validação da modelagem:

- A metodologia EKD foi corretamente aplicada?

- A metodologia EKD serviu para a representação da GC?

\subsection{Técnicas de coleta de dados}

A coleta de dados foi guiada e delimitada pelo modelo proposto, visando sua validação e aprimoramento.

Para a validação da modelagem os dados foram coletados por meio de entrevistas semiestruturadas e questionários semi-estruturados feitos por especialistas em modelagem EKD (Apêndice A e B), já tendo feito a escolha deste método como base para o desenvolvimento do modelo, sendo considerado desta forma não relevante entrevistar especialistas de outras metodologias de modelagem.

Para a validação do modelo os dados foram coletados por meio de questionários semiestruturados com perguntas abertas e fechadas feitos a pesquisadores especialistas em GC (Apêndice C). Foi utilizada a ferramenta e-Survey Pro para a estruturação do questionário.

Por questionário entende-se um conjunto de questões que são respondidas por escrito pelo pesquisado (GIL, 2007). É a forma mais usada para coletar dados, por que permite medir com melhor exatidão o que se deseja. Ele tem um conjunto de questões, todas logicamente relacionadas com um problema central (CERVO; BERVIAN, 1996). 
Segundo Gil (2007) o questionário constitui o meio mais rápido e barato de obtenção de informações, além de não exigir treinamento pessoal e garante o anonimato.

Entrevista pode ser entendida como a técnica que envolve duas pessoas numa situação "face a face" e em que uma delas formula questões e a outra responde (GIL, 2007). É uma conversa orientada para um objetivo definido: recolher, através do interrogatório do informante, dados para a pesquisa (CERVO; BERVIAN, 1996). Segundo Gil (2007), a entrevista tem como vantagens sua aplicabilidade, podendo ser feita a um número maior de pessoas, inclusive às que não sabem ler ou escrever; e a possibilidade de auxilio ao entrevistado com dificuldade para responder, bem como análise de seu comportamento não verbal.

\subsection{Técnica de análise de dados}

Para a análise dos dados das entrevistas foram utilizadas a análise de conteúdo e a análise de discurso. No caso dos questionários foram utilizados principalmente histogramas e a análise de conteúdo.

A análise de conteúdo obtém dados através da observação e análise do conteúdo ou mensagem de texto escrito. Por meio da análise sistemática e da observação, o pesquisador examina a frequência com que as palavras e temas principais ocorrem e identifica o conteúdo e as características de informações presentes no texto (HAIR et al., 2005).

A análise de discurso busca entender as perspectivas em que as relações sociais de poder se constroem no plano discursivo, ela surge em decorrência de insuficiências da análise de conteúdo (ROCHA; DEUSDARÀ, 2005). Na análise de discurso verifica-se o título, resumo, palavras-chave, estrutura, referências e características verbais. Alem disso, a metodologia também é matéria de análise alguns aspectos como, objetivos, tipologia, sujeitos, materiais, procedimentos e variáveis (DUARTE, 2002).

Com relação à validade dos instrumentos de pesquisa foi utilizado a validade aparente e a validade de conteúdo. Segundo Martins (2006), o critério de validade diz respeito à capacidade do instrumento em medir de fato o que se propõe medir.

A validade aparente avalia considerando a definição teórica de uma variável, se ma medida parece, de fato, medir a variável sob estudo. A validade aparente é avaliada por 
um juiz, ou grupo de juízes, que examinam uma técnica de mensuração (questionário) e decidem se ela mede o que seu nome diz. Todo instrumento deve passar pela avaliação da validade aparente (MARTINS, 2006).

A validade de conteúdo refere-se ao grau em que o instrumento evidencie um domínio específico de conteúdo do que pretende medir (SAMPIERI et al., 1996). A área de conteúdo precisa ser sistematicamente analisada a fim de assegurar que todos os aspectos fundamentais sejam, adequadamente, e em proporções corretas, abrangido pelos itens o instrumento de coleta (MARTINS, 2006).

\subsection{Amostragem}

A amostragem foi não probabilística por cotas ou proporcional e intencional.

$\mathrm{Na}$ amostragem por cotas ou proporcional o pesquisador procura obter uma amostra que seja similar apenas em alguns aspectos da população.

$\mathrm{Na}$ amostragem intencional ou por julgamento os elementos da amostra são julgados como adequados baseado em escolhas de casos específicos, na população onde o pesquisador está interessado.

A amostragem não probabilística por cota e intencional deve-se à dificuldade de determinação da população de pesquisadores tanto da GC quanto do EKD, e de empresas com práticas em GC, em todo o Brasil. Sendo assim, foram utilizados critérios particulares para a seleção da amostra.

O questionário e as entrevistas semi-estruturadas que visam a validação da modelagem foram feitas a quatro especialistas em EKD:

1. PhD. Prof. Janis Stirna, Professor da Universidade de Estocolmo, Departamento de Ciência e Sistemas de Computação

2. Prof. Sergio Alexandre de Castro

3. Dr. Prof. Fábio Müller Guerrini, Professor da Universidade de São Paulo, Escola de Engenharia de São Carlos, Departamento de Engenharia de produção.

4. Dr. Prof. Silvia Inês Dallavalle de Pádua, Professora da Universidade de São Paulo, Faculdade de Economia, Administração e Contabilidade - Ribeirão Preto 
O primeiro pesquisador é um dos criadores da metodologia EKD, para ele, foi enviado questionário em inglês (APÊNDICE B).

Os três últimos pesquisadores são os principais representantes e disseminadores da metodologia EKD no Brasil, para eles foi aplicada a entrevista semi-estruturada (APÊNDICE A).

O questionário que visa a validação do modelo foi direcionado a pesquisadores da área de GC no Brasil (APÊNDICE D):

Os pesquisadores indicados foram selecionados em base a sua representatividade na área da GC, seguindo os seguintes critérios:

- Publicações no ISI Web of Science relacionadas à GC nos último três anos.

- Publicações nas principais revistas internacionais relacionadas à GC (Journal of Knowledge Management Research \& Practice, Journal of Information \& Knowledge Management, Journal of Knowledge and Process Management, Journal of Knowledge Management, International Journal of Knowledge Management, Knowledge Management Review) nos últimos três anos.

- Publicações nas principais revistas nacionais relacionadas à GC (Revista Brasileira de Gestão de Negócios, Informação e Sociedade - Estudos, Perspectivas em Ciência da Informação, Transinformação, Gestão \& Produção, Produção, Produção on-line RAE, RAUSP, RAC) realizadas nos último três anos.

- Em artigos com mais de um autor foram selecionados aqueles autores com mais experiência na área, com base na análise de seu Currículo Lattes, considerando que geralmente estudantes de mestrado ou doutorado pesquisam na GC, mas não desenvolvem estudos aprofundados ou acompanham os avanços da área após este período.

- Foi feita uma pesquisa na Plataforma Lattes em busca de currículos com as palavras chaves “Gestão do Conhecimento", sendo analisados 180 currículos, até um índice de relação com as palavras chave e os currículos de $80 \%$.

A delimitação de tempo de três anos para as publicações justifica-se pela alta dinamicidade que a GC tem e pela velocidade no surgimento e mudança dos conceitos e das metodologias na área. Adicionalmente, em geral os artigos publicados são produtos 
de trabalhos de pesquisa de mestrado e doutorado, sendo desenvolvidos geralmente em um lapso de tempo médio de três anos.

\subsection{Procedimentos metodológicos}

Desenvolveu-se uma pesquisa bibliográfica sobre a GC e sobre a modelagem organizacional, especificamente a metodologia de modelagem organizacional EKD. Com base nesta revisão da literatura foi elaborada a primeira versão do modelo, seguindo os procedimentos indicados pela metodologia EKD.

Posteriormente, essa primeira versão foi submetida à análise e apreciação por parte de especialistas com o objetivo de sua validação. Finalmente, o modelo foi aprimorado com base na informação que obtida na fase anterior e obteve-se sua versão final.

A geração de modelos baseados na revisão da literatura e sua validação com especialistas da área também foi utilizada como procedimento metodológico por Handzic (2003), King et al. (2008) e Orzano et al. (2008); trabalhos complementares validaram seus modelos com estudos de caso, relacionando as características dos modelo com as atividades realizadas nas organizações (LEE; KIM, 2001; PEE; KANKANHALLI, 2009). Validações aprofundadas implicariam a aplicação do modelo numa organização e sua avaliação após alguns anos. 


\section{RESULTADOS}

\subsection{Descrição do trabalho de campo}

Com relação à validação da modelagem os quatro pesquisadores selecionados foram entrevistados. Agendou-se uma reunião presencial com os três pesquisadores nacionais, explicou-se o modelo proposto e realizou-se as perguntas, durando cada reunião um aproximado de 30 minutos.

No caso do pesquisador estrangeiro, entrou-se em contato via e-mail e enviou-se o modelo, obtendo-se pelo mesmo meio suas considerações e comentários.

Com relação à validação do modelo proposto, entrou-se em contato via telefônica com os pesquisadores de todo o Brasil, os telefones foram obtidos no Currículum Lattes ou na internet, mas se teve vários números inválidos ou não foi possível comunicar-se com todos os pesquisadores por motivos de viagem, trabalho ou a não disponibilidade do número telefônico. Foram feitas três ligações durante três dias em horários diferentes.

$\mathrm{Na}$ conversa com os especialistas explicou-se resumidamente a pesquisa e se pediu permissão para o envio do questionário via e-mail junto com o modelo proposto. Os endereços eletrônicos obtiveram-se nos site das suas instituições de ensino ou na internet.

O questionário foi enviado para 86 pesquisadores, obtendo-se 19 respostas validas, com uma porcentagem de retorno de $22 \%$. Sendo que uma das potenciais desvantagens das pesquisas on-line é a baixa taxa de resposta, a taxa de retorno considera-se aceitável (GONÇALVEZ, 2008; MALHOTRA, 2006)

Segundo Aaker (2007) a coleta de dados utilizando o e-mail pode proporcionar algumas vantagens como:

- Os questionários podem ser enviados quantas vezes forem necessárias com maior velocidade;

- Maior velocidade também no recebimento das respostas;

- Os questionários podem ser respondidos de acordo com a conveniência e tempo do entrevistado. 
Enviou-se o questionário para os 86 pesquisadores no dias 17, 18, e 19 de agosto de 2010, e realizou-se um segundo envio no dia 08 de setembro de 2010 para aqueles especialistas que nessa data ainda não tinham respondido. Fechou-se o recebimento de respostas o dia 21 de setembro de 2010.

\subsection{Apresentação do modelo e análise de resultados}

A seguir será descrito o modelo proposto por este trabalho na sua versão final aprimorada, considerando os comentários e apreciações dos especialistas. Na referida descrição serão apresentados os resultados das entrevistas e questionários.

\subsubsection{Modelo Integrado para a implantação e desenvolvimento da Gestão do Conhecimento}

\subsubsection{Modelo de objetivos e regras do negócio}

O modelo e objetivos e regras do negócio (MO e MRN) inicia com a explicitação das principais ameaças do ambiente que toda organização enfrenta (ameaças do ambiente organizacional 1, 2 e 3) (Figura 26)
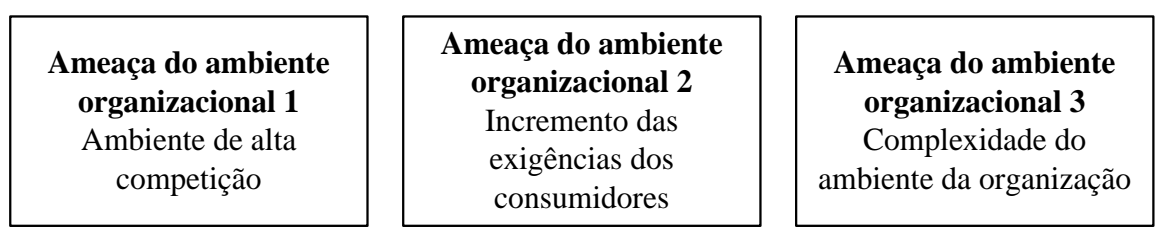

Figura 26 - Ameaças do ambiente organizacional

A alta competição produto da abertura dos mercados, que por sua vez foi produto da globalização, é considerada uma das principais características do ambiente organizacional (ARORA, 2002; CHOI et al., 2008; VALENZUELA et al., 2008). As organizações concorrem globalmente, onde uma empresa brasileira de calçados esportivos pode ter como principais concorrentes empresas no Taiwan, na China, nos EEUU e no Vietnam.

Outro distintivo do ambiente organizacional é o incremento das exigências dos consumidores, produto da disponibilidade de informação, relacionada à Internet e ao acesso à TI; a variedade de produtos e suas fontes de obtenção (HARRIS, 2001). Os consumidores podem em questão de minutos compararem preços, características e até ter acesso a comentários de um determinado produto em diferentes lojas distribuídas no mundo, com o simples acesso a sites especializados nessa tarefa. Exemplificando, se faz 
referência à compra de lap-tops, eletrônicos em geral, livros, etc. Em sites como compara.buscape.com.br; shopping.uol.com.br etc.

Uma terceira característica é a complexidade do ambiente organizacional. São muitos os elementos que intervém em um negócio, com cadeias de valor mais globais, TI em constante mudança, transformação da cultura dos consumidores e da população em geral, fatores econômicos, e até políticos influenciando na prática e os resultados de uma organização.

As respostas dos especialistas apontam como ameaças adicionais às já mencionadas: a) a sobre produção de informação, criando lacunas entre o estado da arte e o conhecimento realmente aplicado nas organizações; b) a rapidez das inovações de natureza mercadológica e tecnológica, principalmente no setor da TI; c) o incremento das exigências dos stakeholders, considerando que os consumidores são apenas parte deles; e d) a forte influência de órgãos reguladores. Apontou-se também que o incremento das exigências dos consumidores poderia ser considerado uma oportunidade e não uma ameaça.

É importante comentar que pelo fato de as respostas serem de especialistas na área, todas elas são consideradas relevantes e de valor para o estudo.

Após a análise dos resultados serão consideradas como ameaças do ambiente organizacional as apresentadas na Figura 27.
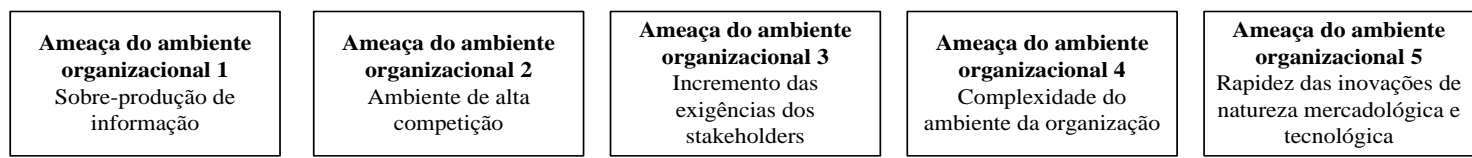

Figura 27 - Ameaças do ambiente organizacional - versão aprimorada

Foram inseridas duas novas ameaças ao modelo original (ameaça do ambiente organizacional 1 e 5) e o termo stakeholders foi adotado incluindo não só os consumidores, mas todos os atores que intervêm na cadeia de valor (ameaça do ambiente organizacional 3). A forte influência dos órgãos reguladores foi considerada como sub-característica da complexidade do ambiente, anteriormente descrita (ameaça do ambiente organizacional 4). Por último, é importante explicitar que determinada ameaça pode ser considerada uma oportunidade dependendo da posição da organização, por exemplo, a rapidez das inovações pode ser um fator útil para uma organização que presta serviço de consultoria, sugerindo cada vez melhores produtos para seus clientes, mas não sendo assim para uma organização que trabalha no desenvolvimento de 
aparelhos eletrônicos ou softwares.

As ameaças descritas criam nas organizações pressões e as obrigam a responder de diferentes formas, objetivos que ao serem atingidos permitirão sua sobrevivência e desenvolvimento no mercado. O modelo proposto os cataloga em: a) efetividade organizacional, b) decisões organizacionais adequadas, c) Inovação organizacional, e d) Mudança organizacional contínua (Figura 28) (ARORA, 2002; CHOI et al., 2008).

A efetividade organizacional compreende o desenvolvimento dos processos e em geral de todas as práticas do negócio com eficiência e eficácia, minimizando o uso de recursos e maximizando os resultados (MAXIMIANO, 2004).

As decisões organizacionais adequadas abrangem todos os níveis da organização, principalmente as decisões estratégias (CASTILLO; CAZARINI, 2009)

A inovação organizacional inclui as inovações em processos e produtos, inovações radicais ou incrementais (CHRISTENSEN, 2002).
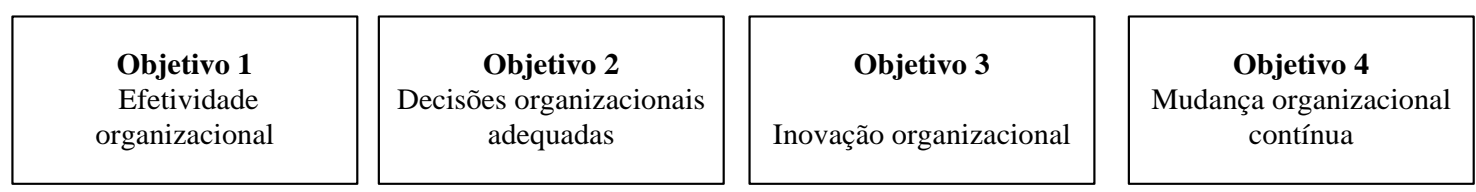

Figura 28 - Objetivos organizacionais para responder às ameaças do ambiente

Ao serem questionados os especialistas na ponderação da importância desses objetivos, os resultados mostram (Quadro 19), sendo 1 mais importante e 4 menos importante, que tanto as decisões organizacionais adequadas quanto a inovação são considerados objetivos primários de todo negócio (35\% de importância 1$)$.

\begin{tabular}{|l|c|c|c|c|c|}
\hline \multicolumn{1}{|c|}{ Objetivo } & $\mathbf{1}$ & $\mathbf{2}$ & $\mathbf{3}$ & $\mathbf{4}$ & $\begin{array}{c}\text { Número de } \\
\text { respostas }\end{array}$ \\
\hline Efetividade organizacional & $10 \%(2)$ & $15 \%(3)$ & $55 \%(11)$ & $20 \%(4)$ & 20 \\
\hline $\begin{array}{l}\text { Decisões organizacionais } \\
\text { adequadas }\end{array}$ & $35 \%(7)$ & $30 \%(6)$ & $20 \%(4)$ & $15 \%(3)$ & 20 \\
\hline $\begin{array}{l}\text { Inovação organizacional } \\
\text { Mudança organizacional } \\
\text { constante }\end{array}$ & $35 \%(7)$ & $45 \%(9)$ & $15 \%(3)$ & $5 \%(1)$ & 20 \\
\hline
\end{tabular}

Quadro 19 - Importância dos objetivos organizacionais

Também é interessante evidenciar que o objetivo de mudança organizacional constante, embora seja crítico no atual ambiente organizacional (THOMPSON, 2010; WEINER, 
2009), é percebido como menos importante quando comparado com os outros objetivos (60\% de importância 4). Podendo ter como origem desta peculiaridade a visão quantitativa e não objetiva ou de resultados concretos que a mudança organizacional oferece, além de sua natureza de objetivo de longo prazo, comparada com os outros três objetivos. Valendo o mesmo fundamento para a atribuição de importância da inovação ou das decisões organizacionais, nestes últimos casos como objetivos com resultados geralmente palpáveis e de curto prazo.

Além dos objetivos descritos, os especialistas sugeriram a incorporação dos seguintes objetivos: A) monitorar o ambiente continuamente; B) ter valores organizacionais; C) ter aprendizagem organizacional; D) ter flexibilidade; E) mudar a cultura da organização; F) gerir a informação e o conhecimento; G) criar um ambiente de trabalho estimulante; H) alinhar as decisões estratégicas; I) ter capacidade de apreender de erros, de se auto-avaliar e auto-criticar; J) manter relacionamento entre organizações; K) fidelizar consumidores; e L) compartilhar conhecimento. Adicionalmente, foi comentado que o objetivo "mudança organizacional constante" poderia ser melhor entendido como uma estratégia em vez de um objetivo organizacional.

Com base na análise dos resultados serão considerados como objetivos organizacionais os apresentados na Figura 29.
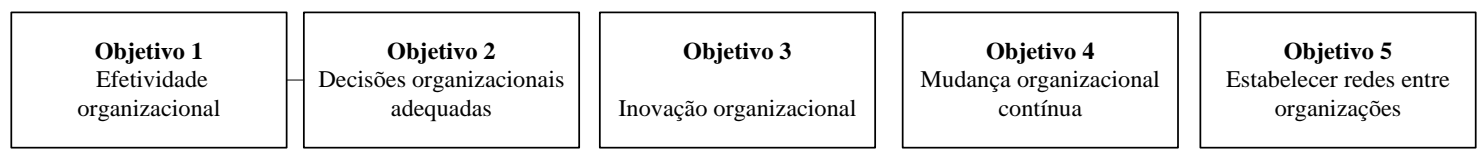

Figura 29 - Objetivos organizacionais para responder às pressões do ambiente - versão aprimorada

Alguns dos objetivos sugeridos não foram inseridos no modelo pelas seguintes razões: 1) estão compreendidos dentro dos objetivos já apresentados, é o caso dos objetivos A, D e E, relacionados com o objetivo 4 do modelo; e o caso dos objetivos B, C, E, F, I e L, relacionados com o principal objetivo do modelo proposto (objetivo 7) e seus subobjetivos, apresentados em itens posteriores; e 2) por não serem considerados objetivos base, ou com suficiente representatividade ou peso para o sucesso organizacional, sendo o caso dos objetivos $\mathrm{G}, \mathrm{H}$ e $\mathrm{K}$.

O objetivo de estabelecer redes entre organizações (objetivo 5) foi adicionado ao reconhecer sua importância no atual ambiente organizacional e a falta de atenção aos relacionamentos externos que a organização possa ter e que o trabalho estava negligenciando. 
Seguindo com a descrição do modelo, este apresenta como denominador comum ou recurso base para a consecução dos objetivos citados ao conhecimento organizacional (objetivo 6). Segundo Dalkir (2005) Wu e Lin (2009), numa economia baseada no conhecimento, as companhias precisam do conhecimento organizacional como o mais importante ativo estratégico para atingir seus objetivos.

Os especialistas ao serem questionados sobre esse enunciado, dentro de uma escala likert de cinco pontos, em sua maioria confirmaram a referida visão (Figura 30), estando $85 \%$ deles de acordo ou fortemente de acordo com o pronunciado.

\begin{tabular}{|l|l|c|c|}
\hline \multicolumn{1}{|c|}{ Escala Likert } & Resultados & $\begin{array}{c}\text { \% das } \\
\text { respostas }\end{array}$ & $\begin{array}{c}\text { Número de } \\
\text { respostas }\end{array}$ \\
\hline Fortemente em desacordo & & $0.00 \%$ & 0 \\
\hline Desacordo & & $10.00 \%$ & 2 \\
\hline Indeciso & & $5.00 \%$ & 1 \\
\hline De acordo & & $35.00 \%$ & 7 \\
\hline Fortemente de acordo & & $50.00 \%$ & 10 \\
\hline & & Respostas totais & 20 \\
\hline
\end{tabular}

Figura 30 - Importância do conhecimento para atingir os objetivos organizacionais

Sendo o conhecimento considerado importante, se não crítico, para garantir o sucesso organizacional, sua gestão torna-se relevante e necessária, fato explicitado no modelo por meio do objetivo 7. Tem-se assim o principal objetivo do trabalho, Gerir Conhecimento. Para poder desenvolver uma adequada Gestão do Conhecimento é imperativo atingir sete sub-objetivos, identificados com base nos fatores críticos de sucesso da GC (APQC 1999; BISHOP et al., 2008; CHANG et al., 2009; CHONG; CHOI, 2005; CHUA; LAM, 2005; DAVENPORT, 1998; HASANALI, 2002; JAFARI et al., 2007; LIEBOWITZ, 1999; SKYRME; AMIDON, 1997; WONG, 2005; YEH et al., 2006) (Figura 31).

Esses sub-objetivos são classificados em objetivos estratégicos: definir e manter uma Estratégia de GC (objetivo 7.1); objetivos de sustento: definir e manter uma Cultura Organizacional de conhecimento (objetivo 7.2), definir e manter uma Estrutura Organizacional de conhecimento (objetivo 7.7), definir e manter uma Equipe de GC (objetivo 7.3), definir e manter ferramentas de GC (objetivo 7.4), definir e manter métricas de GC (objetivo 7.6); e objetivos operacionais: definir e manter processos de GC (objetivo 7.5). 
A estratégia de GC fornece o fundamento de como a organização pode desenvolver suas capacidades e recursos para atingir os objetivos da GC (WONG, 2005). Ela compreende uma visão compartilhada da GC, missão, objetivos, metas e procedimentos bem definidos. Considera-se como referência de estratégia para a GC, a fundamentada por Zack (1999) e Choi et al. (2008), formando um mix de estratégias tácito-internoorientadas e explícito-externo-orientadas. Que dizer, quando for necessário conhecimento tácito-implícito, a organização buscará em fonte internas (gerentes, especialistas, trabalhadores do conhecimento); e quando for necessário conhecimento explícito, a organização buscará em fontes externas (bases de dados, estudos de mercado, newsletters etc.).

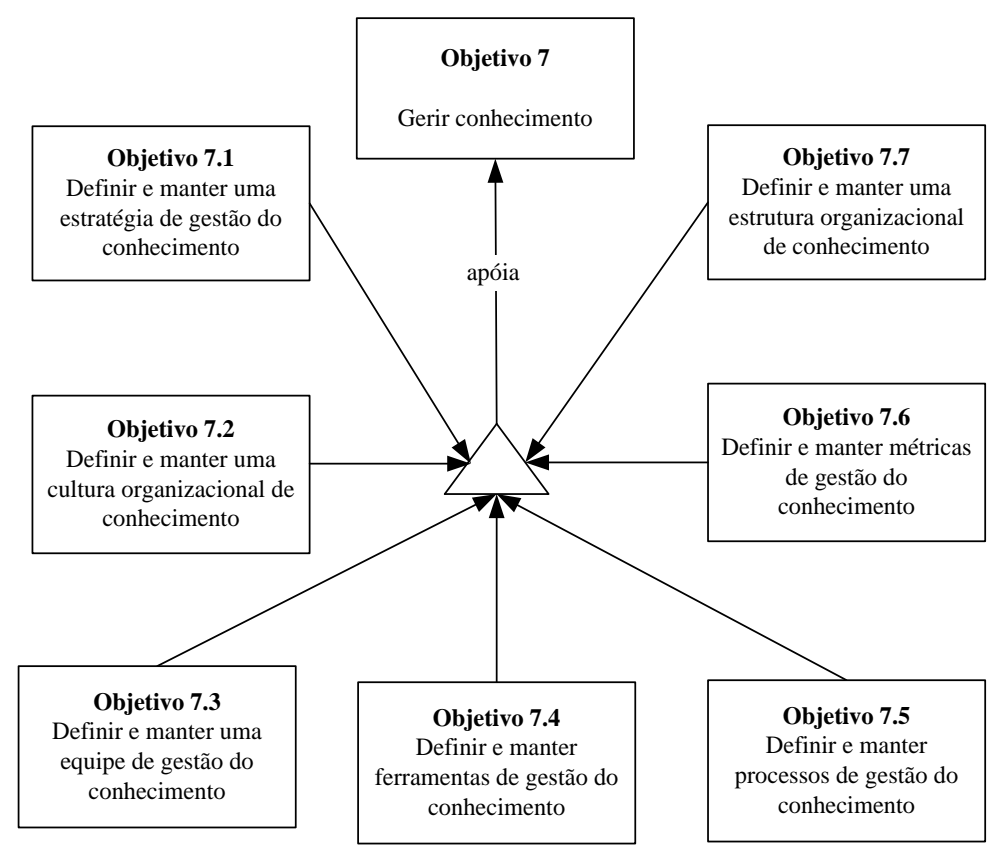

Figura 31 - Objetivo Gerir Conhecimento e os sub-objetivos para atingi-lo

A Cultura Organizacional de conhecimento é uma forma de vida da organização que permite e motiva às pessoas na criação, compartilhamento e utilização do conhecimento para o benefício e duradouro sucesso da organização (OLIVER; KANDADI, 2006). Ela é categorizada em três grupos: fatores orientados ao conhecimento, fatores orientados às pessoas e fatores orientados ao trabalho (ZHENG, 2009).

Os fatores orientados ao conhecimento descrevem as percepções compartilhadas e atitudes sobre o conhecimento pelos membros da organização. Inclui o sentido das pessoas sobre a propriedade compartilhada do conhecimento, a priorização dos diferentes tipos de conhecimento e uma atitude crítica sobre o conhecimento existente. 
Os fatores orientados às pessoas referem-se às atitudes e pressupostos compartilhados que as pessoas têm sobre outros membros da organização. Eles envolvem como as pessoas pensam e se relacionam. Abrangem fatores como a confiança, cuidado, abertura, cooperação e coesão.

Os fatores orientados ao trabalho referem-se às atitudes e normas dos membros da organização sobre seu trabalho. Como o trabalho deve ser realizado? Quais são as expectativas comuns para trabalhar? São considerados principalmente dois fatores: o empreendedorismo e a perspectiva positiva.

A Estrutura Organizacional é geralmente categorizada em três elementos: a formalização, a centralização e a integração (CHEN; HUANG, 2007). Ter uma Estrutura Organizacional de conhecimento compreende ter uma baixa formalização, em que os comportamentos de trabalho são relativamente não estruturados e os membros têm maior liberdade para lidar com as demandas de suas tarefas; uma baixa centralização, em que os indivíduos têm mais independência e discrição para determinar que ações são requeridas e qual é a melhor forma de desenvolvê-las; e alta integração, em que os funcionários devem ter acesso à mais ampla variedade de conhecimento para o trabalho e a solução de problemas (CHEN; HUANG, 2007; CORTÉS et al., 2007).

A equipe de GC compõe-se dos líderes de conhecimento e os trabalhadors do conhecimento. No nível mais alto, os líderes do conhecimento são geralmente diretores que possuem uma visão holística da organização, geralmente o máximo líder do conhecimento e chamado de Diretor do Conhecimento (Chief Knowledge Officer CKO) (BRUSTEIN et al. 2003; OXBROW, 2004). Ele é um executivo de alto grau cuja responsabilidade é impulsionar o conhecimento dentro da organização ao liderar um programa da GC.

Em um nível intermediário de líderes do conhecimento, Carty e Walsh (2007) e Takeuchi (2001) explicitam a importância dos gerentes de nível médio para o sucesso das práticas da GC. Eles são mediadores entre "o que se busca ser", a mentalidade da alta gerência, e "o que é realmente", a mentalidade dos funcionários do chão de fábrica. Podendo ser supervisores das unidades do negócio, líderes de opinião e coordenadores de comunidades de prática, além dos funcionários do departamento de TI. 
No chão de fábrica encontram-se aos trabalhadores do conhecimento, indivíduos que trabalham primordialmente com informação, ou que desenvolvem ou usam o conhecimento para realizar sua função (DRUCKER, 1993). São eles os que fazem acontecer os processos da GC, produzem, avaliam, integram e usam o conhecimento. A GC depende da habilidade, conhecimento e predisposição destes trabalhadores para realizarem esses processos e assim agregar valor para organização (SHOHAM; HASGALL, 2005).

As ferramentas de GC são o conjunto de metodologias, técnicas e tecnologias de informação que apoiarão no desenvolvimento e avaliação das suas práticas. Tem-se as ferramentas que apóiam o desenvolvimento dos processos da GC, as ferramentas de avaliação das práticas da GC e as ferramentas para o desenvolvimento dos outros elementos da GC (estratégia, cultura, estrutura e equipe de GC). Estas ferramentas são melhor explicitadas no modelo de atores e recursos, descrito em pontos posteriores.

As métricas da GC são um conjunto de metodologias e indicadores que oferecem informação sobre como a GC está sendo desenvolvida na organização, se seus objetivos estão sendo atingidos e qual é o impacto da GC nas metas organizacionais. Elas podem ser de natureza financeira e não financeira. Alguns trabalhos relacionados a este assunto: o estudo do Intellectual Capital Managemet (ICM) (1998), os estudos de Roos et al. (1998), o reporte do Canadian Management Accountant (CMA) (1999), e o reporte do Universal Intellectual Capital (VON KROUGH et al.,1999). Algumas metodologias: Balanced scorecard, Valor Econômico Agregado, Skandia Navigator, Benchmarking, Análise de Redes de Trabalho, Auditoria do conhecimento e Método da Casa da Qualidade (DALKIR, 2005; DATTERO et al., 2007; LIEBOWITZ et al., 2000; NISSEN, 2006).

Finalmente têm-se os processos da GC, considerados a base operacional da sua implantação, eles compreendem a produção, avaliação, integração e utilização do conhecimento, nesta utilização geram-se questionamentos que motivam a aprendizagem de circuito simples e de circuito duplo a nível individual, grupal ou organizacional dando início a um novo ciclo (FIRESTONE; McELROY, 2005; McELROY, 2000).

Os especialistas ao serem questionados sobre a importância de cada sub-objetivo ofereceram os pareceres apresentados no Quadro 20. Sendo 1 o mais importante e 7 o menos importante. Embora todos os sub-objetivos tenham origem nos fatores críticos de 
sucesso da GC, os objetivos de definir e manter uma estratégia e uma cultura de conhecimento são considerados pelos especialistas os mais importantes (45 e 50\% respectivamente de importância 1). Com relação à estratégia da GC, os resultados refletem os estudos sustentando por Choi et al. (2008), Greiner et al. (2007), Hasen e Al-hawari (2003), Wu e Lin (2009) e Yang (2008), que evidenciam claramente a relevância da estratégia da GC para o sucesso de suas atividades. Da mesma forma, a cultura organizacional de conhecimento foi considerada como o grande desafio e a peça chave do sucesso da GC por inúmeros autores (LAM, 2005; LEE, 2006; LI et al., 2006; LICHTENSTEIN; BRAIN, 2006; LIEBOWITZ, 2008; OLIVER; KANDADI, 2006; PACANOWSKY; O’DONNELL-TRUJILLO, 1983; ZHENG, 2009).

\begin{tabular}{|l|c|c|c|c|c|c|c|c|}
\hline \multicolumn{1}{|c|}{ Sub-objetivos } & $\mathbf{1}$ & $\mathbf{2}$ & $\mathbf{3}$ & $\mathbf{4}$ & $\mathbf{5}$ & $\mathbf{6}$ & $\mathbf{7}$ & Total \\
\hline Definir e manter uma estratégia & $45 \%$ & $35 \%$ & $5 \%$ & $0 \%$ & $5 \%$ & $10 \%$ & $0 \%$ & 20 \\
de gestão do conhecimento & $(9)$ & $(7)$ & $(1)$ & $(0)$ & $(1)$ & $(2)$ & $(0)$ & \\
\hline Definir e manter uma cultura & $50 \%$ & $25 \%$ & $15 \%$ & $5 \%$ & $0 \%$ & $5 \%$ & $0 \%$ & 20 \\
organizacional de conhecimento & $(10)$ & $(5)$ & $(3)$ & $(1)$ & $(0)$ & $(1)$ & $(0)$ & \\
\hline Definir e manter uma equipe de & $5 \%$ & $20 \%$ & $15 \%$ & $25 \%$ & $15 \%$ & $10 \%$ & $10 \%$ & 20 \\
gestão do conhecimento & $(1)$ & $(4)$ & $(3)$ & $(5)$ & $(3)$ & $(2)$ & $(2)$ & \\
\hline Definir e manter ferramentas de & $0 \%$ & $10 \%$ & $0 \%$ & $25 \%$ & $25 \%$ & $20 \%$ & $20 \%$ & 20 \\
gestão do conhecimento & $(0)$ & $(2)$ & $(0)$ & $(5)$ & $(5)$ & $(4)$ & $(4)$ & 20 \\
\hline Definir e manter processos de & $0 \%$ & $0 \%$ & $40 \%$ & $15 \%$ & $30 \%$ & $15 \%$ & $0 \%$ & 20 \\
gestão do conhecimento & $(0)$ & $(0)$ & $(8)$ & $(3)$ & $(6)$ & $(3)$ & $(0)$ & 20 \\
\hline Definir e manter métricas de & $0 \%$ & $0 \%$ & $15 \%$ & $15 \%$ & $15 \%$ & $35 \%$ & $20 \%$ & 20 \\
gestão do conhecimento & $(0)$ & $(0)$ & $(3)$ & $(3)$ & $(3)$ & $(7)$ & $(4)$ & 20 \\
\hline Definir e manter uma estrutura & $0 \%$ & $10 \%$ & $10 \%$ & $15 \%$ & $10 \%$ & $5 \%$ & $50 \%$ & 20 \\
organizacional de conhecimento & $(0)$ & $(2)$ & $(2)$ & $(3)$ & $(2)$ & $(1)$ & $(10)$ & \\
\hline
\end{tabular}

Quadro 20 - Importância dos sub-objetivos para gerir conhecimento

Outro fato interessante de ressaltar é a percepção da importância da estrutura organizacional do conhecimento para o sucesso da GC, sendo considerada por um $50 \%$ dos especialistas, como a menos importante ao ser comparada com os outros subobjetivos.

Como objetivos adicionais para viabilizar a GC propostos pelos especialistas encontram-se: A) estabelecer conduta de inovação; B) estabelecer parcerias concretas; C) definir e manter recompensas e políticas de incentivos para a GC; D) definir e manter uma governança de GC; E) incorporar a importância do conhecimento nas 
rotinas e instruções operacionais; F) definir e manter políticas de GC; G) definir a oportunidade para se implementar a GC, H) definir a amplitude de implementação e I) definir claramente para que a GC,

Os objetivos A e E são considerados dentro do objetivo de definir e manter uma cultura organizacional de conhecimento (objetivo 7.2). O objetivo $\mathrm{C}$ estará contemplado no modelo por meio da regra 5, apresentada em itens posteriores. O objetivo D, considerado de muita importância, é contemplado no conjunto de todos os sub-objetivos já apresentados, ao entender que governança é um sistema que define quem é responsável pelo que, como as decisões são tomadas, conflitos resolvidos e ações corretivas tomadas. O objetivo $\mathrm{F}$ é considerado dentro do objetivo de definir e manter uma estrutura organizacional de conhecimento (objetivo 7.7). Por último, os objetivos G, H e I são abordados dentro do objetivo de definir e manter uma estratégia de GC (objetivo 7.1).

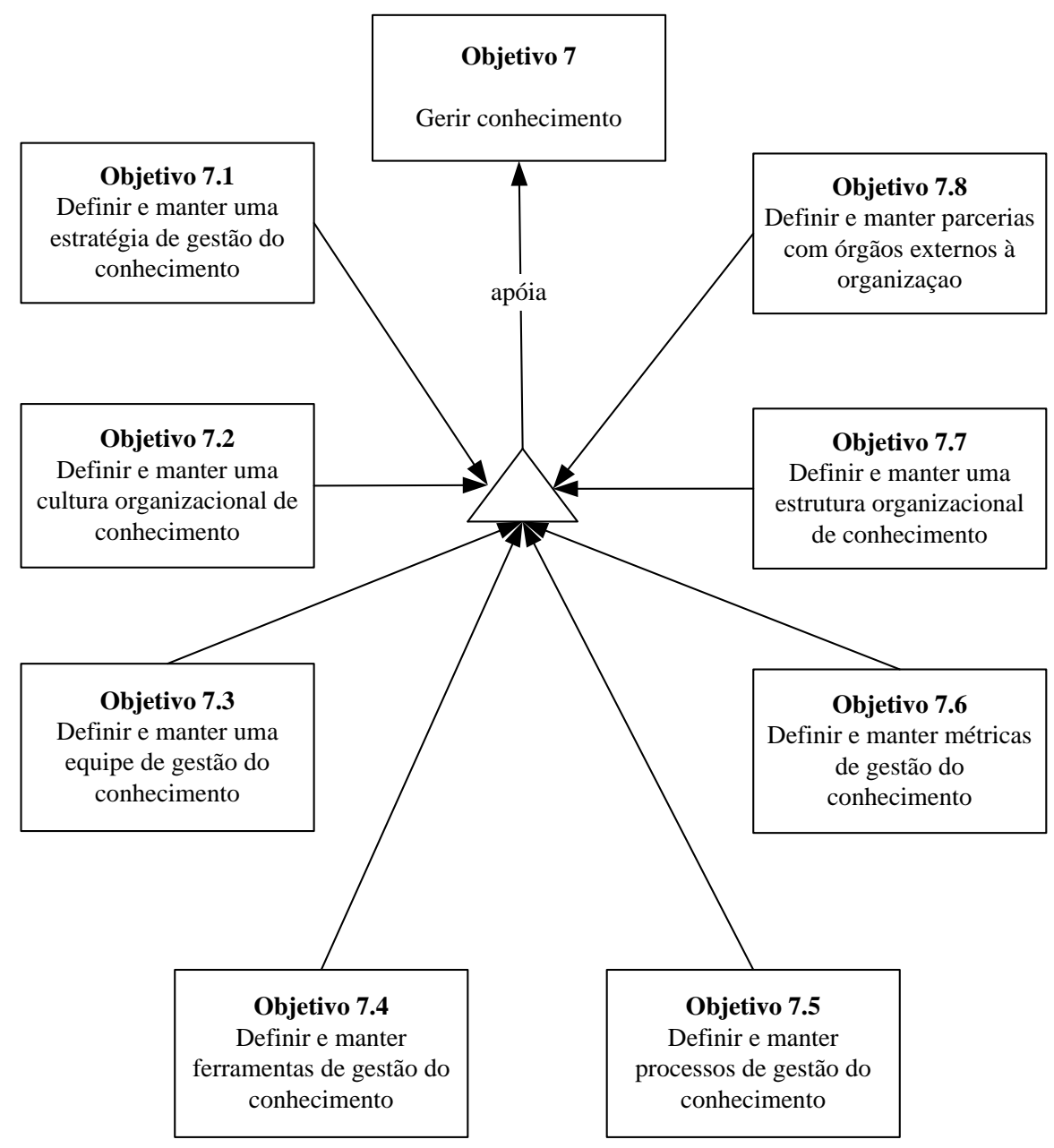

Figura 32 - Objetivo Gerir Conhecimento e os sub-objetivos para atingi-lo - versão aprimorada 
O objetivo B, estabelecer parcerias concretas, alinhado com o objetivo 5 do modelo, que surge também da proposta dos especialistas, é inserido como sub-objetivo para viabilizar a GC. Este fato é motivado pela percepção que se teve que os objetivos até agora apresentados tinham um foco direcionado a aspectos internos da organização, negligenciando elementos externos a ela; desta forma, incorporou-se no modelo o objetivo 7.8, definir e manter parcerias com organizações (Figura 32). Entende-se por este objetivo que a organização precisa estabelecer acordos de colaboração com universidades, centros de pesquisa, organizações do setor, e todo órgão externo a ela que permita aprimorar suas práticas de GC.

Já com relação ao modelo de regras, apresentado na figura 33, atrelado ao modelo de objetivos, explicita-se seis delimitadores. A regra 1, a estratégia da GC deve estar alinhada com as estratégias da organização, visa garantir que todo esforço feito pela GC seja focalizado e que realmente influencie no desempenho organizacional (HASEN; AL-HAWARI, 2003; YANG, 2008), a importância do referido alinhamento foi evidenciado por Choi et al (2008), Ekionea e Swain (2008), Hansen et al. (1999), Vera (2001), Wu e Lin (2009) e Zack (1999).

A regra 2, deve-se considerar o inter-relacionamento da cultura organizacional com a gestão do conhecimento, objetiva a superação do questionamento sobre se a cultura organizacional deve-se mudar antes da implantação da GC, ou se a GC deve-se encaixar na atual cultura da organização, para uma mudança individual que origine posteriormente uma mudança organizacional (LIEBOWITZ, 2008). Desta forma, a regra explicita uma terceira visão que sustenta que a cultura organizacional não é um fator estranho ao conhecimento organizacional, mas constitui parte desse conhecimento; e que a cultura organizacional e a GC compartilham ingredientes comuns, o que quer dizer que gerir o conhecimento implica gerir a cultura organizacional (ZHENG, 2005).

A regra 3, deve-se abordar a cultura organizacional de forma integrada, surge da crítica feita aqueles trabalhos que realizam estudos fragmentados sobre a relação entre a cultura organizacional e a GC, dando como resultados listas longas de elementos culturais que dificultam uma visão integrada que permita a análise critica e avaliação dessa relação. Sendo assim, o modelo propõe, por meio do objetivo 7.2, a referida abordagem integrada, sustentada no trabalho de Zheng (2009), já apresentado anteriormente nesta seção. 
A regra 4 visa a integração das atividades da equipe da $\mathrm{GC}$ com as atividades organizacionais, segundo Burstein et al. (2010), as responsabilidades técnicas e organizacionais devem estar interconectadas e devem ser planejadas tendo um alinhamento com os outros departamentos organizacionais que lidam com fontes de informação e conhecimento.

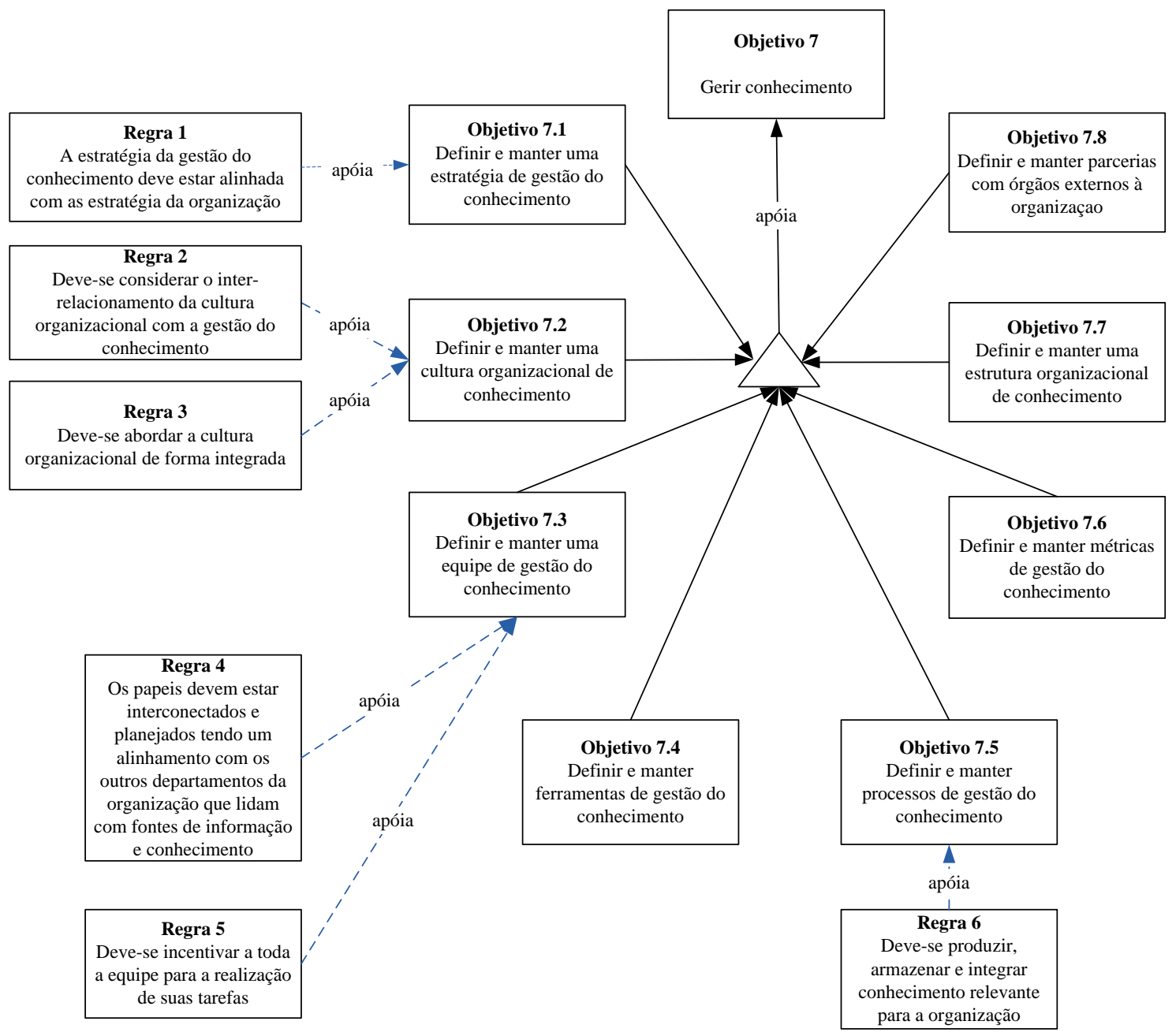

Figura 33 - Modelo Regras atrelado ao Modelo de Objetivos

A regra 5, deve-se incentivar a toda a equipe para a realização de suas tarefas, também considerada como um objetivo principal da GC por alguns especialistas, visa a criação de um sistema de recompensas e incentivos para motivar à equipe da GC no desenvolvimento de suas atividades. A importância do referido sistema foi evidenciado por Burstein et al. (2010), Earl (2001) e Lam (2005).

Por último, a regra 6, deve-se produzir, armazenar e integrar conhecimento relevante para a organização, esclarece que não todo tipo de conhecimento gerado ou adquirido pelos funcionários será útil, sendo conhecimento relevante aquele que ajuda no 
aprimoramento, na tomada de decisão e na inovação organizacional. Esta regra explicita a importância da focalização dos esforços dos funcionários para aquelas tarefas que realmente ajudem na consecução dos objetivos organizacionais.

Os especialistas propuseram como regras adicionais: A) estabelecer valores de longo prazo; B) as ferramentas da GC devem estar intrinsecamente relacionadas com suas atividades; C) As métricas podem ser quantitativas ou qualitativas; D) a manutenção das métricas deve representar um processo de aprendizagem organizacional; E) Deve-se realizar um diagnóstico para a implantação da GC; F) deve-se valorizar a contribuição da GC para a atividade de inovação da empresa; e G) deve-se incentivar institucionalmente o compartilhamento de conhecimento.

As regras A, F e $\mathrm{G}$ são consideradas parte do objetivo 7.2, definir uma cultura organizacional de conhecimento, entendendo que a cultura pode ser desenvolvida em três níveis: nível de artefato, nível de valores e nível de pressupostos (SCHEIN, 1992), e que um dos principais objetivos da cultura organizacional de conhecimento é evidenciar a importância da GC para o sucesso organizacional (LIEBOWITZ, 2008). A regra C é uma característica do objetivo 7.6, definir e manter métricas de GC, já apresentado anteriormente; e a regra $\mathrm{D}$, que denota a aprendizagem organizacional, é considerada não só uma qualidade inerente à manutenção das métricas, mas a todo processo da GC, por estar incorporado na sua ideologia. Por último, a regra $\mathrm{E}$ faz parte do objetivo 7.1, sendo que a estratégia da GC abrange a análise da necessidade da GC por parte da organização em base a sua atual situação, assim como a capacidade que ela tem para adotá-la (EARL, 2001).

A regra $\mathrm{B}$, as ferramentas da GC devem estar intrinsecamente relacionadas com suas atividades, é considerada relevante e merece sua explicitação no modelo, regra 7 (Figura 34). Ela garante que toda metodologia, técnica e tecnologia de informação criada ou incorporada à organização seja realmente útil para o desenvolvimento de suas atividades. Não seria produtivo contar com um sistema de GC de milhões de dólares se ele não vai ser explorado pelos usuários, tornando-se um "elefante branco" para o negócio; ou ter sistemas de comunicação internos, como redes sociais, portais corporativos, programas de mensagem instantânea, se eles serão usados para fins diferentes ao relacionados com a GC. 
Com relação aos problemas relacionados aos objetivos para viabilizar a GC, considerase como o principal as barreiras culturais individuais e organizacionais para a GC (probema 1). Estas barreiras compreendem aspectos como a hiper competitividade entre os funcionários, preocupação dos funcionários sobre a segurança do trabalho e sua desvalorização, estigma associado com a dependência das idéias de alguma outra pessoa, dúvidas sobre a qualidade do conhecimento compartilhado por funcionários menos experientes, o individualismo extremo, a falta do sentido de cooperação e coesão, o egoísmo, a apropriação do conhecimento, a desconfiança, uma postura de crítica destrutiva, falta de espírito empreendedor etc. (LAM, 2005).

Os especialistas ao serem questionados por problemas adicionais indicaram: A) desaprendizado das regras; B) perda de pessoas; C) métricas inadequadas ou não evolutivas; E) excesso de informação; F) falta de comprometimento do nível estratégico; G) Rotatividade na equipe de GC; H) Desatualização das ferramentas de GC utilizadas na organização; I) falta de previsão do "tempo" necessário para a mudança cultural; J) modelo cognitivo do gestor/lider; K) pouca flexibilidade; L) dificuldade de aprender com o ambiente externo; $M$ ) tendência ao discurso sobre GC e pouca ação prática efetiva; N) a comunicação organizacional para a sensibilização e o esclarecimento sobre a política de GC que está sendo estabelecida; O) os responsáveis pela formulação da estratégia empresarial são muitas vezes pouco sensíveis aos desafios envolvendo a criação, o compartilhamento e o registro do conhecimento; e P) linguagens distintas utilizadas por diferentes grupamentos de cargos

A implantação e o desenvolvimento da GC deparam-se com muitos problemas de diferente índole, e isso se reflete nos comentários dos especialistas, mas se precisa ressaltar a natureza de modelo que a proposta deste trabalho tem, em que só aqueles elementos mais importantes e críticos merecem ser explicitados evitando uma eventual a hiper-complexidade.

Sendo assim, foram inseridos como problemas adicionais (Figura 35): 1) a falta de comprometimento do nível estratégico da organização com as atividades de GC (problema 2), problema explicitado por Chong e Choi (2005), Davenport (1998), Greiner et al. (2007), Liebowitz (1999), Wong (2005), Yeah et al. (2006), atores que sustentam que a direção estratégica da organização deve determinar a direção das atividades da GC, e que a GC precisa de um patrocinador, representante da alta direção 
para que advogue por ela e crie seu interesse e necessidade; 2) a tendência ao discurso sobre GC e pouca ação prática efetiva (problema 3), caracterizado pelo fato de se ter uma implantação política da GC, com uma perspectiva do processo burocrático, da negociaçãobarganha e da implantação simbólica (DUFOUR; STEANE, 2007); 3) a alta rotatividade dos membros da equipe da GC e a perda de pessoas (problema 4), implicando por um lado uma falta de seriedade sobre as práticas da GC, e por outro lado, o grande problema que enfrentam as organizações de não saber reter os talentos ou não saber reconhecê-los, sendo um dos principais objetivos da $\mathrm{GC}$, evitar a perda de conhecimento (ARORA, 2002); e 4) as linguagens distintas utilizadas por diferentes agrupamentos de cargos (problema 5), explicitando por meio deste problema a questão de que gerentes compartilham conhecimento com gerentes, mas não entendem a linguagem dos técnicos de informática; vendedores compartilham conhecimento com vendedores, mas não entendem a linguagem dos gerentes, dificultando a interação entre os membros da equipe de GC (CARTY; WALSH, 2007; TAKEUCHI, 2001).

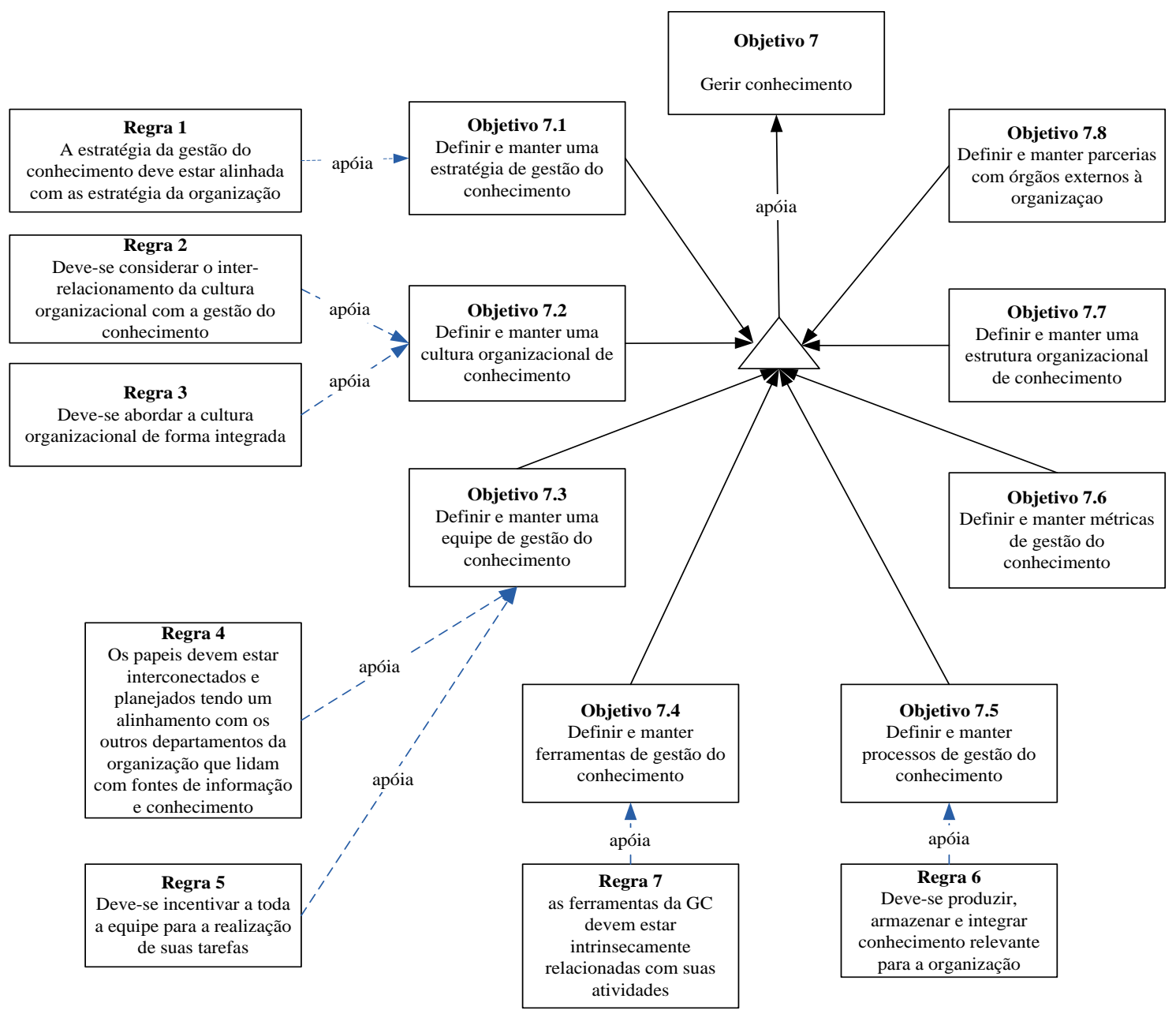

Figura 34 - Modelo de Regras atrelado ao Modelo de Objetivos - versão aprimorada 
Dos problemas sugeridos pelos especialistas, os problemas $\mathrm{A}, \mathrm{C}$ e $\mathrm{H}$ não são considerados, já que se parte do princípio de que o objetivo tem uma condição ideal e a apresentação de sentenças que o contrariam não traz conhecimento relevante.

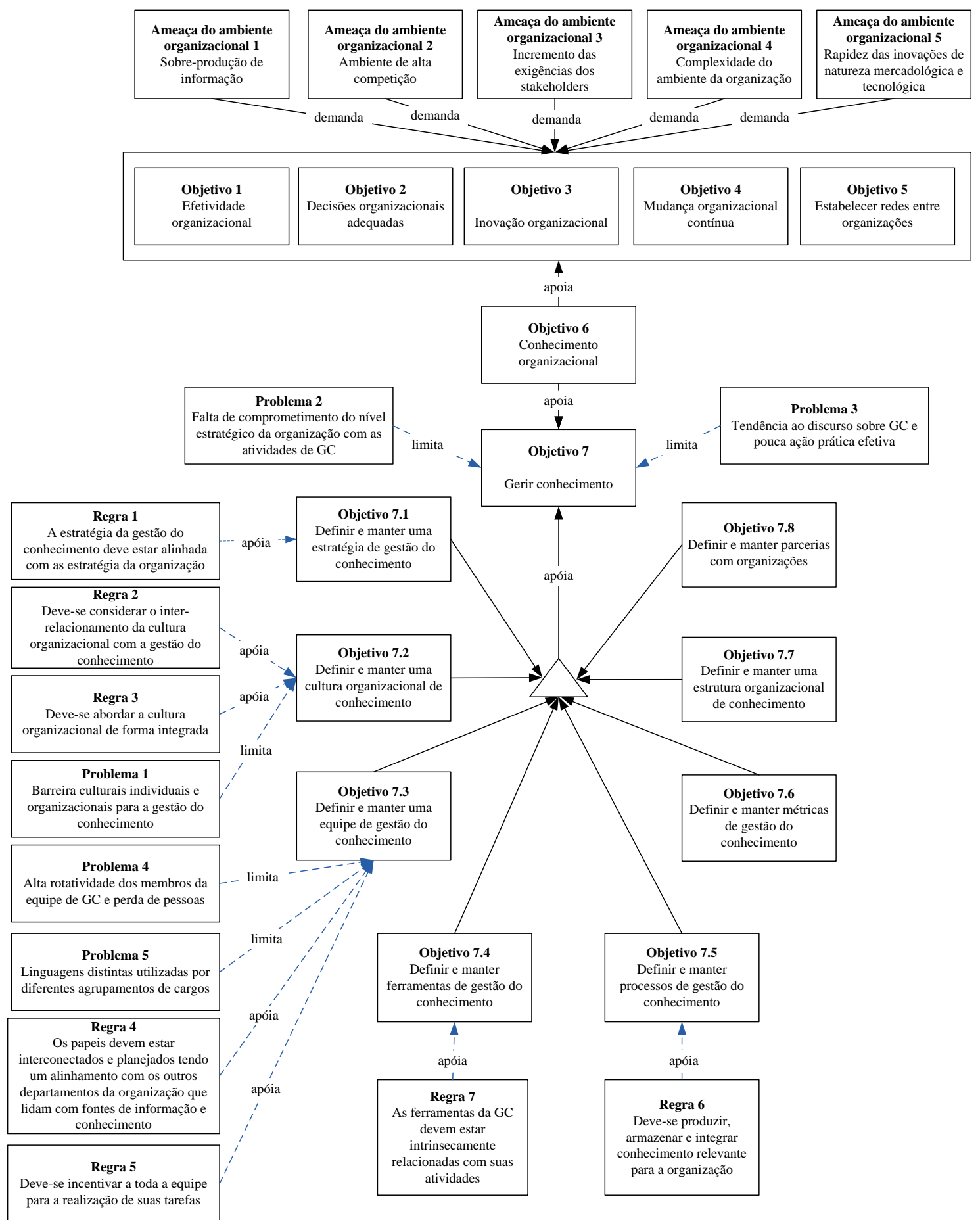

Figura 35 - Modelo de objetivos e Modelo de Regras para a implantação e desenvolvimento da gestão do conhecimento.

Quer dizer que, se o objetivo é definir e manter métricas de GC, o problema de ter métricas inadequadas ou não evolutivas não é considerado relevante, já que contradiz diretamente o objetivo. O problema E foi contemplado como a ameaça do ambiente 
organizacional 1, exposta anteriormente. O Problema I, de forma antônima, é considerado elemento que faz parte do objetivo 7.2. O problema $\mathrm{J}$ é considerado parte do problema 1. Os problemas K e L, em sentido oposto, são considerados características dos objetivos 7.7 e 7.8 respectivamente. Finalmente o problema N é considerado elemento que faz parte do objetivo 7.1.

Tendo-se apresentado todos os elementos do Modelo de Objetivos e do Modelo de Regras, e se analisado as respostas e sugestões dos especialistas, chega-se a sua versão aprimorada, apresentada na figura 35. Adicionalmente, visando um melhor entendimento do trabalho até agora apresentado, proporciona-se uma legenda que facilite sua leitura (Figura 36). Finalmente, é importante evidenciar que os relacionamentos explicitados entre os elementos do modelo não são todos os relacionamentos possíveis. Quer dizer, por exemplo, que o objetivo 2, decisões organizacionais adequadas, está estreitamente relacionado ou influencia ao objetivo 1, efetividade organizacional, mas a seta de relacionamento não é colocada na figura, principalmente para não poluí-la e ter uma melhor visão do modelo. O mesmo acontece com o objetivo 7.2, definir e manter uma cultura organizacional de conhecimento, e o objetivo 7.5, definir e manter processos de GC, sendo que, enquanto o conhecimento é compartilhado ele ajuda a criar uma cultura de compartilhamento, e enquanto programas para motivar a coesão, cooperação e confiança entre funcionários são desenvolvidos, eles visam incentivar uma predisposição deles para o compartilhamento.

Para concluir a descrição desta parte do trabalho, apresentam-se os comentários adicionais feitos pelos especialistas: a) o modelo está ótimo; b) o trabalho é interessante; c) parece-me um modelo bastante completo e complexo. A sua aplicação é que poderá confirmar a sua funcionalidade e viabilidade; d) os modelos se mostram consistentes; e) é difícil adicionar mais comentários a este modelo sem a sua explicação mais detalhada ou sem haver mais tempo para incorporá-lo; f) creio que será uma contribuição válida para os estudos de GC; g) acredito que o modelo é interessante, sendo necessária a sua experimentação para os ajustes necessários. Quanto à generalização, torna-se fundamental caracterizar o porte da organização e o ramo de atuação; h) pela complexidade da GC, os objetivos e regras devem ser apenas indicativos e devem ser adaptados a cada caso; e i) parabéns pelo excelente trabalho, sucesso em sua brilhante pesquisa. 
É interessante ressaltar que a validação ideal para o modelo seria sua aplicação em organizações de diferente natureza, sendo este objetivo difícil de ser atingido, pelo tempo que isso demandaria (três, cinco ou até dez anos). Também é relevante resgatar a generalização dos elementos, tendo que ser customizados, dependendo da realidade e perfil da organização.

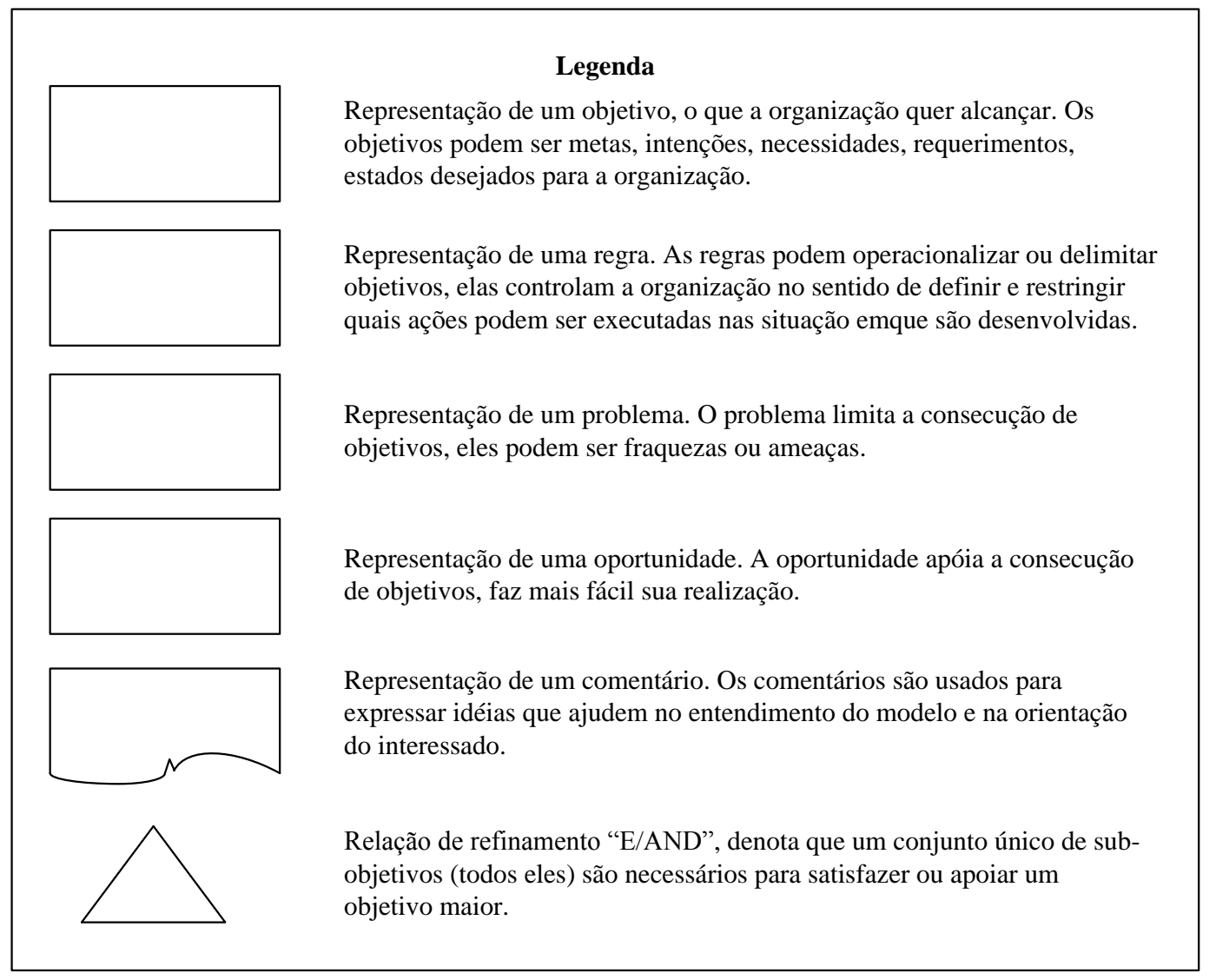

Figura 36 - Legenda do Modelo de Objetivos e Modelo de Regras

\subsubsection{Modelo de conceitos}

O modelo de conceitos apresenta e relaciona os principais termos usados nos outros sub-modelos, tendo como principal objetivo defini-los, para evitar mal entendidos no momento da leitura do modelo por participantes e stakeholders. Desta forma, são definidos os seguintes conceitos e apresentados graficamente na Figura 37:

- Ambiente externo (conceito 14): Refere-se ao ambiente geral, comum a todas as organizações (condições tecnológicas, legais, políticas, econômicas, demográficas, ecológicas e culturais) e ao ambiente de tarefa, ambiente mais próximo e imediato de cada organização (fornecedores, clientes, concorrentes e entidades reguladoras); 
com relação aos responsáveis da gestão do conhecimento, o ambiente externo também abrange o mercado laboral.

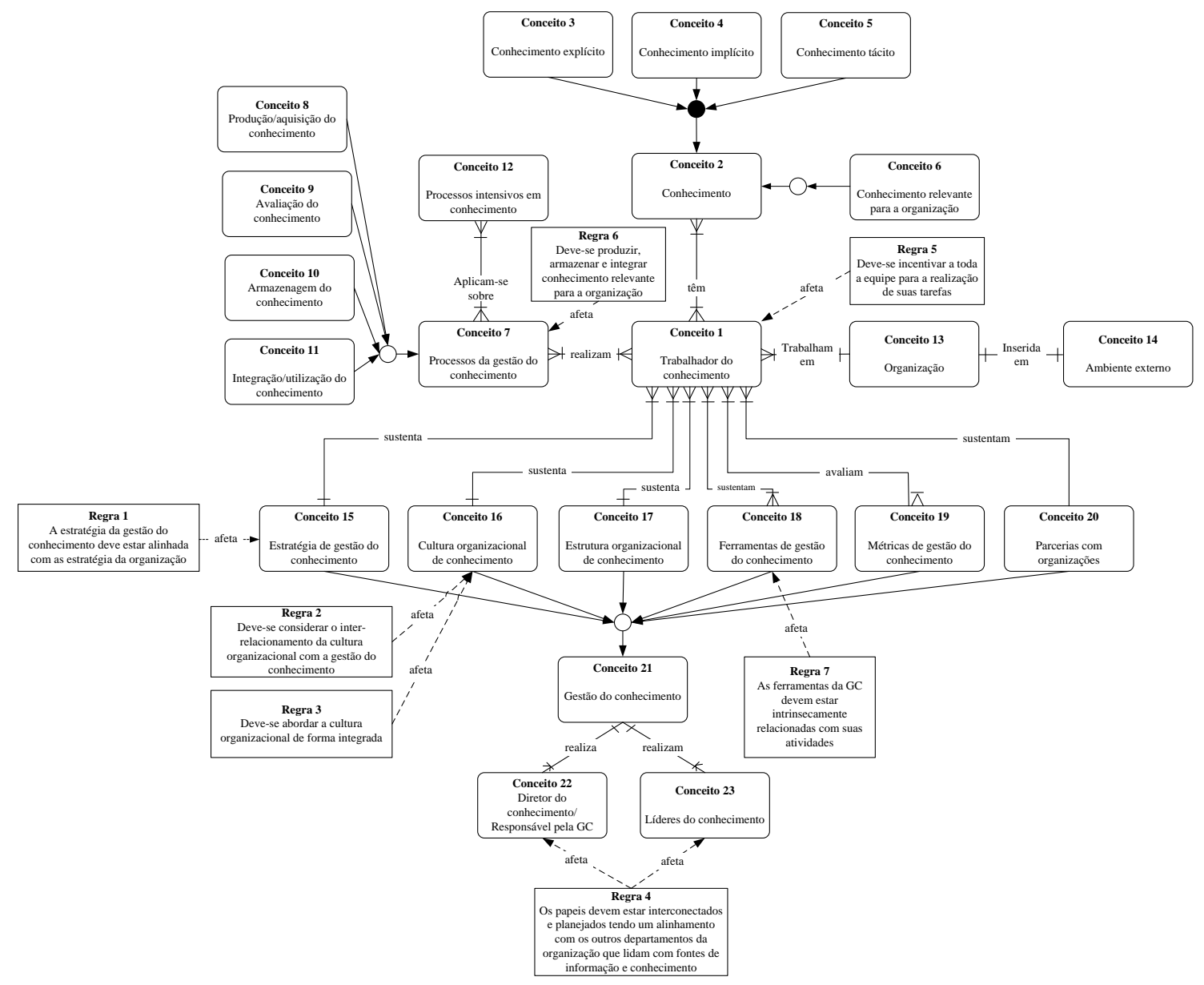

Figura 37 - Modelo de conceitos para a implantação e desenvolvimento da Gestão do Conhecimento

- Armazenagem do conhecimento (conceito 10): É a fase em que as declarações do conhecimento são armazenadas ma mídia e nos sistemas de informação. As crenças e as predisposições das crenças são armazenadas nas mentes dos agentes. Por meio da base do conhecimento organizacional as crenças e as declarações do conhecimento são acessíveis em diferentes graus pelos indivíduos, no processo de tomada de decisão, dentro do ambiente dos processos do negócio e do ambiente dos processos do conhecimento, gerando ciclos contínuos (FIRESTONE; McELROY, 2005; McELROY, 2000).

- Avaliação do conhecimento (conceito 9): Nesta fase, as declarações de conhecimento individual ou de grupo são analisadas, discutidas, modificadas e refinadas. Desta forma novo conhecimento é formado (FIRESTONE; McELROY, 2005; McELROY, 2000). 
- Conhecimento explícito (conceito 3): Conhecimento articulado, pode ser expresso em letras, números, e compartilhado na forma de dados, fórmulas científicas, manuais etc. (NONAKA; TAKEUCHI, 1995).

- Conhecimento implícito (conceito 4): Conhecimento que pode ser articulado, mas que ainda não foi (NICKOLS, 2000).

- Conhecimento relevante para a organização (conceito 6): Conhecimento que ajuda no aprimoramento, na tomada de decisão, na inovação e na mudança organizacional, assim como no estabelecimento de redes de colaboração. Não todo conhecimento aprendido pelos colaboradores é relevante para a organização.

- Conhecimento tácito (conceito 5): Conhecimento que não pode ser articulado em um determinado momento, inclui percepções subjetivas, intuições e palpites, é altamente pessoal. Ele está profundamente enraizado nas ações e experiências do indivíduo, bem como nas suas idéias, valores e emoções (NICKOLS, 2000; POLANYI, 1966).

- Conhecimento (conceito 2): Informação que passou por testes e validações somada ao contexto, compromissos e interpretações, que o indivíduo justificadamente acredita que são verdadeiros (domínio objetivo); e crenças sobre o mundo, o belo e o justo, que o indivíduo acredita que são verdadeiros (domínio subjetivo) (FIRESTONE; McELROY, 2003; ZINS, 2007).

- Diretor do conhecimento (conceito 22): Executivo de alto nível cuja responsabilidade é impulsionar a GC dentro da organização, geralmente ao liderar um programa da GC (BRUSTEIN et al. 2003; OXBROW, 2004)

- Gestão do conhecimento (conceito 21): Atividade de gestão (planejar, organizar, coordenar, dirigir, controlar, avaliar) de pessoas, estrutura, processos, ferramentas e demais componentes organizacionais, com o objetivo de agregar valor para a organização por meio da produção/aquisição, avaliação, armazenagem e integração/utilização do conhecimento (processo da gestão do conhecimento) (DALKIR, 2005; McELROY, 2003).

- Integração/utilização do conhecimento (conceito 11): É a fase em que a comunidade adota o novo conhecimento e o põe em pratica. O novo conhecimento é propagado na organização, seja de forma espontânea (compartilhamento) ou planejada (treinamento, pesquisa, difusão) (FIRESTONE; McELROY, 2005; McELROY, 2000). 
As crenças e declarações do conhecimento quando aplicadas nos processos do negócio geram dois tipos de aprendizagem: aprendizagem de circuito simples, quando um erro é detectado e corrigido sem questionar ou alterar as crenças ou declarações do conhecimento envolvidos no sistema; e aprendizagem de circuito duplo, quando uma desconformidade é corrigida examinando e alterando as crenças e declarações do conhecimento (ARGIRYS; SCHON, 1978; FIRESTONE; McELROY, 2005; McELROY, 2000).

- Líderes do conhecimento (conceito 23): Gerentes de nível médio, mediadores entre "o que se busca ser" a mentalidade da alta gerência e "o que é realmente" a mentalidade dos funcionários do chão de fábrica. Eles sustentam as unidades de negócio e as comunidades de conhecimento. Eles podem ser sintetizadores do conhecimento, trabalhadores de TI, editores de conteúdo, desenvolvedores de Web, publicadores eletrônicos, gerentes de Intranet, treinadores, facilitadores, mentores e todo tipo de colaborador das atividades da GC (ABELL; OXBROW, 1999; CARTY; WALSH, 2007; DALKIR, 2005; TAKEUCHI, 2001).

- Organização (conceito 13): Combinação de esforços individuais que tem por finalidade realizar propósitos coletivos. Conjunto de pessoas, maquinas e outros equipamentos, recursos financeiros e outros orientadosparaa um objetivo comum. Ela abrange a cultura e estrutura, assim como o perfil dos seus colaboradores.

- Processos da gestão do conhecimento (conceito 7): Refere-se ao ciclo de vida do conhecimento, geralmente compreende a produção/aquisição, avaliação, armazenagem e integração/aplicação do conhecimento (FIRESTONE; McELROY, 2005; McELROY, 2000).

- Processos intensivos em conhecimento (conceito 12): Processos organizacionais que criam ou trabalham com conhecimento.

- Produção/aquisição do conhecimento (conceito 8): Tendo como fundamento que todo conhecimento inicia-se na mente do indivíduo, esta fase compreende a aprendizagem individual, a aquisição de informação e a declaração de conhecimento (FIRESTONE; McELROY, 2005; McELROY, 2000).

- Trabalhador do conhecimento (conceito 1): Indivíduo que trabalha primordialmente com informação, ou que desenvolve ou usa o conhecimento para realizar sua função (DAVENPORT, 2002; DRUCKER, 1993; HORVATH, 2001; RAMÍREZ; NEMHARD, 2004). 
Os conceitos 15, estratégia de gestão do conhecimento; 16, cultura organizacional do conhecimento; 17, estrutura organizacional de conhecimento; 18, ferramentas de GC; 19, métricas de GC e; 20, parcerias com organizações, não são descritos no modelo de conceitos para evitar redundância, já que foram expostos amplamente no modelo de objetivos, apresentado no item anterior.

As perguntas do instrumento de pesquisa desta parte do trabalho focalizaram-se sobre os aspectos mais polêmicos da literatura, sendo eles: a) a classificação ou taxonomia do conhecimento utilizada; b) o fato de aceitar que é o trabalhador do conhecimento quem realiza o processo do conhecimento e não o diretor nem os líderes do conhecimento; e c) o fato de aceitar que a GC atua sobre as variáveis independentes da organização e não diretamente no trabalhador do conhecimento, considerada variável dependente.

Com relação ao primeiro questionamento, existe na literatura um grande debate sobre a classificação do conhecimento, variadas propostas de taxonomia, fundamentadas em diferentes perspectivas (AGUAYO, 2004; BLACKLER, 1995; BOISOT, 1998; FIRESTONE; MCELROY, 2003; FRAPPAOLO, 2008; GRAYSON, 1998; LEE et al., 2006; LINDE, 2001; LUNDVALL; JOHNSON, 1994; MACHLUP, 1961; MOORRADIAN, 2005; MORKY, 2003; NICKOLS, 2000; NONAKA, 1994; NONAKA; KROGH, 2009; NONAKA; TAKEUCHI, 1995; POLANYI, 1966; PRICE, 1963; SCHINDLER, 2002; SCHWALBE, 2005; SPENDER, 2003; TAKEUCHI, 2001; TEECE, 1998; WIIG, 1999; ZACK, 1999). Após uma análise desses trabalhos escolheu-se como base teórica para modelo proposto, a classificação em que o conhecimento pode ter explícito, implícito ou tácito (NICKOLS, 2000; NONAKA; TAKEUCHI, 1995; POLANYI, 1966).

A classificação proposta está relacionada à taxonomia proposta por Firestone e McElroy (2000), catalogando o conhecimento do mundo 3 como conhecimento explícito, e o conhecimento do mundo 1 e 2 como conhecimento não-explícito. Sendo assim, o conhecimento biológico (conhecimento do mundo 1) e o conhecimento mental (conhecimento do mundo 2) são considerados conhecimentos não-explícitos, que podem ser implícitos ou tácitos, é dizer, passiveis de serem explicitados ou não, em um determinado momento; e o conhecimento cultural (conhecimento do mundo 3) é considerado conhecimento explícito. 
Os especialistas ao serem questionados sobre seus pareceres com este enunciado explicitaram os resultados apresentados na figura 38.

É evidente a dispersão das respostas, embora se tenha $47 \%$ de aceitação da classificação proposta, é alta a porcentagem que discorda ou está indeciso sobre ela. Esta característica reflete a falta de consenso da literatura, mas é considerada positiva por permitir o desenvolvimento de novas pesquisas.

\begin{tabular}{|c|c|c|c|}
\hline Escala Likert & Resultados & $\begin{array}{c}\% \text { das } \\
\text { respostas }\end{array}$ & $\begin{array}{l}\text { Número de } \\
\text { respostas }\end{array}$ \\
\hline Fortemente em desacordo & 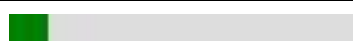 & $5.26 \%$ & 1 \\
\hline Desacordo & 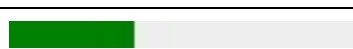 & $15.79 \%$ & 3 \\
\hline Indeciso & 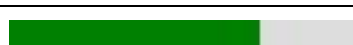 & $31.58 \%$ & 6 \\
\hline De acordo & $\bar{u}$ & $21.05 \%$ & 4 \\
\hline Fortemente de acordo & & $26.32 \%$ & 5 \\
\hline \multicolumn{3}{|c|}{ Respostas totais } & 19 \\
\hline
\end{tabular}

Figura 38 - Parecer sobre a classificação do conhecimento proposta

Comentários adicionais referente a este aspecto indicam que talvez seja pouco relevante ter a classificação dos três tipos de conhecimento, e se sugere adotar a classificação clássica em que o conhecimento pode ser explícito ou tácito, por permitir a compreensão e a ação sobre o tipo do conhecimento mais direta e óbvia.

Sobre este assunto, considerar a existência do conhecimento implícito e do conhecimento tácito é importante por que influencia na perspectiva de tratamento da GC; aceitar que há um tipo de conhecimento que em um determinado momento não pode ser explicitado (conhecimento tácito), faz pensar no desenvolvimento de novas estratégias de compartilhamento e abordagem do conhecimento, como cursos de treinamento em mapas mentais, discursos, uso de metáforas, uso de casos, mentoring etc. Adicionalmente, rejeita-se a classificação feita por Nonaka e Takeuchi (1995) por considerá-la simplista e generalista, ao pensar que um termo tão complexo como é o conhecimento pode ter uma classificação de só dois itens, mostrando que a referida simplificação pode prejudicar as futuras ações e estratégias da GC, tornando-as também generalistas, questão difícil de aceitar quando o centro do negócio são as pessoas.

Também foi sugerido que o conhecimento tácito seja tratado de "tácito intrínseco", e o conhecimento implícito como "tácito extrínseco", já que o termo implícito ainda assemelha a idéia de algo que o mantém tácito, pudendo gerar confusão entre os participantes. 
Por último, foi recomendado pesquisar os estudos de Chai (2000), sobre conhecimento local, e os estudos de Granger (1989), sobre conhecimento sensível. Sendo que cada um desses conhecimentos influenciam respectivamente, na percepção de oportunidade de aplicação e nos modelos de aprendizagem. A referida pesquisa será indicada para trabalhos futuros por que permitirá ampliar e aprofundar o referencial teórico desta parte do estudo, e por que na proposta atual não contradiz o já apresentado.

Com relação ao fato de aceitar que é o trabalhador do conhecimento quem realiza o processo do conhecimento e não o diretor nem os líderes do conhecimento, os especialistas explicitaram as respostas apresentadas na figura 39.

\begin{tabular}{|l|l|c|c|}
\hline \multicolumn{1}{|c|}{ Escala Likert } & Resultados & $\begin{array}{c}\text { \% das } \\
\text { respostas }\end{array}$ & $\begin{array}{c}\text { Número de } \\
\text { respostas }\end{array}$ \\
\hline $\begin{array}{l}\text { Fortemente em } \\
\text { desacordo }\end{array}$ & & $21.05 \%$ & 4 \\
\hline Desacordo & & $26.32 \%$ & 5 \\
\hline Indeciso & & $10.53 \%$ & 2 \\
\hline De acordo & & $21.05 \%$ & 4 \\
\hline Fortemente de acordo & & $21.05 \%$ & 4 \\
\hline \multicolumn{2}{r|r|}{ Respostas totais } & $\mathbf{1 9}$ \\
\hline
\end{tabular}

Figura 39 - Parecer sobre o responsável pelo desenvolvimento do processo do conhecimento

De novo apresenta-se uma dispersão nas respostas, desta vez com $47.37 \%$ de pareceres em contra do enunciado. Os comentários dos especialistas sobre esta tendência sustentam que é difícil separar o trabalhador do conhecimento, dos líderes ou do diretor do conhecimento, que também seriam considerados como trabalhadores do conhecimento, e que a definição ou atribuição de papeis, por vezes, pode criar exclusões práticas prejudicais aos processos de GC. Sendo assim, é toda a equipe de GC quem realiza os processos da gestão do conhecimento.

O fato de enfatizar que o trabalhador do conhecimento é responsável pelos processos da GC não foi direcionado para uma exclusão dos outros membros da equipe (líderes e diretor do conhecimento), mas no intuito de superar a limitação identificada na literatura (DIAO; YU; LIANG, 2006; LU; YANG, 2007; ZHENG; BAO; QIAN, 2009), que aponta uma falta de interesse dos funcionários do chão de fábrica para com as atividades de GC, acreditando que é o diretor ou os líderes do conhecimento os únicos responsáveis pelos referidos processos, e que os trabalhadores são simplesmente os usuários do conhecimento, eles não criam, buscam, avaliam, nem disseminam ou compartilham conhecimento. 
Por último, o fato de aceitar que a GC atua sobre as variáveis independentes da organização e não diretamente no trabalhador do conhecimento, considerada variável dependente, foi catalogado pelos especialistas como mostra a figura 40.

\begin{tabular}{|l|l|c|c|}
\hline \multicolumn{1}{|c|}{ Escala Likert } & Resultados & $\begin{array}{c}\text { \% das } \\
\text { respostas }\end{array}$ & $\begin{array}{c}\text { Número de } \\
\text { respostas }\end{array}$ \\
\hline $\begin{array}{l}\text { Fortemente em } \\
\text { desacordo }\end{array}$ & & $10.53 \%$ & 2 \\
\hline Desacordo & & $5.26 \%$ & 1 \\
\hline Indeciso & & $42.11 \%$ & 8 \\
\hline De acordo & & $26.32 \%$ & 5 \\
\hline Fortemente de acordo & & $15.79 \%$ & 3 \\
\hline \multicolumn{2}{|c|}{ Respostas totais } & $\mathbf{1 9}$ \\
\hline
\end{tabular}

Figura 40 - Parecer sobre a ação direta da GC sobre o trabalhador do conhecimento

Embora se tenha uma aceitação de $42.11 \%$ dos especialistas, a forte indecisão (42.11\%) poderia explicar-se devido a uma falta de consenso na literatura (DALKIR, 2005; DAVENPORT; PRUSAK, 1998; FRAPPAOLO, 2006), e uma possível incompreensão do questionamento. Considera-se no enunciado variável independente aquela que não depende do trabalhador do conhecimento, quer dizer que seu gerenciamento é em base a políticas, ferramentas, recursos e elementos em volta dele (estratégia da GC, cultura organizacional do conhecimento, estrutura organizacional do conhecimento, ferramentas de GC, métricas de GC e parcerias com organizações). Reforçando a idéia sustentada por Davenport e Prusak (1998), que a GC não realiza o gerenciamento direto do conhecimento e sim dos elementos envolta dele.

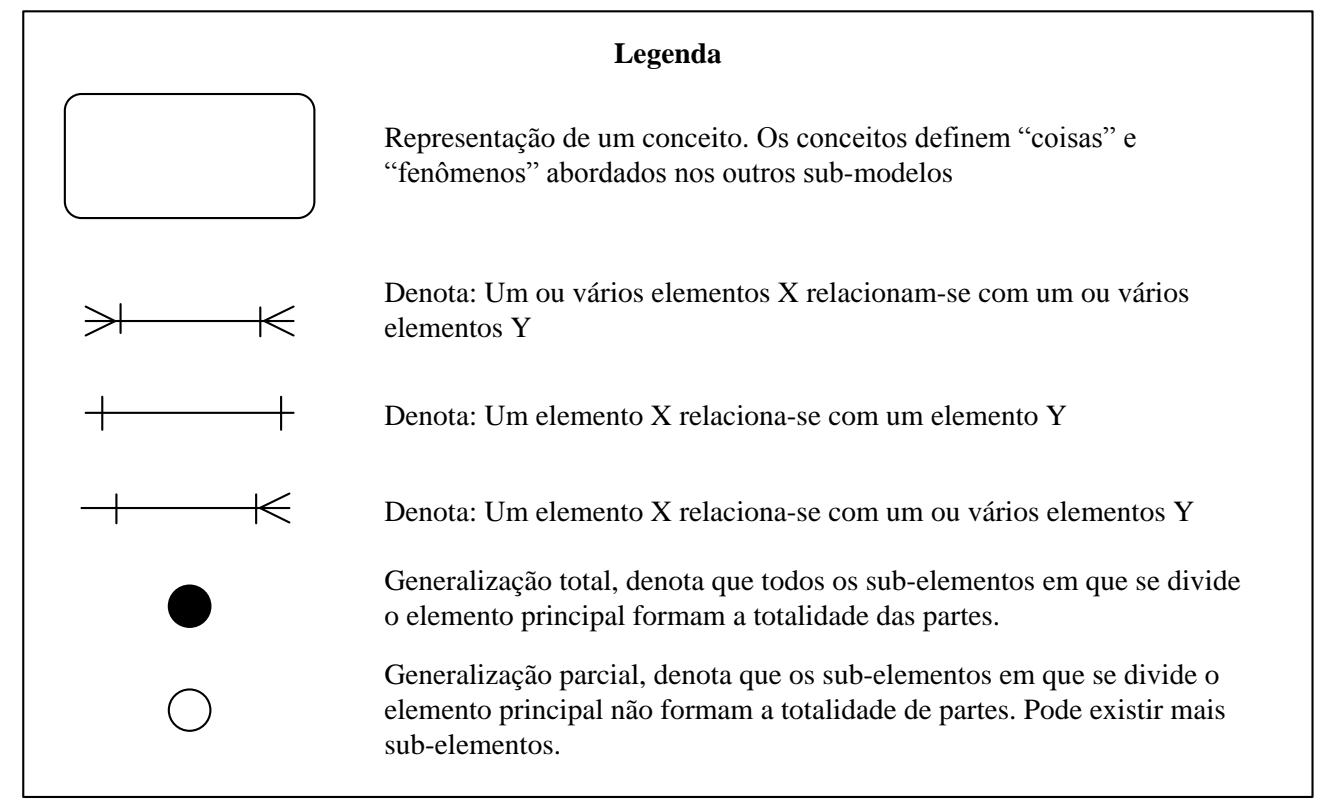

Figura 41 - Legenda do modelo de conceitos 
O modelo reforça a importância do apresentado por meio da regra 5, que sustenta a relevância do incentivo não só ao trabalhador do conhecimento, mas para toda a equipe, para a realização de suas tarefas. A equipe motivada (produto da estratégia, cultura, estrutura, ferramentas, métricas e parcerias de conhecimento) realiza o processo da GC efetivamente.

Finalmente apresenta-se na figura 41 uma legenda que visa ajudar aos participantes e aos stakeholders no melhor entendimento do modelo de conceitos.

\subsubsection{Modelo de processos}

O modelo de processos permite mostrar quais atividades e processos são reconhecidos, ou deveriam sê-lo, para a implantação e desenvolvimento da GC de acordo com seus objetivos (Figura 42).

O modelo inicia com duas fontes de informação, a organização (proc. ext. 1) e o ambiente externo (proc. ext. 2). A informação sobre a organização compreende um diagnóstico dos elementos organizacionais (estratégia do negócio, cultura, estrutura, capital intelectual, parcerias atuais, recursos disponíveis, processos e atividades diversas) relevantes para a GC. Por outro lado, a informação sobre o ambiente externo compreende um diagnóstico do ambiente organizacional (competidores, consumidores, mercado profissional, normas e regulamentos, contexto sócio-cultural etc.).

Com base nessas duas fontes de informação contrata-se (se precisar) ou determina-se o responsável (diretor do conhecimento) ou equipe responsável pela GC (processo 1). Neste caso específico, a organização fornece informação sobre seus membros, de forma que se possa escolher à pessoa mais competente para liderar o empreendimento da GC. Por outro lado, com o mesmo objetivo, é coletada informação sobre profissionais da GC e perfis que o mercado desenvolve para esta prática.

Embora a organização e o ambiente sejam fontes de informação para cada um dos processos apresentados no modelo, não são explicitados esses relacionamentos por meio de setas para não dificultar sua visualização, mas a aclaração é importante. Por exemplo, para poder desenvolver uma cultura organizacional de conhecimento (processo 5) será preciso saber qual é a atual situação cultural dos funcionários, quais valores prevalecem entre os grupos dentro da organização e a possível resposta à mudança a ser empreendida, toda essa informação é considerada parte do proc. Ext. 1 (organização). 


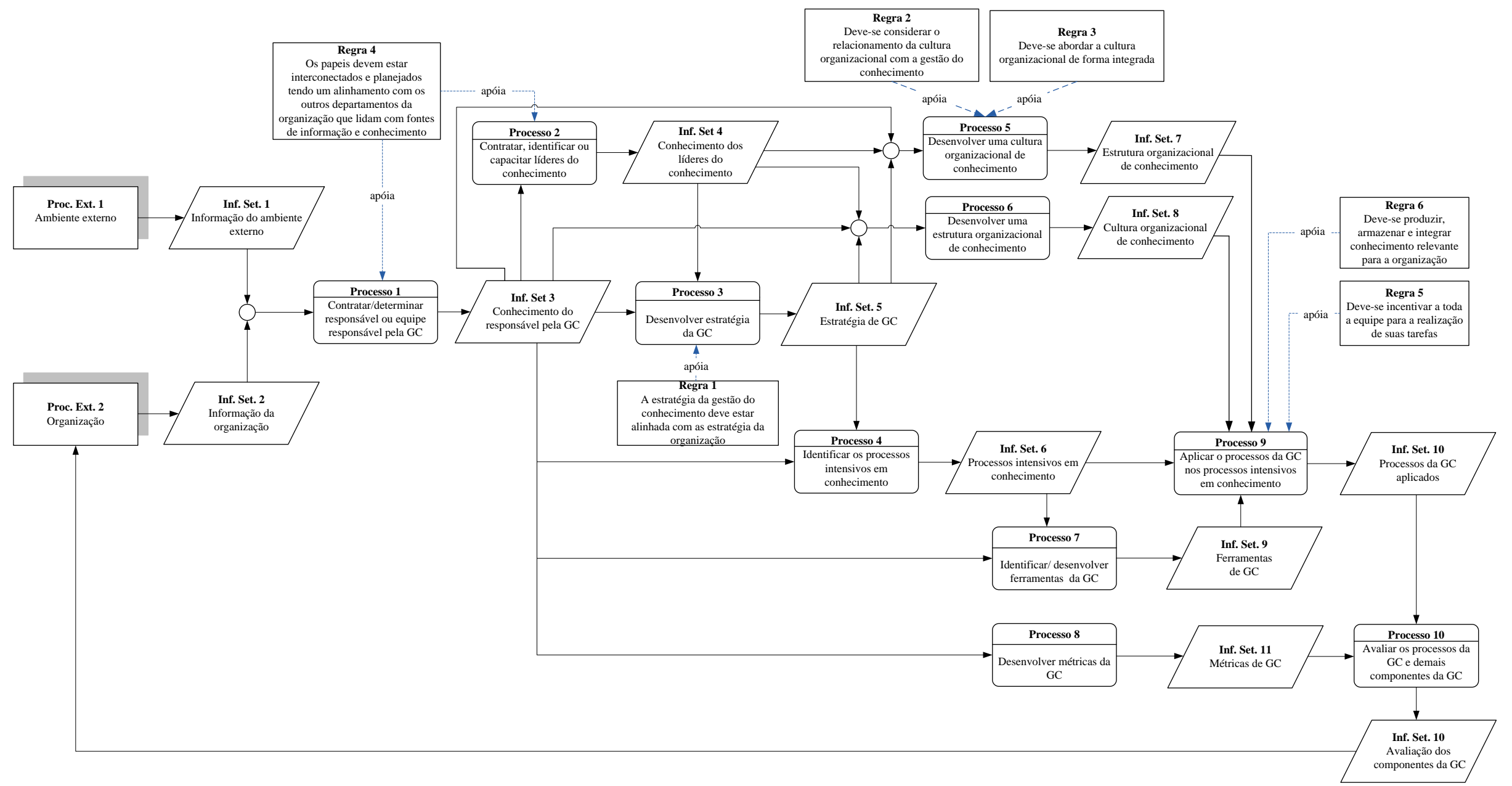

Figura 42 - Modelo de processos para a implantação e desenvolvimento da Gestão do Conhecimento 
Um segundo exemplo pode ser explicado por meio do processo 6, desenvolver parcerias com organizações; para poder cumprir com este processo precisa-se saber quais parceiras a organização já tem concretizado (informação interna) e quais parceiras poderiam ser úteis efetivar (informação externa).

Seguindo com a sequência do modelo, tendo o responsável ou equipe responsável da GC, o seguinte processo será a contração, identificação ou treinamento de líderes do conhecimento (processo 2) (líderes de opinião, moderadores de comunidades de prática, funcionários de TI, gerentes de nível médio etc.). Por exemplo, o diretor do conhecimento poderá identificar um funcionário potencial para ser líder do conhecimento na área de produção, devido a suas características pessoais e profissionais, a seguir, ele será capacitado para que desempenhe suas tarefas dentro da equipe de GC.

O diretor do conhecimento junto com seus colaboradores desenvolverão a estratégia da GC (processo 3), estabelecendo os lineamentos e ações para a implantação e desenvolvimento da GC na organização.

Com base na estratégia iniciar-se-ão ações para o desenvolvimento de uma estrutura organizacional de conhecimento (processo 4), de uma cultura organizacional de conhecimento (processo 5 ) e de parcerias com organizações. Por outro lado, identificarse-ão os processos intensivos em conhecimento (processo 7), e sobre eles serão aplicados os processos da GC (processo 9).

Para a consecução efetiva do processo 9, este se vê alimentado pelos resultados obtidos nos processos 4, 5 e 6 e pelas ferramentas de GC desenvolvidas após a análise dos processo intensivos em conhecimento pelo diretor e líderes do conhecimento (processo 8). Para o melhor entendimento desta parte do processo cita-se o seguinte exemplo: Uma empresa farmacêutica identificou como processo intensivo em conhecimento a seleção de fornecedores de determinada sustância (processo 7), o diretor, junto aos líderes de conhecimento identificaram como ferramentas úteis para cumprir com este processo um motor de busca especializado na área e disponível na internet para a localização do fornecedor e um sistema de apóio à decisão para sua seleção; também desenvolveram uma comunidade de prática para o debate constante do tópico e a avaliação dos fornecedores, e consideraram o portal corporativo o melhor meio para a difusão dos resultados (processo 8). Para fazer com que os trabalhadores do 
conhecimento, que no caso seriam os funcionários que efetivamente fazem a seleção dos fornecedores, utilizem as ferramentas identificadas ou criadas, o diretor do conhecimento junto aos líderes do conhecimento desenvolveram uma cultura que fomente o uso da tecnologia, o uso de sistemas de informação e a rejeição por decisões empíricas, assim como uma cultura de compartilhamento do conhecimento, isto pode ser feito por meio de palestras ou programas de conscientização (processo 5); eles também trabalharam na estrutura organizacional para oferecer liberdade $\mathrm{e}$ independência aos funcionários sobre a decisão a ser tomada, diminuindo a formalização e o centralismo com a alta gerência (processo 4); finalmente eles reforçam as fontes de informação e o apoio ao funcionário com parcerias com outras empresas farmacêuticas ou com universidades (processo 6). Tudo isto somado aos incentivos feitos aos trabalhadores do conhecimento (regra 5), faz que eles tenham vontade, predisposição e interesse pela aplicação dos processos da GC para a escolha do fornecedor, usando as ferramentas disponibilizadas.

Após a aplicação dos processos da GC, realiza-se a avaliação de todos os elementos do modelo (diretor, líderes, estratégia, cultura, estrutura, parcerias, processos intensivos em conhecimento, processos da GC, trabalhador do conhecimento e ferramentas) (processo 11), com base em métricas previamente desenvolvidas (processo 10). No exemplo apresentado avaliam-se as atividades do diretor e dos líderes do conhecimento, se a estratégia foi bem concebida, se os programas de conscientização foram efetivos, se realmente se logro a flexibilização do centralismo, se as parcerias feitas foram úteis, se as ferramentas disponibilizadas serviram aos trabalhadores do conhecimento, se a identificação e seleção dos processos intensivos em conhecimento realmente foram relevantes para a organização, se os processos da GC foram efetivamente realizados pelos funcionários, e se os fornecedores escolhidos realmente deram beneficio para a empresa.

Após esta avaliação, os resultados, considerações, possíveis mudanças e lições aprendidas alimentam a organização, iniciando um novo ciclo de desenvolvimento das atividades da GC que garante seu constante aprimoramento.

$\mathrm{O}$ instrumento de pesquisa visou o questionamento dos aspectos considerados mais relevantes e polêmicos do modelo: a) a sequência dos processos; b) a importância de ter uma equipe responsável pela GC; e c) a aplicação dos processos da GC delimitada só aos processos intensivos em conhecimento e não a todos os processos da organização. 
Com relação à sequência dos processos os especialistas tiveram as respostas apresentadas na figura 43 .

\begin{tabular}{|l|c|c|c|}
\hline \multicolumn{1}{|c|}{ Escala Likert } & Resultados & $\begin{array}{c}\text { \% das } \\
\text { respostas }\end{array}$ & $\begin{array}{c}\text { Número de } \\
\text { respostas }\end{array}$ \\
\hline Fortemente em desacordo & & $0.00 \%$ & 0 \\
\hline Desacordo & & $15.79 \%$ & 3 \\
\hline Indeciso & & $26.32 \%$ & 5 \\
\hline De acordo & & $47.37 \%$ & 9 \\
\hline Fortemente de acordo & & $10.53 \%$ & 2 \\
\hline
\end{tabular}

Figura 43 - Parecer dos especialistas sobre a sequência dos processos

Embora a concordância seja relativamente alta $(57,9 \%)$, a porcentagem de indecisão $(26.32 \%)$ somada à porcentagem em desacordo $(15,79)$ poderiam ser explicadas devido à alta complexidade que caracteriza aos processos de GC. Por exemplo, o processo de desenvolver uma cultura organizacional do conhecimento (processo 5), é considerado um desafio entre os especialista da área, de todos os países e em todo tipo de organizações, sendo assim, reconhece-se a relativa simplicidade em que o modelo apresenta este processo, pudendo ser detalhado até níveis operacionais, e ampliando a referida complexidade, segundo a necessidade da organização.

Com relação à importância de ter uma equipe responsável pela GC, os especialistas explicitaram os pareceres apresentados na figura 44.

\begin{tabular}{|l|c|c|c|}
\hline \multicolumn{1}{|c|}{ Escala Likert } & Resultados & $\begin{array}{c}\text { \% das } \\
\text { respostas }\end{array}$ & $\begin{array}{c}\text { Número de } \\
\text { respostas }\end{array}$ \\
\hline Fortemente em desacordo & & $0.00 \%$ & 0 \\
\hline Desacordo & & $21.05 \%$ & 4 \\
\hline Indeciso & & $5.26 \%$ & 1 \\
\hline De acordo & & $42.11 \%$ & 8 \\
\hline Fortemente de acordo & & $31.58 \%$ & 6 \\
\hline \multicolumn{2}{|c|}{ Respostas totais } & $\mathbf{1 9}$ \\
\hline
\end{tabular}

Figura 44 - Parecer dos especialistas sobre a importância de ter uma equipe responsável pela GC

O enunciado apresenta uma alta aceitação $(73,69 \%)$, mas os $21,05 \%$ em desacordo reflete ligeiramente o debate identificado na literatura. Têm-se duas visões sobre a necessidade de contar ou não com uma equipe específica para as atividades de GC; a primeira sustenta que a GC deve ser incorporada no dia a dia da organização, em que todos os funcionários, de todos os níveis, devem participar e formar parte dela, a GC deve ser uma ação natural e espontânea, visão alinhada às idéias que caracterizam o movimento da Qualidade Total; a segunda visão sustenta que devido ao fato de a GC ser 
uma forma de gestão nova e diferente às tradicionais, ela precisaria de uma equipe especializada que ajude à organização na sua adoção, por meio de capacitações e conscientização dos funcionários da importância de se desenvolver práticas de GC (BISHOP et al., 2008; HASANALI, 2002; JAFARI et al.,2007; WONG, 2005). O modelo proposto está ancorado na segunda visão, por ser um modelo de implantação de desenvolvimento da GC, mas não descarta que em níveis de alta maturidade da GC em determinadas organizações, ela possa ser espontânea e disseminada amplamente de modo que não esteja sujeita a uma equipe especializada.

Com relação ao enunciado que sustenta que a aplicação dos processos da GC é delimitada só aos processos intensivos em conhecimento e não a todos os processos da organização, os especialistas apresentaram os resultados da Figura 45.

\begin{tabular}{|l|l|c|c|}
\hline \multicolumn{1}{|c|}{ Escala Likert } & Resultados & $\begin{array}{c}\text { \% das } \\
\text { respostas }\end{array}$ & $\begin{array}{c}\text { Número de } \\
\text { respostas }\end{array}$ \\
\hline Fortemente em desacordo & & $15.79 \%$ & 3 \\
\hline Desacordo & & $31.58 \%$ & 6 \\
\hline Indeciso & & $21.05 \%$ & 4 \\
\hline De acordo & & $21.05 \%$ & 4 \\
\hline Fortemente de acordo & & $10.53 \%$ & 2 \\
\hline
\end{tabular}

Figura 45 - Parecer dos especialistas sobre a aplicação dos processos da GC sobre os processos intensivos em conhecimento

Os resultados evidenciam um desacordo de 47,37\%, uma alta indecisão de 21,05 \%, e uma relativamente baixa aceitação do enunciado de 31,58\%. Comentários dos especialistas sobre o tópico relatam que embora se dê prioridade aos processos intensivos em conhecimento, é necessário, para um nível de maturidade mais elevado, que todos os processos organizacionais sejam analisados, a médio ou longo prazo. Também é ressaltado que os executores de aqueles processos supostamente não intensivos em conhecimento poderiam se sentir excluídos, e que na verdade, a GC pode ser útil mesmo em processos não intensivos em conhecimento; os executores desses processos poderiam contribuir muito mais se tiverem ao menos uma noção dos processos da organização, independente de serem intensivos ou não em conhecimento.

Sendo assim, muda-se o modelo primário, especificamente os processos 7 e 9, adotando a visão que sustenta que os processos da GC devem ser aplicados a todos os processos organizacionais, mas priorizando os processos intensivos em conhecimento (Figura 46). 


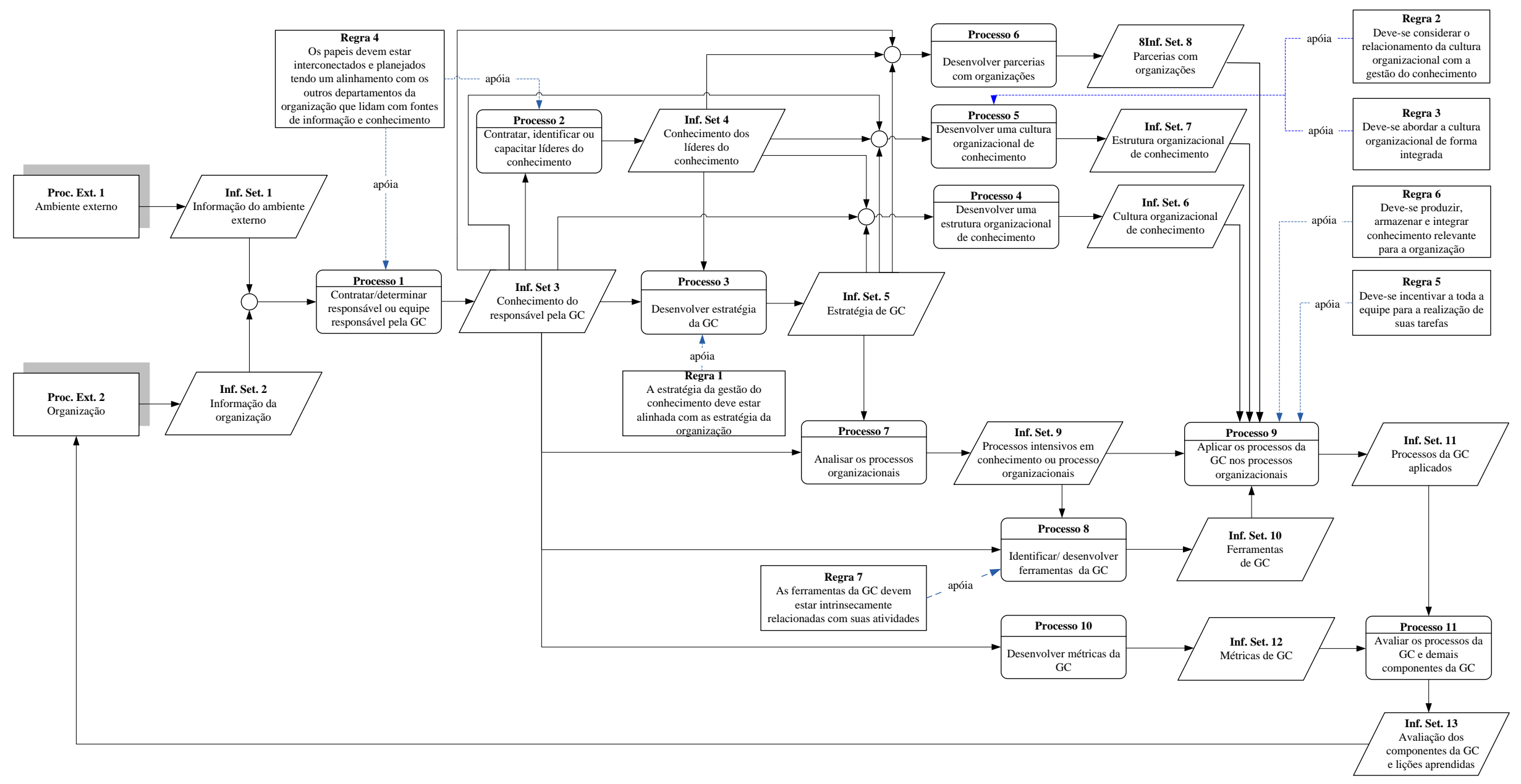

Figura 46 - Modelo de processos aprimorado para a implantação e desenvolvimento da Gestão do Conhecimento - versão aprimorada 
Um último esclarecimento é necessário, cada processo explicitado no modelo atinge um nível de maturidade determinado que é aprimorado constantemente em cada execução do ciclo; desta forma, rejeita-se situações ideais ou estáticas para os processos. Por exemplo, o desenvolvimento de uma cultura organizacional de conhecimento (processo 5) é considerado um processo muito demorado que leva anos para alcaçar um nível satisfatório, mas não é por esta razão que a aplicaçaõ dos processos da GC sobre os processos organizacionais não será realizada (processo 9); ressaltando o fato de que a referida aplicação reforça o desenvolvimento de uma cultura organizacional de conhecimento; sobre este particular é comentado no modelo de regras do negócio, por meio da regra 3 , descrita anteriormente.

Finalmente apresenta-se na figura 47 uma legenda que visa ajudar aos participantes e aos stakeholders no melhor entendimento do modelo de processos.

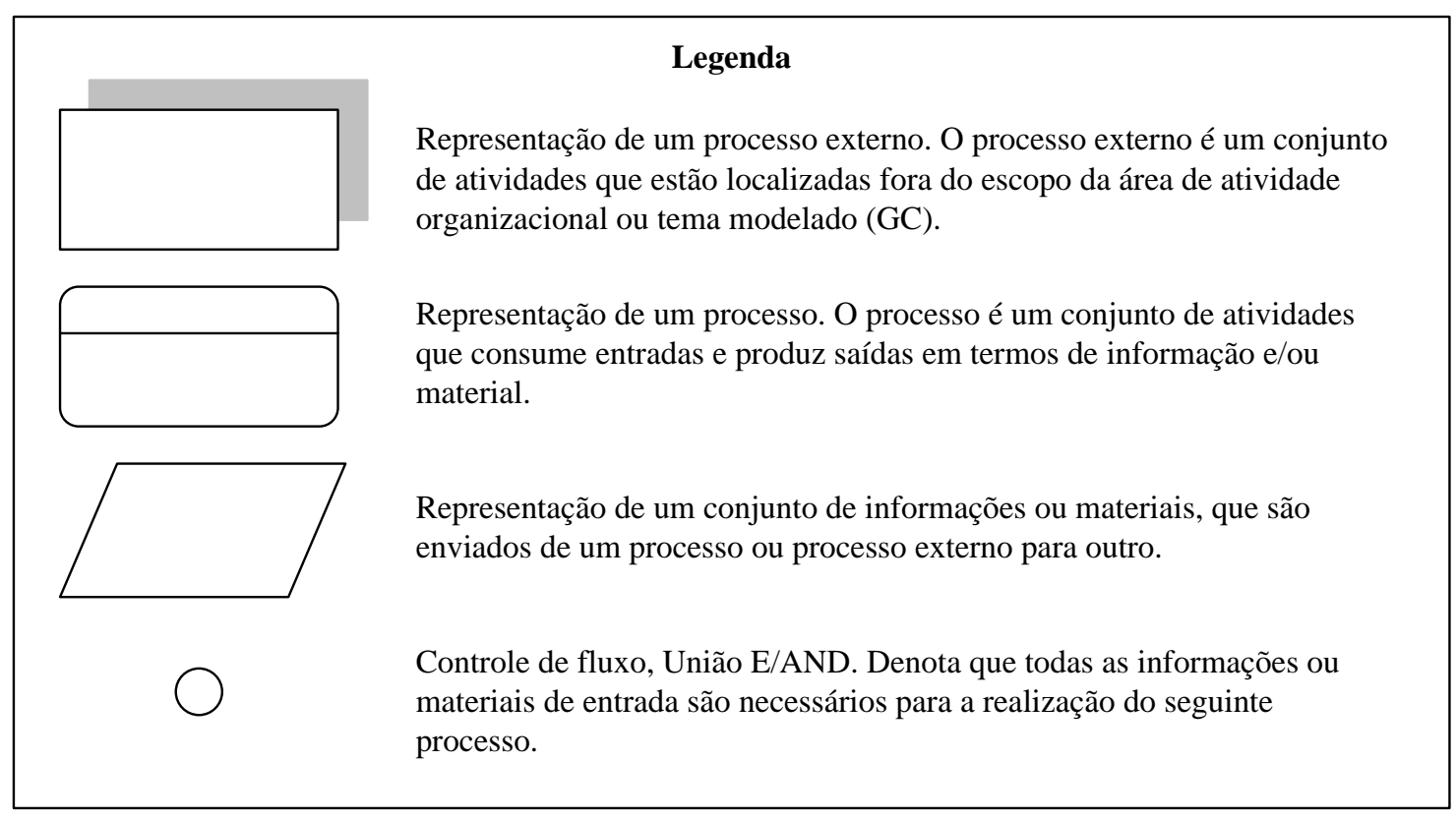

Figura 47 - Legenda do modelo de conceitos

\subsubsection{Modelo de atores e recursos}

O modelo de atores e recursos (Figura 47) apresenta cinco papeis importante para a GC: o trabalhador do conhecimento (papel 1), os líderes do conhecimento (papel 2), o diretor do conhecimento (papel 3), a organização (papel 4), e o ambiente externo (papel 5); cada um deles foi definido no modelo de conceitos.

Os especialistas indicaram como papeis adicionais: a) o mediador ou gatekeeper, entre a organização e os trabalhadores do conhecimento; b) intermediários como bibliotecários 
e profissionais de comunicação; e c) tradutor do conhecimento.
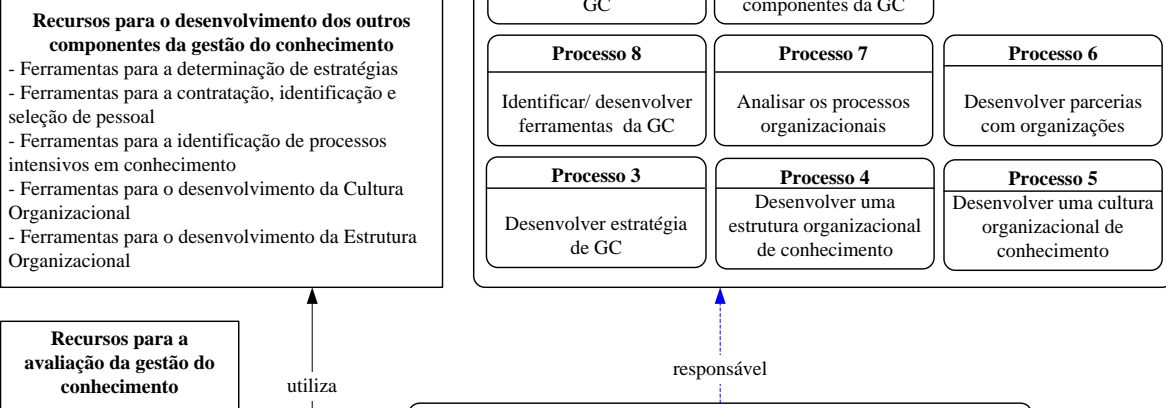

Indicadores da GC - BSC - VEA
- Bandia Navigato - Benchamarking
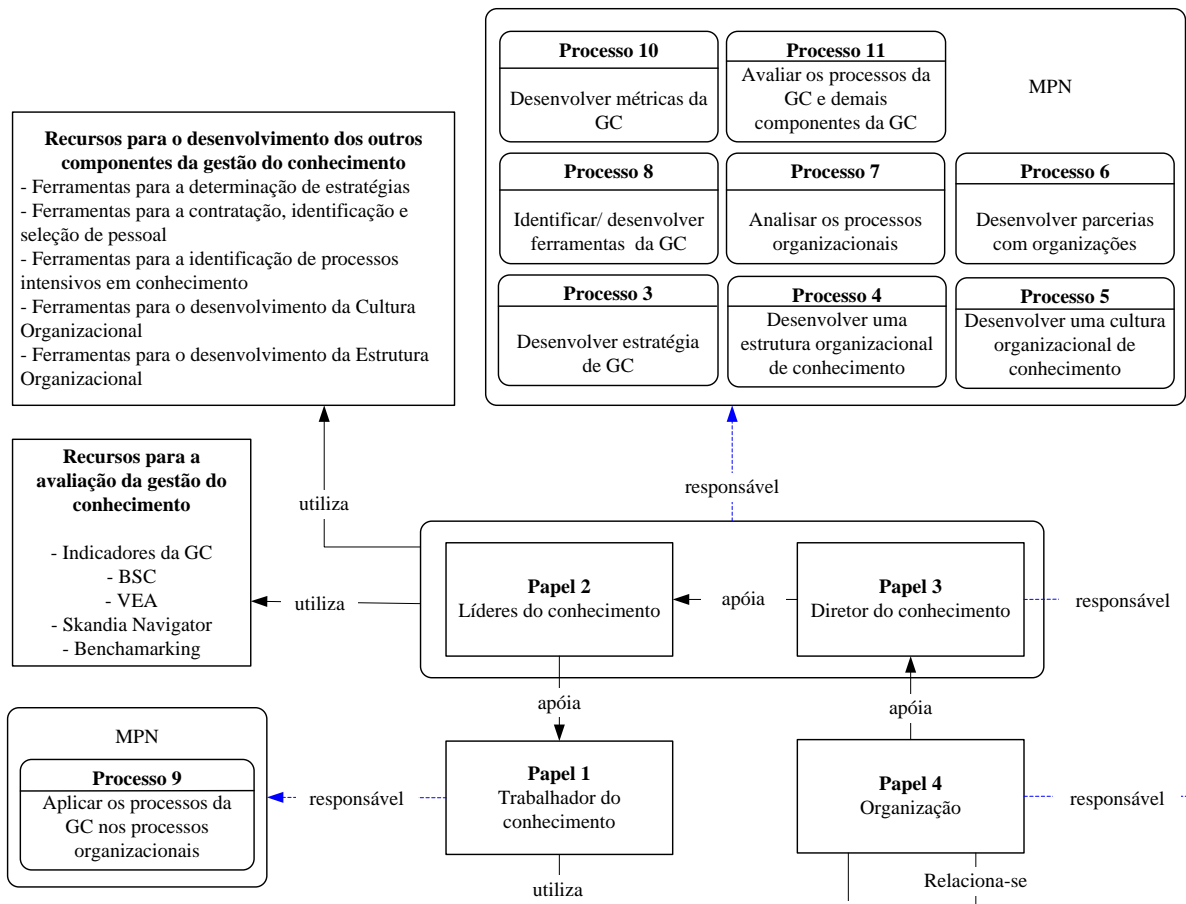

responsável

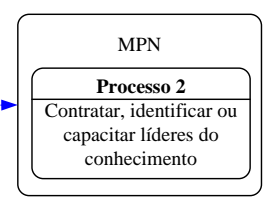

$\downarrow$

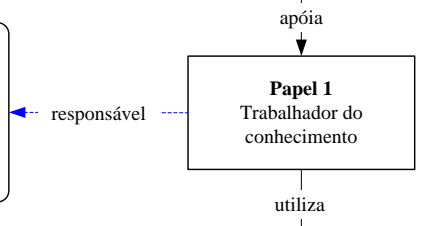

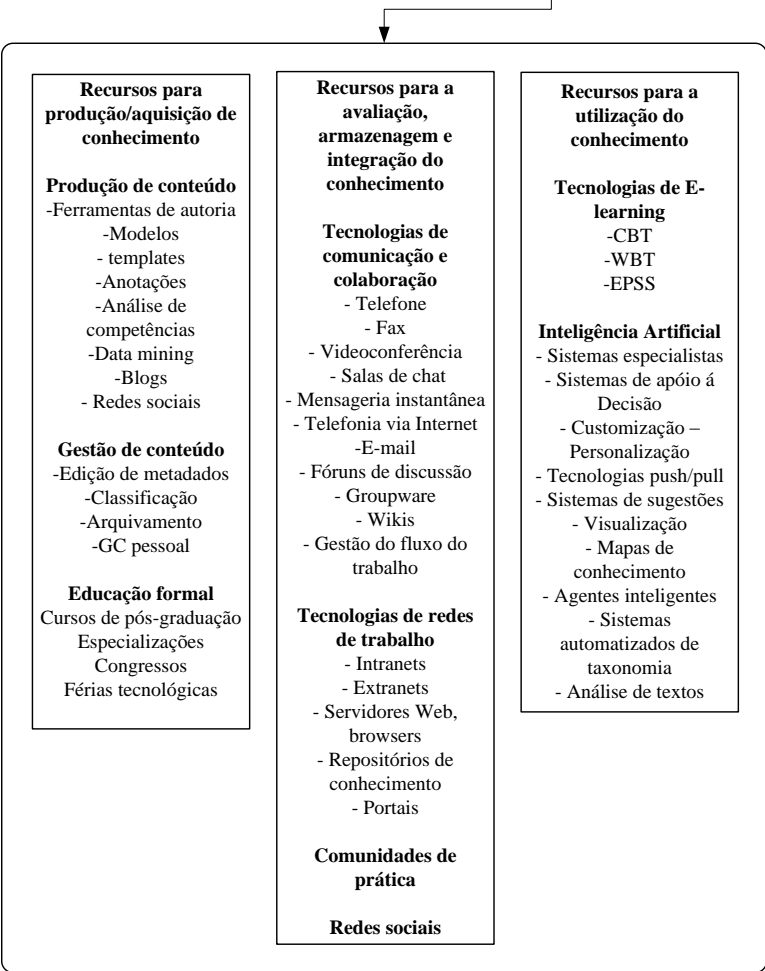
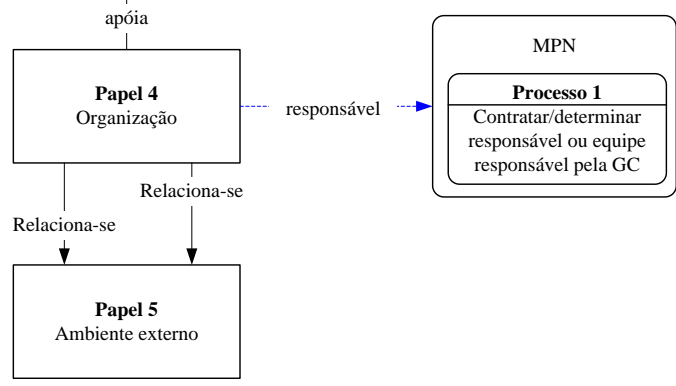

Papel 5

ente externo

Figura 48 - Modelo de atores e recursos para a implantação e desenvolvimento da Gestão do Conhecimento

A literatura analisada complementa esta lista apresentado os seguintes papeis (ABELL;

OXBROW, 1999; DALKIR, 2005):

- Campeões da GC e estrategistas

- Planejadores da GC e facilitadores 
- Colaboradores da GC

- Gerentes do Conhecimento

- Navegadores do conhecimento

- Sintetizadores do conhecimento

- Editores de conteúdo

- Desenvolvedores de Web, Publicadores eletrônicos, Gerentes de Intranet

- Treinadores e mentores

O diretor do conhecimento assim como os líderes do conhecimento compreende os papeis sugeridos pelos especialistas e os apresentados na literatura, lembrando que a referida compactação das responsabilidades destas pessoas teve como principal objetivo facilitar a leitura do modelo proposto e que a descrição ampla destes papeis se faz no modelo de conceitos anteriormente apresentado.

Por outro lado o modelo explicita três principais conjuntos de recursos para a GC: recursos que auxiliam o desenvolvimento dos processos da GC (recursos para produção/aquisição de conhecimento, recursos para a avaliação, armazenagem e integração do conhecimento, e recursos para a utilização do conhecimento), recursos para a avaliação da GC, e recursos para o desenvolvimento dos outros componentes da gestão do conhecimento.

Os especialistas sugeriram como recursos adicionais a educação formal, por meio de cursos de pós-graduação, especializações, congressos e férias tecnológicas. Também foi levantado que é importante considerar os recursos já existentes para os trabalhos e rotinas da empresa, e neles incorporar a GC. As referidas sugestões já foram acrescentadas na figura 48, dentro dos recursos para a produção e aquisição do conhecimento.

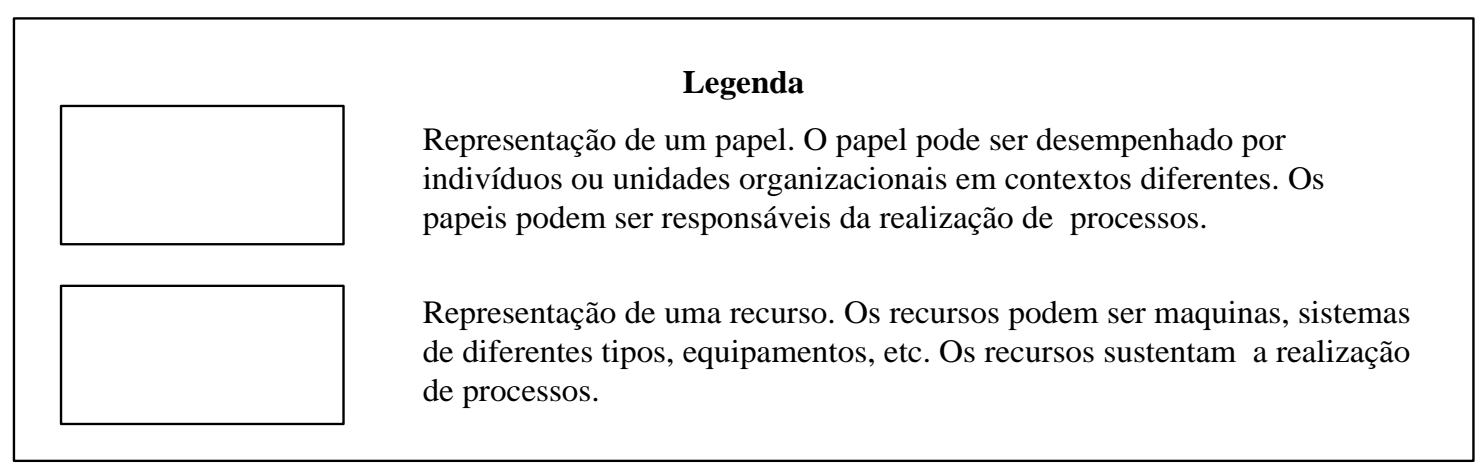

Figura 49 - Legenda do modelo de atores e recursos 
Adicionalmente, o modelo de atores e recursos relaciona-se com o modelo de processos com o objetivo de evidenciar as responsabilidades de cada papel na GC.

Finalmente apresenta-se na figura 49 uma legenda que visa ajudar aos participantes e aos stakeholders no melhor entendimento do modelo de atores e recursos.

\subsubsection{Modelo de requisitos e componentes técnicos}

O MRCT, apresentado na figura 50, permite explicitar a informação necessária para atingir determinado objetivo. Sendo assim, o principal alvo desse modelo é manter informação confiável (objetivo SI 1), o detalhamento dessa informação compreende os objetivos S. I. 1.1 ao 1.6. Deste modo, será necessário contar com informação sobre a organização (objetivo SI 1.1), sobre o ambiente externo e as mega-tendências (objetivo SI 1.2), sobre os membros da organização e sobre membros potenciais (mercado de trabalho) (objetivo SI 1.3), sobre os processos da organização (objetivo SI 1.4), sobre as avaliações das atividades da GC (objetivo SI 1.5) e sobre as ferramentas utilizadas e disponíveis no mercado (objetivo SI 1.6).

Como sugestões para este modelo, os especialistas indicaram: a) criar e sistematizar documentação eletrônica de documentos; b) manter informação sobre a documentação da organização; c) manter informação sobre competências individuais e coletivas; d) manter informação sobre clientes, atuais e potenciais, sobre fornecedores, sobre a concorrência e sobre parceiros; e e) manter informação sobre a memória organizacional. Foi sugerido também que o sistema de informação que apoiará as atividades da GC precisa ser montado para ajudar pessoas a encontrar pessoas, sendo simples e focado, evitando desperdícios com a dispersão dos conhecimentos.

O sistema ou conjunto de sistemas de informação que terão que cumprir com os objetivos de informação deste modelo deverão estar integrados e alinhados com todas as atividades organizacionais. Por exemplo, uma organização poderá ter um sistema ERP, um sistema CRM, um SAD, um sistema de inteligência competitiva, sistemas especializados, um portal corporativo e um sistema para a GC; tendo que estar todos eles integrados, sendo que embora se tenha um sistema especializado para a GC, este deverá explorar os outros sistemas em busca de informação útil para satisfazer os objetivos do modelo. Desta forma, as recomendações feitas pelos especialistas estarão dentro do referido sistema integrado, que deverá desempenhar funções como a exploração do conhecimento, codificação, organização, transferência, formatação, 


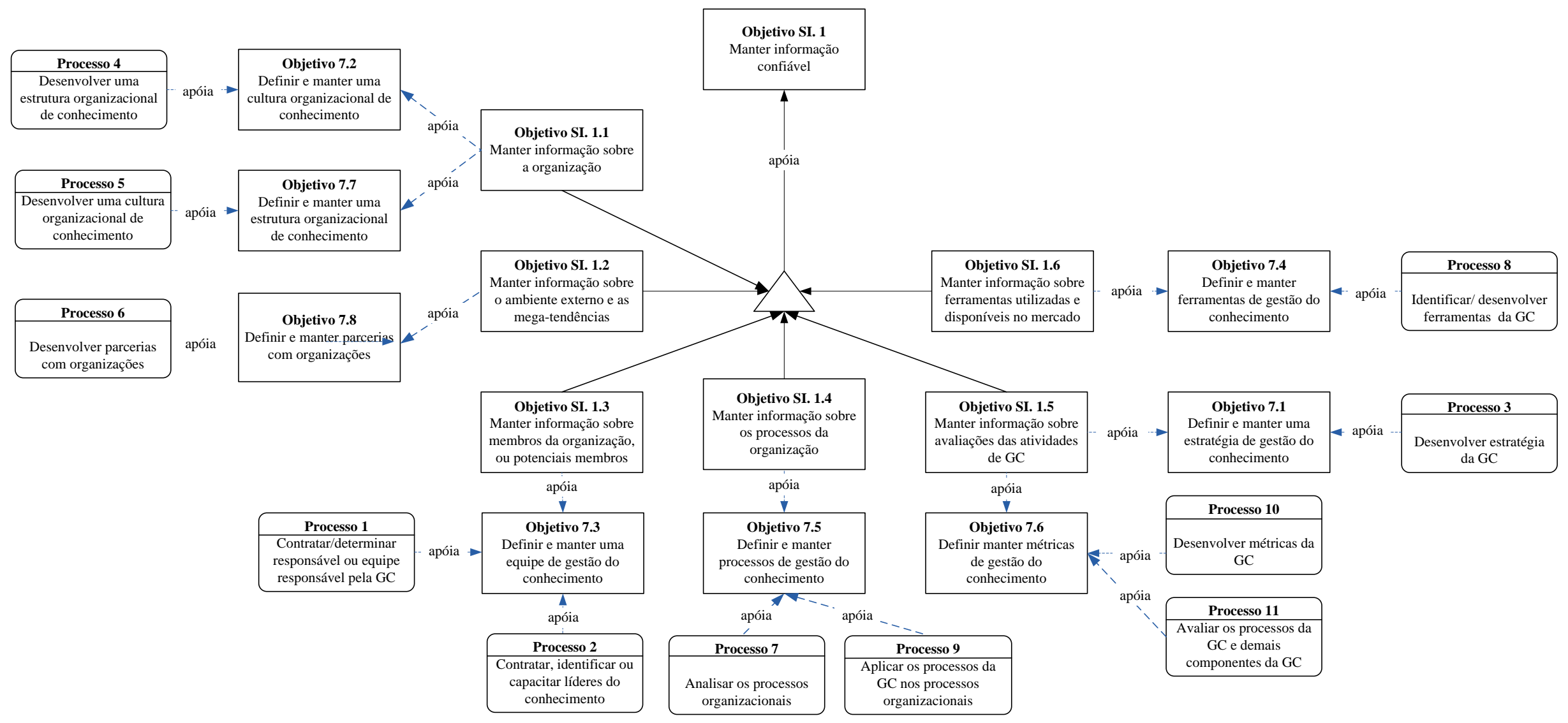

FIGURA 50 - Modelo de requisitos e componentes técnicos. 
facilitar a comunicação das pessoas, e formar a memória organizacional, não só de conhecimento e lições aprendidas, mas do conjunto de pessoas que atuam nas atividades organizacionais.

O MRCT permite estabelecer relacionamentos de apoio entre as necessidades de informação e os objetivos da GC, e entre esses objetivos e os processos que visam sua consecução, permitindo uma visão parcial da integração, relacionamento e alinhamento existente entre os componentes dos modelos propostos.

Por último, é relevante mencionar um comentário feito pelos especialistas e evidenciado na literatura que se refere ao fato de considerar a tecnologia da informação como um meio e não a finalidade da GC. Os sistemas de informação sustentam as atividades da GC, eles sós não fazem GC, é necessário de outros componentes como a cultura e estrutura organizacional, processos de conhecimento, trabalhadores do conhecimento entre outros.

Finalmente apresenta-se na figura 51 uma legenda que visa ajudar aos participantes e aos stakeholders no melhor entendimento do MRCT.

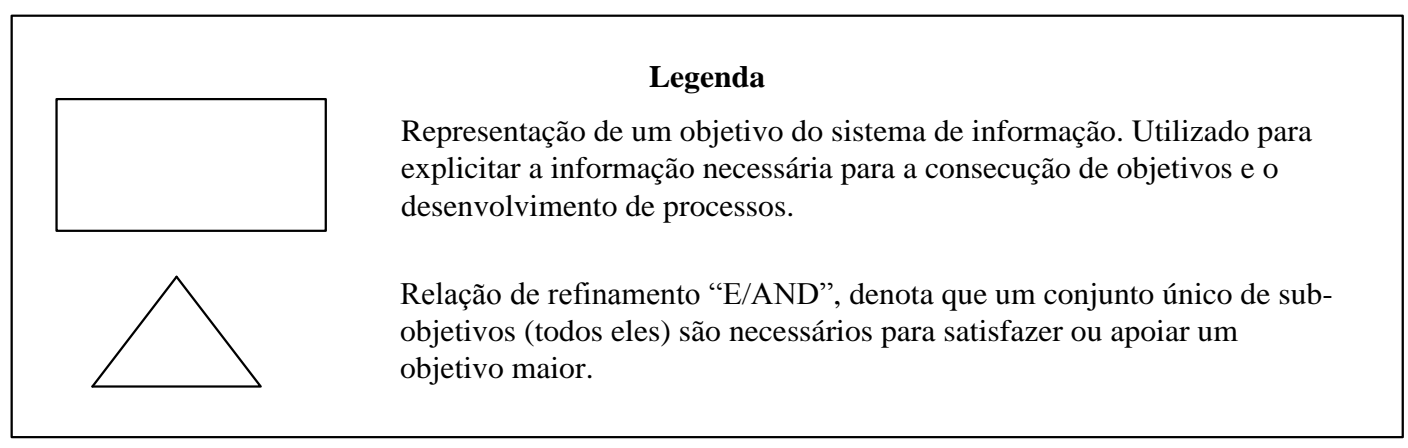

Figura 51 - Legenda do modelo de requisitos e componentes técnicos

\subsubsection{Integração do modelo proposto}

O modelo proposto, em seu conjunto, pode ser considerado como integrado quando une todos os elementos dos modelos apresentados (Modelo de objetivos, regras, conceitos, processos, atores, recursos, requisitos e componentes técnicos).

Os especialistas ao serem questionados sobre este enunciado explicitaram as respostas apresentadas na figura 52.

Os resultados mostram a forte aceitação do enunciado $(78,94 \%)$ indicando que o modelo proposto oferece integração de seus componentes e pode ser compreendido sob 
uma visão sistêmica que abrange os principais elementos que compõem a GC. Ressaltando que a referida integração é uma das principais características da metodologia de modelagem EKD.

\begin{tabular}{|l|l|c|c|}
\hline \multicolumn{1}{|c|}{ Escala Likert } & Respostas & $\begin{array}{c}\text { \% de } \\
\text { respostas }\end{array}$ & $\begin{array}{c}\text { Número de } \\
\text { respostas }\end{array}$ \\
\hline Fortemente em desacordo & & $0.00 \%$ & 0 \\
\hline Desacordo & & $0.00 \%$ & 0 \\
\hline Indeciso & & $21.05 \%$ & 4 \\
\hline De acordo & & $57.89 \%$ & 11 \\
\hline Fortemente de acordo & & $21.05 \%$ & 4 \\
\hline \multicolumn{2}{r|r|}{} \\
\hline
\end{tabular}

Figura 52 - Parecer dos especialistas sobre a integração dos modelos propostos

Comentários finais dos especialistas sobre o trabalho como um todo relatam: a) uma ligeira falta de flexibilidade; b) conceitualmente, abrangem praticamente todas as dimensões da GC. A integração das várias perspectivas poderá proporcionar uma visão sistêmica e ímpar desses elementos, auxiliando sobremaneira a sua gestão. Ressalte-se apenas a necessária observância da relação custo-benefício quando da aplicação do modelo; c) acredita-se que os modelos devem ser facilitadores da compressão do tema proposto. Por este motivo devem ser concisos e flexíveis, em não deixar com que a construção teórica obstrua a prática; e d) o trabalho seria um modelo full, acredita-se que deveria ter etapas intermediárias, módulos crescente até chegar ao modelo full.

É relevante evidenciar a importância da relação custo-benefício quando da aplicação do modelo, sendo que resultados concretos em termos de GC são difíceis de serem percebidos no curto prazo. A complexidade do tema tratado, abrangendo muitas áreas de estudo e diversas perspectivas, o que dificulta uma apresentação simples, flexível e genérica sem cair em extremos de simplicidade e generalização. Por último, o modelo pode ser detalhado até níveis operacionais dependendo da necessidade e perfil da organização, capturando as particularidades de cada caso, mas o resultados do atual trabalho visam apresentar uma visão holística e com aplicabilidade alta, livre de situações específicas, pudendo que o motivo da visão de modelo full citada pelos especialistas.

\subsubsection{Comparação do modelo proposto com os modelos da literatura}

Analisou-se na revisão teórica e o estado da arte deste trabalho os principais modelos propostos na literatura (HANZICK, 2003; LEE; KIM, 2001; NONAKA; TAKEUCHI, 1995; NONAKA et al., 2000; ORZANO et al.; 2008; PEE; KANKANHALLI, 2009), 
explicitando suas características por meio de cinco perspectivas (processos da GC, capacitadores ou fatores críticos de sucessos da GC, resultados da GC, tipos de conhecimento e níveis de maturidade). Com base na referida análise, apresenta-se no quadro 21, o modelo proposto por este estudo, descrito dentro das cinco perspectivas mencionadas junto aos modelos identificados na literatura.

O modelo proposto aborda amplamente as perspectivas tratadas pelos outros modelos, além de oferecer como diferencial as seguintes características:

- Associa os componentes culturais e tecnológicos da GC: o modelo proposto por meio do objetivo 7.2 (definir e manter uma cultura organizacional de conhecimento) e do objetivo 7.4 (definir e manter ferramentas de gestão do conhecimento) do modelo de objetivos aborda a perspectiva humana e tecnológica da GC, superando a limitação identificada nos modelos da literatura, apontada na justificativa deste trabalho, que se refere à excessiva orientação sobre as tecnologias de informação e a falta de atenção aos fatores humanos e culturais.

- Alinha as atividades da GC com as atividades organizacionais: por meio da regra 1 (a estratégia da gestão do conhecimento deve estar alinhada com as estratégia da organização) do modelo de regras no negócio, o modelo explicita a importância do referido alinhamento, problema também negligenciado por alguns trabalhos da literatura apresentados e analisados no referêncial teórido deste estudo.

- Integra os principais componentes da GC: o modelo proposto, como principal característica, apresenta de forma holística e sistêmica os elementos fundamentais da GC (estratégia, cultura, estrutura, equipe, ferramentas, processos, métricas e parcerias), superando a abordagem dividida do tema e permitindo seu melhor entendimento e adoção.

- Detalha cada elemento que compõe a GC: o modelo não só aborda graficamente a GC, mas descreve com fundamentos teóricos cada elemento que a constitui, tendo como principal objetivo o esclarecimento dos conceitos e temas polêmicos da literatura, e a formação de uma linha teórica que o fundamente. 


\begin{tabular}{|c|c|c|c|c|c|}
\hline Modelo & Processos da GC & Capacitadores da GC & Resultados da GC & Tipos de conhecimento & $\begin{array}{c}\text { Níveis de } \\
\text { maturidade }\end{array}$ \\
\hline $\begin{array}{l}\text { Nonaka e } \\
\text { Takeuchi } \\
(1995) \text { e } \\
\text { Nonaka et al. } \\
\text { (2000) }\end{array}$ & $\begin{array}{l}\text { •Criação } \\
\text { •Compartilhamento } \\
\text { •Justificação } \\
\text { •Construção de arquétipo } \\
\text {-Difusão }\end{array}$ & $\begin{array}{l}\text { •Intenção } \\
\text { •Autonomia } \\
\text { •Flutuação/Caos criativo } \\
\text { •Redundância } \\
\cdot \text { Variedade de Requisitos } \\
\text { •Cuidado, amor, confiança e } \\
\text { compromisso } \\
\text {-Ba }\end{array}$ & $\begin{array}{l}\text {-Ativos de conhecimento } \\
\text { experienciais } \\
\text {-Ativos de conhecimento } \\
\text { conceituais } \\
\text {-Ativos de conhecimento } \\
\text { sistemáticos } \\
\text {-Ativos de conhecimento } \\
\text { rotineiros }\end{array}$ & $\begin{array}{l}\text {-Conhecimento tácito } \\
\text {-Conhecimento explícito }\end{array}$ & - \\
\hline $\begin{array}{l}\text { Orzano et al. } \\
\text { (2008) }\end{array}$ & $\begin{array}{l}\text {-Descoberta } \\
\text {-Compartilhamento } \\
\text {-Desenvolvimento }\end{array}$ & $\begin{array}{l}\text {-Redes ativas } \\
\text {-Prática reflexiva } \\
\text {-Relacionamentos úteis } \\
\text {-Infra-estrutura robusta } \\
\text {-Tecnologia acessível } \\
\text {-Liderança de apoio } \\
\text {-Comunicação efetiva } \\
\text {-Clima de confiança }\end{array}$ & $\begin{array}{l}\text { - Tomada de decisão } \\
\text { - Aprendizagem } \\
\text { organizacional } \\
\text {-Desempenho organizacional }\end{array}$ & $\begin{array}{l}\text {-Conhecimento tácito } \\
\text {-Conhecimento explícito }\end{array}$ & - \\
\hline $\begin{array}{l}\text { Lee e Kim } \\
(2001)\end{array}$ & $\begin{array}{l}\text { • Aquisição } \\
\text { •Criação } \\
\text { •Compartilhamento } \\
\text { •Integração }\end{array}$ & $\begin{array}{l}\text { - Trabalhadores do conhecimento } \\
\text { •Conhecimento organizacional } \\
\text {-Tecnologias da informação } \\
\text {-Processos da GC }\end{array}$ & -Desempenho organizacional & - & $\begin{array}{l}\text { •Iniciação } \\
\text {-Propagação } \\
\text { •Integração } \\
\text {-Trabalho em rede }\end{array}$ \\
\hline Hanzick (2003) & • Geração & - Ambiente Organizacional & -Desempenho organizacional & -Know-that explícito & - \\
\hline
\end{tabular}




\begin{tabular}{|c|c|c|c|c|c|}
\hline & $\begin{array}{l}\text {-Transferência } \\
\text {-Aplicação }\end{array}$ & $\begin{array}{l}\text {-Infra-estrutura tecnológica } \\
\text { •Medição }\end{array}$ & & $\begin{array}{l}\text { - Know-that tácito } \\
\text { - Know-how explícito } \\
\text { - Know-how tácito }\end{array}$ & \\
\hline $\begin{array}{l}\text { Pee e } \\
\text { Kankanhalli } \\
(2009)\end{array}$ & $\begin{array}{l}\text {-Captura } \\
\text {-Compartilhamento } \\
\text { - Reutilização }\end{array}$ & $\begin{array}{l}\cdot \text { Pessoas } \\
\cdot \text { Processos } \\
\text {-Tecnologia }\end{array}$ & -Desempenho organizacional & - & $\begin{array}{l}\cdot \text { Inicial } \\
- \text { Consciente } \\
\text {-Definido } \\
\text {-Gerido } \\
\text {-Otimizador }\end{array}$ \\
\hline $\begin{array}{l}\text { Modelo } \\
\text { proposto }\end{array}$ & $\begin{array}{l}\text {-Produção/aquisição do } \\
\text { conhecimento } \\
\text { • Avaliação do conhecimento } \\
\text { • Armazenagem do } \\
\text { conhecimento } \\
\text { •Integração/utilização do } \\
\text { conhecimento }\end{array}$ & $\begin{array}{l}\cdot \text { Estratégia de gestão do } \\
\text { conhecimento } \\
\text { •Cultura organizacional de } \\
\text { conhecimento } \\
\cdot \text { Estrutura organizacional de } \\
\text { conhecimento } \\
\text { •Equipe de gestão do conhecimento } \\
\text { •Ferramentas de gestão do } \\
\text { conhecimento } \\
\text {-Processos de gestão do } \\
\text { conhecimento } \\
\text {-Métricas de gestão do } \\
\text { conhecimento } \\
\text {-Parcerias com organizações }\end{array}$ & $\begin{array}{l}\text {-Efetividade organizacional } \\
\text {-Decisões organizacionais } \\
\text { adequadas } \\
\text {-Inovação organizacional } \\
\text {-Mudança organizacional } \\
\text { contínua } \\
\text {-Estabelecer redes entre } \\
\text { organizações }\end{array}$ & $\begin{array}{l}\text {-Conhecimento implícito } \\
\text {-Conhecimento tácito } \\
\text {-Conhecimento explícito }\end{array}$ & $\begin{array}{l}\text { Ciclo de } \\
\text { aprimoramento } \\
\text { constante para o } \\
\text { desenvolvimento da } \\
\text { GC }\end{array}$ \\
\hline
\end{tabular}

Quadro 21 - Comparação do modelo proposto com os modelos da literatura 
- Baseia-se em uma metodologia de modelagem: a diferença dos modelos identificados na literatura, o modelo proposto teve como base para seu desenvolvimento uma metodologia de modelagem (EKD), permitindo sua melhor estruturação e oferecendo uma base científica não só ao conteúdo, mas também à sua forma de apresentação. 


\section{CONSIDERAÇÕES FINAIS}

\subsection{Conclusões do trabalho}

Apresentam-se as seguintes conclusões do trabalho:

- O objetivo de propor um modelo integrado para a implantação e desenvolvimento da Gestão do Conhecimento nas organizações, com uma descrição detalhada de seus componentes e utilizando a metodologia de modelagem Enterprise Knowledge Development (EKD) como base para sua estruturação, foi atingido.

- A revisão da literatura sobre a GC visou a construção de uma linha teórica como fundamento para o modelo proposto.

- Existe uma alta evolução de conceitos e aplicações na área de GC, mostrando cada vez mais uma elevada conscientização da importância do tema para as organizações.

- A amostra de pesquisadores, assim como a quantidade de respostas, foi aceitável, oferecendo representatividade à validação do modelo proposto.

- O instrumento de pesquisa, assim como a ferramenta utilizada para sua geração e gestão, foi considerado útil e facilitou os processos de coleta e análise de dados.

- A pesquisa qualitativa e o uso de histogramas foram considerados satisfatórios, permitindo a captura de comentários abertos e quantificando as escolhas dos especialistas.

- O modelo foi avaliado em termos gerais como relevante e útil para a área de conhecimento estudada, apresentando particularidades, descritas no decorrer do trabalho.

\subsection{Limitações do estudo}

No desenvolvimento do trabalho identificaram-se como limitações do estudo:

- A sobre-produção científica de artigos sobre a GC e a constante evolução dos conceitos, modelos, metodologias etc. da GC, não sendo possível uma revisão exaustiva desses trabalhos, e evidenciando o risco de obsolescência dos conceitos tomados como referência para a geração do modelo proposto.

- As diferentes linhas de pensamento e escolas da GC, sendo fundamentada cada uma delas em pressupostos e conceitos variados, diferentes e muitas vezes contraditórios; 
o que dificultou a construção de uma base conceitual uniforme como alicerce para a geração do modelo.

- A dificuldade de uma validação prática do modelo, principalmente pelo tempo necessário para sua implantação em uma organização e a posterior avaliação de seu sucesso ou fracasso.

- A amostragem dos especialistas da GC e modelagem organizacional, principalmente pela dificuldade do mapeamento da população desses especialistas.

- O número elevado, mas necessário, dos elementos do modelo proposto, dificultando sua validação quantitativa, e a análise do relacionamento entre esses componentes.

- O modelo proposto foi criado com base em trabalhos que estudam e surgem de organizações de grande porte, não sendo possível a afirmação de sua viabilidade para organizações menores.

\subsection{Trabalhos futuros}

A proposta desenvolvida neste estudo poderia ser considerada base para a realização dos trabalhos futuros descritos a seguir:

- O modelo proposto poderia ser readequado para organizações de pequeno porte, considerando suas particularidades, oferecendo dessa forma um referencial para que esse tipo de organização possa empreender práticas em GC.

- O modelo proposto poderia ser readequado para organizações do setor público, considerando suas particularidades, oferecendo dessa forma um referencial para que esse tipo de organização possa empreender práticas em GC.

- O modelo proposto não aborda a sustentabilidade da GC, assim como o apóio da GC para a sustentabilidade da organização e do ambiente em geral (terceira geração da GC). Desse modo, devido ao elevado interesse desse tema, trabalhos futuros poderiam visar sua inclusão no modelo proposto.

- A metodologia EKD, principalmente o MRCT, visa a construção de um Sistema de Informação para a organização, portanto, trabalhos futuros poderiam desenvolver o sistema referido, que seria utilizado como ferramenta complementar para a implantação da GC.

- Cada objetivo, regra, problema, processo ou algum outro elemento do modelo poderia ser detalhado, utilizando a metodologia $\mathrm{EKD}$, até níveis operacionais segundo a necessidade organizacional. 
- A validação do modelo poderia abranger especialistas do setor organizacional, gerentes de gestão do conhecimento, TI ou RH, sendo que a amostra trabalhada só abarcou especialistas da área acadêmica.

- A validação do modelo poderia abranger especialistas, tanto do setor acadêmico quanto do setor industrial, de nível internacional, envolvendo pessoas do mundo inteiro e ampliando a análise das visões e percepções sobre o modelo.

- O instrumento de coleta de dados poderia ser complementado com entrevistas semi-estruturadas feitas aos especialistas, tendo a possibilidade de capturar melhores e mais aprofundados pareces sobre o modelo.

- A validação do modelo poderia ser feita com base na sua real aplicação em uma ou várias organizações, pudendo oferecer resultados muito mais significativos e fidedignos com a realidade empresarial, mas considerando uma demanda de tempo maior para atingir esse objetivo.

- Os conhecimentos explicitados no trabalho e no modelo propostos poderiam ser recodificados utilizando outra metodologia de modelagem, com o objetivo de aprimorar sua compreensão e facilitar sua aplicação por parte das organizações.

- A análise de dados poderia ser ampliada para uma análise estatística usando técnicas de regressão, correlação, análise de variância e demais recursos que um estudo quantitativo possa oferecer, reforçando os resultados do trabalho. 


\section{REFERÊNCIAS}

AAKER, D.A.; KUMAR, V.; DAY, G.S. (2007). Pesquisa de marketing. 2.ed. São Paulo: Atlas.

ABELL, A.; OXBROW, N. (1999). People who make knowledge management work. In: LIEBOWITZ, J. (Ed.). Knowledge management handbook. New York: CRC Press. p.4-1-4-17.

ACKOFF, R.L. (1989). From data to wisdom. Journal of Applied Systems Analysis, Lancaster, v.16, p. 3-9.

AGUAYO, R. (2004). The Meta knowledge advantage: the key to success in the new economy. New York: Free Press.

ALAVI, M.; LEIDNER, D.E. (2001). Review: knowledge management and knowledge management systems: conceptual foundations and research issues. MIS Quarterly, Minneapolis, v.25, n.1, p.107-136.

AL-SHARAMMARI, M. (2008). Toward a knowledge management strategy framework in the arab region. International Journal of Knowledge Management, Farmington Hills, v.4, n.3, p.44-63, July/Sept. 2008.

APOSTOLOU, D.; MENTZAS, G. (2003). Experiences from KM implementation in companies of the software sector. Business Process Management Journal, Wagon Lane, v.9, n.3, p.354-82.

AMERICAN PRODUCTIVITY AND QUALITY CENTER. (1999). Benchmarking study. Houston, 1999.

ARGIRYS, C.; SCHÖN, D.A. (1978). Organizational learning: a theory of action perspective. Boston: Addison-Wesley.

ARORA, R. (2002). Implementing KM - a balanced score card approach. Journal of Knowledge Management, Wagon Lane, v.6, n.3, p.240-249.

BACKER, K.R. (1995). Elements of sequencing and scheduling. Hanover: Dartmouth College.

BARTH, S. (2001). Learning from mistakes. Knowledge Management, v.4., n. 4, p.41-47, Apr.

BASKERVILLE, R.; DULIPOVICI, A. (2006). The Theoretical foundations of knowledge management. Knowledge Management Research \& Practice, Hampshire, v.4, n.2, p.83-105, May.

BELL, D. (1999). The Coming of the Post-Industrial Society: a venture in social forecasting. New York: Basic Books.

BHATT, G. (2000). Organizing knowledge in the knowledge development cycle. Journal of Knowledge Management: journal of business transformation, Wagon Lane, v.4, n.1, p.15-26.

BIERLY, P.; CHAKRABARTI, A. (1996). Generic knowledge strategies in the US Pharmaceutical Industry. Strategic Management Journal, Chichester, v.17, p.123-135, Winter. Winter Special Issue.

BIERLY, P.E. et al. (2000). Organizational learning, knowledge and wisdom. Journal of Organizational Change Management, Wagon Lane, v.13, n.6, p.595-618.

BIRKINSHAW, J.; SHEEHAN, T. (2002). Managing the knowledge life cycle. Sloan Management Review, Cambridge, v.44, n.1, p.75-83.

BISHOP, J. et al. (2008). Ensuring the effectiveness of a knowledge management initiative. Journal of Knowledge Management, Wagon Lane, n.12, v.4, p.16-29. 
BLACKLER, F. (1995). Knowledge, knowledge work and organizations: an overview and interpretation. Organization Studies, Berlin, v.16, n.6, p.1021-1046.

BOISOT, M. (1998). Knowledge assets: securing competitive advantage in the information economy. Oxford: Oxford University Press.

BOSE, R. (2004). Knowledge management metrics. Industrial Management \& Data Systems, Wagon Lane, v.104, n. 6, p.457-468.

BUBENKO JR., J.A.; PERSSON, A.; STIRNA, J. (2001). User guide of the knowledge management approach using enterprise knowledge patterns, ist programme project hypermedia and pattern based knowledge management for smart organizations. Sweden: KTH.

BUBENKO JR., J.A.; STIRNA, J.; BRASH, D. (1998). EKD user guide. Stockholm: Royal Institute of Technology, Department of Computer and Systems Sciences.

BUHLER, P. (2002). Building the learning organization for the $21^{\text {st }}$ Century: a necessary challenge. SuperVision, San Francisco, v.63, n.12, p.20-23.

BURNS, T.; STALKER, G.M. (1961). The Management of innovation. London: Tavistock.

BURSTEIN, F.V. et al. (2003). Leading knowledge management strategies in Australia and New Zealand: a comparative study of public and private sector organisations. In: AUSTRALASIAN CONFERENCE ON INFORMATION SYSTEMS, 14., Perth, 2003. Proceedings... Perth: Cowan University. p.1-10.

(2010). Understanding of knowledge management roles and responsibilities: a study in the Australian context. Knowledge Management Research \& Practice, Hampshire, v.8, n.1, p.76-88, Mar.

CAMPOS, R.R.; CAZARINI, E.W. (2005). As Planilhas eletrônicas e as pequenas empresas: recursos disponíveis para auxílio à tomada de decisão. Interface Tecnológica, Taquaritinga, v.1, n.2, p.41-52.

CANADIAN MANAGEMENT ACCOUNTANTS. (1999). Focus group draft: measuring knowledge assets. Mississauga: CMA.

CARTY, R.; WALSH, S. (2007). The Role of middle managers in knowledge transfer. Journal of Information \& Knowledge Management, Hackensack, v.6, n.4, p.297-302.

CASTILLO, L.A.M.; CAZARINI, E.W. (2008). A Modelagem organizacional como ferramenta para a implementação e monitoramento de práticas de comércio eletrônico. In: SIMPÓSIO DE ENGENHARIA DE PRODUÇÃO, 15., 2008, Bauru. Anais... Bauru: FEB/UNESP.

(2009). A Aprendizagem organizacional da tomada de decisão utilizando a modelagem EKD. In: ENCONTRO NACIONAL DE ENGENHARIA DE PRODUÇÃO, 29., 2009, Salvador. Anais... Salvador: ABEPRO. CD-ROM.

CASTRO, S.A.; CAZARINI, E.W. (2005). Um Modelo de mudança organizacional contínua através da gestão do conhecimento integrando tecnologia da informação e pessoas. Revista Gestão Industrial, Ponta Grossa, v.1, n.4, p.18-25.

(2006a). Alinhamento do ERP com o negócio da empresa através do EKD. In: SIMPÓSIO DE ADMINISTRAÇÃO DA PRODUÇÃO, LOGÍSTICA E OPERAÇÕES INTERNACIONAIS, 9., 2006, São Paulo. Anais... São Paulo: FGV/EAESP.

(2006b). Integração da informação através do EKD para gestão do conhecimento. In: SIMPÓSIO DE ENGENHARIA DE PRODUÇÃO, 13., 2006, Bauru. Anais... Bauru: FEB/UNESP.

CERVO, A.L.; BERVIAN, P.A. (1996). Metodologia científica. 4.ed. São Paulo: Makron Books. 
CERVO, A.L.; BERVIAN, P.A; SILVA, S. (2007). Metodologia científica. 6.ed. São Paulo: Pearson Prentice Hall.

CHAI, K.H. (2000). Knowledge sharing and reuse international manufacturing networks. Cambridge: Institute for Manufacturing Engineering, University of Cambridge.

CHALMETA, R.; GRANGEL, R. (2008). Methodology for the implementation of knowledge management systems. Journal of Americam Society for Information Science and Technology, Malden, v.59, n.5, p.742-755, Mar.

CHANG L.K.; LEE, S.; WON, K.I. (2005). KMPI: measuring knowledge management performance. Journal of Information Management, Atlanta, v.42, n.3, p.469-482, Mar.

CHANG, M.Y. et al. (2009). The Research on the critical success factors of knowledge management and classification framework project in the executive Yuan of Taiwan Government. Expert Systems with Applications, Amsterdam, v.36, n.3, p.5376-5386, Apr.

CHEN, J.C.; HUANG, W.J. (2007). How organizational climate and structure affect knowledge management-The social interaction perspective. International Journal of Information Management, Amsterdam, v.27, n.2, p.104-118, Apr.

CHEN, Y.M.; CHEN, P.A. (2006). Knowledge management performance evaluation: a decade review from 1995 to 2004. Journal of Information Science, Amsterdam, v.32, n.1, p.17-38, Feb.

CHOI, B.; POON, K.S.; DAVIS, G.J. (2008). Effects of knowledge management strategy on organizational performance: a complementarity theory-based approach. OMEGA: the international journal of management science, Amsterdam, v.36, n.2, p.235-251, Apr.

CHONG, S.C.; CHOI, Y.S. (2005). Critical factors in the successful implementation of knowledge management. Journal of Knowledge Management Practice, v.6, June. Disponível em:<http://www.t;ainc.com/artic190.htm>. Acesso em: 10 Jan. 2010.

CHRISTENSEN, C.M. (2002). The Innovator's dilemma: the revolutionary national bestseller that changed the way we do business. New York: HarperBusiness.

CHUA, A.; LAM, W. (2005). Why KM projects fail: a multi-case analysis. Journal of Knowledge Management, Wagon lane, v.9, n.3, p.6-17.

CHURCHMAN, C.W. (1971). Inquiring systems: basic concepts of systems and organization. New York: Basic Books.

CORTES, C.E.; PATRONICIO, Z.S.; EVA, P.O. (2007). Organizational structure features supporting knowledge management processes. Journal of Knowledge Management, Wagon Lane, v.11, n.4, p.4557.

DAGHFOUS, A.; KAH, M.M.O. (2006). Knowledge management implementation in SMEs: a framework and a case illustration. Journal of Information and Knowledge Management, Hackensack, v.5, n.2, p.107-115.

DALKIR, K. (2005). Knowledge management in theory and practice. Burlington: Elsevier Butterworth- Heinemann.

DATTERO, R.; GALUP, S.D.; QUAN, J.J. (2007). The knowledge audit: meta-matrix analysis. Knowledge Management Research \& Practice, Hampshire, v.5, n.3, p.213-221, Aug.

DAVENPORT, T.H. (1998). Ecologia da informação: por que só a tecnologia não basta para o sucesso na era da informação. São Paulo: Futura.

(2002). Missão crítica: obtendo vantagem competitiva com sistema de gestão empresarial.

Porto Alegre: Bookman. 
DAVENPORT, T.H.; PRUSAK, L. (1998). Working knowledge: how organizations manage what they know. Cambridge: Harvard Business School Press.

DIAO, F.; YU, T.; LIANG, Z. (2006). Study on motivation method to knowledge worker: micro-usage of organizational commitment theory. In: WUHAN INTERNATIONAL CONFERENCE ON EBUSINESS, 5., 2006, China. Integration and innovation through measurement and management. Wuham: Lakeview Garden Hold. P.1784-1788.

DILLON, R.D.; OWERS, J.E. (1997). EVA(r) as a financial metric: attributes, utilization, and relationship to NPV. Financial Practice and Education, Tampa, v.7, n.1, p.32-40.

DOVE, R. (1998). Knowledge management - it's not just in the IT department. Production, Plymouth, v.110, n.3, p.26-28.

DRUCKER, P.F. (1993). Sociedade pós-capitalista. São Paulo: Pioneira.

(1999). Knowledge-worker productivity: the biggest challenge. California Management Review, Berkeley, v.41, n.2, p.79-85, Winter.

DUARTE, R. (2002). Pesquisa qualitativa: reflexões sobre o trabalho de campo. Cadernos de Pesquisa, São Paulo, v.6, n.115, p.139-154, Mar.

DUFOUR, Y.; STEANE, P. (2007). Implementing knowledge management: a more robust model. Journal of Knowledge Management, Wagon Lane, v.11, n.6, p.68-80.

DUSSELROP, V. (2002). Knowledge management market steams ahead. EuropeMedia, Amsterdam, p.1, Oct.

DZINKOWSKI, R. (2001). Removing boundaries to learning. Knowledge Management, v.4, n.5, p.20.

EARL, M. (2001). Knowledge management strategies: toward a taxonomy. Journal of Management Information Systems, Armonk, v.18, n.1, p.215-233, Summer.

EDWARDS, J.S. (2003). Managing software engineers and their knowledge. In: AURUM, A. et al. (Ed.). Managing software engineering knowledge. Berlin: Springer.

EKIONEA, B.P.J.; SWAIN, E.D. (2008). Developing and aligning a knowledge management strategy: towards a taxonomy and framework. International Journal of Knowledge Management, Farmington Hills, v.4, n.1, p.29-45, Jan./Mar.

EYSENCK, H.J. (1979). The Structure and measurement of intelligence. Berlin: Springer.

F3 CONSORTIUM. (1994). F3 Reference manual. [S.1]: F3 Consortium. (ESPRIT III Project 6612). $\overline{6612) .}$

(1995). Requirements engineering handbook. [S.1]: F3 Consortium. (ESPRIT III Project

FIRESTONE, J.M. (2001). Key issues in knowledge management. Knowledge and Innovation: journal of the KMCI, Alexandria, v.1, n.3, p.8-38.

FIRESTONE, J.M.; MCELROY, M.K. (2003). Key issues in the new knowledge management. Burlington: KMCI Press/Butterworth Heinemann. p.189-212.

(2005). Doing knowledge management. The Learning Organization, Bradford, v.12, n.2,

FRAPPAOLO, C. (2006). Knowledge management. West Sussex: Capstone. 
FRAPPAOLO, C. (2008). Implicit knowledge. Knowledge Management Research \& Practice, Hampshire, v.6, n.1, p.23-25, Mar.

GANGA, G.M.D.; GUERRINI, F.M.; CARPINETTI, L.C.R. (2008). Arquiteturas de referência para redes de cooperação em sistemas produtivos dinâmicos segundo a abordagem EKD. Revista Gestão Industrial, Ponta Grossa, v.4, n.2, p.78-103.

GIL, A.C. (2007). Métodos e técnicas de pesquisa social. 5.ed. São Paulo: Atlas.

GONÇALVES, D.I.F. (2008). Pesquisas de marketing pela internet: as percepções sob a ótica dos entrevistados. Revista de Administração Mackenzie, São Paulo, v.9, n.7, p.70-88, nov./dez.

GRANGER, G.G. (1989). Por um conhecimento filosófico. Campinas: Papirus.

GREINER, E.M.; BOHMANN, T.; KRCMAR, H. (2007). A Strategy for knowledge management. Journal of Knowledge Management, Wagon Lane, v.11, n.6, p.3-15.

HANSEN, M.T.; NOHRIA, N.; TIERNEY, T. (1999). What's your strategy for managing knowledge?. Harvard Business Review, New York, v.77, n.2, p.106-116, Mar./Apr.

HANZICK, M. (2003). An Integrated framework of knowledge management. Journal of Information and Knowledge Management, Hackensack, v.2, n.3, p.245-252.

HARRIS, G.R. (2001). The Knowledge-based economy: intellectual origins and new economic perspectives. Interntional Journal of Management Reviews, Malden, v.4, n.1, p.21-40, Mar.

HASANALI, F. (2002). Critical success factors of knowledge management. Disponível em:<http://www.kmadvantage.com/docs/km_articles/Critical_Success_Factors_of_KM.pdf $>$. Acesso em: 10 Dec. 2009.

HASEN, H.; AL-HAWARI, M. (2003). Management styles and performance: a knowledge space framework. Journal of Knowledge Management, Wagon Lane, v.7, n.4, p.15-43.

HAYWOOD, T. (1995). Info-rich - info-poor: access and exchange in the global information society. London: Bowker-Saur.

HOFFMANN, W.A.M. (2009). Gestão do conhecimento: desafios de aprender. São Carlos: Compacta. v.1.

HORVATH, D. (2001). Knowledge worker definition. In: SEARCH CRM technical dictionary by tech target. [S.1.:s.n.].

ICM GROUP. (1998). What are the companies currently measuring?. Disponível em:<www.icmgroup.com>. Acesso em: 15 Jan. 2010.

JAFARI, M. et al. (2007). Knowledge management in Iran aerospace industries: a study on critical factors. Aircraft Engineering and Aerospace Technology: an international journal, Wagon Lane, v.79, n. 4 , p.375-389.

JANZ, B.D.; PRASARNPHANICH, P. (2003). Understanding the antecedents of effective knowledge management: the importance of a knowledge-centered culture. Decision Sciences, Atlanta, v.34, v.2, p.351-384.

JASIMUDDIN, S. (2008). A Holistic view of knowledge management strategy. Journal of Knowledge Management, Wagon Lane, v.12, n.2, p.57-66.

JONES, N.; HERSCHEL, R.; MOESEL, D. (2003). Using knowledge champions to facilitate knowledge management. Journal of Knowledge Management, Wagon Lane, v.7, n.1, p.49-77. 
KAPLAN, R.S.; NORTON, D.P. (1996). The Balanced scorecard. Boston: Harvard Business School Press.

KESKIN, H. (2005). The Relationships between explicit and tacit oriented KM strategy, and firm performance. Journal of American Academy of Business, Cambridge, v.7, n.1, p.169-175, Sept.

KING, W.R.; CHUNG, T.R.; HANEY, M.H. (2008). Knowledge management and organizational learning. Omega: the international journal of management science, Amsterdam, v.36, n.2, p.167-172, Apr.

KJÆRGAARD, A.; KAUTZ, K. (2008). A Process model of establishing knowledge management: insights from a longitudinal field study. Omega: the international journal of management science, Amsterdam, v.36, n.2, p.282-297, Apr.

KOCH, H. (2002). An Investigation of knowledge management within a university IT group. Information Resources Management Journal, Farmington Hills, v.5, n.1, p.13-21, Jan./Mar.

LAM, W. (2005). Successful knowledge management requires a knowledge culture: a case study. Knowledge Management Research \& Practice, Hampshire, v.3, n.5, p.206-217, Nov.

LANGEFORS, B. (1968). System för företagsstyrning, studentlitteratur, lund. In: WILSON, L.T. Knowledge harvesting. Disponível em:<http://www.knowledgeharvesting.org/default.htm>. Acesso em: 20 Jan. 2010.

LEE, J.H. (2006). Effects of managerial drivers and climate maturity on knowledge management performance: empirical validation. Information Resources Management Journal, Farmington Hills, v.19, n.3, p.48-60, July/Sept.

LEE, J.H.; KIM, Y.G. (2001). A Stage model of organizational knowledge management: a latent content analysis. Expert Systems With Applications, Amsterdam, v.20, n.4, p.299-311, May.

LEE, S.F.C.K.; GOH, D. (2006). On The concept and types of knowledge. Journal of Information \& Knowledge Management, Hackensack, v.5, n.2, p.151-163.

LI, L.C. et al. (2009). Evolution of Wenger's concept of community of practice. Implementation Science, London, v.4. Disponível em: $<$ http://www.implementationscience.com/content/4/1/11 $>$. Acesso em: 15 july 2010 .

LI, Z.; YEZHUANG, T.; ZHONGYING, Q. (2006). The Impact of organizational culture and knowledge management on organizational performance. In: INFORMATION RESOURCES MANAGEMENT ASSOCIATION, 2006, Washington. Emerging Trends and Challenges in IT Management. Washington: Idea Group.

LICHTARSKI, J.M. (2009). Organizational structure and knowledge management. Argumenta Oeconomica, v.22, n.1, p.88-101.

LICHTENSTEIN, S.; BRAIN, M. Organizational strategy, structure and culture: influences on organizational knowledge sharing. In: INFORMATION RESOURCES MANAGEMENT ASSOCIATION, 2006, Washington. Emerging Trends and Challenges in IT Management. Washington: Idea Group.

LIEBOWITZ, J. (1999). Key ingredients to the success of an organization's knowledge management strategy. Knowledge and Process Management, Chichester, v.6, n.1, p.37-40, Mar.

(2008). 'Think of others' in knowledge management: making culture work for you. Knowledge Management Research \& Practice, Hampshire, v.6, n.1, p.47-51, Mar.

LIEBOWITZ, J.; MEGBOLUGBE, I. (2003). A Set of frameworks to aid the project manager in conceptualizing and implementing KM initiatives. International Journal of Project Management, Amsterdam, v.21, n.3, p.189-199, Apr. 
LIEBOWITZ, J. et al. (2000). The Knowledge audit. Knowledge and Process Management, Chichester, v.7, n.1, p.3-10, Jan./Mar.

LINDE, C. (2001). Narrative and social tacit knowledge. Journal of Knowledge Management, Wagon Lane, v.5, n.2, p.160-171.

LOUADI, M. (2008). Knowledge heterogeneity and social network analysis: towards conceptual and measurement clarifications. Knowledge Management Research \& Practice, Hampshire, v.6, n.3, p.199-213, Sept.

LU, Y.; YANG, C.J. (2007). Research on impacts of some antecedents on knowledge workers' organizational commitment. In: WUHAN INTERNATIONAL CONFERENCE ON E-BUSINESS, 6. 2007, Wuham. Management challenges in a global world. [S.1.:s.n.].

LUNDVALL, B.Å; JOHNSON, B. (1994). The Learning economy. Journal of Industry Studies, Kensington, v.1, n.2, p.23-42.

MACHLUP, F. (1961). Are the social sciences really inferior?. The Southern Economic Journal, Stillwater, v.27, n.3, p.173-184.

MAIER, R.; REMUS, U. (2002). Defining process-oriented knowledge management strategies. Knowledge and Process Management, Chichester, v.9, n.2, p.103-118, Apr./june.

MAlHOtra, N. (2006). Pesquisa de marketing: uma orientação aplicada. 4.ed. Porto Alegre: Bookman.

MALHOTRA, Y. (2004). Why Knowledge management systems fail: enablers and constraints of knowledge management in human enterprise. In: KOENIG, E.; SRIKANTAIAH, T.K. (Ed.). Knowledge Management: what works and what doesn't. Medford: Information Today. (ASIS Monograph Series).

MARTIN, B. (2000). Knowledge management within the context of management: an evolving relationship. Singapore Management Review, Singapore, v.22, n.2, p.17-37.

MARTINS, A.G. (2006). Sobre confiabilidade e validade. Revista Brasileira de Gestão de Negócios, São Paulo, v.8, n.20, p.1-12.

MAXIMIANO, A.C.A. (2004). Introdução à administração. São Paulo: Atlas.

MCELROY, M.W. (2000). The New knowledge management. Knowledge and Innovation: journal of the KMCI, Alexandria, v.1, n.1, p.43-67.

MCMANUS, D.J.; SNYDER, C.A. (2003). Knowledge management: the missing element in business continuity planning. In: COAKES, E. Knowledge management: current issues and challenges.

London: IRM Press. p.79-91.

MEEHAN, B.; RICHARDSON, R. (2002). Identification of software process knowledge management. Software Process Improvement and Practice, Malden, v.7, n.2, p.47-55, June.

MINTZBERG, H. (1994). The Fall and rise of strategic planning. Harvard Business Review, New York, v.72, n.1, p.107-114, Jan./Feb.

MOORADIAN, N. (2005). Tacit knowledge: philosophic roots and role in KM. Journal of Knowledge Management, Wagon Lane, v.9, n.6, p.104-113.

MULLER-MERBACH, H. (2006). Eysenck's advice: why and when to define knowledge. Knowledge Management Research \& Practice, Hampshire, v.4, n.3, p.250-251, Aug.

NEVES, F.V.F. ; GUERRINI, F.M.; CAZARINI, E.W. (2006). Modelo de requisitos e componentes técnicos para auxiliar a formação e gerência de redes entre empresas da construção civil brasileiras. In: 
ENCONTRO NACIONAL DE ENGENHARIA DE PRODUÇÃO, 26., 2006, Fortaleza. Anais... Fortaleza: ABEPRO.

NICKOLS, F. (2000). The Knowledge in knowledge management. In: CORTADA, J.W.; WOODS, J.A. (Ed.). The Knowledge management yearbook. Boston: Butterwoth-Hineman.

NISSEN, M.E. (2002). An Extended model of knowledge-flow dynamics. Communications of the Association for Information Systems, Singapore, v.8, n.1, p.251-266.

(2006). Harnessing knowledge dynamics. Hershey: IRM Press.

NONAKA, I. (1994). A Dynamic theory of organizational knowledge creation. Organization Science, Berlin, v.5, n.1, p.14-37, Feb.

NONAKA I.; KROGH, G.V. (2009). Tacit knowledge and knowledge conversion: controversy and advancement in organizational knowledge creation theory. Organization Science, Berlin, v.20, n.3, p.635-652.

NONAKA, I.; TAKEUCHI, H. (1995). The Knowledge-creating company: how Japanese companies create the dynamics of innovation. New York: Oxford University Press.

NONAKA, I.; TOYAMA, R.; KONNO, N. (2000). SECI, Ba and leadership: a unified model of dynamic knowledge creation. Long Range Planning, Amsterdam, v.33, n.1, p.5-34, Feb.

O'DELL, C.; GRAYSON, C.J. (1998). If Only we knew what we know: the transfer of internal knowledge and best practice. New York: The Free Press.

O’DELL, C.; LEAVITT, P. (2004). The Executives role in knowledge management. Houston: APQC.

OLIVER, S.; KANDADI, K.R. (2006). How to develop knowledge culture in organizations? A multiple case study of large distributed organizations. Journal of Knowledge Management, Wagon Lane, v.10, n.4, p.6-24.

ORZANO, A.J. et al. (2008). A Knowledge management model: Implications for enhancing quality in health care. Journal of the American Society for Information Science \& Technology, Malden, v.59, n.3, p.489-505, Feb.

OXBROW, N. (2004). 'Sticky' knowledge strategies CKO. London: TFPL.

PACANOWSKY, M.E.; O'DONNELL-TRUJILLO, N. (1983). Organizational communication as cultural performance. Communication Monographs, v.50, n.2, p.126-147.

PÁDUA, S.I.D.; CAZARINI, E.W.; INAMASU, R.Y. (2004). Modelagem organizacional: captura dos requisitos organizacionais no desenvolvimento de sistemas de informação. Gestão e Produção, São Carlos, v.11, n.2, p.197-209, maio/ago.

PAI, D.C. (2005). Knowledge strategies in Taiwan's IC design firms. The Journal of American Academy of Business, Cambridge, v.7, n.2, p.73-77, Sept.

PEE, L.G.; KANKANHALLI, A. (2009). A Model of organizational knowledge management maturity based on people, process, and technology. Journal of Information \& Knowledge Management, Hackensack, v.8, n.2, p.1-21.

PILLANIA, R.K. (2004). State-of-art of knowledge management in Indian industry. Management and Change, India, v.9, n.1, p.32-43. n.2, p.96-99.

(2009). Demystifying knowledge management. Business Strategy Series, Wagon Lane, v.10,

POLANYI, M. (1966). The Tacit dimension. Londres: Routledge \& Kegan Paul. 
POPPER, K. (1999). Conhecimento objetivo. Belo Horizonte: Itatiaia.

PÓR, G. (1997). The "data to wisdom" curve. Disponível em:<http://www.co-i-1.com/coil/knowledgegarden/dkescop/dwcurve.shtml>. Acesso em: 5 July 2009.

PRICE, D.J.S. (1963). Little science, big science. New York: Columbia University Press.

RAMÍREZ, Y.W.; NEMBHARD, D.A. (2004). Measuring knowledge worker productivity: a taxonomy. Journal of Intellectual Capital, Wagon lane, v.5, n.4, p.602-928.

ROCHA, D.; DEUSDARÁ, B. (2006). Análise de conteúdo e análise do discurso: o lingüístico e seu entorno. Delta: documentação de estudos em lingüística teórica e aplicada, São Paulo, v.22, n.1, p.29-52.

ROCKART, J. (1979). Chief executives define their own information needs. Harvard Business Review, New York, v.57, p.81-93, Mar.

ROOS, J. et al. (1998). Intellectual capital: navigating in the new business landscape. New York: University Press.

RUS, I.; LINDVALL, M. (2002). Knowledge management in software engineering. IEEE Software, Los Alamitos, v.19, n.3, p.26-38, May/June.

SAMPIERI, R.H.; COLLADO, C.F.; LUCIO, P.B. (1996). Metodologia de investigação. México: McGraw Hill.

SCHEIN, E. (1992). Organization culture and leadership: a dynamic view. San Francisco: Jossey Bass.

SCHINDLER, R. (2002). Knowledge sharing by means of lessons learned repositories: how to assist understanding, reflection and transfer. In: INTERNATIONAL CONFERENCE ON THE FUTURE OF KNOWLEDGE MANAGEMENT, 2002, Berlin. Proceedings... [S.1.:s.n].

SCHULZ, M.; JOBE, L.A. (2001). Knowledge management; international business enterprise. Journal of High Technology Management Research, Amsterdam, v.12, n.1.

SCHWALBE, M. (2005). The Sociologically examined life: pieces of the conversation. $3^{\text {th }}$ ed. Boston: McGraw-Hill.

SETZER, V.W. (1999). Dado, informação, conhecimento e competência. DataGramaZero - revista de ciência da informação, Rio de Janeiro, n.0, Artigo 1, dez.

SHANKAR, R. et al. (2003). Strategic planning for KM implementation in engineering firms. Work Study, Wagon Lane, v.52, n.4, p.190-201.

SHOHAM, S.; HASGALL, A. (2005). Knowledge workers as fractals in a complex adaptive organization. Knowledge and Process Management, Chichester, v.12, n.3, p.225-36, July/Sept.

SILVA, S.L. (2004). Gestão do conhecimento: uma revisão crítica orientada pela abordagem da criação do conhecimento. Ciência da Informação, Brasília, v.33, n.2, p.143-151, maio/ago.

SINGH, S.K. (2008). Role of leadership in knowledge management. Journal of Knowledge Management, Wagon lane, v.12, n.4, p.3-15.

SKYRME, D.; AMIDON, D. (1997). The Knowledge agenda. Journal of Knowledge Management, Wagon lane, v.1, n.1, p.27-37.

SPENDER, J.C. (2003). Knowledge fields: some post-9/11 thoughts about the knowledge-based theory of the firm. In: HOLSAPPLES, C.W. (Ed.). Handbook on knowledge management 1: knowledge matters, Berlin: Springer Verlag. p.43-58. 
SPENDOLINI, M.J. (1992). Benchmarking. São Paulo: Makron Books.

STIRNA, J.; PERSSON, A.; SANDKUHL, K. (2007). Participative enterprise modelling: experiences and recommendations. In: KROGSTIE, J.; ANDREAS, L.; OPDAHL,G.S. (Ed.). Advanced information systems engineering: 19th International Conference, CAiSE 2007, Trondheim, Norway, June 11-15, 2007 - proceedings. Berlin: Springer. (Lecture Notes in computer Science).

SVEIBY, K.E. (1998). A Nova riqueza das organizações: gerenciando e avaliando patrimônios de conhecimento. Rio de Janeiro: Campus.

SWAN, J.; NEWELL, S.; ROBERTSON, M. (2000). Limits of IT-driven knowledge management for interactive innovation processes: towards a community-based approach. In: JAWAII INTERNATIONAL CONFERENCE ON SYSTEMS SCIENCES, 33., 2000, Island. Proceedings... Hawai: University of Hawai.

TAKEUCHI, H. (2001). Toward a universal management concept of knowledge. In: NONAKA, I.; TEECE, D. (Ed.). Managing industrial knowledge. London: Sage. p.315-329.

TEECE, D.J. (1998). Capturing value from knowledge assets: the new economy, markets for know-how, and intangible assets. California Management Review, Berkeley, v.40, n.3, p.55-79, Spring.

THOMPSON, J.M. (2010). Understanding and managing organizational change: implications for public health management. Journal of Public Health Management and Practice, Baltimore, v.16, n.2, p.167173.

TIWANA, A. (2000). The Knowledge management toolkit: practical techniques for building a knowledge management system. New York: Prentice-Hall.

TOVSTIGA, G. (1999). Profiling the knowledge worker in the knowledge-intensive organization: emerging roles. International Journal Technology Management, v.18, n.5/8, p.731-744.

TUOMI, I. (1999). Data is more than knowledge: implications of the reversed knowledge hierarchy for knowledge management and organization memory. Journal of Management Information Systems, Armonk, v.16, n.3, p.103-117, Winter.

VALENZUELA, B.M. et al. (2008). Defining the problem: key element for the success of knowledge management. Knowledge Management Research \& Practice, Hampshire, v.6, n.5, p.322-333, Dec.

VERA, D. (2001). Co-alignment between business strategy and knowledge strategy and its impact on performance. In: ACADEMY OF MANAGEMENT CONFERENCE, 2001, Washington.

Proceedings... [S.l:s.n].

VON KROUGH, G.; ROOS, J.; KLEINE, D. (1999). Knowing in firms: understanding, managing, and measuring knowledge. Walnut Creek: Altamira Press.

WEINER, B.J. (2009). A Theory of organizational readiness for change. Implementation Science, London, v.4, n.1. Disponível em:<http://www.implementationscience.com/content/4/1/67>. Acesso em: 10 Mar. 2010.

WENGER, E.; McDERMOTT, R.; SNYDER, W.M. (2002). Cultivating communities of practice: a guide to managing knowledge. Boston: Harvard Business School Press.

WIIG, K.M. (1993). Knowledge management foundations: thinking about-how people and organizations create, represent, and use knowledge. Arlington: Schema.

(1999). Introducing knowledge management into enterprise. In: LIEBOWITZ, J. (Ed.).

Knowledge management handbook. Boca Ratón: CRC Press. 
WONG, Y.K. (2005). Critical success factors for implementing knowledge management in small and medium enterprises. Industrial Management \& Data Systems, Wagon lane, v.105, n.3, p.261-279.

WU, L.I.; LIN, C.H. (2009). A Strategy-based process for implementing knowledge management: an integrative view and empirical study. Journal of the American Society for Information Science and Technology, Malden, v.60, n.4, p.789-802, Apr.

YANG, J. (2008). Antecedents and consequences of knowledge management strategy: the case of Chinese high technology firms. Production Planning \& Control: the management of operations, Singapore, v.19, n.1, p.67-77.

YEH, Y.J.; LAI, S.Q.; HO, C.T. (2006). Knowledge management enablers. Industrial Management \& Data Systems, Wagon Lane, v.106, n.6, p.793-810.

ZACK, M.H. (1999). Developing a knowledge strategy. California Management Review, Berkeley, v.41, n.3, p.125-145, Spring.

ZHENG, M.L.; BAO, G.M.; QIAN, Y.Y. (2009). Employee commitment, knowledge sharing and knowledge integration: an empirical study of professional staffs in chinese firms. In: PICMET 09 TECHNOLOGY MANAGEMENT IN THE AGE OF FUNDAMENTAL CHANGE, 2009, Portland. Proceedings... New York: IEEE.

ZHENG, W. (2005). Organizational cultural factors that affect knowledge management effectiveness. In: ACADEMY OF HUMAN RESOURCE DEVELOPMENT CONFERENCE, 2005, Bowling. Proceedings... Bowling Green: Academy of Human Resource Development. p.497-504. (2009). A Conceptualisation of the relationship between organisational culture and knowledge management. Journal of Information \& Knowledge Management, Hackensack, v.4, n.2, p.113-124.

ZINS, C. (2007). Conceptual approaches for defining data, information, and knowledge. Journal of the American Society for Information Science, Malden, v.58, n.4, p.479-493, Feb. 


\section{APÊNDICE}

Apêndice A - Instrumentos de coleta de dados, entrevista semi-estruturada para a validação da modelagem

1. O modelo de objetivos e regras do negócio proposto cumpre com as diretrizes da metodologia EKD?

2. O modelo de processos do negócio proposto cumpre com as diretrizes da metodologia EKD?

3. O modelo de atores e recursos proposto cumpre com as diretrizes da metodologia EKD?

4. O modelo de requisitos e componentes técnicos propostos cumpre com as diretrizes da metodologia EKD??

5. Os relacionamentos entre os elementos dos modelos cumprem com as diretrizes da metodologia EKD? integração

6. A metodologia de modelagem utilizada facilita a representação das atividades da GC 
Apêndice B - Instrumentos de coleta de dados, questionário semi-estruturado para a validação da modelagem (Perguntas Apêndice A em inglês)

7. The Objective Model and Business Rules Model proposed complies with the guidelines of the EKD methodology?

8. The Business Process Model proposed complies with the guidelines of the EKD methodology?

9. The Actors and Resources Model complies with the guidelines of the EKD methodology?

10. The Technical Components and Requirements model complies with the guidelines of the EKD methodology?

11. The relationships between the elements of the models comply with the guidelines of the EKD methodology?

12. The modeling methodology used facilitates the representation of the activities of the Knowledge Management? 
Apêndice C - Instrumentos de coleta de dados, questionário semi-estruturado para a validação do modelo

\section{MODELO DE OBJETIVOS E MODELO DE REGRAS PARA A IMPLANTAÇÃO E DESENVOLVIMENTO DA GESTÃO DO CONHECIMENTO}

O Modelo de Objetivos está focado na descrição de objetivos para a implantação e desenvolvimento da gestão do conhecimento e todas as questões associadas para atingilos.

O Modelo de Regras é usado para definir e manter explicitamente regras para a gestão do conhecimento. Podem operacionalizar ou delimitar objetivos.

1. O modelo apresenta três ameaças (ameaça do ambiente organizacional 1,2 e 3) como principais características do atual ambiente organizacional. Segundo sua experiência, quais outras características do ambiente organizacional poderiam ser consideradas como ameaças para a organização?

2. Segundo o modelo, a organização precisa atingir principalmente quatro objetivos para poder responder às ameaças do atual ambiente organizacional (objetivo 1, 2, 3 e 4). Segundo sua experiência, classifique a importância desses objetivos, sendo 1 o mais importante e 4 o menos importante.

\begin{tabular}{|c|c|c|c|c|}
\hline & 1 & 2 & 3 & 4 \\
\hline Efetividade organizacional & 6 & $\mathrm{C}$ & $\mathrm{C}$ & $\mathrm{C}$ \\
\hline Inovação organizacional & $\mathrm{C}$ & 6 & $\mathrm{C}$ & $\mathrm{C}$ \\
\hline Decisões organizacionais adequadas & $\mathrm{C}$ & $\mathrm{O}$ & 6 & $\mathrm{C}$ \\
\hline Mudança organizacional constante & $\mathrm{C}$ & $\mathrm{C}$ & $\mathrm{C}$ & 6 \\
\hline
\end{tabular}


3. Segundo sua experiência, quais outros objetivos precisariam ser atingidos para poder responder às ameaças do atual ambiente organizacional?

4. Segundo o modelo, o conhecimento organizacional (objetivo 5) pode ser considerado como denominador comum para a consecução dos objetivos 1, 2, 3 e 4 . Qual é seu parecer sobre esse enunciado?

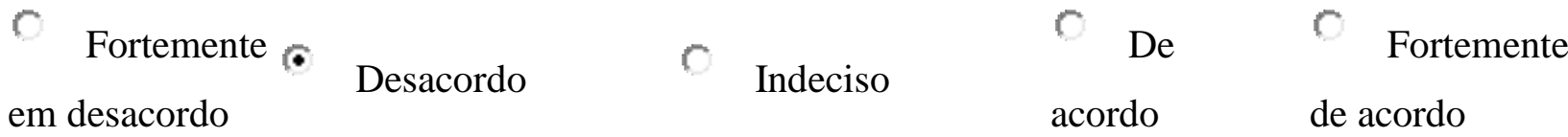

5. Devido à importância do conhecimento, o modelo tem como principal objetivo sua gestão (objetivo 6). Ele é apoiado por sete sub-objetivos (objetivo 6.1, 6.2, 6.3, 6.4, 6.5, 6.6 e 6.7). Segundo sua experiência, classifique a importância desses subobjetivos, sendo 1 o mais importante e 7 o menos importante

\begin{tabular}{|c|c|c|c|c|c|c|c|}
\hline & 1 & 2 & 3 & 4 & 5 & 6 & 7 \\
\hline $\begin{array}{l}\text { Definir e manter uma estratégia de gestão do } \\
\text { conhecimento }\end{array}$ & 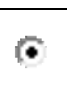 & 0 & 0 & 0 & 0 & 0 & 0 \\
\hline $\begin{array}{l}\text { Definir e manter uma cultura organizacional de } \\
\text { conhecimento }\end{array}$ & 0 & $\bullet$ & $C$ & 0 & $C$ & $c$ & $C$ \\
\hline $\begin{array}{l}\text { Definir e manter uma equipe de gestão do } \\
\text { conhecimento }\end{array}$ & $c$ & $C$ & 6 & 0 & $C$ & 0 & 0 \\
\hline $\begin{array}{l}\text { Definir e manter ferramentas de gestão do } \\
\text { conhecimento }\end{array}$ & 0 & 0 & 0 & 6 & 0 & 0 & 0 \\
\hline $\begin{array}{l}\text { Definir e manter processos de gestão do } \\
\text { conhecimento }\end{array}$ & 0 & $C$ & $C$ & 0 & $\bullet$ & 0 & 0 \\
\hline $\begin{array}{l}\text { Definir e manter métricas de gestão do } \\
\text { conhecimento }\end{array}$ & 0 & 0 & $C$ & 0 & $C$ & $\bullet$ & 0 \\
\hline $\begin{array}{l}\text { Definir e manter uma estrutura organizacional de } \\
\text { conhecimento }\end{array}$ & 0 & 0 & 0 & $C$ & 0 & 0 & 6 \\
\hline
\end{tabular}

6. Segundo sua experiência, quais outros sub-objetivos precisariam ser atingidos para viabilizar a Gestão do Conhecimento? 
7. O modelo explicita seis regras (regra $1,2,3,4,5$ e 6 ) que delimitam e orientam alguns sub-objetivos (objetivo 6.1, 6.2, 6.3 e 6.5). Segundo sua experiência, quais outras regras precisariam ser consideradas para delimitar e orientar os sub-objetivos apresentados no modelo?

8. O modelo explicita um problema (problema 1) que limita um dos sub-objetivos (objetivo 6.2). Segundo sua experiência, quais outros problemas precisariam ser considerados como limitantes dos sub-objetivos apresentados no modelo?

9. Comentários adicionais sobre o Modelo de Objetivos e o Modelo de Regras para a Gestão do Conhecimento.

\section{MODELO DE CONCEITOS PARA A IMPLANTAÇÃO E DESENVOLVIMENTO DA GESTÃO DO CONHECIMENTO}

O Modelo de Conceitos permite definir e relacionar os elementos abordados nos outros modelos.

10. Segundo o modelo, o conhecimento (conceito 2) é composto pelo conhecimento explícito, implícito e tácito (conceitos 3, 4 e 5). Segundo sua experiência, qual é seu parecer sobre esse enunciado

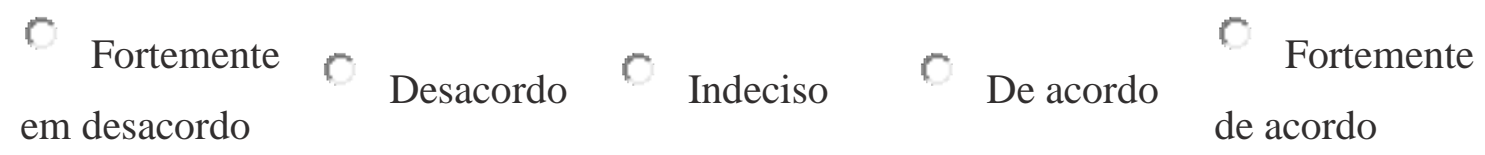

11. Segundo o modelo, o trabalhador do conhecimento (conceito 1) é quem realiza o processo da Gestão do Conhecimento (conceito 7) (criação/aquisição, disseminação/compartilhamento, armazenagem e aplicação do conhecimento), e não o diretor (conceito 19) nem os líderes do conhecimento (conceito 20). Segundo sua experiência, qual é seu parecer sobre esse enunciado? 


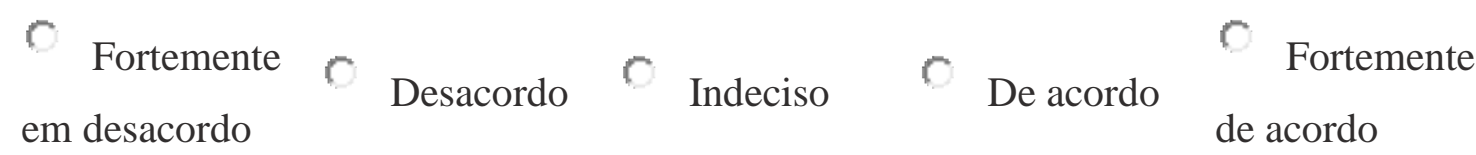

12. Segundo o modelo, a Gestão do Conhecimento (conceito 18) atua sobre as variáveis independentes da organização (conceito 13,14, 15, 16 e 17) e não diretamente no trabalhador do conhecimento, considerada variável dependente (conceito 1). Segundo sua experiência, qual é seu parecer sobre esse enunciado?

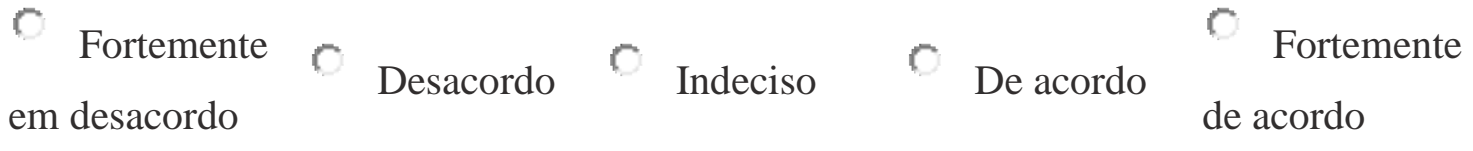

13. Comentários adicionais sobre o Modelo de Conceitos

\section{MODELO DE PROCESSOS PARA A IMPLANTAÇÃO E DESENVOLVIMENTO DA GESTÃO DO CONHECIMENTO}

O Modelo de Processos para a Implantação de Desenvolvimento da Gestão do Conhecimento é utilizado para a formulação dos processos, a forma como eles interagem e a forma como eles processam a informação e os materiais. Ele permite mostrar quais atividades e processos são reconhecidos na gestão do conhecimento, ou deveriam ser, para gerenciá-la de acordo com seus objetivos.

14. Segundo sua experiência, qual é seu parecer sobre a sequência apresentada no

Modelo de Processos para a Implantação e Desenvolvimento da Gestão do Conhecimento?

\begin{tabular}{ll|l|l|l} 
Fortemente & & & & \\
em desacordo & & Desacordo & Indeciso & Fortemente \\
de acordo
\end{tabular}

15. Segundo o modelo, é importante ter uma equipe responsável pela Gestão do Conhecimento (processo 1 e 2). Segundo sua experiência, qual é seu parecer sobre esse enunciado?
Fortement
em desacordo
Desacordo Indeciso
De acordo
Fortemente de acordo 
16. Segundo o modelo, os processos da gestão do conhecimento (criação/aquisição, disseminação/compartilhamento, armazenagem e aplicação do conhecimento) são aplicados somente nos processos intensivos em conhecimento (processo 9) (aqueles que criam e/ou trabalham com conhecimento) e não em todos os processos da organização. Segundo sua experiência, qual é seu parecer sobre esse enunciado?

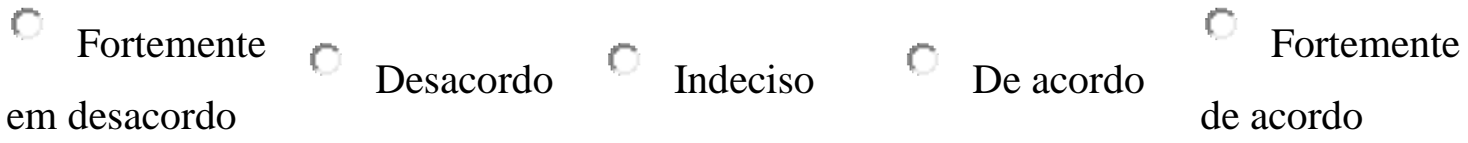

17. Comentários adicionais sobre o Modelo de Processos para a Implantação e Desenvolvimento da Gestão do Conhecimento.

\section{MODELO DE ATORES E RECURSOS PARA A IMPLANTAÇÃO E DESENVOLVIMENTO DA GESTÃO DO CONHECIMENTO}

O Modelo de Atores e Recursos define os tipos de atores e recursos evolvidos nas atividades da Gestão do Conhecimento, ele descreve como os diferentes atores e recursos estão relacionados entre eles e entre os componentes dos outros modelos.

18. O modelo considera cinco papeis principais para a Gestão do Conhecimento (papel 1, 2, 3, 4 e 5). Segundo sua experiência, quais outros papeis deveriam ser considerados para formar parte da Gestão do Conhecimento?

19. O modelo apresenta alguns dos principais recursos que auxiliam a Gestão do Conhecimento. Segundo sua experiência, quais outros recursos deveriam ser explicitados como recursos da Gestão do Conhecimento? 
20. Comentários adicionais sobre o Modelo de Atores e Recursos.

\section{MODELO DE REQUISITOS E COMPONENTES TÉCNICOS PARA A IMPLANTAÇÃO E DESENVOLVIMENTO DA GESTÃO DO CONHECIMENTO}

O Modelo de Requisitos e Componentes Técnicos é uma tentativa inicial de definir toda a estrutura e propriedades do sistema de informação que irá apoiar as atividades da gestão do conhecimento. Nele são definidas as necessidades de informação para atingir os objetivos do Modelo de Objetivos.

21. O modelo explicita os objetivos do sistema de informação (objetivo SI 1.1, 1.2, 1.3, 1.4, 1.5 e 1.6) necessários para a Gestão do Conhecimento. Segundo sua experiência, quais outros objetivos do sistema de informação precisariam ser considerados para a Gestão do Conhecimento?

22. Comentários adicionais sobre o Modelo de Requisitos e Componentes Técnicos.

\section{INTEGRAÇÃO DO MODELO}

Um modelo integrado é considerado aquele que une todos os elementos dos modelos apresentados (Modelo de objetivos, regras, conceitos, processos, atores, recursos, requisitos e componentes técnicos).

23. Os componentes dos seis modelos (modelo de objetivos, regras, conceitos, processos, atores e recursos e requisitos e componentes técnicos) estão integrados formando um macro modelo para a implantação e desenvolvimento da Gestão do Conhecimento? 


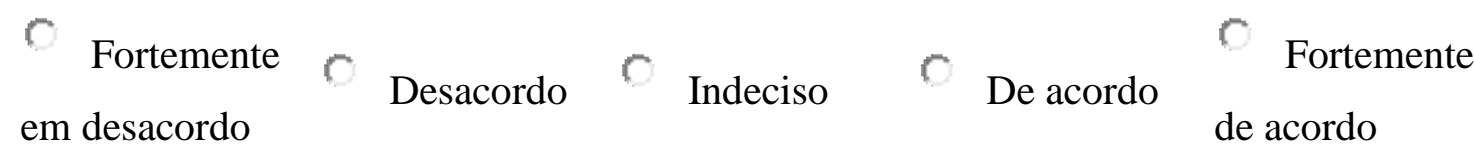

24. Comentários finais sobre todos os modelos apresentados. 
ANEXO

ANEXO I - estudos para a determinação das métricas para os ativos do conhecimento

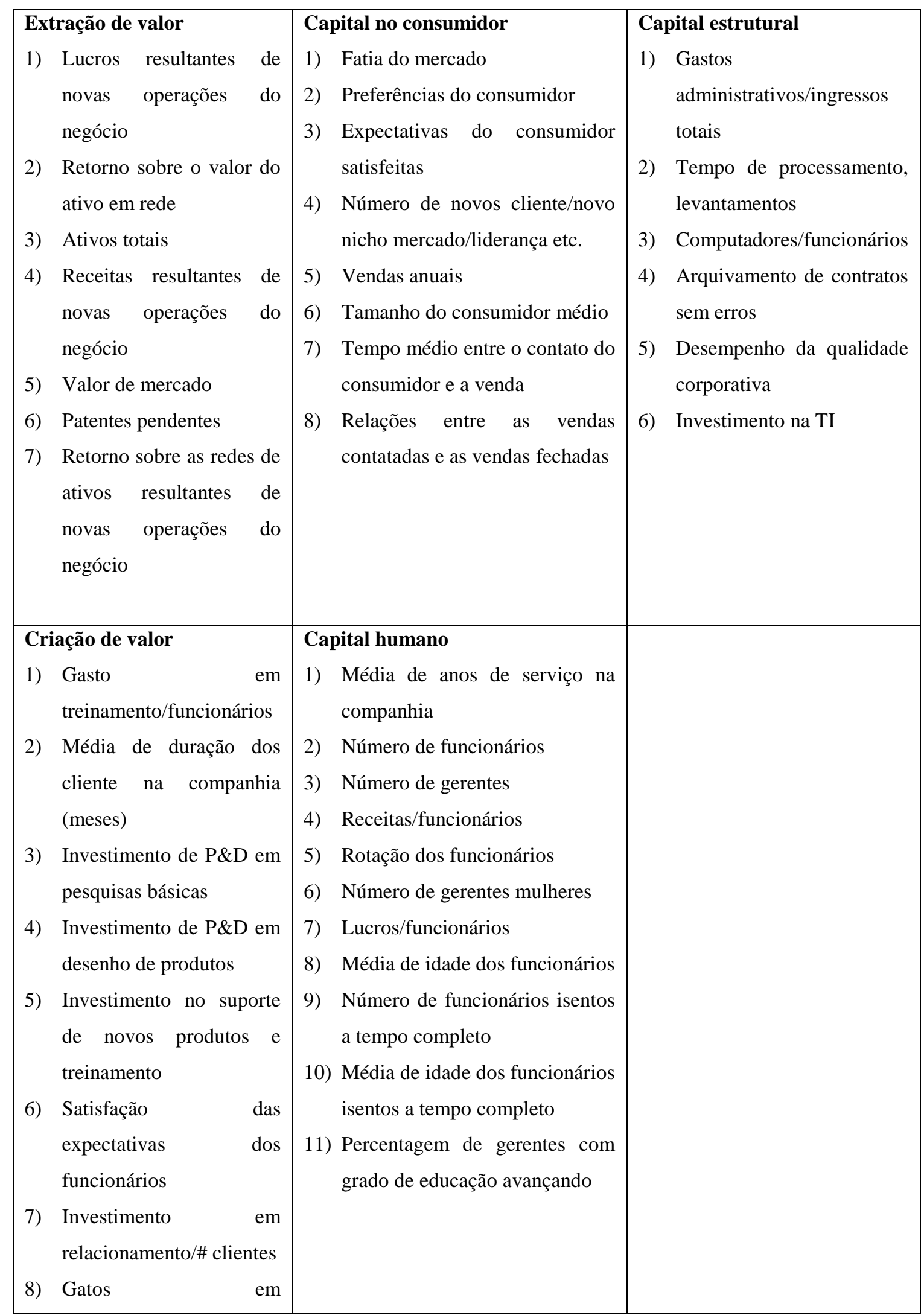




\begin{tabular}{|l|l|l|}
\hline treinamento/gasto & & \\
administrativo & & \\
Investimento de P\&D em & & \\
aplicaçoes & & \\
\hline
\end{tabular}

Quadro 22 - Estudo do Intellectual Capital Management Group. Fonte: ICM, 1998.

\begin{tabular}{|c|c|}
\hline $\begin{array}{l}\text { Capital humano (competência, atitude e } \\
\text { agilidade intelectual) }\end{array}$ & $\begin{array}{l}\text { Capital estrutural(relacionamentos, } \\
\text { organização, renovação e desenvolvimento) }\end{array}$ \\
\hline $\begin{array}{l}\text { 1) Porcentagem de funcionários com educação } \\
\text { superior }\end{array}$ & $\begin{array}{l}\text { 1) Porcentagem de fornecedores/negócios do } \\
\text { cliente representados }\end{array}$ \\
\hline 2) Grau de formação de TI & 2) Tempo de relacionamento \\
\hline 3) \# de horas de treinamento/\# funcionários & 3) Índice de satisfação dos parceiros \\
\hline 4) Duração média da empregabilidade & 4) Retenção dos consumidores \\
\hline 5) Horas gastas no balanço & 5) Gastos administrativos/receitas totais \\
\hline $\begin{array}{l}\text { 6) Horas gastas por gerentes na explicação de } \\
\text { estratégias e ações }\end{array}$ & $\begin{array}{l}\text { 6) Receitas por patentes/softwares/dados/bases } \\
\text { de dados/etc. }\end{array}$ \\
\hline 7) Índice de liderança & 7) Processos completados sem erros \\
\hline 8) Índice de motivação & 8) Tempos de processo \\
\hline $\begin{array}{l}\text { 9) Poupança logradas pela implementação de } \\
\text { sugestões dos funcionários }\end{array}$ & $\begin{array}{l}\text { 9) Porcentagem de negócios de novos produtos } \\
\text { 10) Esforços de treinamento - gastos/funcionários, }\end{array}$ \\
\hline $\begin{array}{l}\text { 10) Novas soluções/produtos/processos } \\
\text { sugeridos }\end{array}$ & $\begin{array}{l}\text { horas/funcionários } \\
\text { 11) Gastos de renovação/gastos operacionais }\end{array}$ \\
\hline $\begin{array}{l}\text { 11) Índice da variedade de know-how (a nível } \\
\text { individual e coletivo) } \\
\text { 12) Índice de diversificação da companhia }\end{array}$ & 12) Novas patentes/software/etc. \\
\hline
\end{tabular}

Quadro23 - Indicadores proposto por Ross et al. (1998). Fonte: Ross et al. (1998)

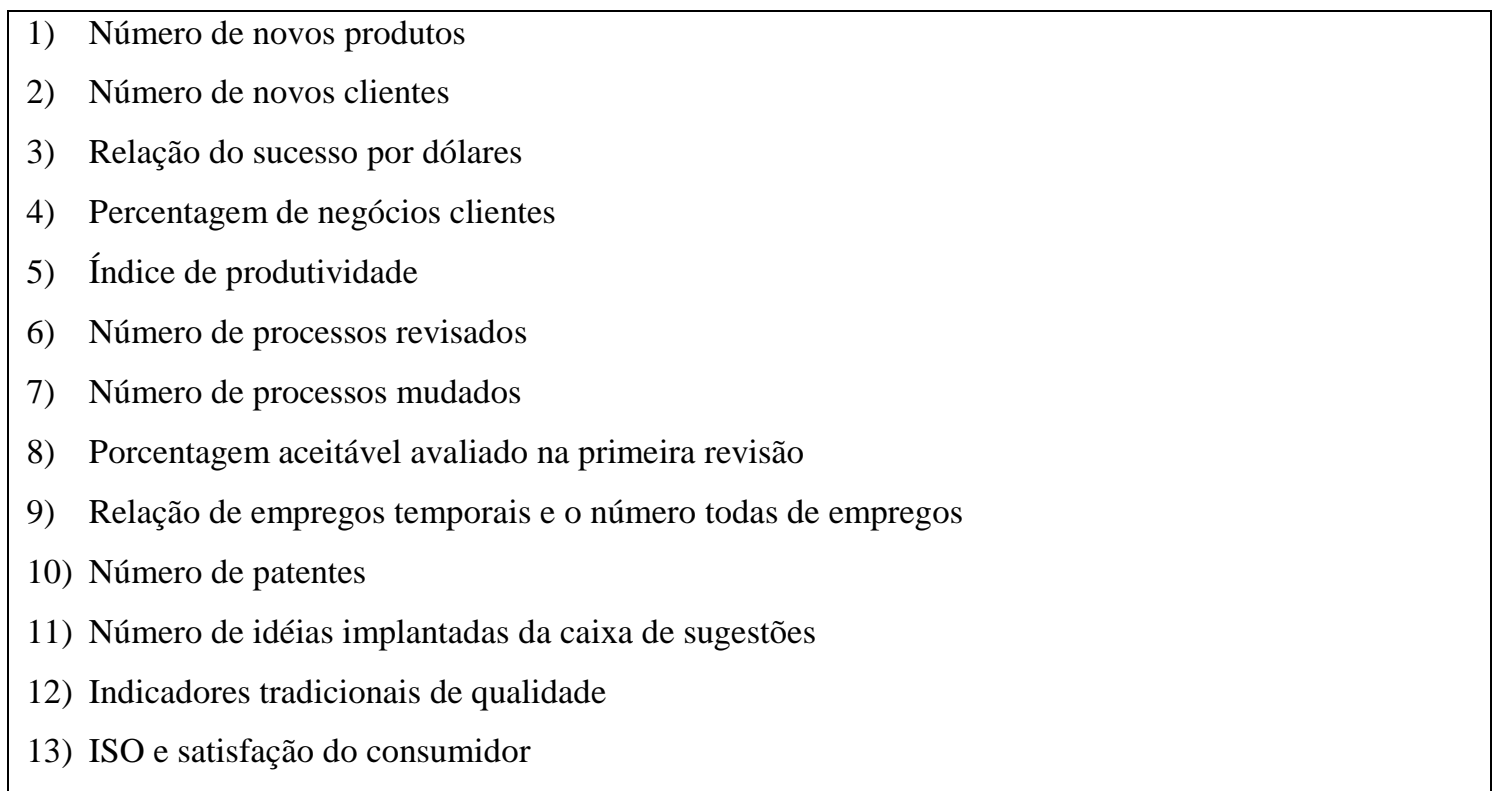

Quadro 24 - Reporte do Canadian Management Accountant. Fonte: CMA, 1999. 


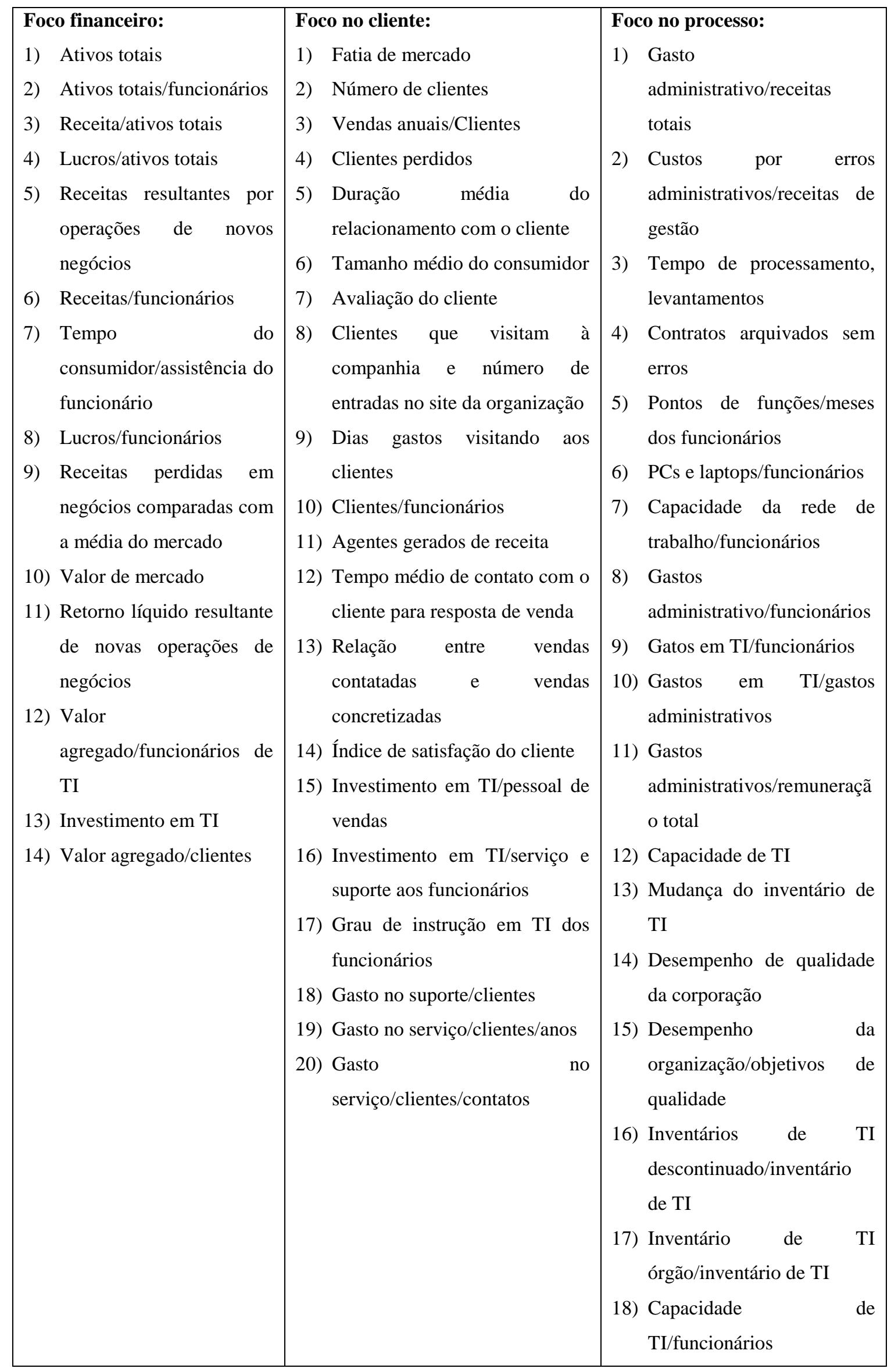




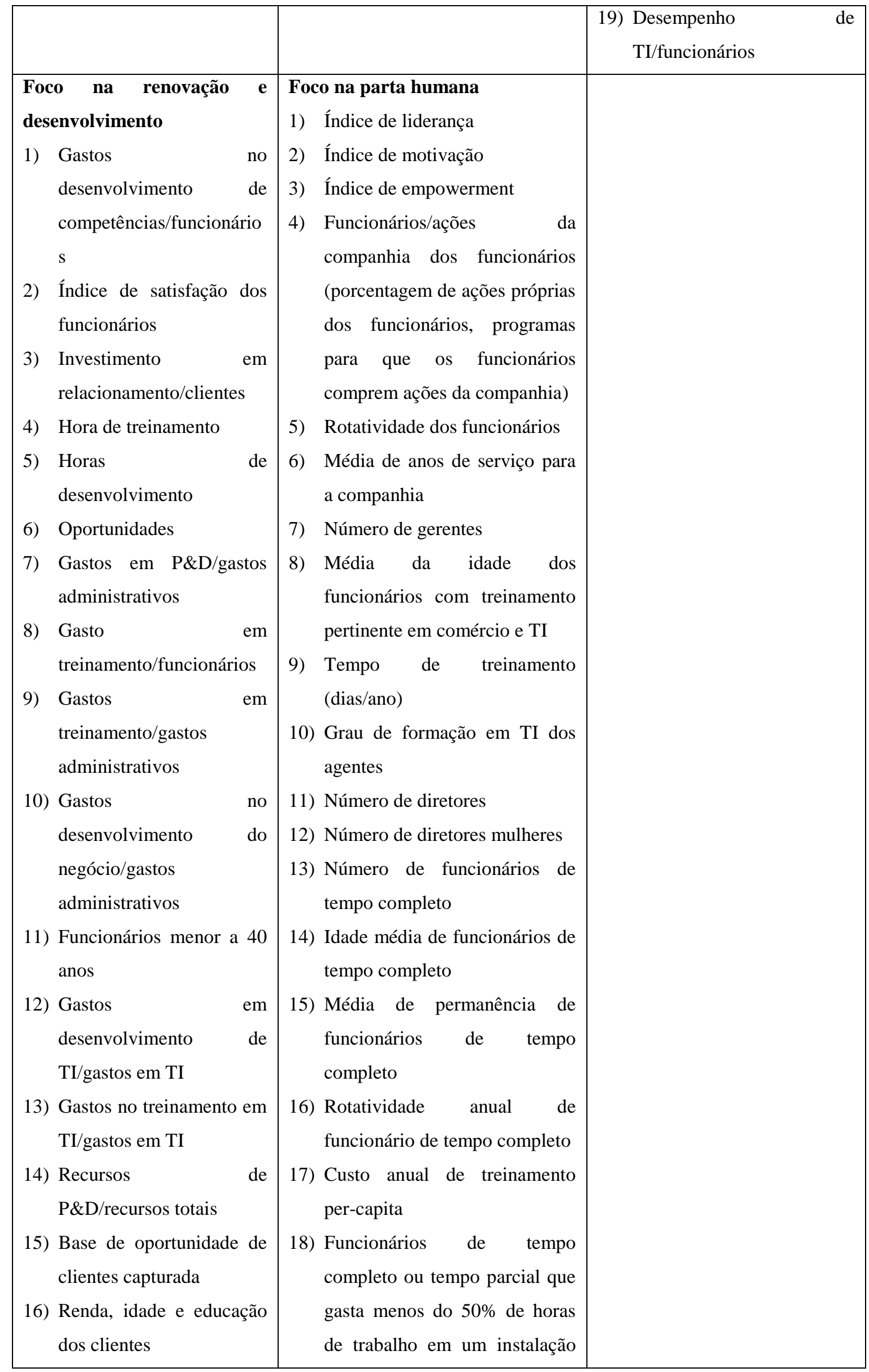




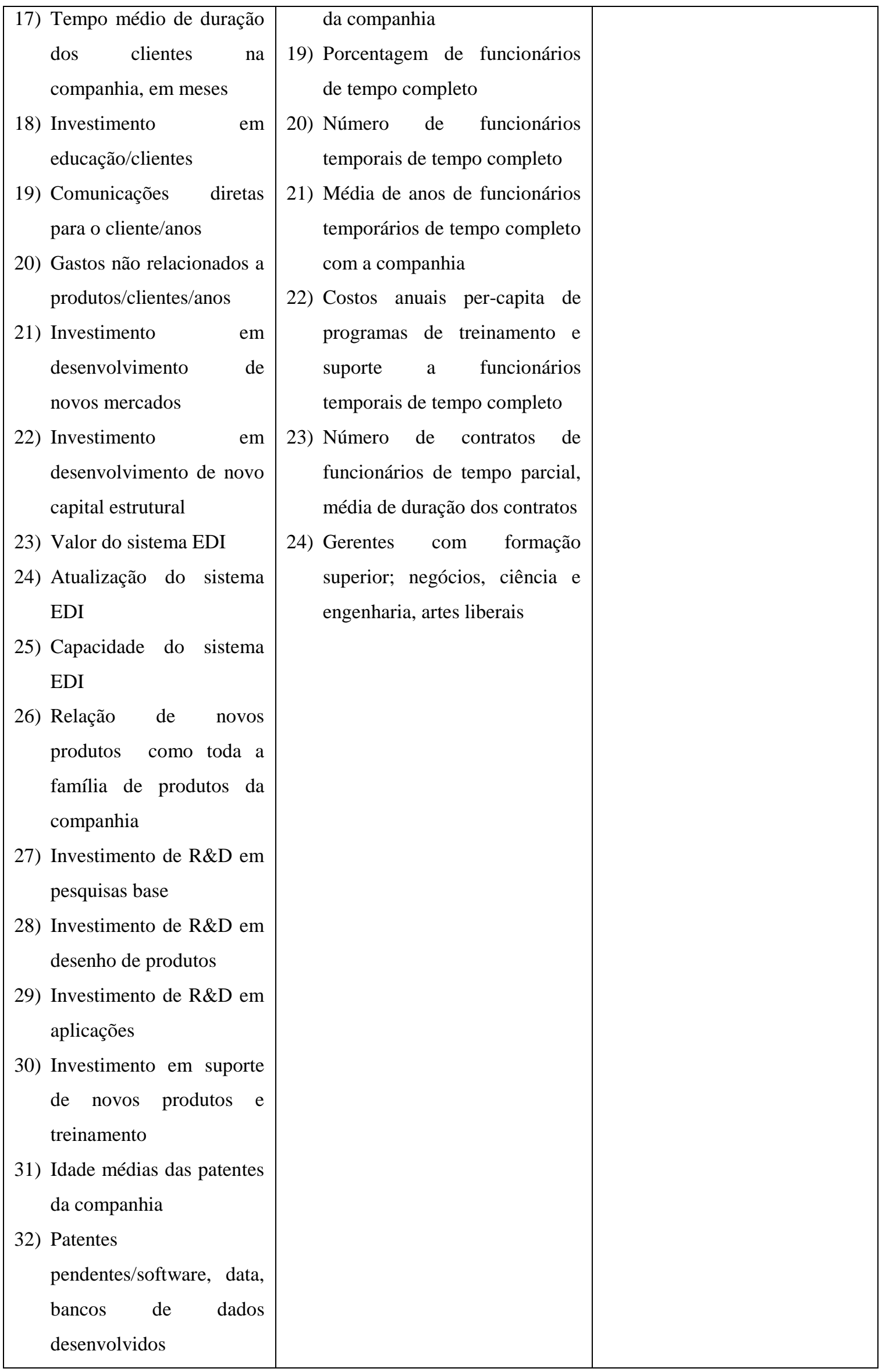

Quadro 25 - Reporte do Universal Intellectual Capital

Fonte: Von Krough et al. (1999) 